\title{
Revisiting the Contemporary Flow of Influence in Political Marketing
}

\author{
by
}

Simon Patrick Robert Vodrey

A thesis submitted to the Faculty of Graduate and Postdoctoral

Affairs in partial fulfillment of the requirements

for the degree of

Doctor of Philosophy

in

Communication

Carleton University

Ottawa, Ontario

(C)2020

Simon Patrick Robert Vodrey 
"It was written."

- Nas 


\begin{abstract}
This dissertation examines the extent to which the flow of influence and innovation between commercial and political marketers is bidirectional and operating as a feedback loop rather than merely being a unidirectional flow from commercial to political marketers as is commonly assumed in the political marketing literature. It uses in-depth elite interviews to examine that subject matter and those interviews are also used to answer three research questions: First, to what extent is political marketing influencing the practice of commercial marketing? Second, how have changes in marketing strategies and technology impacted both political and commercial marketing? Third, what are the likely consequences of the relationship between political marketing and commercial marketing? With these research questions in mind, analysis focuses on two broad areas that exemplify the bidirectional flow of influence and innovation being sought for: marketing and technology.
\end{abstract}




\section{Acknowledgments}

Researching and writing this dissertation was like trench warfare. That said, I would like to thank those who made the process a little more survivable. They are: my parents, my girlfriend, my supervisor André Turcotte, Mary Francoli, David Coletto, my external (Ken Cosgrove) and internal examiners (Scott Bennett) as well as my friends and fellow grad students. Special mention should also go to coffee at Rooster's Coffeehouse, Debt Rage Lager at Mike's Place, the Grad Recreational Softball League (GRSL) and — last but not least — those who said I wouldn't finish my PhD. This one's for you. 


\title{
Table of Contents
}

\author{
Abstract \\ Acknowledgements \\ List of Tables

\section{List of Illustrations}

\section{List of Appendices}

\section{Chapter I: A Beginning}

The Basics of Political Marketing ........................................ 4

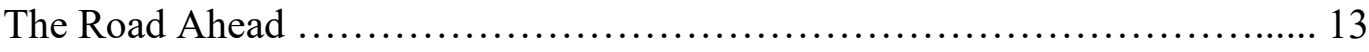

\section{Chapter II: The Marketing Conduit}

Tribal Marketing, Consumer Tribes, \& Wedge Politics ....................... 18

A Caveat \& a "Consumer Citizen" .............................................. 29

Market Intelligence ............................................... 37

\section{Chapter III: The Technology Conduit}

A Brief History of Technology in Political Campaigning .................... 40

Data-Driven Political Campaigning ....................................... 44

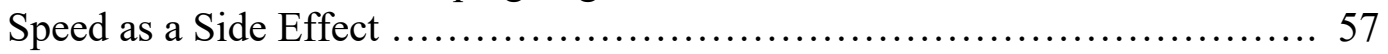

\section{Chapter IV: The Method}

Why Use In-Depth Elite Interviews? .................................. 74

How to Use In-Depth Elite Interviews? ............................... 80

\section{Chapter V: Marketing Conduit Findings}

What's in a Name? .................................................... 97

Relationship Marketing Redux ............................................ 102

Speed, Risk, \& Opportunity ......................................... 125

The End of Neutrality? .................................................. 152

Consumer Citizenship \& Corporate Social Responsibility .................. 164

Talking Tribal Marketing ............................................. 173

\section{Chapter VI: Technology Conduit Findings}

The Ebb \& Flow of Microtargeting ................................... 193

Discipline \& Efficacy of Targeting .................................... 203

The Impact of Speed on Targeting \& Beyond ........................... 210

The Dark Side of Targeting .................................................. 214

Silver Bullet Wishful Thinking ..................................... 214

Privacy Problems — or the Lack Thereof? ............................. 235 


\section{Chapter VII: An Ending}

Marketing Conduit Conclusions ............................................ 249

Technology Conduit Conclusions ........................................ 255

Returning to the Research Questions One Last Time ...................... 264

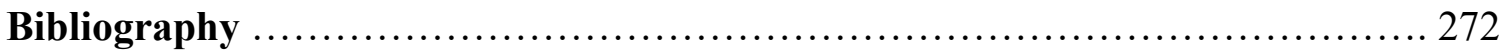

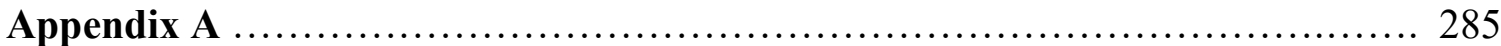

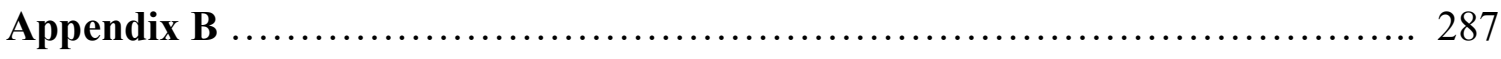

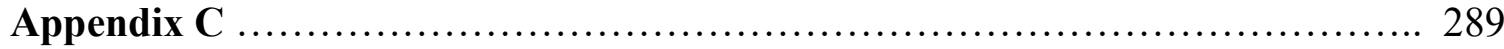

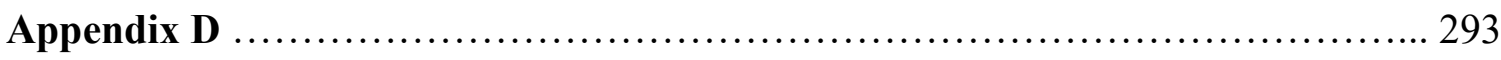

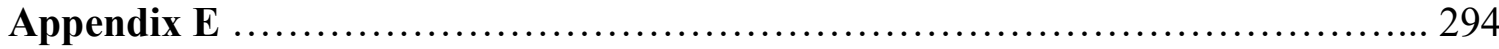




\section{List of Tables}

Table 1. Gender Breakdown of Respondents (Appendix D)

Table 2. Employment Breakdown of Respondents (Appendix E) 


\section{List of Illustrations}

Figure 1. Two-Way Flow of Influence \& Innovation Flowchart 


\section{List of Appendices}

Appendix A: Consent Form

Appendix B: Interviewer Guide

Appendix C: Interviewee Profiles

Appendix D: Gender Breakdown of Respondents

Appendix E: Employment Breakdown of Respondents 


\section{I \\ A Beginning}

In The Art of War (2006), Sun Tzu wrote that, "in war the victorious strategist only seeks battle after the victory has been won, whereas he who is destined to defeat first fights and afterwards looks for victory" (p. 18). With that in mind, and with hindsight being 20/20, the argument could be made that it is fitting that Donald Trump, a man who has spent his entire adult life as a marketer (marketing everything from buildings and casinos to steaks and beauty pageants), would win the American presidency in the turbulent 2016 election, thereby providing, in true Trump fashion, a less than subtle reminder of the fact that, in the twenty-first century, politics and marketing go hand in hand. To put it another way, today there are few aspects of life that have escaped the impact of marketing - and politics is no exception. In fact, marketing and politics have a long history of working together (Lees-Marshment, Conley, \& Cosgrove, 2014; Newman, 1994; Scammell, 1995). The election of Donald Trump is just the most recent and perhaps the most striking example of that relationship.

Susan Delacourt (2013) aptly describes the nature of that relationship by explaining that: "The marketing world would come up with efforts to reach customers better; then, the American political world would borrow and adapt those lessons; and finally, Canadians would import the techniques north of the forty-ninth parallel" (p. 262). This pattern of influence has been the theoretical underpinning for most of the recent scholarly research on the subject. It was articulated best by Jennifer Lees-Marshment who was influential in the development of the field of study that came to be known as political marketing, a discipline which formally represents the fusion of politics and 
marketing. Jennifer Lees-Marshment (2001a) explains that, "Political marketing is about political organisations adapting business marketing concepts and techniques to help them achieve their goals" (p. 22). Put differently,

As an activity, political marketing is about political organisations (such as political parties, parliaments and government departments) adapting techniques (such as market research and product design) and concepts (such as the desire to satisfy voter demands) originally used in the business world to help them achieve their goals (such as win elections or pass legislation). (Lilleker \& LeesMarshment, 2005, p. 6-7)

In essence, political marketing entails that marketing has infiltrated virtually all aspects of politics — be it fundraising, campaigning, or governing (Giasson, Lees-Marshment, \& Marland, 2012; Lees-Marshment, 2009; Lees-Marshment, Conley \& Cosgrove, 2014). While this pattern of influence has dominated the literature, some scholars, including Sasha Issenberg (2012) and Clive Veroni (2014), have recently suggested that the pattern of influence between politics and marketing may well be in the process of evolving.

The goal of this dissertation is to examine whether this pattern of influence between marketing and politics may indeed be changing. Building on the works of Issenberg (2012), Veroni (2014), Daniel Kreiss (2016) and Bruce I. Newman (2016), this project examines whether commercial marketers may also be learning from political practitioners and, more specifically, from political marketers. Essentially, this project examines the extent to which the flow of influence and innovation between commercial and political marketers is bidirectional and operating as a feedback loop rather than merely being a unidirectional flow from commercial to political marketers, as is commonly assumed in the political marketing literature. The depth and breadth of a change in the flow of influence and innovation within the discipline of political marketing is investigated. It is a change that is characterized by the fact that the influence 
and innovation required to campaign competitively may very well be being crafted increasingly in less traditional incubators and by less traditional practitioners than in the past.

Three research questions will be the driving force of this project: First, to what extent is political marketing influencing the practice of commercial marketing? Second, how have changes in marketing strategies and technology impacted both political and commercial marketing? Third, what are the likely consequences of the relationship between political marketing and commercial marketing?

The third research question is a central concern in political marketing literature and this area of study has been inherently tied to discussions about democracy, including the implications of political marketing on the practice and future of democracy (Cormack, 2012; Delacourt, 2013; Newman, 1994). Much of the literature has dealt with the possibility that political marketing may be adversely affecting democracy by reducing citizens to mere consumers, thereby allowing for cynical discussions about voter apathy and pandering politicians. While I will undoubtedly tackle this matter in this dissertation, I will approach it from a more nuanced political marketing perspective reminiscent of that offered by Patricia Cormack (2012) who claims that, "Much has been written on the issue of marketing politics — that is, turning the citizen into a consumer; considerably less has been written on the opposite move - turning the consumer into a citizen" ( $\mathrm{p}$. 219).

Furthermore, these three research questions - and the broader project of which they are an essential part — constitute a necessary revisiting of the Jennifer Lees- 
Marshment framework of political marketing, the framework that has been guiding the field for close to two decades now.

To answer the research questions and to investigate the extent to which the flow of influence and innovation between commercial and political marketers may be bidirectional and operating as a feedback loop rather than merely a unidirectional flow from commercial to political marketers, my analysis will focus on two areas that exemplify that possibility: marketing and technology. Those two areas will serve as pillars around which much of my analysis will be organized. They will also serve as conduits for bringing in a wide array of communication theories and concepts to anchor my research into a broader theoretical context.

This introductory chapter proceeds in the following manner: First, the basic tenets of political marketing as a discipline will be analyzed and the traditional flow of political influence and the crafters of it will be discussed to acquaint the reader with the key assumptions of the discipline of political marketing from the outset of this dissertation. Second, this introductory chapter will come to a close by revealing the skeletal structure of the remainder of this dissertation, outlining the ordering of the chapters that follow and the matters to be examined within them.

\section{The Basics of Political Marketing}

Rightly or wrongly when discussing either the political or the commercial realm, influence has long been viewed as a substantial form of power (Birnbaum, 2000; Green, 2002; Samples, 2006; Soruaf, 1992). But if influence is widely perceived in that way, it should be recognized that influence is not generated in a vacuum. It must be crafted by individuals who have a certain set of skills. Throughout the twentieth century, when it 
came to creating successful political campaigns, the individuals who typically possessed the requisite skills for purveying influence were thought to reside in one area: the commercial advertising and marketing world. New York City's Madison Avenue, the home to the American advertising industry, was seen as the cradle for the innovative thinking and techniques which, when harnessed by a receptive politician and his staff, could manifest themselves as a significant form of political influence in the American political landscape (Delacourt, 2013; Newman, 1994; Veroni, 2014). Toronto's renowned advertising and marketing hub was thought to be the equivalent Canadian incubator for political influence (Delacourt, 2013; Veroni, 2014).

Political marketing suggests that marketing has permeated nearly every facet of politics (Lees-Marshment, 2009; Lees-Marshment, Conley \& Cosgrove, 2014). It is also predicated on a give and take relationship between the governing and the governed. Or, as Jennfier Lees-Marshment, Brian M. Conley, and Kenneth Cosgrove (2014) put it,

In particular, political marketing offers a way of structuring an organization so as to satisfy internal and external stakeholders, and to communicate in a way that not only persuades and sells the political product but also forges a positive, interactive relationship between elites and their public. (p. 2)

Thus, political marketing does not assume that the public is a passive mass that merely needs to be convinced of the merit of a particular candidate, party, policy, or perspective by way of creative marketing techniques or "spin." As such, political marketing as a discipline is no adherent to the often maligned, if rightfully so, Hypodermic Needle Theory, which entails that the public is quick to accept the perspectives and viewpoints fed to them via the mainstream media (Lasswell, 1938).

The notion that political marketing borrows and adapts for the political world the thinking, strategies, techniques, and tools of commercial marketing grew out of a 
consumer marketing theory known "Market Orientation" (Lafferty \& Hult, 2001; Ormrod, 2006). Barbara A. Lafferty and G. Thomas M. Hult (2001) set the stage for our introduction of the concept of market orientation and its pivotal transition into the political marketing realm. They do so by noting how, "The marketing concept and the related construct of market orientation have been important components of marketing academe and practice for several decades" (p. 92).

Ajay K. Kohli and Bernard J. Jaworski (1990) help us begin to deconstruct the notion of market orientation and its pivotal transition into that political marketing realm by identifying the fact that, "Though the marketing concept is a cornerstone of the marketing discipline, very little attention has been given to its implementation" (p. 1). They expand upon this by explaining that, "The marketing concept is essentially a business philosophy, an ideal or a policy statement" (p. 1). In a nutshell, the marketing concept is the business philosophy that drives any given company.

But returning to Kohli and Jaworski (1990) reminds us that, "The business philosophy can be contrasted with its implementation reflected in the activities and behaviors of an organization" (p. 1). It is only when it comes to the implementation of the market concept that the notion of "market orientation" finally comes into frame. Referencing the work of earlier marketing theoreticians such as Barksdale and Darden (1971) and McNamara (1972), Kohli and Jaworski (1990) state that, "we use the term 'market orientation' to mean the implementation of the marketing concept. Hence, a market-oriented organization is one whose actions are consistent with the marketing concept" (p. 1). All accusations of repetition and circular reasoning aside, Kohli and Jaworski flesh out their thinking by providing a concrete definition of market orientation, 
which holds that, "Market orientation is the organizationwide generation of market intelligence pertaining to current and future needs, dissemination of the intelligence across departments, and organizationwide responsiveness to it” (p. 6).

As can be gleaned from the discussion thus far, market orientation is more than simply affirming the two common clichés that the customer is always right and that businesses should merely give their customers what they want. As such, "The marketing concept and the related construct of market orientation have been important components of marketing academe and practice for several decades" (Lafferty \& Hult, 2001, p. 92). And the reason for this fact can be summed up by a single word: performance (p. 92). John C. Narver and Stanley F. Slater (1990) efficiently encapsulate this idea by noting that, "A business that increases its market orientation will improve its market performance" (p. 20).

Although this logic has migrated to the political world, that migration has been anything but fast-paced. For example, on this matter, Robert P. Ormrod (2006) succinctly states that, "One of the most important concepts in commercial marketing, market orientation, has only recently been applied to political parties (e.g. Lees-Marshment, 2001a and 2001b; O'Cass, 1996, 2001a and 2001b; Ormrod, 2004 and 2005)" (Ormrod, 2006, p. 110). Ormrod provides a concise but complete discussion of that migration pattern by explaining that,

The concept of 'market orientation' in the commercial marketing literature was first introduced more than 40 years ago by Theodore Levitt (1960), who argued that more attention should be paid to the markets that the business served instead of concentrating on the product that the business made. (Ormrod, 2006, p. 111)

Accordingly, "interest in the concept grew in the 1990s after the publication of two articles (Kohli and Jaworkski, 1990; Narver and Slater, 1990)," at a particular historical 
moment when markets were becoming increasingly interconnected and liberalized (Ormrod, 2006, p. 111). If market orientation's entrance into the political lexicon is a relatively recent phenomenon, one scholar has more extensively documented that entrance than others: Jennifer Lees-Marshment (p. 110). As Ormrod himself puts it, when it comes to analyzing marketing orientation's migration to politics, "by far the largest amount of empirical work has examined Lees-Marshment's (2001a and 2001b) marketoriented party" (p. 110).

Yet prior to discussing that entity, we need to recognize the fact that, regardless of whether we are discussing the traditional consumer marketing world or the political marketing world, there is not one single, solitary, form of market orientation that applies (Lafferty \& Hult, 2001; Ormrod, 2006). Addressing that reality is truly the starting point for the proposed political marketing-based discussion in my dissertation. That starting point will be an examination of the three different types of "market orientations" and their historical migration patterns — from the business and commercial marketing world to the political marketing world — and also the first sustained instance where LeesMarshment's (2001a) work comes into the picture. According to Lees-Marshment, "Conceptually, marketing uses several orientations to explain business behaviour: product, sales and market orientations" (p. 23).

A product-oriented business is a business that is reminiscent of "take it or leave it" logic. This is largely because such businesses "concentrate [...] on producing the best product it can, as efficiently and cheaply as possible" - end of story (Lees-Marshment, 2001a, p. 23). Essentially, product-oriented businesses are predicated on the assumption that there is an unfettered demand for the product being offered to consumers (p. 23). 
Consequently, product-oriented businesses "assume [...] that the good will then sell. [And] if it does not, the business would argue that this is because the customer is ignorant and lacks appreciation of how good the product is" (p. 23). In other words, productoriented businesses are the epitome of inflexibility.

Unlike the "take it or leave it" logic, sales-oriented businesses are more closely aligned with the "ABCs" of business, as Alec Baldwin famously described them in a 1992 film called Glengarry Glen Ross. Playing the role of a successful salesman, Baldwin delivers an aggressive, profanity-laced motivational speech about the blood, sweat and tears that it takes to be a "closer" in the business world (Tokofsky, Zupnik \& Foley, 1992). Midway through that motivational speech, Baldwin flips a blackboard around to reveal the "ABCs" of business: "A (Always), B (Be), C (Closing). Always be closing" (Tokofsky, Zupnik \& Foley, 1992). In light of the ABCs, "A sales-oriented business has the same attitude towards designing its product [as the product-oriented business] but puts much more effort into selling the good" (Lees-Marshment, 2001a, p. 23-4). In accordance with the ABCs of business, sales-oriented businesses are anything but passive. They actively attempt to stimulate demand for their goods regardless of whether or not demand exists, by way of innovative marketing techniques and persuasion tactics (Lees-Marshment, 2001a).

Market-oriented businesses are cut from a different cloth. They are the polar opposite of the inflexibility offered by their product-oriented counterparts. LeesMarshment (2001a) illuminates why this is the case by explaining that, "A marketoriented business will design its product to provide consumer satisfaction to achieve its goals. It is continually altered in response to changing customer demands" (p. 24). Due to 
this customer-focused fluidity, market-oriented businesses are more likely to please a larger segment of the population and therefore are more likely to attract a greater number of prospective consumers since the product itself appears to be reflective of the consumers' desires. The goal from a business perspective is not only to gain the consumers' business but to do so repetitively - thereby arriving at the relationship marketing discussed earlier by way of Newman (1994) and Small (2012).

In sum, market-oriented businesses still adhere to the ABCs of business which are the mainstay of sales-oriented businesses. Nevertheless, they precede the production of the product that they are constructing and, ultimately, aiming to "close" (sell) by ensuring that the product itself — rather than just its marketing — is tailored to the demands of the consumer they envision (Lees-Marshment, 2001a; Ormrod, 2006). Essentially, marketoriented businesses precede the $\mathrm{ABC}$ mantra by ensuring that ample market research is conducted to understand both the pulse and impulses of the target consumers before the pen is put to paper to draft the blueprints for the product (Lees-Marshment, 2001a; Ormrod, 2006). Furthermore, they rely upon such market research on a rolling basis to gauge whether or not their product continues to meet consumers' demands even after its initial release. If it does not, they adjust their product to do so over the course of time (Lees-Marshment, 2001a; Ormrod, 2006).

The breakdown of businesses into these three market orientations is reminiscent of the typical political marketing pattern outlined earlier by Delacourt (2013) wherein the techniques of influence were crafted in the marketing industry and then were subsequently adopted by the political industry. Put differently, despite the fact that there are substantial differences between private sector businesses and political parties or 
politicians, these three orientations have been superimposed onto political parties and politicians themselves and have altered the way they function (Lees-Marshment, 2001a \& 2004). Hence we now have the following entities: the "Market-Oriented Party" (MOP), the "Product-Oriented Party" (POP), and the "Sales-Oriented Party" (SOP).

Generally speaking, a "Market-Oriented Party" (MOP) is a political party that is "actively engaging in efforts to identify voters' concerns and priorities and incorporate them into the design of its product offerings" (Giasson, Lees-Marshment \& Marland, 2012, p. 7). Consequently, MOPs are unlike either a "Product-Oriented Party" (POP) or a "Sales-Oriented Party" (SOP) since the former (POP) is a party which

Is depicted as employing a marketing strategy that is guided by the assumption that voters will recognize the normative value of their ideas and, as such, will vote for it. Hence, little consideration is given to gathering and using market intelligence to design or communicate its product offering. (p. 7)

The latter (SOP) "relies on the use of market intelligence to design strategies for selling or push-marketing its product offerings to targeted segments of the voting population" ( $\mathrm{p}$. 7). In these types of parties, "much emphasis is placed on research for advertising and message design, as opposed to the design of the party's actual product offering” (p. 7).

At this point, the following question may come to mind: Why is knowing the distinction between MOPs, POPs, and SOPs a logical starting point for the political marketing-based discussion in this project? The answer to this question comes by way of the fact that, for close to two decades now, the federal political parties that have been elected to serve as the federal government in the world's best known political marketing playing fields (those being the United States, the United Kingdom, and Canada), could be classified as being MOPs (Giasson, Lees-Marshment \& Marland, 2012; Knuckey \& Lees-Marshment, 2005; Lees-Marshment, 2004). Essentially, MOPs 
[Make] use of 'various tools to understand and then respond to voter demands, but in a way that integrates the need to attend to members' needs, ideas from politicians and experts, and the realities of governing, and to focus more on delivering and making a difference than employing sales techniques to persuade or manipulate opinion.' (Giasson, Lees-Marshment \& Marland, 2012, p. 7)

For the sake of clarification, the marketing process for MOPs must be addressed.

As Lees-Marshment (2001b) puts it, "To achieve these orientations, political parties engage in various activities, going through a marketing process" (p. 696). As may be expected, the marketing process is not interchangeable between MOPs, SOPs, and POPs (Lees-Marshment, 2001c). Their different orientations and philosophies ensure this. And like the aforementioned SOP, a MOP also utilizes market intelligence. However, it does so for very different purposes (Lees-Marshment, 2001a, b, c). This is due to the fact that "A market-oriented party designs its behaviour to provide voter satisfaction" (LeesMarshment, 2001c, p. 1078). And market intelligence is an essential component of creating voter satisfaction. A MOP "uses market intelligence to identify voters' demands, then designs its product to suit them" (p. 1078). But it varies from a SOP since, "It does not attempt to change what people think, but to deliver what they need and want" (p. 1078). But there is a catch. Offering voters what they need and want is no easy task. Due to this undeniable fact, "A market-oriented party will not simply offer what they want, because it needs to ensure that it can deliver the product on offer. If it fails to deliver, voters will become dissatisfied and the party will risk losing electoral support in the longterm" (p. 1078). With these challenges in mind, the marketing process for a MOP consists of eight chronological stages. Stage One: Market Intelligence; Stage Two: Product Design; Stage Three: Product Adjustment; Stage Four: Implementation; Stage Five: Communication; Stage Six: Campaign; Stage Seven: Election; and Stage Eight: 
Delivery (Giasson, Lees-Marshment \& Marland, 2012; Lees-Marshment, 2001a, b, \& c; Lees-Marshment, 2004).

But the insight needed to navigate and implement the marketing process (be it that of a POP, SOP, or MOP) typically does not come to the party or candidate naturally. For decades, it has been crafted, massaged, and managed by a web of consultants and firms specializing in the cultivation of the influence and innovation needed to win political campaigns. Those influencers and innovators are generally thought to have learned their trade in commercial marketing and then to have applied their knowledge to political marketing. However, there are very few constants in life.

\section{The Road Ahead}

With that in mind, the remainder of this dissertation consists of seven chapters. Chapter II introduces the possibility that the flow of influence and innovation between commercial marketers and political marketers may be bidirectional and operating as a feedback loop rather than merely being a unidirectional flow from commercial marketers to political marketers as is generally thought. It also identifies two broad areas that exemplify the possibility of this bidirectional flow of influence: marketing and technology. The rest of that chapter is devoted to isolating and exploring more fully the first of these potentially bidirectional conduits of influence: marketing. To that end, discussion centers upon how and why tribal marketing could be seen as the first signpost of a likely bidirectional flow of influence. Attention is also given to relationship marketing, the "consumer citizen," and the importance of the changing nature and everincreasing importance of market intelligence. 
Chapter III examines in detail how technology can be thought of as another conduit of influence that can exemplify the possible bidirectional flow of influence between commercial marketing and political marketing. Technology has historically been thought of as another true form of influence in politics whether it is in the form of the allimportant television advertisements (traditionally the most important purchase made during election campaigns) or in the form of the more recent (yet arguably as important) methodical building of online party databases. Those databases serve as the nerve center for a more micro-targeted form of campaigning and get-out-the-vote (GOTV) effort that can lay the knowledge-based foundation for what is best described as the brave new world of online retail campaigning. With this in mind, discussion in the third chapter will focus on data-driven political campaigning and also the impact of technology on the speed at which marketing — whether commercial or political — must be conducted to avoid losing control of one's message.

Chapter $I V$ is devoted to identifying and describing the methodology used to answer this study's proposed research questions. In addition, the chapter describes, in great detail, the way that the research sample will be gathered and analyzed. It also discusses how the sample for this project addresses the two conduits of influence which serve as the focal point for much of the analysis. Chapters V and VI focus on the results of my primary research analysis. Chapter VII draws this dissertation to a close by fully revealing the findings of my research which, in a nutshell, assesses the flow of influence in federal political campaigning. In this concluding chapter, I relate my findings back to those of other studies dealing with the flux of political influence. Finally, this chapter allows me to examine the implications of my research findings and to draw some 
conclusions in the hope of establishing their relevance for the discipline of communications research. 


\section{II \\ The Marketing Conduit}

This chapter shines light upon the main focus of the dissertation itself: examining how the flow of influence and innovation between commercial marketers and political marketers may be bidirectional and therefore seen as indicative of a two-way street with bidirectional interplay between commercial marketers and political marketers rather than as a one-way street with one-way traffic from commercial to political marketers. But making such an argument requires examples that can be seen as focal points for that bidirectional flow. Consequently, in this dissertation, two phenomena or conduits of influence are used to investigate the extent of the possible bidirectional flow of influence and innovation between commercial and political marketers: The first is that of marketing itself and the second is that of technology. In other words, marketing and technology represent two broad areas where the potential bidirectional flow of influence and innovation manifest and therefore warrant a thorough examination herein.

This chapter serves the purpose of examining the current state of marketing with an eye towards how it is emblematic of the aforementioned bidirectional flow of influence. To accomplish that task, tribal marketing in both the commercial and political marketing ecosystems is discussed as are notions of relationship marketing and the socalled "consumer citizen" with its impact upon both commercial and political marketing — not to mention the increasingly important and evolving nature of market intelligence.

All three are increasingly important marketing phenomena that could be seen as being indicative of the bidirectional flow of influence and innovation. However, given the fact that the gathering, interpretation, and strategic implementation of market intelligence is increasingly dependent upon sophisticated data mining techniques and computer 
programs to analyze the information siphoned from those data mining techniques for predictive purposes, the market intelligence discussion in this chapter will function as a teaser for, and pivot point to, the following chapter in this dissertation. That third chapter will isolate the second exemplary phenomenon or signpost of the possible bidirectional flow of influence and innovation, that being technology. Interestingly, that process begins with a discussion of politics and soap.

With an eye towards highlighting the potential bidirectional flow of influence and innovation between commercial and political marketers, an important distinction should be addressed. Newman (1994) provides this distinction for us by explaining that, "Some people have likewise referred to a candidate as a bar of soap, suggesting that a candidate is marketed like a product. This, however, is a myth that has circulated in the popular press for some time now" (p. 9). Or, as Alex Marland (2003) puts it, "despite its colourful history, the 'selling soap' analogy is outdated" (p. 106). Furthermore,

It presumes that candidates are sold with a selling concept rather than promoted within a 'marketing concept' (where marketing research is used to adjust promotional tactics). It requires that parties or candidates share characteristics with commodity goods when in fact they are specialised service providers. (p. 106)

To flesh out this line of reasoning, according to Newman (1994) and Marland (2003), a political candidate is a service provider just as a doctor, solicitor, electrician, or countless other professionals are service providers.

In other words, when it comes to political marketing, what we have is more akin to "service marketing" than to "product marketing" (Newman, 1994, p. 9-10). Thus, "when applying marketing to politics, the exchange process centers on a candidate who offers political leadership in exchange for a vote from the citizen" (p. 10). And, as 
Richard Speed, Patrick Butler, and Neil Collins (2015) remind us, in politics, "what characterizes the offer and differentiates it from the common or commercial understanding of a product is that it is a distinctly multi-component phenomenon that combines the ideology, the person, and the party" (p. 132). In sum, to simplistically and wrongly - think of political candidates as akin to being sold like a bar of soap (or any other consumer product for that matter) is to assume that politicians and the political parties which they represent are bound to either the product-oriented or the sales-oriented market orientations outlined in the previous chapter courtesy of the writings of Kohli and Jaworski (1990), Narver and Slater (1990), Lafferty and Hult (2001), and Ormrod (2006), but that they are unable to bear the mantle of the more sophisticated and self-reflexive market-oriented perspective.

\section{Tribal Marketing, Consumer Tribes, \& Wedge Politics}

A crucial element of the contemporary play between political marketing and commercial marketing relates to brand neutrality or, more accurately, to a lack thereof. Neutrality has never been a prerequisite for successful political campaigning. In fact, quite the opposite is true. Politicians and the political parties to which they are conjoined are expected to stand for something and are expected to have policy positions on most issues of the day. In Churchill's Wit: The Definitive Collection (2009), it is noted how, in 1902, Winston Churchill pithily remarked: “'[A politician] is asked to stand, he wants to sit and he is expected to lie"' (p. 168). Cynical though it may be, few would deny that statement. But what about commercial marketing and the brands it promotes?

Douglas Atkin (2004) sets the stage for answering this question by stating that, "One of the greatest dreads of marketers is turning off any potential customers" (p. 17). 
Commercial marketers and the brands they promote have been engaged in a longstanding game of tug of war when it comes to the matter of neutrality. At issue has been the fear of offending, thereby likely losing a potential customer (Atkin, 2004; Scammell, 2015; Veroni, 2014). A great deal of consumer marketing has reflected this tendency and has subsequently resulted in insipid marketing to say the very least. The result is that, "trying to avoid any sort of negative impression frequently results in marketing that avoids leaving any impression at all" (Veroni, 2014, p. 63). As Atkin (2004) puts it in a more vivid fashion: "In the attempt to please everyone and offend no one most of the ideas [put forth by marketers] were compromised, their destiny to be relegated to dusty laminated sheets on cubicle walls and the old coffee mug in the company kitchen" ( $p$. 24).

The point being made here is that, with very few exceptions, commercial marketers have generally striven to attract the median or average consumer by way of inoffensive marketing campaigns, strategies, and tactics that are increasingly falling upon deaf ears (Atkin, 2004; Cova \& Cova, 2002; Veroni, 2014). They do so for a reason. With the escalating abundance of information provided by media via the many platforms that are frequently consulted on a daily basis, and with the general tendency to gravitate towards information that the user already finds appealing (thus sidelining unappealing information), there are fewer and fewer "average consumers" to cater to.

In the not-so-distant past, the key to creating effective marketing was tailoring your pitch to the middle of the bell curve of public opinion on any given matter (Atkin, 2004; Veroni, 2014). According to Veroni (2014), "Riding that curve is the focus of most marketing efforts. The goal is to make that bulge as high and as wide as possible, with the 
aim of achieving the highest common denominator" (p. 21). Unfortunately, the "highest common denominator" no longer lives up to its namesake for the simple reason that, "this focus on the middle of the curve results in a narrowing of vision. It ignores what's happening at the outer edges. And it's there, on the fringes, where passion lies. And it's passion that can make or break a brand" (p. 21). With a bit of elbow grease, and their near evangelical passion, "a small group of ardent believers at the tapering end of the bell curve can influence what the entire rest of the group thinks and does" (p. 21).

Those small groups of "ardent believers" have come to be known as "consumer tribes" or, if we are using the language of politics, one's "base of supporters" (Cova, Kozinets, \& Shankar, 2007; Chua, 2018; Goldberg, 2018; Sharkey, 2012; Veroni, 2014). But what exactly are consumer tribes, and how are they related to the potential bidirectional flow of influence between commercial marketing and political marketing? To begin to formulate an answer to that double-barreled question requires acknowledging a philosophical truth that helps us to understand and to frame our discussion of consumer tribes and tribal marketing. That truth is expressed by Bernard Cova, Robert V. Kozinets, and Avi Shankar (2007) when they state that: "Social life is a rich, complex, kaleidoscopic confusion that cannot ever be represented by 'causes' and 'effects"' (p. 5). However, it is more complicated than that. In essence, the aforementioned middle of the bell curve (a.k.a. the average or median consumer) is shrinking in terms of size and energy. This is further complicated by the fact that "Today's consumers are not in the market because they want to feel that they are buying something mass produced, confirming conformist longing, commercial" (p. 22). They are seeking the benefits of group identity that come with its exclusivity and cohesion, but are reframing that group 
identity on their own terms in a manner that, somewhat counterintuitively, is predicated on notions of uniqueness and individualism (Chua 2018; Goldberg, 2018; Tett, 2015).

In essence, exclusivity, whether real or merely perceived, is the driving force of the state of marketing at the current moment in time - or at least it should be. In this vein, the argument could be made that this is simply a natural side effect of the decadeslong trajectory that much of Western society has been on, a trajectory in which we have tended to foster the belief that uniqueness conquers all and that anything is achievable with the supposed power of positive thinking, thereby spawning a participation ribbon culture that has recently been intensified by the self-indulgence and navel gazing — not to mention ego boosting - and false intimacy provided by social media. As Bernard Cova and Veronique Cova (2002) aptly put it, "The process of narcissism, induced by the development and widespread use of computers in all aspects of human existence, seems to characterise [sic] our daily life" (p. 596). While this is outside the scope of this dissertation, it warrants further study.

To bring the discussion back to the matter at hand in this chapter, Atkin (2004) reminds us that, "Habits are slow to change" (p. 57). Consequently, "the marketing community has only just heaved itself, reluctantly, away from the belief that its consumer is a mass and homogeneous market" (p. 57). And, in the process of doing so, "It's moved from the broadcast 'Yell and Sell' to the extreme opposite point of view-seeing its customers as isolated individuals to whom one conducts 'one-to-one marketing'" (p. 578). As a result, "The pendulum has swung too far and entirely missed an insight on how to market effectively" (p. 58). Today, knowing the ins and outs of consumer tribes and tribal marketing is an essential component in "marketing effectively." In a nutshell, 
consumer tribes and the tribal marketing that constructs such tribes hinge upon not mere exclusivity but the relationship between exclusivity and community (Busby \& Cronshaw, 2015; Cova \& Cova, 2002; Cova, Kozinets, \& Shankar, 2007). Or, Robert Busby and Sue Cronshaw (2015) concisely put it, "Consumer tribe theory suggests that the most successful brands provide a foundation to community, they give consumers a voice and provide a sense of belonging that supports their identity" (p. 99). That "sense of belonging" is built upon two visceral instincts: passion and community. Veroni (2014) gives us an even clearer identification of the tenets of consumer tribes by explaining that,

In recent years there has been much talk in the marketing world about the growing power and presence of consumer 'tribes.' The term refers to the idea that consumers tend to cluster around common needs and desires, and want to connect with others who are like them. Brands that help them make this connection, and that can lead the tribe, will be more successful. (p. 50)

Cova and Cova (2002) clarify the fact that, "the common denominator of postmodern tribes [such as consumer tribes] is the community of emotion or passion" ( $p$. 598). It is the community of emotion or passion that tribe members feel for the product in question which creates the aura of exclusivity amongst the tribe's members and which ultimately comes to define the product itself (Cova \& Cova, 2002; Scammell, 2007; Scammell, 2015; Veroni, 2014). The community of emotion or passion that accompanies those in a tribe is not individualistic; it is shared amongst tribe members and crafted via the symbolism that is tied to the product itself (Cova \& Cova, 2002; Ostergaard \& Jantzen, 2000).

In this sense, tribal marketing could be viewed as the natural progression of recent thinking which holds that emotions are more significant in either making or breaking political campaigns than are pragmatic choices or considerations which affect voters 
personally, or political platforms that offer a wide variety of promised transactional outcomes (Butler \& Harris, 2009; Keller, 2002; Scammell, 2015; Westen, 2007). To capture the essence of this dynamic, in speaking about Drew Westen's (2007) influential book entitled, The Political Brain: The Role of Emotion in Deciding the Fate of the Nation, Patrick Butler and Phil Harris (2009) state that, "successful campaigns compete in the marketplace of emotions rather than in the marketplace of ideas" (p. 155). In that book, Westen (2007) himself sums up the role of emotion in contemporary politics by simply stating that, "The political brain is an emotional brain [emphasis in original]. It is not a dispassionate calculating machine, objectively searching for the right facts, figures, and policies to make a reasoned decision" (p. xv). Writing ten years after the release of The Political Brain, Michael Serazio (2017) echoes Westen's (2007) thinking by noting that, "Indeed, emotion, rather than reason, represents the essence $[\ldots]$ and the central orientation within branding a political candidate as a cultural product" (Serazio, 2017, p. 234). There is no disputing that the practice of tribal marketing recognizes and subscribes to this line of reasoning.

Related to emotion and passion is authenticity. Speaking about "cult brands," which operate by the same logic as consumer tribes, Atkin (2004) notes that authenticity is crucial in contemporary marketing and, more specifically, in the task of branding. He even goes so far as to say that "You cannot get [...] sustained buy-in if there is a whiff of inauthenticity" (p. 171). Channeling Douglas Holt (2002), Serazio (2017) explains how authenticity fits into the equation when he states that, "To achieve this authenticity $[\ldots]$ the brand has to seem 'disinterested' in the 'commercial intent' that is its ultimate reason for existence and furnish itself, rather, as the resource needed to enable production of the 
consumer's self" (p. 227). Put differently, the brand needs to offer the consumer something more than just its mere use value. With that in mind, "weightlessness" is becoming increasingly relevant in branding, be it for the commercial or political realm (Klein, 2000; Serazio, 2017). For example,

Just as corporations have sought to make themselves organizationally 'weightless,' by detaching from the manufacture of goods on balance sheets in favor of a less tangible, but more profitable brand meaning (Klein, 2000), so, too, is branded politics an effort to make the candidate 'weightless' - detached from the manufacture of policies in their media and advertising representations in favor of a more persuasive cultural meaning. (p. 234)

Regardless of whether or not that desired weightlessness is actually achieved, of vital concern in tribal marketing is cohesion (Chua, 2018; Cova \& Cova, 2002; Goldberg, 2018; Ostergaard \& Jantzen, 2000; Muniz \& O’Guinn, 2001; Veroni, 2014). Tribal marketing "supports products and services that hold people together as a group of enthusiasts or devotees" (Cova \& Cova, 2002, p. 603). And when trying to enhance the sense of cohesion within a tribe by stoking the aforementioned emotion and passion of its members and their devotion to the product or service being marketed, "linking value" is of great importance (p. 603). When speaking about linking value, what is at stake is "the product's, or service's, contribution to establishing and/or reinforcing bonds between individuals" (p. 603). When speaking about tribal marketing, as when speaking about most things in life, the less-is-more approach does not apply since, "The greater the contribution of a product or service to the development and strengthening of the tribal bond, the greater its linking value will be" (p. 603).

Unfortunately, there is a catch: linking value is difficult to manufacture and it is often separate from the "use value" of the product or service itself (Cova \& Cova, 2002, p. 603). In other words, that all-important linking value is usually created not by the 
product itself nor by its marketers, but instead by its consumers. The product may be consumed in the manner envisioned by the producer of the product or service, or be appropriated in a manner that is anything but what the producer of the product or service envisioned (Cova \& Cova, 2002; Scammell, 2007; Scammell, 2015; Veroni, 2014). To express the drawback of linking value a bit differently: tribal marketing, and the linking value that it relies upon, requires the consumers of a product or service to acquire a substantial sense of agency to communally define the brand image, functionality, and values of the product or service in question (Atkin, 2004; Cova \& Cova, 2002; Scammell, 2007; Veroni, 2014). Furthermore, as Atkin (2004) reminds us: "Ownership of the brand must be shared with its membership for it to thrive" (p. 188). But what is a "brand" and what do brands do? Scammell (2007) helps us fill in the blanks. She does so by explaining that, "In marketing, a brand is defined as 'the psychological representation' of a product or organization: its symbolic rather than tangible use-value" (p. 177).

Not surprisingly, consumer agency with respect to defining a brand's image is not the most appealing proposition for many brands and the advertisers that they rely upon in the attempt to craft and control their image in the eye of the public (Scammell, 2007; Veroni, 2014). The reason for this is that allowing the consumer to assume a role in defining a brand's image or meaning is a risky endeavour since it represents a loss of control from the perspective of the brand itself and the marketers or advertisers of that brand (Atkin, 2004; Scammell, 2015; Veroni, 2014). Yet, today, the argument could be made that it is an even riskier endeavour to try to retain every last ounce of control in crafting and maintaining a brand's image and that the process would likely prove to be little more than an exercise in futility anyway (Atkin, 2004; Veroni, 2014). For example, 
as Veroni (2014) aptly explains, "Just as the Internet and social media have ushered out the age of mass marketing, they have also shown the door to the age of centralized brand control" (p. 125). In other words, at the risk of sounding like a technological determinist, relatively recent developments in technology have already altered, and will continue to alter more systemically, the standard operating procedures of marketing and the craft of advertising (a subject that will be explored more fully in the next chapter).

Some have classified the current break with the status quo by labeling it the "Postadvertising Age" (Ries \& Ries, 2002; Scammell, 2007), a perspective which entails that "Advertising cannot substitute for the longer-term, more wide-ranging creation of reputation through sustained public relations" (Scammell, 2007, p. 178). Others, the most noteworthy of whom would be Veroni (2014), have labeled it the "End of Mass Marketing" which maintains that the old rules of marketing (i.e. the tailoring of a pitch to the middle of the bell curve that represented the median consumer) no longer apply since, "Today $[\ldots]$ content $[\ldots]$ is consumable in an infinite variety of ways. Information flow used to be determined by the media outlet; now it's determined by the media consumer" (p. 16). Typically this means that a brand and its image - whether at the moment of conception or through the continuing process of brand maintenance - is a process that is negotiated between the producer and the consumer. It is in this environment that the agency of the consumer has increased exponentially, leading to a situation wherein "the challenge is how to tap into the creativity of others [i.e. consumers] to help promote the brand while still maintaining sufficient control, because full control is no longer an option" (p. 125-6). And this logic has come to be called "Open Branding" (Mooney \& Rollins, 2008; Veroni, 2014) or “User Generated Branding” (Arnhold, 2010). 
An important caveat must be mentioned at this point. Open branding may require a loosening of control of a brand and its image by the traditional brand image cultivators (the product itself and the marketers of it), but it does not require granting the consumer full agency in such matters (Arnhold, 2010; Mooney \& Rollins, 2008; Veroni, 2014). To claim otherwise would be unrealistic and naïve. In light of that fact, Veroni (2014) reminds us that, "Open branding is not about letting go completely; it's about understanding that others will inevitably have their say" (p. 126). And when it comes to letting others have their say, "Rather than trying to silence those other voices, marketers must find ways to ensure that those outsiders are singing in harmony with the brand and not creating discord" (p. 126). That is a difficult task. Still, as difficult and unnatural as that task may be, its necessity has been recognized by political marketers for quite some time (Veroni, 2014). The reason for this is inherently tied to the fact that open branding and tribal marketing go hand in hand. That notion was alluded to earlier by referencing how, for any given consumer tribe to remain vibrant, the consumers therein should be active participants in the creation of the meaning of the tribe and the brand that it coalesces around (Atkin, 2004; Cova \& Cova, 2002; Cova, Kozinets, \& Shankar, 2007; Veroni, 2014).

Referring back to the discussion of neutrality (or the lack thereof) in marketing that was had earlier in this chapter, Veroni (2014) notes that, "Smart marketers, like smart political strategists, understand that avoiding consumer anger and controversy is increasingly difficult. The trick is not to attempt to dodge it but to learn how to manage it and turn it to your advantage" (p. 50). In other words, marketing effectively in our current landscape, which is increasingly populated by various competing consumer tribes, 
requires applying the logic and "lessons of wedge politics" to the practice of commercial marketing (p. 50). Thus, the mantra of wedge politics that you should "say or do something that appeals to your base of supporters [i.e. your tribe], even though you know it will antagonize others" represents an important consideration and tactic to be used in our increasingly fragmented marketing landscape (p. 54). Based upon this logic, "Smart marketers will understand that using the anger of some will allow them to win the support of others," thereby growing the size of one's tribe and also its energy and passion (p. 54). But Atkin (2004) reminds us that this is a fine line to walk since, "Difference is a fickle beast" (p. 158). This is because, to be successful, cult brands (a.k.a. consumer tribes) need to be "able to artfully manipulate the tension dial to be different enough, but appear similar enough [emphasis in original]" (p. 160). As was referenced earlier, they need to offend the wrong people to attract the right people to their brand or cause.

Furthermore, when it comes to branding, "the minute you create a tribe, with its internal cohesion, you are by default creating an opposing tribe, with its attendant conflict" (Veroni, 2014, p. 51). With that in mind, Amy Chua (2018) offers an important philosophical reminder: "Humans are tribal. We need to belong to groups $[\ldots]$ but the tribal instinct is not just an instinct to belong. It is also an instinct to exclude" (p. 1). In her words, tribalism "creates a virtuous Us [those in one's tribe] and a demonized Them [those outside of one's tribe]" (p. 203). In his jeremiad entitled Suicide of the West: How the Rebirth of Tribalism, Populism, Nationalism, and Identity Politics is Destroying American Democracy (2018), Jonah Goldberg also notes this dark side of tribalism by simply stating that "Americans [are] break[ing] up into 'tribal' coalitions against other 
Americans they only see as the "other"' (p. 43). Political marketers are aware of these patterns. That being the case,

This is where political strategists depart from [commercial] marketers. While the [commercial] marketer is focusing all of his or her attention on the internal workings of the tribe, trying to understand its every characteristic and nuance, the political operative recognizes that it's equally important to understand the opposing tribe. It is the tension that exists between tribes that, to the politician, can be a source of tremendous power and leverage. (p. 52)

Political marketers have long been successful at developing consumer tribes, knowing what makes opposing tribes tick and then tailoring their messaging accordingly to either bolster the support of one's own tribe or, conversely, to attempt to siphon support away from members of opposing tribes. This thinking is now permeating the practice of commercial marketing. That permeation is occurring precisely because, "these days, in virtually every consumer arena, people are splintering into tribal groups and demanding to know where the brands they purchase stand on any number of issues" that extend beyond the scope of the use value of the product itself (p. 50). And this is where the notion of the "Consumer Citizen" comes into play.

\section{A Caveat \& a "Consumer Citizen"}

Regardless of whether one takes a sophisticated or a more uncomplicated approach to discussing political marketing, there is a consideration that must be borne in mind in any such discussion. Lees-Marshment (2009) draws our attention to it by stating that, "Market-oriented politics $[\ldots]$ suggests that the relationship between citizen and state is changing" (p. 220). Further, she states that "market-oriented behavior by governments suggests that the public should be treated like consumers," thereby opening up an ideological powder keg which "threatens the notion of citizens and associated democratic values [...not to mention] the desire to improve society, rather than just meet 
market demand" (p. 220-1). In other words, there is a fear that the selflessness and the often incremental process of consensus building long associated with democratic governance will be supplanted by selfishness and the trajectory towards instantaneous gratification that can be associated with consumer marketing (Savigny, 2008; Scammell, 2003). No matter how you put it, as a discipline, political marketing is no stranger to accusations that it damages democracy by altering the aim of political campaigning, and ultimately governance, for the worse (Dermody \& Scullion, 2001 \& 2003; Moloney \& Colmer, 2001; Lilleker, 2005). Stephen C. Henneberg, Margaret Scammell, and Nicholas J. O'Shaughnessy (2009) sum up the situation by stating that: "In general, the merging of the two worlds of marketing and politics, perceived to be that of the trivial and the superficial in contrast to the spiritual and substantial, to paraphrase Werner Sombart (1915), “provokes profound anxiety” (Henneberg, Scammell, \& O’Shaughnessy, 2009, p. 166). In fact, some adherents of this line of reasoning will even go so far as to claim that, "The use of marketing instruments in politics is argued to imply atrophy and aberration" (p. 166). Strong words.

Being aware of this often visceral debate directs attention to a line in the sand that was drawn by Newman (1994) more than two decades ago. Newman did so by claiming that, "There are, however, three glaring differences between marketing and politics" (p. 10). The first is philosophical in nature (p. 10). For instance, "In business the goal is to make a profit, whereas in politics the goal is the successful operation of democracy" (p. 10). The second is what can best be described as a matter of margins. In essence, the margins in marketing and politics are not interchangeable. The reason for this is that, "winning in politics is sometimes based on a few percentage points, whereas in business 
the difference between winning and losing is based on huge variations" (p. 10). For Newman, the third and final difference between marketing and politics is what can be described as a matter of philosophical malleability. It is a philosophical malleability which is typically in shorter supply in the political camp since, "[a] business often follows through with the implementation of actions based on marketing research results if the business stands to profit, whereas in politics the candidate's own political philosophy often shapes the extent to which marketing research results are followed" (p. 10).

However, that line in the sand is now being crossed. In fact, it is Newman (1994) himself who notes that, "The differences between marketing and politics have not prevented the practitioners in both areas from working to merge the two" (p. 10). The momentum of that merger has only intensified since the time that it was noted by Newman (Lees-Marshment, $2001 \&$ 2009; Scammell, 2003). The underlying reason is captured in the statement that, quite simply, "marketing can bring a number of benefits" into the political process (Lees-Marshment, 2009, p. 221). Those benefits are duly noted by Lees-Marshment (2009) who posits that, "It [marketing] enables governments to understand public concerns more effectively not just at elections and re-connect government with the governed" (p. 221). Additionally, "Marketing can provide a means for governments to listen to the public, which in turn can improve policy-making and implementation" (p. 221). In essence, this dissertation requires a recognition of the fact that, despite its many warts and potential for ideological squabbles, "There needs to be a $[\ldots]$ redefinition of the consumer as a political consumer that incorporates some notion of citizenship" (Lees-Marshment, 2004, p. 237). 
Such a redefinition may already be underway, though. That is good news since, in light of the earlier discussion of some of the common criticisms lobbed at the discipline of political marketing, as Henneberg, Scammell, and O'Shaughnessy (2009) note, "political marketing needs to engage with theories of democracy in order to provide itself with legitimacy. While political marketing may arguably be 'conceptually neutral,' its application and practice is not and needs to be imbued with normative aim" (p. 181). If one of the chief criticisms of political marketing is its potential to reduce political campaigning and governing to mirror the consumer world's supposedly more transactional, selfish, and short term consumption-based gratification, as was implied earlier by way of Savigny (2008) and Scammell (2003), I argue that that line of reasoning is off the mark. To take that perspective misses a number of facts and is blind to a number of benefits that political marketing brings to the table.

For instance, consumption itself and, more specifically, political marketing's association with consumption should not be a damning factor for the discipline. Dhavan V. Shah, Douglas M. McLeod, Lewis Friedland, and Michelle R. Nelson (2007) reveal the reason that this may be so by reminding us that, "Consumption can be altruistic (e.g., gift giving), political (e.g., boycotts and buycotts) and democratic (e.g., the 'egalitarian ambience' of McDonald's). Conversely, civic and political activity may serve to advance personal desires or to enhance the egotistical joy of victory" (p. 13). In other words, no subject - no matter how noble it should be — can extinguish the good, the bad, and the ugly traits of human nature. And, more crucially, consumption itself can be a political act and has been so for a very long time (Breen, 2004; Schudson, 2007; Scammell, 2015; Shah et al., 2007). Probably the clearest example of this is how consumption habits 
played a role in sparking the American Revolution (Breen, 2004; Schudson, 2007; Shah et al., 2007). Nearly two and a half centuries ago, "Consumer politics shaped the American Revolution and laid the groundwork for nationhood" (Shah, McLeod, Kim, Lee, Gotlieb, Ho, \& Breivik, 2007, p. 217). In particular, "The colonists, who differed in many respects, shared an identity as aggrieved consumers of British goods. It was through their behavior as consumers that the colonists developed their most innovative and potent form of political action: boycotts" (p. 217). In essence, consumption and politics are not antithetical. In fact, the argument can be made that politics is merely a form of consumption by another name (Breen, 2004; Schudson, 2007; Scammell, 2015; Shah et al., 2007).

Equating politics and consumption opens the door to discussions of "Political Consumerism" or the so-called "Consumer Citizen." Notions of the consumer citizen and the political consumerism which he or she practices essentially hold that participation in politics is not limited solely to voting and the other traditional hallmarks of political participation, such as joining a political party or working on a political campaign (Breen, 2004; Scammell, 2015; Shah et al., 2007). It entails that there are more subtle, but equally as important, ways of participating in contemporary politics. Quite often, an essential component of this argument is based upon the fact that one can "'vote with one's pocketbook' rather than only at the polling place" (Shah, McLeod, Kim, Lee, Gotlieb, Ho, \& Breivik, 2007, p. 233).

But how does this work? While there are many definitions of political consumerism, the one I use here — given its clarity and brevity — is the following: "The act of selecting among products and producers based on social, political, or ethical 
considerations [...which] may provide people with an alternative mode to engage with public issues outside of conventional political and civic behaviors such as voting or volunteering” (Shah, McLeod, Kim, Lee, Gotlieb, Ho, \& Breivik, 2007, p. 219). To put it differently, "People might prefer participating in informal, life-style based mobilization as a way to avoid traditional politics" (p. 220). Such "informal life-style based mobilization" might include purchasing certain products based on their corporate social responsibility track record - or their lack thereof (Breen, 2004; Schudson, 2007; Scammell, 2015; Shah et al., 2007). In so doing, the consumer citizen is a reminder of the increasing lack of neutrality which has long been typical in the practice of political marketing and which is increasingly becoming more prevalent in the world of commercial marketing, as was described earlier on in this chapter. To take this notion of socially conscious consumption even further, as do Dhavan V. Shah, Douglas M. McLeod, Lewis Friedland, and Michelle R. Nelson (2007), "socially conscious consumption [like that practiced by the consumer citizen...] has become $[\ldots]$ a badge of belonging" to those who pursue this nuanced form of political participation (p. 7).

Similarly, it is worth pointing out, as do Butler and Harris (2009), that the nature of politics is changing and becoming more acute, but no less significant, than in the past. For example, they state that, "The transformation in political life in western-type societies in recent times includes the shift from the abstract to the tangible; from the consideration of principles to the emphasis on the immediate outcome" (p. 158). Again, some may criticize this statement in light of the aforementioned accusation that the increasing proliferation of political marketing has resulted in the transposition of more fickle traits, habits, and expectations from the commercial realm onto the political realm. However, 
that ignores an obvious benefit of the current situation which is also noted by Butler and Harris: "Citizens are measuring more closely such outputs of political systems" (p. 158). Political accountability is never unwelcome, nor is it a commodity where the less-is-more approach applies.

Additionally, increasing voter participation should always be a key concern as well as an objective in political campaigning and, ultimately, governing. Should using the teachings and practices of political marketing help with that process, it would certainly be a boon for the democratic process. Thus,

To ensure meaningful participation in our democratic system, understanding the nexus between party and marketing is vital. In this context, value and value creation are the central elements of political marketing strategy and the success of parties depends on the extent to which they create for the voter-citizen what is of value to them. (O’Cass, 2009, p. 205)

Lately, more often than not, "what is of value" to the voter-citizen comes via a kind of intrapersonal relationship pattern that is related to the notion of consumer tribes and the tribal marketing discussed earlier. At issue here is how "Marketing is in some ways moving away from the marketplace to the customer, from transactions to interactions, from product-centred [sic] logic to service-centred [sic] logic and to an organizational function and a set of processes, and from exchanges to long-term relationships" (p. 200). Enter the practice of "Relationship Marketing."

Tamara A. Small (2012) gives us a clear description of relationship marketing by explaining that, "Rather than a one-off exchange between a business and a consumer, relationship marketing is concerned with establishing long-term associations. This relationship is akin to a marriage" (p. 193). Repeat business is the calling card of this marriage-like relationship between the business and the consumer or, in the political 
context, between the candidate or party and the voter (Foster \& Lemieux, 2012; Marland, 2012; Newman, 1994; Small, 2012; Veroni, 2014).

Writing more than twenty years ago, Newman (1994) pointed out that continual advancements in technology have affected the concept of relationship marketing and amplified its importance. For instance, as he explains, "Marketing technology in the commercial marketplace has evolved [...] with companies concentrating on building long-term relationships with their customers" (p. 26). In doing so, "companies are now taking their products and their message directly to the consumer without reliance on the standard channels of distribution" (p. 26). In essence, "The emphasis in relationship marketing is on using information technology to send targeted messages to specific segments of consumers" (p. 26). Regardless of whether or not the middleman has truly been cut out, relationship marketing is a crucial component of any modern discussion of marketing in any realm, either commercial or political.

Yet, if we are thinking about relationship marketing in the context of the ebb and flow of influence between commercial and political marketing in the twenty-first century, there are a number of systemic setbacks built into that marketing practice itself which, after careful consideration, could sway one to conclude that the tribal marketing doctrine discussed earlier on is a more effective strategy to undertake at this current juncture (Cova, 1997; Cova \& Cova, 2002; Muniz \& O’Guinn, 2001). Cova and Cova (2002) reveal why this is the case by stating that, "one-to-one marketing and other relationship marketing panaceas can be criticised [sic] on two fronts" (p. 603). They are the following:

(1) They are limited in their attempt to be the closest to known customers, without sharing any emotion with them. They confuse proximity and intimacy, and base 
everything on customer service. In fact, increasingly people do not want to be simply the object of an individualized [sic] service in terms of customisation [sic] of functions. They also want an emotional bond of a collective nature.

(2) Relationship marketing approaches are short-sighted in how they look at what they call the 'relation.' Whereas the individualistic approach to relationship marketing aims at creating and developing a relation between the brand or the firm (even a member of the firm) and a customer, the tribal approach to marketing prefers to recreate and support the relation between customers. Products, services, physical supports and employees are dedicated to supporting the tribal link, not substituting for it - an often unfeasible and counter-productive task. The tribal interrelations exert pressure on members to remain loyal to the collective and consequently to the brand. (p. 604)

In other words, if the end goal of political marketing is to increase the effectiveness of the political process or, as O'Cass (2009) puts it, “[If] the central purpose of political marketing is its ability to enable political parties and voters to make informed, needoriented political decisions," (p. 198), tribal marketing is a better-suited approach to examine within the confines of this project. Despite its criticisms, I would argue that market intelligence helps with this task and is where we must now turn our attention in continuing to paint a picture of the possible shifting flow of influence.

\section{Market Intelligence}

As was alluded to earlier, market research and public opinion research have long been important components of both commercial and political marketing. They hinge upon the gathering of consumer or voter preferences through various forms of quantitative and qualitative research techniques in order to then craft products in the commercial realm or policies in the political realm that reflect those preferences (Giasson, Lees-Marshment \& Marland, 2012; Kohli \& Jaworski, 1990; Lees-Marshment, 2013). In the 1990s and early 2000s, political marketing researchers largely reframed the generations-old thinking about market and public opinion research by positing that those practices were 
undergoing an evolution into what could be better defined as market intelligence (LeesMarshment, 2013; Turcotte, forthcoming).

Unlike market research and public opinion research which prioritize the homogenous, market intelligence prioritizes the heterogeneous (Turcotte, forthcoming). As Andre Turcotte (forthcoming) puts it: "The key dimension of market intelligence is that it no longer looks at the electorate homogeneously but adopts strategic segmentation techniques that permit for policies and communication to be designed for targeted groups" (p. 6). Based on this reasoning, one could argue that we are living in a "postmass marketing world" (Veroni, 2014, p. 81). As Veroni explains, "In the post-mass marketing world, the emphasis will be less and less on reaching large numbers of people with the same message and more and more on reaching specific people with highly individualized messages" (p. 81). Thus, the name of the game is "connecting with millions of individuals and sending out customized messages in order to tell a general story about a product or brand" (p. 83).

As was teased out earlier, this practice has been executed by political marketers for well over a decade using a process that has generally been referred to as segmentation/micro-targeting (Issenberg, 2012; Kreiss, 2016; Lees-Marshment, 2013; Veroni, 2014). But, telling the true story of segmentation/micro-targeting and how political marketers may indeed have better implemented this practice than have their commercial counterparts entails turning our attention to the technology conduit portion of this dissertation, since effective segmentation/micro-targeting requires the use of technology - be it in the form of databases, analytics, algorithms, tracking polling, or all of the above. 


\section{III \\ The Technology Conduit}

This chapter picks up where the previous chapter left off, both literally and figuratively. It does so by examining the second conduit of influence, wherein the flow of influence moves bidirectionally between commercial marketers and political marketers rather than merely from the former to the latter. The second area that exemplifies the potential bidirectional flow of influence and innovation between commercial and political marketers concerns the impact of technology on the political marketing world.

To thoroughly mine this subject matter, this chapter will be organized in a threepronged manner. The first prong establishes the much needed historical context by identifying the impact of some of the most crucial technological developments to influence the practice of political campaigning over the years. The second prong brings us back to the present day by expanding upon the discussion in Chapter Two concerning voter segmentation and micro-targeting, exploring how analytics-based campaigning that relies upon data — be it gathered transparently or clandestinely — is becoming more commonplace. Attention here will be given to the way that analytics-based campaigning is conjoined with ever more advanced forms of fundraising for political purposes as well as to the fact that, whether rightly or wrongly, money is often regarded as the lifeblood of politics. The third and final prong examines an important consequence of increasingly technology-dependent political campaigning: speed and the challenges it poses. And, in the spirit of the bidirectional flow of influence that is examined in this dissertation, substantial discussion will examine how political marketers are more experienced in 
contending with this accelerating speed than are their commercial marketing counterparts.

The discussion of technologically induced speed is a crucial component of this dissertation. I also argue that it is a clear indication that the bidirectional feedback loop of influence and innovation between commercial marketers and political marketers is already occurring. Further, discussing the impact of speed on political marketing points to a visible evolution from the original political marketing framework developed by Jennifer Lees Marshment and others.

\section{A Brief History of Technology in Political Campaigning}

Technology has always had a role to play in political campaigning; but its importance has increased exponentially over the years. While much of this chapter is devoted to examining how the datafication of life in an increasingly digital society is indicative of the bidirectional flow of influence between political marketers and commercial marketers, particular attention will be paid to the current appetite for connectivity via the Internet and how it has helped facilitate this trend. It will also be noted that analog technologies have had an indelible impact upon political campaigning well before the Internet was conceived. A few such influential analog technologies included the telegraph, the telephone, the radio, and television.

However, since thoroughly examining the impact that any one of these four influential analog technologies, alone or combined, has had upon the practice of political campaigning could easily be the topic of a dissertation in and of itself, it is safe to say that that discussion is well beyond the scope of my project. Instead, I will briefly take this opportunity to touch upon the way that the telegraph, the telephone, radio, and television 
played a role in altering political campaigning and, in so doing, laid the groundwork for the Internet-based digital campaigning that is currently in practice. My reasoning is that context counts and that, while our current state may feel timeless, it is always linked back to the past that preceded it.

Katherine Hayles (2012) states that the electric telegraph was "the first globally pervasive binary signaling system" (p. 123). While the telegraph is often regarded as the first technology to successfully harness the power of electricity for communication purposes, its role in the context of political campaigning can be characterized as one of increasing the efficiency of the management of political campaigns (Hanson, 2008; Hayles, 2012; Lubrano, 1997). Given the fact that the electric telegraph truly separated communication from transportation, the speed of message transmission that it provided allowed political campaigns to have a more up-to-date understanding of how well any given campaign was going because it allowed candidates, campaign managers, and precinct captains to communicate more quickly than when a message had to be physically carried from point A to point B via a messenger (Carey, 1989; Czitrom, 1982; Postman, 1992; Thompson, 1995). In other words, with the advent of the electric telegraph, running a large-scale political campaign was less of a blind affair. However, while the telegraph has often been characterized as the "Victorian Internet," such a characterization misses the fact that the telegraph systems which were used throughout much of the nineteenth century, and even into the early twentieth century, were fragile and extremely costly to operate (Copeland, 2003; John, 2010; Wheeler, 2006). Consequently, in the context of political campaigning, telegraphy was generally used solely for candidate to campaign 
communication and for internal campaign communications rather than for campaign to electorate communications (Hanson, 2008; Lubrano, 1997).

The telephone further heightened the speed at which political campaigns could communicate amongst themselves and thereby also intensified the efficiency of running a campaign; but it too was a technology whose impact was largely felt inside rather than outside political campaigns (Carlson, 2001; de Sola Pool, 1983; Nownes, 2013). Put differently, by the early twentieth century, the telephone had further sped up the connectivity of life as we know it, since it was slowly penetrating North American and Western European society as it was harnessed for both recreational and commercial usage. However, as was the case with the telegraph, its use by political campaigns was still primarily for internal communications rather than for external communication with the electorate itself (Carlson, 2001; de Sola Pool, 1983). Voter contact had not yet been married to technology. Radio, or wireless as it was commonly referred to, changed all this (Bennett, 2012; Craig, 2005; Czitrom, 1982).

With the radio came the opportunity to communicate directly with the electorate, although the direct communication was one-way: from the campaign to the voters (Bennett, 2012; Craig, 2005; Czitrom, 1982). Savvy candidates could get on the air and talk directly to the public whose votes they were trying to earn, whether in the form of a campaign advertisement or by more subtle and elegant forms of persuasion. American President Franklin Delano Roosevelt pioneered and perfected the latter tactic in the 1930s through his well-known "fireside chats" (Craig, 2005; Houchin Winfield, 1990; Levine \& Levine, 2010). Furthermore, key campaign speeches and events, such as nomination conventions, could (and were) broadcast over the radio thereby allowing the average 
voter a closer "look" at the political process than ever before (Bennett, 2012; Craig, 2005; Czitrom, 1982). But "look" may be a misplaced descriptor here since radio only broadcast sound.

Television brought campaign-electorate intimacy — or at least the perception of it — to a previously unimaginable level. It allowed voters to not only hear what a candidate sounded like, and to hear what was happening along the campaign trail, but it allowed them to see it with their own eyes. No longer would the only glimpse voters had of a national-level candidate be provided by attending, in person, events on the campaign trail, or through reading campaign literature or the daily newspapers. Television also created what has typically been the largest source of campaign expenditures since political campaigns embraced the medium: television advertisements (Allen \& Parnes, 2017; Bennett, 2012; Cornfield, 2017). The televising of the first U.S. presidential election debate between Democrat John F. Kennedy and Republican Richard Nixon in 1960 established the now all-too-familiar main event of any presidential campaign and also made candidate image and appearance a requisite variable to be crafted, maintained, and manipulated if one hoped to have any chance of winning on Election Day (Bennett, 2012; Harding, 2008; McGinniss, 1969). Richard Nixon was the first presidential candidate to learn this lesson the hard way in the aftermath of that pivotal 1960 presidential debate (Bennett, 2012; Cacciotto, 2017; Harding, 2008). Marco M. Cacciotto (2017) paints a richer picture of the impact of television upon political campaigning by explaining that,

The establishing of television as the dominant medium of political communication implied that candidates and parties had to adapt and accept the standards of the new medium. This resulted in campaigns being centered more on candidates and 
their personalities, rather than [being] party-centered, as they had been in the past. (p. 54)

Cacciotto also neatly sums things up for us at this point by noting that, "In the history of political communication, every new technology has helped those politicians who have managed to master it" (p. 54). As we will see throughout this chapter, this pattern has not been bucked with the development of the Internet and the new, more surgical, political campaigning to which it gave birth.

\section{Data-Driven Political Campaigning}

As the previous discussion suggested, while the use of technology in politics is by no means a new phenomenon, recent advancements in information communications technologies (ICTs) have greatly increased the potential for political parties and candidates to reach out to voters and develop "get out the vote" campaigns which are far more intricate than was imaginable even a few short election cycles ago (Dufresne \& Marland, 2012; Hersh, 2015; Magleby, 2011). While data has long been an ingredient in political campaigning, only relatively recently could it be claimed that data has become one of the main ingredients in a campaign. It could be argued that the shift from the former to the latter occurred in the aftermath of the successful campaign to re-elect Democrat President Barack Obama in November of 2012 (Cacciotto, 2017; Hersh, 2015; Issenberg, 2012; Kreiss, 2016; Kreiss \& Jasinski, 2016; Kreiss \& Saffer, 2017; Veroni, 2014).

Obama's initial victory in 2008 was heralded as a watershed moment in American history for many reasons - some more obvious than others. One of the less obvious was its harnessing of the Internet for political campaigning in new and innovative ways (Issenberg, 2012; Kreiss, 2016; Veroni, 2014). For example, quoting Michael T. Heaney, 
Matthew E. Newman, and Dari E. Sylvester (2011), William J. Miller (2013) notes that "Obama's Internet presence in 'the 2008 election helped to do for the Internet what the 1960 election did for television: legitimize its role and demonstrate its potential"” (p. 332). In so doing, it expanded upon earlier successful endeavors of that nature such as Howard Dean's grassroots insurgent campaign for the Democratic presidential nomination during the 2004 Democratic Primary; Republican President George W. Bush's successful re-election campaign in 2004 (the first to truly shed light upon the symbiotic relationship between data and micro-targeting) and, of course, Republican Senator John McCain's pioneering use of the Internet for fundraising and communication purposes during the divisive 2000 Republican presidential Primary (Kreiss, 2016). More recently, in the Obama campaign in 2008,

The relentlessly quantitative approach of the analytics department reflected a different approach to measuring public opinion, one with little texture for the ways people talked but the ability, through statistical models, to draw inferences about not only where the population stood but also where it would end up. (Issenberg, 2012, p. 346)

And that quantitative approach was further refined in the 2012 presidential campaign (Kreiss, 2016; Veroni, 2014) since "his campaign team had accumulated decades of political learning on how to operate in a highly divisive atmosphere, and they combined it with the latest in technology, data analysis, and social media communication to break through the noise and get their message heard" (Veroni, 2014, p. 13).

The logic of the data-driven campaigning that had been masterfully executed in 2012 by the Obama campaign was still fresh in the memory of both Republican and Democrat candidates and their consultants as the 2016 presidential season began to take shape. And, as the 2016 primary season transitioned to the general election season, the "if 
it ain't broke, don't fix it" logic applied — especially within the campaign of Democrat presidential nominee Hillary Clinton (Allen \& Parnes, 2017; Halpern, 2017). For instance, in the attempt to put another Clinton in the White House, Robby Mook, the campaign manager for Hillary Clinton's 2016 pursuit of the presidency, relied upon data analytics reminiscent of those from the 2012 Obama campaign (Allen \& Parnes, 2017; Green, 2017; Halpern, 2017). As Jonathan Allen and Amie Parnes (2017) aptly put it: "All of it [the entirety of the Clinton campaign's strategy] was informed by analytics models that projected how the vote would turn out in each district" (p. 172).

In fact, as one consultant remarked: "'Every investment decision we made—like how many staff to put into a state, how frequently she [Hillary] would visit some placewas all driven by analytics"” (Allen \& Parnes, 2017, p. 230). Attempting to divine the outcome of the election by relying overwhelmingly on analytics, prioritizing a campaign strategy that aimed predominantly at turning out the Democratic party's base and taking for granted that the Obama coalition would vote the same way as it had in 2012, the Clinton campaign spent the lion's share of its resources on GOTV rather than on persuading new undecided voters to come into the fold (Allen \& Parnes, 2017; Halpern, 2017). This meant that Clinton avoided retail campaigning in - or even visiting - a number of states that her analytics team told her would vote for her no matter what (Allen \& Parnes, 2017; Halpern, 2017).

To make matters worse, although there was an abundance of analytics data guiding the 2016 Clinton campaign, there was a relative paucity of traditional internal polling that allowed for daily tracking polling across all fifty states (Allen \& Parnes, 2017; Halpern, 2017). Allen and Parnes (2017) explain that, "Mook had chosen not to 
spend money on polling, to the great frustration of some of the campaign's aides and advisers in key states" (p. 367). The method to Mook's madness was that he "believed it [traditional polling] was a waste of money" (p. 367). Again, 2012 was the reason that Mook made that call which, in hindsight, proved to be a colossal miscalculation. During the Clinton campaign in 2016, Mook

Had learned from David Plouffe, Obama's campaign manager, that old-school polling should be used for testing messages and gauging the sentiments of the electorate and that analytics were just as good for tracking which candidate was ahead and by how much in each state. Plus, the analytics were quicker and much cheaper. (p. 367)

But hindsight is always $20 / 20$ - and most of the polls which were conducted by nonpartisan polling firms that were referenced ad nauseum showed no sign of Clinton losing on Election Day (Allen \& Parnes, 2017; Cornfield, 2017; Green, 2017).

Across the aisle, Donald J. Trump's unlikely ascent to the Republican party nomination and then to the presidency in November 2016 also relied upon data but in a different manner than did the Clinton campaign (Allen \& Parnes, 2017; Halpern, 2017). According to Sue Halpern (2017),

In the course of the 2016 election, the Trump campaign ended up relying on three voter databases: the one supplied by Cambridge Analytica, with its 5,000 data points on 220 million Americans including, according to its website, personality profiles on all of them; the RNC's enhanced Voter Vault, which claims to have more than 300 terabytes of data, including 7,700,545,385 microtargeting data points on nearly 200 million voters; and its own custom-designed one, called Project Alamo, culled in part from the millions of small donors to the campaign and e-mail addresses gathered at rallies, from sales of campaign merchandise, and even from text messages sent to the campaign. Eventually, Project Alamo also came to include data from the other two databases. (Halpern, 2017)

As Joshua Green (2017) recounts, “Trump had access to three different sources of polling [...and] none of them pointed toward victory" throughout much of the campaign (p. 7). However, shortly before Election Day 2016, “The Cambridge Analytica model had 
picked up a late shift in the electorate toward Trump. But it was only a model. [The] exit polls were based on thousands of interviews with actual voters, and they were telling a much different story" (p. 12). Yet, as is now all too clear, the model was right and the exit polls were wrong.

The principal alchemist behind the Trump campaign's below-the-radar data operation was Brad Parscale, a longtime friend and commercial marketer who, before becoming the Trump campaign's digital director, had marketed various Trump-brand services and products via Parscale's digital marketing and design firm called GilesParscale, Inc. (Green \& Issenberg, 2016; Halpern, 2017; Winston, 2016). Importantly, in addition to those three voter databases, Facebook became an essential weapon for the Trump campaign (Ferguson, 2017; Green \& Issenberg, 2016; Halpern, 2017; Winston, 2016).

Some viewed the Trump campaign's use of Facebook as a psychological weapon in the Trump campaign's toolbox, arguing that Cambridge Analytica

had used psychological data culled from Facebook, paired with vast amounts of consumer information purchased from data-mining companies, to develop algorithms that were supposedly able to identify the psychological makeup of every voter in the American electorate. The company then developed political messages tailored to appeal to the emotions of each one. (Halpern, 2017)

But early analysis reveals that that was likely not the case — or, at least, that such claims were likely exaggerated (Halpern, 2017; Hersh, 2018; Wylie, 2018). For instance, "Though there is little doubt that Cambridge Analytica exploited members of the social network, Facebook's real influence came from the campaign's strategic and perfectly legal use of Facebook's suite of marketing tools" (Halpern, 2017) to conduct surgical micro-targeting to an extent never before seen and then to use the information gleaned for 
an ambitious form of retail campaigning by Trump himself which, unlike the Clinton campaign, aimed to persuade numerous unlikely voters to vote for the Republican candidate and, by default, for the Republican pitch for the presidency (Ferguson, 2017; Halpern, 2017).

With the talk of psychological datamining for political purposes (whether founded or not), we may be witnessing what Turcotte (Forthcoming) describes as a shift from market intelligence to "market surveillance." The key characteristic of market surveillance is its surreptitious gathering of data, as well as the scope and scale of the data gathered (Turcotte, Forthcoming). As Turcotte (Forthcoming) explains,

The emergence of this market surveillance model will also impact political communication. The focus of any communication will be at a very granular level, effectively the individual voter. The model is influenced by information technologists and software engineers rather than social scientists and the objective will be to follow and track individual behaviour and preferences and develop a strategy to communicate with individuals with highly personalize[d] and effective target messages and behavioural triggers to influence them to behave in a predetermined preferred way, be it purchasing a product, watch an ad, sign a petition or vote for a particular candidate. (p. 17)

With Donald J. Trump now residing in the White House instead of Trump Tower, we may already be there.

While it may be stating the obvious, it should be pointed out that data-driven campaigning is dependent upon what has largely come to be known as "big data." Big data is one of many popular buzzwords that often populate academic and non-academic discussions alike about the ever-increasing impact of technology upon our daily lives. But what exactly is big data?

In a fitting fashion, the definition of big data is certainly not small. It is also complicated. Tim Kraska (2013) offers us a taste of the typically complicated definitions 
of big data. But even before so doing, he gives us a disclaimer, warning that, "The biggest misnomer actually comes from the name itself — that is, that 'big data' is about big data" (p. 84-5). He explains by noting that, "I'd argue that the current big data trend only partially deals with its size" (p. 85). For Kraska, size is relative (p. 85). He offers a second disclaimer (and common misnomer of big data as well) by stating that big data is often thought of as being "Only about analytics — this, however, is only half the story. Without considering the system that stores the data in the first place, analytics would be impossible" (p. 85). Moving beyond the misnomers and on to a definition of big data, Kraska proclaims that, "I therefore see big data as two issues: big throughput and big analytics. The former includes the problems associated with storing and manipulating large amounts of data (in relation to the available resources) and the latter those concerned with transforming this data into knowledge" (p. 85). Hardly a simple definition. Marcus R. Wigan and Roger Clarke (2013) provide a more straightforward one by explaining that, "'Big data,' an expression that's been in the formal literature since the 1990s, typically refers not only to specific, large datasets, but also to data collections that consolidate many datasets from multiple sources, and even to techniques used to manage and analyze the data" (p. 46).

To be specific, big data does not mean new data (Wigan \& Clarke, 2013, p. 46). According to Wigan and Clarke, "Large quantities of health and social welfare data already exist[ed]" long before big data as we think of it came into the common parlance (p. 46). However, in the recent past, new originators of big data have become available (p. 46). They include "Locational data arising from traffic management, and from the tracking of personal devices such as smartphones" (p. 46). Furthermore, referring back to 
Kraska (2013) illuminates three more specific reasons why we now "live in the age of big data" (p. 84). To this end, Kraska states that,

First, mobile sensors, social media services, genomic sequencing, and astronomy are among myriad applications that have generated an explosion of abundant data [...] Second, storage capacity for the past 30 years has roughly doubled every 14 months, making storing data cheaper than ever [...] Third, and most importantly, recent advances in machine learning and information retrieval let us convert previously useless data into knowledge. (p. 84)

He elaborates on the third of these by noting that in the private sector there is now "a compulsion in companies to record and collect everything possible" (p. 84). Despite the technological determinist reasoning and given the speed of technological progress, what is useless this year may be useful next year (p. 84). Beyond that, the current logic goes something like this: "Most of this [data] might not be useful today, but could be tomorrow. [And because of this], companies now regard data as one of their biggest assets, and the urge to collect more seems to have no boundaries" (p. 84). The greatest of attention should be paid to the last part of that sentence: that is, that "the urge to collect more seems to have no boundaries" (p. 84).

On this matter, Wigan and Clarke (2013) claim that "Businesses and governments exploit big data without regard for issues of legality, data quality, disparate data meanings, and process quality" (p. 46). Essentially, "Corporations see big data as a tool for commercial advantage, particularly in consumer marketing" (p. 46). Micro-targeted marketing made possible through the surreptitious gathering, storing and analyzing of big data is the end goal from their point of view (p. 47). For example, "Managerial applications $[\ldots]$ lean toward using analyses of big data not for generalization but for particularization. The payoff is the discovery of individuals of interest and the customization of activities targeted at specific individuals or categories of individuals" ( $p$. 
47). Typically, the data collected for such purposes is accumulated via loyalty cards, social media usage, and the sensors located within the ubiquitous sea of mobile devices usage (Wigan \& Clarke, 2013). We are constantly leaving a hidden data trail behind us (p. 49-50). And, our data trails "can be used for more than originally intended [...] and with or without informed, freely given, granular consent" (p. 50). When it comes to consent for such usage, the latter rather than the former is often the standard operating procedure (Wigan \& Clarke, 2013).

It should also be noted, as Wigan and Clarke (2013) do, that "Smartphones, tablets, and other mobile devices can not only be located with considerable precision with or without the user's knowledge and meaningful consent — but also accurately tracked, in real time" (p. 50). So much for the often-touted anonymity that is frequently considered to be an incontestable characteristic of Internet usage. To say that the border between public and private is increasingly blurry would be a colossal understatement. As Wigan and Clarke put it, "In less than a decade, the explosion in smartphone usage has resulted in almost the entire population in many countries having been recruited as unpaid, high-volume suppliers of highly detailed data about their locations and activities" (p. 50). Furthermore, "this data is highly personal even before it's combined with loyalty card data, marketers' various sources of consumer data, and the locations and activities of other people" (p. 50). Given the circumstances, maybe German philosopher and historian Oswald Spengler (1931) really was right when he remarked that "Optimism is cowardice" (p. 104). Especially since this data syphoning has clearly permeated the practice of politics as well. 
Eitan D. Hersh (2015) gives us an important notice to keep in mind when thinking about the types of data that make up the recipe of the so-called data-driven political campaign that garners such attention today. To this end, he states that, "So far, social networks have not provided campaigns with clear perceptions of voter attitudes that campaigns can compensate for the limits of public records" (p. 184). Put differently, public records still remain the essential data foundation to which virtually all forms of data-driven campaigns add supplementary data in the form of consumer data, not to mention social network-generated data, in the hope of more accurately predicting voters' attitudes and behaviors (Elder \& Phillips, 2017; Hersh, 2015; Miller, 2013).

But nothing in life is truly free and public records are no exception to this rule. For instance, "A key part of this story [i.e. data-driven politics] is that through carefully crafted laws to election data, politicians have repurposed administrative personal information to serve their electioneering needs" (Hersh, 2015, p. 6). More specifically,

The point is that the basis for voter engagement depends not on what campaigns would like to do in theory, but on the data they can access that allows them to form impressions about the electorate. Because the data that campaigns access often comes from public records, the laws within a jurisdiction that govern how personal information is collected and disseminated serve as levers that affect how and why political campaigns engage with some voters but not others. (p. 7)

Consequently, there is a tendency to pull the levers (a.k.a. design laws) that serve one's own electoral advantage and that disadvantage one's competitors (Hersh, 2015; Kreiss, 2016). Incumbency is a powerful force and human nature rarely changes.

Even so, data-driven political campaigning is undeniably changing the nature of political campaigning particularly in national-level races since, amongst other things, such campaigning is extremely expensive to successfully implement and execute (Hersh, 2015; Issenberg, 2012; Kreiss, 2016; Miller, 2013). But we must strive to avoid being 
seduced by the all-too-frequent infatuation with the mystique of technology in the political profession. To this end, Daniel Kreiss (2016) offers us an important disclaimer that should be kept in mind: "technology-intensive campaigning [...] means parties devoting significant resources and attention to the comparatively mundane, behind-thescenes work of infrastructure building" and these include "the production of technologies, organizations, trained staffers, knowledge, and practices in between elections that affects the technology, digital media, data, and analytics resources that future campaigns can draw on" (p. 4). Furthermore, it is important to remember that,

Many of the technologies [...that political campaigns rely upon], such as the parties' database and interface systems, are not simply available 'off the shelf' from commercial providers, and they cannot be assembled quickly. Even more, they are inextricably intertwined with the broader infrastructures of the parties as well as the expertise the parties have for maintaining them, and they must be institutionalized and cared for over time or they break down or disappear. (p. 4)

Consequently, contextualizing and then analyzing the role of technology in the potential bidirectional flow of influence and innovation between commercial and political marketers traced by this project involves transitioning from the consumer marketing and political marketing concepts discussed earlier to several communications theories. Two in particular warrant substantial attention: First, the technological or mechanical sublime and its offspring, the electrical sublime; Second, the distinction between technological determinism and symptomatic technology.

Returning to Spengler's (1932) previously cited maxim that "Optimism is cowardice" helps us with this endeavor (p. 104). That maxim is not the maxim of an adherent to either the technological or mechanical sublime or to its offspring, the electrical sublime, two concepts discussed by James Carey and John J. Quirk (1989) in Communication as Culture: Essays on Media and Society. In Communication as Culture, 
Carey and Quirk co-wrote an essay entitled "The Mythos of the Electronic Revolution" in which they shed light upon what they view as a dominant, but peculiar and misinformed, understanding of Americans' perception of both the scope and scale of the influence of technology in society and its supposed inherent transformative qualities.

In the first half of the nineteenth century, intellectuals and others from all walks of life optimistically assumed that new developments in mechanical technology would enable this vision to become a reality (Carey \& Quirk, 1989, p. 118-9). Many of these individuals believed "the hyperboles of technological sublimity" which were projected as an unwavering optimism in a better, easier and more prosperous future made possible by advancements in mechanical technologies (p. 120).

The optimism disparaged by Spengler (1932) would manifest itself once again when what Carey and Quirk (1989) identify as "a turn from the mechanical to electrical sublime" occurred in the final quarter of the nineteenth century (p. 121). Like its predecessor (the technological or mechanical sublime), the notion of the electric sublime was misinformed, inaccurate and naïve (p. 139-40). Yet, these theories - especially that of the electrical sublime - remain prevalent in our society. In fact, the theory of the electrical sublime has entered new realms that would not have been on the horizon when Communication as Culture was published in 1989. Today, it has gathered a new group of adherents who, once again, proclaim the ability for electricity to decentralize existing power structures. The political industry and its practitioners are one such group.

As was noted earlier, despite the fact that the use of technology in politics itself is not a recent development, the extent of its usage in that domain has expanded and intensified in the recent past to such a degree that one could argue that we are now 
witnessing what could be viewed as an appearance of the electrical sublime therein. It is in the deifying of data and databases, in conjunction with analytics-based political organizing, that the new political edition of the electric sublime may manifest itself. For instance, speaking of data analytics-based political campaigning, Sasha Issenberg (2012) captures the establishment-challenging nature of those newer forms of technology in the political profession and also the line of thinking that is reminiscent of the rhetoric of the electric sublime by explaining that,

Analytics had been greeted by the old guard in campaigns as a disruptive force, but in many respects it represented the purest return to the electorate as it is viewed by local candidates: as a collection of people, each of them approachable on his or her own terms, their changing levels of support and interest and enthusiasm open to measurement, and thus to respect. (p. 349)

I intend to dissect this perspective while examining the role of technology as a conduit for the broader flow of political influence that my project will map.

A second related communications discussion that helps unpack this conduit of influence is the distinction between technological determinism and symptomatic technology. That distinction comes out of a 1974 book by Raymond Williams entitled Television: Technology and Cultural Form. Therein, Williams draws a line between two different schools of thought for interpreting the interaction between technology and culture (Zielinski, 2011/2013, p. 71-2). Siegfried Zielinski distills this distinction by explaining that Williams (1990) "distinguishes between two main interpretations, referring to them as 'technological determinism' on the one hand and 'symptomatic technology' on the other" (p. 72). As Zielinski puts it, "In the first view technology is held to be a commanding determinant" (p. 72). In fact, it is held to be the determinant in society (Marx \& Smith, 1994; Smith, 1994; Smith, 1994; Williams, 1990). 
The notion of symptomatic technology as espoused by Williams (1990) views the interaction between technology and culture from a different perspective. Turning back to Zielinski (2011/2013) allows us to flesh out that different perspective. As he describes it, "The second view of technology as a symptom emphasizes the accidental nature of technical innovations. Here the determinants are located in different elements of social development, for example, in economics or politics, which singularly or together determine the model society" (p. 72). In essence, according to Williams (1990), for the adherent of the theory of symptomatic technology, "Technology becomes a mediating byproduct" (Zielinski, 2011/2013, p. 72). It represents nothing less and nothing more.

In this vein, by way of the methodology that will be outlined in the next chapter of this dissertation, I intend to contextualize the technology conduit of the flow of influence by examining where the ever-increasing usage of technology in political campaigning fits in the technological determinism versus symptomatic technology divide and how it compares to that in the commercial sector incubators of influence. A particular subject matter which will help with that task concerns this ever-increasing datafication of politics and the faith that has been placed in it, whether rightly or wrongly.

\section{Speed as a Side Effect}

Speed has long been a defining characteristic of the relationship between communication and technology. In other words, much of the impetus for developing new communication technologies, regardless of its intended function and purpose, has been to increase the efficiency and the speed by which a message can be sent. The various types of communications technologies utilized in political campaigning do not challenge this pattern. However, speed has largely been neglected as a concept and as a force in the 
literature pertinent to this dissertation and the broader study of political marketing. In other words, the impact of speed has been documented sparingly and researched with regards to political marketing and politics writ large. This is a particularly vexing omission since, "In an atmosphere of instantaneous communication, being the first to say something can mean the difference between success and failure" (Veroni, 2014, p. 191).

The Democratic political strategist and architect of Bill Clinton's successful 1992 campaign for the presidency, James Carville, understood and put this thinking into practice during that particular campaign (Veroni, 2014). In other words, "He understood that speed was critical to controlling the political narrative" (p. 191). The same is true of the so-called narrative in the commercial marketing environment as well but, as will be discussed later, this fact is often missed and notions of speed and urgency often differ drastically between the commercial marketing and political marketing environments.

Furthermore, "It was Carville who determined that when it comes to shutting down your opponent, rapid response is the key" (p. 191). With that in mind, "One of the greatest innovations of the Clinton campaign was the speed at which it responded to attacks and statements from the Republicans" (p. 191). The 1992 Clinton campaign did so by the use of its so-called War Room, or rapid response campaign office, that housed a cadre of staffers whose sole purpose was to fact check and challenge the statements and accusations made against Bill Clinton and to relay favorable Clinton campaign spin to the press via fax machine and telephone in as close to real time as possible (Bolton, 2008; Veroni, 2014). In essence, "Carville coined several important maxims during the 1992 Clinton presidential campaign, but the one that formed the campaign's core operating principle was “'Speed kills!”” (p. 191). And, 
Since Carville's days on the Clinton campaign, that adage has only become more important as the pace of communications has increased. But [commercial] marketers, for all their vaunted creativity, are slow to change. Embracing speed might prove to be one of the more difficult changes marketers have to make in this time of rapid response. In part, that's because most marketing organizations have complex decision-making hierarchies that create a drag on rapid action. The capacity to react quickly is dependent on having all the decision makers in the same room at once. That's rarely the case in a large marketing driven organization. That's the other innovation Carville and the Clinton campaign team developed. They understood that if you're going to speed up reaction time, you need to get rid of the decision-making hierarchy, and to do that you need to get rid of the physical hierarchy that separates decision makers from each other. (p. 1912)

Put differently, speed requires flexibility — and that flexibility appears to be in greater supply among political marketers than commercial marketers (Kreiss, 2016; Veroni, 2014).

But there are always exceptions such as the extreme hierarchy that hobbled the digital communications team within the 2012 Mitt Romney presidential campaign (Kreiss, 2016; Kreiss \& Jasinski, 2016; WIRED, 2016). Romney’s digital director, Zac Moffatt, a veteran Republican strategist and "cofounder of the GOP's leading analytics shop, Targeted Victory" (WIRED, 2016, January 19), illuminated that particular instance of inflexibility by recounting that the 2012 Romney campaign produced " the best tweets ever written by 17 people...It was the best they all could agree on every single time'" (Kreiss, 2016, p. 29). And Mitt Romney's failed 2012 bid was neither the last nor the most infamous instance where the inflexible nature of a campaign hierarchy would condemn an American presidential campaign to defeat. The highest profile example of such an instance occurred a mere four years later, in the 2016 U.S. presidential election which was explicitly discussed earlier in this chapter. 
It is important to revisit the turbulent 2016 election solely for the purpose of discussing how it highlights a key difference between two very distinct organizational structures which, in this particular instance, refer to organizing a political campaign for "the highest office in the land," but which can also apply to less prestigious campaigns as well as non-political organizations of all endeavors. Those two different organizational structures are hierarchies and networks. A combination of the candidate himself or herself, the candidate's consultants and staffers, the organizational structure and chain of command within a campaign and, of course, the social environment in which a campaign itself is run all play a role in determining whether a campaign is organized in accordance with the hierarchy or the network model of organization - or some combination of the two. Turning to Niall Ferguson's (2017) recent book, The Square and the Tower: Networks and Power, from the Freemasons to Facebook, helps to differentiate between the two organizational structures and highlights how knowing the telltale signs of each represents yet another gap in the existing political marketing literature.

Ferguson (2017) states that, "This is roughly how most people think about hierarchies: as vertically structured organizations characterized by centralized and topdown command, control and communication" (p. 21). Hierarchies have been the de facto organizational structure for many successful enterprises given the fact that that particular organizational structure easily provided a combination of clarity and efficiency in the effort to achieve a desired ends. To put it differently,

The crucial incentive that favored hierarchical order was that it made the exercise of power more efficient: centralized control in the hands of the 'big man' eliminated or at least reduced time-consuming arguments about what to do, which might at any time escalate into internecine conflict. (p. 21) 
Thus, a hierarchical organizational structure clarifies the chain of command within an organization or enterprise thereby minimizing uncertainties about duties and, in so doing, boosting the efficiency of that organization or enterprise.

Networks are a different matter. They are more informal, fluid, and social than hierarchies (de Vaan, Stark, \& Vedres, 2015; Ferguson, 2017; Kreiss, 2016). As such, they "are the structures that human beings naturally form" (Ferguson, 2017, p. 17). More precisely, "All that has happened — beginning with the invention of written language is that new technologies have facilitated our innate, ancient urge to network" (Ferguson, 2017, p. 17). The fact that networks vary in shape and size is no insignificant fact in and of itself. As in many things in life, when it comes to networks, size counts - and it counts since networks adhere to Metcalfe's Law,

Which (in its original form) stated that the value of a telecommunications network was proportional to the square of the number of connected compatible communicating devices. This is in fact true of networks generally: put simply, the greater the number of nodes in a network, the more valuable the network to the nodes collectively. (p. 33).

In essence, with networks (barring certain circumstances) the bigger the network, the wider its reach and the greater its potential power or, at the very least, its reach. And a network's reach matters.

However, the reach of a network is certainly not predetermined merely by the size of the network alone (de Vaan, Stark, \& Vedres, 2015; Ferguson, 2017). Its true reach is determined by a combination of size and the agency of the members (a.k.a. nodes) of the network itself. Ferguson (2017) elaborates on this matter by explaining that, "The key point, as with disease epidemics, is that network structure can be as important as the idea 
itself in determining the speed and extent of diffusion" (p. 34-5). Ferguson notes that this is because,

In the process of going viral, a key role is played by nodes that are not merely hubs or brokers but 'gate-keepers - people who decide whether or not to pass information to their part of the network. Their decision will be based partly on how they think that information will reflect back on them. (p. 34-5)

In other words, when speaking about a network and its potential reach, self-interest and agency are conjoined. Yet networks also foster creativity to a far greater extent than their hierarchical counterparts (de Vaan, Stark, \& Vedres, 2015; Ferguson, 2017; Kreiss, 2016). The reason for this was alluded to earlier: the flexibility that is part and parcel of the network organizational structure but which is lacking in the hierarchical organizational structure (de Vaan, Stark, \& Vedres, 2015; Ferguson, 2017; Kreiss, 2016). For instance, "Because of their relatively decentralized structure, because of the way they combine clusters and weak links, and because they can adapt and evolve, networks tend to be more creative than hierarchies" (Ferguson, 2017, p. 43). However, that greater creativity comes with an important caveat: "The problem is that networks are not easily directed 'towards a common objective...that requires concentration of resources in space and time within large organizations, like armies, bureaucracies, large factories, vertically organized corporations. Networks may be spontaneously creative but they are not strategic" (p. 43).

The reason that networks are thought to be more creative (and one could therefore say innovative) than hierarchies is a side effect of their generally informal and "decentralized nature" mentioned by Ferguson (2017). That informal and decentralized nature has been known to foster a phenomenon called "Structural Folding" (de Vaan, Stark, \& Vedres, 2015; Kreiss, 2016; Kreiss \& Jasinski, 2016; Kreiss \& Saffer, 2017). 
Mathijs de Vaan, David Stark, and Balazs Vedres (2015) define Structural Folding in layman's terms for us by explaining that it is "the network property of a cohesive group whose membership overlaps with that of another cohesive group" (p. 1145). And if one wants to get the most mileage out of their network (which consists merely of the members who together represent the nodes in said network), the old proverb that "birds of a feather flock together" should not be your guiding light. As de Vaan, Stark, and Vedres put it: "The effects of structural folding on inventiveness and game changing creative success are especially strong when overlapping groups are cognitively distant. Restated, teams are most likely to be creatively successful when their cognitively heterogeneous groups have points of intersection" (p. 1147). Furthermore, "Folding does not eliminate or conquer distance. It does not harmonize. Instead, it channels and mobilizes a productive tension of rules, and codes that promotes successful innovation" (p. 1147). The result of this is "Cognitive Diversity" (de Vaan, Stark, \& Vedres, 2015; Kreiss, 2016; Kreiss \& Jasinski, 2016; Kreiss \& Saffer, 2017).

Naturally, de Vaan, Stark, and Vedres (2015) flesh out cognitive diversity for us by noting that,

In order to be creative, [a] team needs the requisite diversity of stylistic elements available for reworking. In cultural fields, where teams assemble, dissolve, and reassemble in the episodic project form, the knowledge base of the team does not reside in an organizational repository (Bird 1994; Rowlinson et al. 2010). Instead, it is a function of its members' experience with various styles during prior episodes of production. A team will be more diverse to the extent that its players have more varied exposure to stylistic practices in the field. (de Vaan, Stark, \& Vedres, 2015, p. 1150)

By their very nature of consisting of quickly-assembled groups of politically motivated and passionate individuals from different backgrounds and walks of life, political campaigns are prime breeding grounds for cognitive diversity (Kreiss, 2016; Kreiss \& 
Jasinski, 2016; Kreiss \& Saffer, 2017). Daniel Kreiss (2016) maintains that "What is important with respect to successful political innovation are the points of intersection between and among people who cross fields to enter politics and groups of comparatively more experienced campaign veterans" (p. 9). In fact, Kreiss helps us by neatly summing up the situation in his claim that: "The teams that achieve critical success (defined in terms of winning the acclaim of the field) are made up of cohesive groups that have both overlapping ties ('structural folds') and are diverse in their ideas and insights ('cognitive diversity')" (p. 8). With this in mind, Daniel Kreiss and Adam J. Staffer (2017) hold that "The innovative Obama 2012 campaign was almost the perfect case for the blending of cognitive diversity and structural folding" (p. 538). They support this assertion by explaining that,

There were people who had both the institutional memory from the 2008 run and experiential knowledge gained through work for the party in the intervening years before the reelection bid. They were joined by those who were able to step outside the fold after the 2008 campaign, work for other political organizations, and chart new technological developments in between presidential elections. (p. 538)

A crucial component in the importance of the frictionless blending of cognitive diversity and structural folding (and which was present in the 2012 Obama reelection campaign) is the sourcing of campaign staffers and consultants from the technology industry (Kreiss, 2016; Kreiss \& Jasinski, 2016; Kreiss \& Saffer, 2017).

Even so, we should note that, "while it is important to bring people in [to political campaigns] from the technology industry [...] it is important that diversity is also grounded in commonality so there are familiar resources to be recombined, which makes innovation recognizable to the field" (p. 530). In other words, there needs to be a recognition of the fact that bringing staffers from the technology industry onboard a 
political campaign is likely to be beneficial given the escalating importance of ICTs in the usage of both the persuasion and mobilization aspects of any political campaign as well as the familiarity with such tools that tech industry staffers bring to the table. This is clearly a key variable to consider especially since, as Daniel Kreiss and Christopher Jasinski (2016) remind us, at the national campaign level, "The effective use of technology can translate into millions of additional dollars, voter contacts, identifications, registrations, and ultimately supporters that turned out at the polls" (p. 549). Yet technology is still no panacea for any given campaign.

While there are many reasons why this is likely to be the case, two stand out more than others. The first was referenced earlier in this chapter by Issenberg (2012), who stated that "Analytics had been greeted by the old guard in campaigns as a disruptive force" (p. 349). In essence, to effectively capitalize on the tech industry's well-known penchant for "disrupting" traditional hierarchies and status quo ways of thinking and conducting business would require giving staffers from that environment an unfamiliar form of agency and autonomy in a campaign, something which is not a natural pattern in most traditional political campaigns (Allen \& Parnes, 2017; Issenberg, 2012; Kreiss, 2016; Kreiss \& Jasinski, 2016). A quick comparison between the 2012 Romney and Obama presidential election campaigns illustrates this point. For instance, on Romney's campaign,

the digital team $[\ldots]$ was essentially in service to the communications department. The campaign had an extensive vetting process that included communications staffers and the campaign's leadership for all of the content digital staffers produced across platforms. Obama's digital team in Chicago, by contrast, had the autonomy to post its own content, enabling it to respond in the moment to events on social media. (Kreiss \& Jasinski, 2016, p. 557) 
The Democrats' greater willingness to provide that unfamiliar form of agency and autonomy to its digital staffers in 2012, and also four years earlier in the 2008 presidential election, in addition to the fact that a greater number of Democrat-friendly digital campaigning consultancies and other business ventures were formed in the timeframe between those two epochal presidential elections, firmly gave the Democrats the edge in the analytics-based political campaigning arms race (Allen \& Parnes, 2017; Issenberg, 2012; Kreiss, 2016; Kreiss \& Jasinski, 2016; Kreiss \& Saffer, 2017; Miller, 2013). But with the innovative, but highly controversial and convoluted, data operation of Republican President Donald J. Trump that was discussed earlier (as well as the Tea Party's blending of grassroots campaigning with boundary-pushing developments in digital campaigning), we can safely say that the Democrats' edge in that arms race is waning.

The second reason that digital campaigning and its reliance upon staffers from the tech industry is no panacea in the political marketing realm deals with the margins. For instance, "Technology, digital media, data, and analytics will not win an election for a candidate, but they are valuable on the margins with respect to enabling staffers to more efficiently and effectively reach citizens across the hundreds of platforms that form the backdrop for much of daily life" (Kreiss \& Jasinski, 2016, p. 549).

In seeking the evidence of a bidirectional flow of influence between commercial marketers and political marketers, I reason that the best way to think about feedback loops is a combination of the first and second perspectives. For instance, campaigns generally consist of a network of volunteers and paid employees from an array of divergent backgrounds who consolidate their varied experiences and skills for the 
purpose of electing a politician and, to that end, the market conditions and reactions are revealed by whether or not the politician in question is successfully elected. Plainly stated, if the politician was elected, the market conditions and reactions were positive; if the politician was not elected, the market conditions and reactions were negative. In politics, a win is a win and the verdict that the voters deliver in the privacy of the polling booth is the ultimate feedback loop.

Hillary Clinton and those working on her 2016 presidential campaign found this out the hard way on Election Day with the distinction between hierarchies and networks playing a substantial role in that electoral upset. Ferguson (2017) helps us with the electoral autopsy. He prefaces that task by claiming that "technology has enormously empowered networks of all kinds relative to traditional hierarchical power structures" and that this was represented in the 2016 presidential election (p. 399). As he explains, in that campaign, “Trump's scale-free network [i.e. his large network which consisted of numerous influential hubs such as Fox News, Breitbart News Network, and his tens of millions Twitter followers], based on a combination of self-organization and viral marketing, beat Clinton's hierarchically organized but over-complicated campaign" (p. 384). Furthermore, "It was not that the Clinton campaign lacked networks. It suffered almost from a surfeit of them [...and] lost in all the complexity was the simple reality that the candidate was connecting with key voters far less effectively than her most dangerous rival" (p. 384). Or, as William J. Miller (2013) reminds us: "We must be clear to not equate poor strategy with failures of social media" (p. 341).

Furthermore, examining speed and its implications for the flow of influence between commercial marketing and political marketing is an important consideration for 
a project such as this precisely because it adds a new dimension to the dominant LeesMarshment framework. The absence of this dimension is understandable given the fact that that framework was being developed at the turn of the twenty-first century and rose to its dominant position in the political marketing literature shortly thereafter - a time when we were not drowning in today's sea of information. In 2001, when LeesMarshment's seminal book, Political Marketing and British Political Parties: The Party's Just Begun, was published, the Internet had already made an indelible impact on much of the developed world by increasing the amount of information that was available to the average individual on a daily basis — should they be able to log on to a computer. But people were not yet constantly connected and therefore swimming against a relentless stream of information in the form of emails, notifications, SMS text messages and SPAM, to name but a few.

The smartphone with the portability and constant connectivity that it offered changed that. Ferguson (2017) goes so far as to posit that, "the critical variable that made the social changes of the early twenty-first century so explosive was the exponential growth of mobile telephony" (p. 365). Why was this the case? Quite simply, "With mobile phones, and even more with smartphones, social networks could be online all the time" (p. 365). And, for the most part, we are. As Evgeny Morozov (2013) explains, “These days, 'the state of permanent receptivity' has become the birthright of anyone with a smartphone. We are under constant assault by 'interestingness,' as new-media aficionados — 'curators,' they call themselves — prowl for bizarre factoids and quaint cartoons" (p. 33). In essence, today we are suffering from anything but a shortage of information. Instead, we face an ever rising sea of information and status updates on a 
minute-by-minute basis, no matter where we go. As Mark Bauerlein (2009) puts it, "Reality is personalized, and the world outside steadily tallies the ego inside" (p. 137). Egocentricity aside, the key consequence of this trend has become a veritable information overload which has far-reaching implications. Morozov (2013) sheds light on the situation. For him, "Information overload can bore us as easily as information underload. But this form of boredom, mediated boredom, doesn't provide time to think; it just produces a craving for more information in order to suppress it" (p. 34). According to Morozov, non-mediated boredom acts as an innovative and creative incubator, but it is increasingly being drowned out by mediated boredom. This happens stealthily as well because, "It [mediated boredom] cloaks itself in the rhetoric of nowness and newness" (p. 34). Yet it goes beyond boredom. Rebecca Solnit (2013) tells us how this is so by explaining that:

There is so much information that our ability to focus on any piece of it is interrupted by other information, so that we bathe in information but hardly absorb or analyze it. Data are interrupted by other data before we've thought about the first round, and contemplating three streams of data at once may be a way to think about none of them. (p. 32).

How then does this relate to the state of political marketing today and the impact of technology upon it?

As was made clear earlier by way of the well-known maxim "speed kills," coined by James Carville on the campaign trail with Bill Clinton in 1992 and by the brief chronological discussion of certain essential new communication technologies and their impact on political campaigning that began this chapter, political campaigns have always had to contend with the consequences of speed, but the Internet and its subsequent proliferation of web-based applications and products has greatly heightened this necessity 
(Cacciotto, 2017; Kreiss, 2016; Serazio, 2015). Kreiss (2016) explains why the noun greatly is not misplaced in its use here: "While campaigns have long had to adapt to changing media environments, the pace, scale, and social consequences of change are qualitatively different in an era of rapid shifts in the application layer of the Internet" (p. 3). The change to which campaigns have had to adapt is "qualitatively different" since the boundaries of the Internet are constantly expanding, as are the web of apps and services that political marketers must master to effectively campaign for their candidate. In other words, as innovative as any previous campaign may have been in terms of its digital campaigning efforts and tactics, many of the techniques and apps from past campaigns are already out of date and in need of refinement or jettisoning in favor of newer methods and platforms by the time a new campaign begins (Kreiss, 2016; Kreiss \& Jasinski, 2016; Kreiss \& Saffer, 2017).

The short lifespan of web-based technologies or platforms on a campaign is amplified by two factors. The first was discussed earlier in this chapter with the help of Kreiss (2016), who shone some much needed light on the daunting reality that there is no "one size fits all" approach to digital campaigning. This is largely true since such campaigning requires a great deal of party-provided infrastructure building and maintenance to accumulate, clean up, maintain, analyze, and, ultimately, utilize the vast surplus of quantitative data required to effectively campaign with the help of data (Hersh, 2015; Kreiss, 2016; Kreiss \& Jasinski, 2016; Kreiss \& Saffer, 2017). The second factor is that there is a distinctive ebb and flow to any campaign that is not conducive to consistent staffing and can be characterized as an abundance of turnover (Kreiss, 2016; Kreiss \& Jasinski, 2016; Kreiss \& Saffer, 2017). For instance, campaigns are often cobbled 
together quickly and attract a great number of volunteers, consultants, and other paid employees who work feverishly from the calling of an election to the time that the last ballots are counted and a winner is declared. However, after that moment in time, campaign operations shrivel up since volunteers return to their other endeavors, consultants move onto the next campaign or revenue source and paid campaign employees either go on to become staffers when their candidate wins or, when their candidate loses, they too return to their other endeavors (Kreiss, 2016; Kreiss \& Jasinski, 2016; Kreiss \& Saffer, 2017).

In sum, thus far this dissertation has laid the groundwork for an analysis of the extent to which the flow of influence and innovation between commercial and political marketers may be bidirectional and operating as a feedback loop rather than merely being a unidirectional flow from commercial to political marketers as many scholars have assumed. To support that claim, I have focused my attention on two phenomena or, as I call them, conduits of influence: marketing and technology. Put another way, I have demonstrated that marketing and technology represent two general areas where the potential bidirectional flow of influence and innovation manifest themselves most notably.

In the marketing conduit (Chapter II), I made the case for the way that a combination of tribal marketing, relationship marketing and the "consumer citizen" highlighted a bidirectional flow of influence and innovation within the realm of marketing. In the technology conduit (Chapter III), I examined some of the most important technological developments to impact the practice of political marketing and analyzed the way that the increasingly pervasive practice of data-driven campaigning has 
affected the flow of influence and innovation between commercial and political marketers. I also drew attention to how the increased speed facilitated by new communications technologies in the ever-increasing technologically dependent campaign is indicative of a scenario where political marketers may well be out-innovating their commercial marketing counterparts.

With that concise summary of matters so far, it makes sense to recap the research questions that this project strives to answer. Again, those three research questions ask:

(1) To what extent is political marketing influencing the practice of commercial marketing?

(2) How have changes in marketing strategies and technology impacted both political and commercial marketing?

(3) What are the likely consequences of the relationship between political marketing and commercial marketing?

Further, with those research questions in mind, a number of testable hypotheses can be formulated:

- $\mathrm{H}_{1}$ : Political marketers are more comfortable than are commercial marketers with the speed at which successful marketing campaigns must be run.

- $\mathrm{H}_{2}$ : Political marketers are better suited than are commercial marketers to craft and mobilize tribes due to political marketers' longstanding experience with mobilizing the small, but energetic, segments of the populace needed to win elections.

- $\mathrm{H}_{3}$ : Political marketers are better at conducting data-based microtargeting strategies and doing so on tighter budgets than are commercial marketers. 
- $\mathrm{H}_{4}$ : Politics is seeping into more areas of contemporary life and, consequently, commercial marketing is becoming less value-neutral.

Now, in order to transition from secondary to primary research and to begin the discussion on how I sought evidence of a bidirectional flow of influence and innovation on the aforementioned conduits of influence — and also to actively move towards answering this study's research question and testing its hypotheses — attention must now be given to an examination of the methodology upon which this dissertation relies. 


\section{IV \\ The Method}

While the selection of an appropriate research method is a crucial component in the successful completion of a dissertation, the act of selection itself is a delicate matter. It is delicate precisely because the wrong method can prejudice a project either by way of preventing the project from reaching completion or by providing results that do not answer the project's research questions (Babbie, 2005; Bryman \& Teevan, 2005; Leslie, 2010). In essence, not all research methods are created equal and not all research methods can be used to execute a given project.

After reviewing the literature and reflecting at length on the matter at hand, I determined that assessing the flow of political influence in light of the two conduits of influence examined in this dissertation requires using qualitative, in-depth elite interviewing as a research method. With this established, two additional questions should be asked and then answered at this juncture: First, why are in-depth elite interviews the appropriate research method to be used in this project? Second, how were in-depth elite interviews used to answer my three research questions? Let's proceed chronologically.

\section{Why Use In-Depth Elite Interviews?}

The reason for this is captured by Deborah K. van den Hoonaard (2015) who explains that, "the purpose of in-depth interviews is to allow people to explain their experiences, attitudes, feelings, and definitions of the situation in their own terms and in ways meaningful to them" (p. 102). Thus, in-depth interviewing is the best method to utilize for a project such as this one, since its flexible yet thorough nature allows participants' perspectives to be fleshed out without any attempt to limit responses to a particular mold via a standardized interview relying upon closed-ended questions (Leslie, 
2010; van den Hoonaard, 2015; Yeo, Legard, Keegan, Ward, McNaughton Nicholls, \& Lewis, 2014).

I should also take a moment to clarify that, when speaking of in-depth interviews, what I am referring to has also known as semi-structured interviewing. This overlap in terminology is noted by Alan Bryman and James J. Teevan (2005) who claim that, "There is a growing tendency for semi-structured and unstructured interviewing to be referred to collectively as in-depth interviewing or as qualitative interviewing [emphasis in original]" (p. 184). The in-depth interviews that I conducted were clearly of the semistructured nature since they adhered to the key characteristics of semi-structured interviewing which, amongst other things, holds that

The researcher has a list of questions or fairly specific topics to be covered, [...] but the interviewee still has a great deal of leeway in how to reply [...] Questions may not follow the exact order on the schedule and some questions not included in the [interview] guide may be asked as the interviewer picks up on things said by the interviewee. But, by and large, all of the questions are asked and a similar wording is used from interviewee to interviewee. (p. 184)

As was hinted at already, in-depth interviews have a number of important attributes that are seen as beneficial when it comes to the odds of successfully answering the research questions that drive this dissertation. Let's look at the advantages first. While it is unrealistic to discuss all of the advantages of interviewing as a research method, we will broach a few of the most pertinent. One advantage associated with in-depth interviews is the flexibility of the method itself (Babbie, 2005; Bryman \& Teevan, 2005; Neuman, 2000; van den Hoonaard, 2015; Yeo, Legard, Keegan, Ward, McNaughton Nicholls, \& Lewis, 2014). More specifically, "the flexibility of the interview and its economy of time and effort are what really make it so attractive [as a research method]" (Bryman \& Teevan, 2005, p. 182). In other words, an advantage commonly associated 
with interviewing as a research method is that the method itself is malleable for both the interviewer and the interviewee (Babbie, 2005; Bryman \& Teevan, 2005; Merrigan, Huston, \& Johnston, 2012; van den Hoonaard, 2015). For instance, from the perspective of the interviewer, "While interviewing, transcribing interviews, and the analysis of transcripts are all very time-consuming, they can be more readily accommodated into researchers' personal lives" (Bryman \& Teevan, 2005, p. 182). From the perspective of the interviewee, interviewing is malleable in the sense that the very nature of the method itself gives the interviewees a great deal of agency, since they are the gatekeepers who determine whether or not an interviewer can actually conduct an interview (Babbie, 2005; Neuman, 2000; van den Hoonaard, 2015; Yeo, Legard, Keegan, Ward, McNaughton Nicholls, \& Lewis, 2014). Additionally, the interviewee can answer a question any way he or she deems appropriate, regardless of whether or not the interviewee is actually responding in the manner that the interviewer had hoped for (Babbie, 2005; Marland \& Esselment, 2018; Yeo, Legard, Keegan, Ward, McNaughton Nicholls, \& Lewis, 2014).

A second advantage of interviewing is the perspective, or point of view, that it offers (Neuman, 2000; van den Hoonaard, 2015; Yeo, Legard, Keegan, Ward, McNaughton Nicholls, \& Lewis, 2014). As was hinted at earlier, in-depth interviewing strives to see the world through the eyes of the interviewee (Babbie, 2005; Bryman \& Teevan, 2005; Neuman, 2000; van den Hoonaard, 2015; Yeo, Legard, Keegan, Ward, McNaughton Nicholls, \& Lewis, 2014). Thus, interviewing is predicated on uncovering and expressing how "participants understand their social worlds" (van den Hoonaard, 2015, p. 105). 
A third advantage associated with interviewing is the depth of the data gathered by this method and the richness of the analysis that that data can provide (Babbie, 2005; Bryman \& Teevan, 2005; van den Hoonaard, 2015; Yeo, Legard, Keegan, Ward, McNaughton Nicholls, \& Lewis, 2014). That depth and richness can be provided by interviewing, especially in-depth interviewing, primarily because that "format allows the researcher to explore the factors that underpin participants' answers: their values, past experiences, circumstances, reasoning, feelings, opinions and beliefs" (Yeo, Legard, Keegan, Ward, McNaughton Nicholls, \& Lewis, 2014, p. 184)

Another important advantage of interviewing is that it is a particularly generative research method (Bryman \& Teevan, 2005; Merrigan, Huston, \& Johnston, 2012; van den Hoonaard, 2015; Yeo, Legard, Keegan, Ward, McNaughton Nicholls, \& Lewis, 2014). Interviewing "is generative in the sense that new knowledge or thoughts are likely to be created" (Yeo, Legard, Keegan, Ward, McNaughton Nicholls, \& Lewis, 2014, p. 184). To take this further, "The intensity of focus [in interviewing] creates a space for thought and reflection, [and therefore] it is likely that the participant will at some point take themselves, or be taken by the researcher, down avenues of thought they have not explored before" (p. 184).

But, as Bruce L. Berg (2011) reminds us, "there's no such thing as a perfect methodology - one that does not have weaknesses and limitations" (p. 218). Interviewing is no exception here. Consequently, a number of disadvantages associated with the interviewing research method had to be kept in mind as I gathered my data and crafted my analysis. The first was that it is challenging to find a representative sample from which to make generalizable inferences to a broader population beyond the scope of 
a study's interviewees (Berger, 2011). This is often accentuated by the fact that, while interviewing often excels in the realm of validity, it can fall short in the realm of reliability (Babbie, 2005; Neuman, 2000). Focusing on the latter, the reason for this is best captured by Earl Babbie (2005) who states that, in "in-depth [...] field research [such as the in-depth interviewing that this dissertation relies upon] measurements are often very personal" (p. 322). As such, they are not likely to be replicable from one interview to the next since, as was mentioned when discussing some of the key attributes of the interviewing research method, each interviewee brings something unique to the table in the responses that are provided.

A second disadvantage of interviewing is also related to the representativeness of a sample. In interviewing, it is difficult to ascertain if and when one has a representative sample size (Bryman \& Teevan, 2005; Neuman, 2000; van den Hoonaard, 2015; Yeo, Legard, Keegan, Ward, McNaughton Nicholls, \& Lewis, 2014). This is further complicated by the fact that the nature of the subject of analysis, as well as the suitability of interviewees that the subject matter itself dictates, may result in a researcher's having to rely upon a relatively small sample size thereby limiting the generalizability of the findings (Bryman \& Teevan, 2005; Neuman, 2000). This research project falls into that camp, as will be discussed in the following section which outlines the scope and scale of the sample that I was able to gather. However, it should be noted that, in comparison to quantitative research, generalizability is always limited in qualitative research, and not just in this particular qualitative research project (Babbie, 2005; Berger, 2011; Bryman \& Teevan, 2005; van den Hoonaard, 2015). 
A third disadvantage of interviewing is the inescapable fact that, quite simply, it requires a great deal of time and patience to conduct all elements of the interviewing process (Bryman \& Teevan, 2005; Neuman, 2000; van den Hoonaard, 2015). For example, one must develop an interview guide which includes a sufficient number of appropriate questions that will allow the interviewer to obtain the answers to the research questions that are motivating their research in the first place. One must then assemble a list of potentially suitable interviewees. Next, the researcher must attempt to contact each of those potential interviewees to gauge their interest in participating in the study at hand. That process is often very time-consuming since many potential interviewees are nonresponsive to any given researcher's interview solicitation request. Furthermore, once an interviewee agrees to participate, the logistics of the interview must be established and acted upon. Following this often lengthy process, the actual interview must be conducted and then the recordings must be transcribed and analyzed, knowing full well that it takes numerous hours of manual transcription for every single hour of recorded interviewing. Finally, after all of these steps are completed, the researcher can begin to craft the arc of an analysis based on the acquired data.

While these disadvantages are all important considerations, I felt that the advantages of utilizing in-depth elite interviews outweighed the disadvantages associated with the method. Additionally, I operated from the assumption that a well-organized research design would allow me to minimize the aforementioned potential disadvantages inherent in interviewing. 


\section{How to Use In-Depth Elite Interviews?}

After determining that in-depth elite interviews were the most appropriate research method to use, the next task was to determine how to use them most reliably to adequately answer my three research questions. To this end, I came to the conclusion that this project required interviews with both Canadian and international political marketers, market researchers, political researchers, pollsters and commercial marketers. The proportion of interviews between all five types of practitioners was as close to evenly balanced as the interviewee response rates allowed, with the issue of response rates being discussed more thoroughly later in this chapter. Furthermore, because this project seeks to re-examine the traditional flow of influence in the field of political marketing rather than to adopt the position that political marketing alone represents the application of commercial marketing techniques to the practice of politics, an inductive approach is most appropriate. I interviewed those who are deeply embedded in the worlds of political marketing and commercial marketing which, it was hoped, could lead to a theoretical refinement in the existing political marketing literature. In other words, in true inductive form, "theory is the outcome [emphasis in original] of research" (Bryman \& Teevan, 2005, p. 7). A combination of purposive sampling and network sampling (or snowball sampling) was used to assemble the sample of interviewees. Purposive sampling, was utilized since,

In this approach, the selection of participants, settings or other sampling units is criterion-based or purposive [...and, as such,] the sample units are chosen because they have particular features or characteristics which will enable detailed exploration and understanding of the central themes and questions which the researcher wishes to study" (Ritchie, Lewis, Elam, Tennant \& Rahim, 2014, p. $113)$. 
Gerianne Merrigan, Carole L. Huston, and Russell Johnston (2012) rightfully point out that representativeness may not be one of the attributes of purposive sampling. But randomization is not a priority in a project such as this, since I only sought to examine the flow of influence and innovation between commercial and political marketers.

Piggybacking off the purposive sampling, network sampling was utilized since interviewees who were gathered via the aforementioned purposive sampling strategy were solicited for the recommendation of additional interviewees who would be suitable resourceful sources of knowledge on the subject matter of this study (Merrigan, Huston, \& Johnston, 2012; Ritchie, Lewis, McNaughton Nicholls, \& Ormston, 2014). To that end, participants may tell other potentially suitable participants about this study to gauge their interest in being interviewed by me. In order to protect participants to the greatest extent possible, it was intended that the potential additional interviewees resulting from the snowballing be initially contacted by the recommender rather than by myself. However, upon expressing this thought to my interviewees, the lion's share of interviewees who provided me with interviewee recommendations advised me to contact their recommended interviewee on my own instead of relying upon them as an intermediary.

That said, each interviewee who gave me a recommendation gave me permission to mention that they had referred me to the recommended interviewee in order to break the ice with the recommended interviewee and to minimize the odds that the recommended interview request email appeared as spam in the recipient's email inbox. To further minimize the appearance as spam, and to maximize the odds that a recommended interviewee would participate, the name of the recommender was included 
in the subject line of the recommended interview request email. This was the only instance wherein the anonymity of any of the participants in my research was sacrificed. However, as mentioned previously, since all of the interviewees who provided me with recommendations told me to contact their recommended interviewees myself by email, and to mention in that email that they had agreed to refer me to said recommended interviewees, doing so did not invalidate the systemically anonymous nature of my project and did not jeopardize the safety of either the recommender or the recommended interviewee. In every other instance (and as will be seen at length in the following two chapters), anonymity was preserved since interviewees were stripped of all potentially identifying features and were referred to simply as Interviewee $\# 1$, Interviewee $\# 2$, etc.

How, then, were the prospective interviewees chosen? In addition to searching for recurring names appearing in the texts from which my preliminary literature review was crafted, as well as searching the web pages of numerous market-leading public affairs and research firms in the chosen countries slated for analysis, a substantial portion of the names of the prospective interviewees was gathered by conducting a Twitter-centric form of purposive sampling. For instance, I sought out renowned American, Canadian, and British political commentators and practitioners on Twitter and then would follow them later wading through their followers to find another layer of seemingly appropriate interviewees. In other words, I used Twitter's social network to preempt the required network sampling that this project would utilize once the actual interviewing began.

To be more precise in this discussion of the all important process of sampling, potential participants were contacted via email, relying upon email addresses that were found in the public domain on the websites for the firms that employ them or on their 
own personal websites. This is because many political marketers, market researchers, political researchers, pollsters and commercial marketers offer their services as consultants and therefore have their own websites to advertise their services, to showcase their past experiences and clients, and to solicit potential future clients. Additionally, since many of these potential participants are active social media users, their public Twitter pages were consulted and the plan was to send a letter of invitation to them via a private Direct Message (DM) within Twitter. However, as the old saying goes, "The bestlaid plans of mice and men often go awry." Since the ability to send a DM to an individual would require me not only to follow the intended recipient, but also to have the recipient follow me on Twitter (which was not the case for any of my potential interviewees), I was unable to send any interview requests via Twitter's DM function. Consequently, I had no choice but to resort to an alternative means of interviewee solicitation, a process that will be described shortly. But a vexing question should be answered before opening that discussion: why prioritize Twitter in the sampling process as opposed to any of the other social media platforms — especially given the unforeseen difficulty it presented?

While Twitter has a smaller user base than other popular social media platforms, the most notable of which are Facebook and Instagram, it is widely used by so-called "elites," such as journalists, politicians and other public figures who utilize the micro blogging platform to publicly broadcast news, updates and to increase their audience reach (Gottfried, 2014; Page \& Duffy, 2018; Ryoo \& Bendle, 2018). Given its application for these purposes, Twitter provides a more public online presence than do other social media platforms like Facebook and Instagram, consequently making it easier 
for the researcher to find potentially suitable interviewees on Twitter than elsewhere. Just as importantly, because of the more public nature of Twitter, it is less of an invasion of privacy to solicit contact with potential interviewees through that medium as opposed to any of the other less public and generally more recreational use oriented social media platforms. The invasion of privacy factor is an important consideration since, as Alex Marland and Anna Esselment (2018) remind us,

When a researcher seeks an interview, it is the equivalent of a self-invitation to enter a privileged world. How deeply these elite networks can be penetrated is heavily dependent on the references of past interviewees and the willingness of respondents to grant the interview and talk candidly. (p. 31)

With that in mind, the aforementioned purposive and network sampling strategy was put into action in the following manner. Potential participants were sent a letter of invitation via email and, if they were willing to participate in this study, their interviews were scheduled accordingly. Prior to conducting any interviews, participants were sent (via email or Twitter direct message) a consent form (as seen in Appendix A) and were asked to fill it out and send it back to me using the same method by which it was sent to them. Participants were then asked to grant permission for my audio recording of the interview process.

If the request to audio record the interview was denied by the participant, their decision stood. It was assumed that, in those rare cases when interviewees did not wish to have their interview recorded with the digital audio-recorder, the interview would be recorded in shorthand. Thankfully that was not necessary since no interviewee requested that our conversation not be recorded. Participants were informed (both verbally and in writing) that it was within their rights to withdraw from the study, without penalty, both during and after the interviewing process. Similarly, and thankfully, not a single 
interviewee requested that their participation in this project be withdrawn. They were also informed that the data and consent forms will be kept for a year after the study has been completed and defended. After that time, all the data will be destroyed. The audiorecorded interviews were stored on a password protected and encrypted USB stick. Both the USB stick and the digital voice-recorder will be stored in a locked drawer in my office (4208 River Building, Carleton University).

As for the interviews themselves, the thinking was that they be conducted in person, on the telephone, or via Skype. The selection of the most appropriate of the three methods of interviewing would depend upon the availability and convenience of the interviewee. That said, in-person interviews were prioritized, especially for interviewees living in the Ottawa area. In-person interviews were to take place either at the interviewee's place of employment (if the interviewee was the operator of a one-person consulting firm or had their own office space) or at a mutually agreeable public space (if the interviewee worked for a larger firm or worked in shared office space) to ensure a sufficient level of confidentiality and privacy. Ultimately, the convenience of interviewees dictated that every single interview be conducted via telephone.

It was thought that between 20 and 40 participants would be interviewed based upon the assumption that it was likely that this study would reach the point of saturation after that many interviews had been conducted. With that in mind, interview requests were sent to a total of 122 potential interviewees between September 2018 and February 2019. Of the 122 interview requests sent, 75 were sent to international potential interviewees and 47 were sent to Canadian potential interviewees. It should be noted that this apparent imbalance between the number of international and Canadian interview 
requests sent was predicated on the fact that both the international political marketing field and the international commercial marketing field (by their very nature of being international) are larger than their Canadian counterparts and also that international interviewees would probably be less likely to participate due to their being less familiar with Carleton University's School of Journalism and Communication and less likely to respond to the interview request from one of its students, as opposed to an interview request from a student at a university in their own country. With that in mind, but given the availability of my interviewees and also the highly competitive but somewhat secretive world of commercial and political marketing (Goldstein, 2002; Jiwani \& Krawchenko, 2014; Lilleker, 2003; Marland \& Esselment, 2018), a total of 33 interviews were completed prior to reaching the saturation point, all of which represents a cumulative response rate of $27 \%$.

While some may be tempted to say that a $27 \%$ response rate is anemic, that would be a hasty claim when taking into account the aforementioned guarded nature of many marketers - be they commercial or political practitioners. As Alex Marland and Anna Esselment (2018) put it, "Researchers interested in gaining insights from political elites in Canada can experience difficulty securing interviews. Requests for sit-downs are often denied or ignored" (p. 29). But why is this case? The shortest and most likely answer hinges upon two variables: inconvenience and risk aversion. For instance, "In an environment in which private remarks can end up in the online public sphere, political elites are acutely aware of the importance of copiously vetting requests and requesters, and for many it is safer to decline an interview invitation" (p. 29). As will be seen shortly when turning our attention to comparing and contrasting the response rates of political 
marketers and commercial marketers, inconvenience and risk aversion are also important variables when considering the response rates of international political marketers and of commercial marketers, both foreign and domestic.

That $27 \%$ cumulative response rate can be broken down more fully by drawing attention to a few important demographic facets about what it represents. First, of the interview requests sent to the 75 potential international interviewees, 12 individuals replied and participated in my study, thereby representing a 16\% international interviewee response rate. Of those 12 international interviewees, 11 were Americans and 1 was a New Zealander. In other words, despite numerous attempts to gain respondents from the United Kingdom which is one of the most-well known political marketing playing fields, that effort was largely — but not completely — in vain. While the New Zealander included in my sample may reside in New Zealand, he has worked as a political consultant, pollster, blogger, and activist not only in his native country, but also in the United Kingdom and, to a lesser extent, in the United States. In essence, the "international" portion of the sample in this project was truly more American than international in its nature.

When it came to the interview requests sent to the 47 Canadian potential interviewees, 21 individuals replied and ultimately participated thereby producing a 45\% Canadian interviewee response rate. In other words, the decision to oversample international interviewees due to the likelihood that their response rates would be lower than their Canadian counterparts was warranted. Second, of the 33 interviewees who make up the sample in this dissertation, $26(79 \%)$ were male and $7(21 \%)$ were female. This apparent gender imbalance in my sample is largely reflective of the well-known 
gender imbalance to be found in both the commercial marketing and political marketing environments as a whole. See Table 1 (Appendix D) for a geographical gender breakdown of this study's respondents.

The 33 telephone interviews that serve the purpose of being the sample in this project cumulatively represent 20 hours and 39 minutes of conversations with the men and women who are best suited to provide evidence for or against the sought after bidirectional flow of influence and innovation between commercial and political marketers. See Appendix $C$ for a quick reference interviewee profile guide that provides some important information about each interviewee without compromising their anonymity. The shortest interview ran 12 minutes and 53 seconds and the longest interview ran 1 hour, 21 minutes and 37 seconds. Overall, the average length of an interview was 38 minutes and 52 seconds. Interestingly, male respondents typically spoke longer than female respondents. For instance, the average length of interview provided by a male respondent was 41 minutes and 49 seconds. The shortest length interview with such an interviewee ran 25 minutes and 36 seconds and the longest ran 1 hour, 21 minutes and 37 seconds. On the other hand, the average length of interview provided by a female respondent was 22 minutes and 25 seconds. The briefest interviewee provided by a female interviewee ran 12 minutes and 53 seconds and the most extensive ran 41 minutes and 17 seconds. That said, it should be borne in mind, as Bryman and Teevan (2005) remind us: "[That] it should not be assumed that shorter interviews are necessarily inferior to longer, with the exception of those marked by interviewee non-cooperation or anxiety about being recorded" (p. 191). 
It should also be noted that presenting qualitative data is a tricky affair and that, in light of marketers' research-related risk aversion (as was mentioned earlier) and also the spirit of presenting as transparent a representation of the thoughts of the individuals in this study, respondents were encouraged to speak in their own voices as much as possible. The goal here was to present as unvarnished and as authentic a look into the fields of commercial marketing and political marketing as possible - even if that meant including profanity in the interview transcripts and, ultimately, the evidence that is woven into this dissertation. Or, as Jennifer Lees-Marshment (2012) writes on the matter of using unvarnished qualitative interviews such as the kind used here, "the starting ontology for this research was to better understand the empirical reality of political marketing by listening to practitioners" (Lees-Marshment, 2012, p. 92).

Given the nature of the subject matter being examined, it is safe to say that this study was very low risk. For instance, it did not pose the risk of any social and or economic harm to the participants. It also did not pose psychological or physical risks for the participants. It merely sought to have a discussion about the ebb and flow of influence and innovation between the commercial marketing and political marketing worlds. In other words, participants in this project were not exposed to any more risk than they would experience in their daily lives as commercial or political marketers. Additionally, political marketers, market researchers, political researchers, pollsters and commercial marketers are certainly not considered a vulnerable population. Even so, interview responses were stripped of any interviewee identifying characteristics. The interviewee in each transcript was assigned a pseudonym (ranging from Interviewee \#1 to Interviewee \#33 based upon the chronological order in which the interviews were conducted) and the 
interview transcripts were altered by the removal of all identifying material from the raw interview (e.g. the employer of the interviewee). Separating commercial marketers from political marketers proved harder than expected, since the boundaries between commercial marketers and political marketers were less sharply defined than expected a point which is beneficial when considering the feedback loop between commercial and political marketers that this project searches for and which will subsequently be discussed more thoroughly in the following chapter. For example, upon carefully examining the credentials and biographic details of the 33 interviewees in this sample, it was revealed that 18 could be classified as strictly political marketers in terms of the work they did and the clients with whom they worked. A further 15 interviewees could be thought of as hybrid marketers, since they practiced a combination of both political marketing and commercial marketing. No pure commercial marketers were represented in this study's sample, but not for a lack of trying. All interview requests sent to such candidates were fruitless. For a visual representation of both the geographic and employment breakdown of the respondents, consult Table 2 (Appendix E). While it may have been advisable to breakdown the geographic location of respondents to a more granular level than merely the country in which they practiced their trade, it was thought that doing so could compromise their anonymity.

Given the opt-in consent process described earlier, there was no deception involved in any aspect of this research project. Furthermore, incidental findings were neither expected nor arrived at. The risk of a data breach was also minimal since all data was anonymized through the use of pseudonyms and no personal information was asked of the interviewees. Further, as was also pointed out earlier, this study posed no 
emotional, psychological, physical, economic or social risks to the participants, thus ensuring that, in the unlikely event of a data breach occurring, its effect would have been minimal.

As mentioned earlier, although the interviewing process was conducted between September 2018 and February 2019, the subsequent data analysis occurred over the course of the winter of 2019 and drew to a close with the arrival of summer. But what evidence did the interviews actually search for? The specific details are revealed in Appendix $B$, the interview guide that was used throughout the interviewing process. Taking a step back and speaking more generally as one must do in a methodology chapter such as this, the interviews were organized around the two aforementioned conduits which exemplify the potential bidirectional flow of influence and innovation between commercial and political marketers: marketing and technology.

Concerning marketing, attention was focused upon three things in particular. The first was the more general interplay between commercial marketing and political marketing as well as the use of personality-based candidates and their relation to commercial marketing. Some of the key questions designed to directly address my first research question included the following:

- What role does marketing play in political campaigning?

- Has the role of marketing in political campaigning changed over the years?

If so, how?

- Where are the most innovative marketing techniques and strategies being formulated?

- What comes to mind when you hear the term "political marketing"? 
- What can political consultants and practitioners learn from commercial marketers?

- What can commercial marketers learn from political consultants and practitioners?

- Where is the most innovative thinking about political campaigning occurring?

The second was the use of micro-targeting in relation to brand tribalism/tribal marketing and relationship marketing. The following set of questions was central to this particular step in my overall enquiry:

- What comes to mind when you hear the term "relationship marketing"?

- What comes to mind when you hear the term "consumer tribe" or "brand tribe"?

- What comes to mind when you hear the term "market intelligence"?

The third dealt with a potential lack of neutrality in positions/stances, be it in political or commercial marketing, and with notions of a "consumer citizen." Specifically, it explored whether or not politics' long-standing lack of neutrality on certain issues is bleeding over into commercial marketing and also whether or not there was a relationship between that possibility and the changing notions of citizenship and the norms that accompany it. Essential questions along this line of enquiry included the following:

- Do you think that commercial advertising of brands in a fashion that appears to abandon political brand neutrality (e.g. Nike's Colin Kaepernick campaign or Gillette's recent \#MeToo campaign) in favor of taking firm political 
stances on hot-button political issues will become more common, or will it still remain the exception that proves the rule?

- What comes to mind when you hear the term "consumer citizen"?

- What role does social pressure play in political campaigning?

- What role does social pressure play in commercial marketing?

As for technology, I used my interviews to search for evidence of two specific matters. The first was the use of data and data integration in commercial and political marketing. On this matter, discussion was directed towards the "datafication" of commercial and political marketing highlighted earlier. It was hoped that that conversation would cover the increasing quantification of commercial and political marketing, with an emphasis on the tools of the data mining trade in commercial marketing in comparison with political data mining programs like NationBuilder which are becoming ever more widely used in political campaigning. The second matter concerned the impact of technology-induced speed on politics and commercial marketing. Here attention was given to the possibility that, due to the increasing compression of time caused by the accelerated pace of the news cycle and the widespread sense of urgency created by the proliferation of various social media platforms, commercial marketers may have to learn from political marketers in terms of rapid response/war room strategizing in dealing with crisis communication and the unforeseen. In this light, some of the key questions in the interviews included the following:

- What role does technology play in commercial marketing?

- What role does technology play in political campaigning? 
- Has the role of technology in commercial marketing changed over the years?

○ If so, how?

- Has the role of technology in political campaigning changed over the years?

○ If so, how?

- Where is the most innovative technology for the purposes of political campaigning being developed and by whom?

- What comes to mind when you hear the term "datafication"?

- Are political parties or third-party vendors better suited to develop, test, implement, and maintain new campaign technologies?

- What role does microtargeting play in political campaigning?

- What role does microtargeting play in commercial marketing?

- Does the role of data vary between federal, state/provincial, and municipal races?

- Do you think that all of the mainstream political parties are on equal footing with their use of data for the purposes of political campaigning?

- How do you think speed factors into political campaigning?

- How do you think speed factors into commercial marketing?

With the particular research method utilized in this dissertation having been dissected, we must now turn our attention to the following two chapters to see the interview results and their analysis and, of course, to establish whether or not the anticipated bidirectional flow of influence is indeed fact. 


\section{$\mathbf{V}$ \\ Marketing Conduit Findings}

While the previous chapter provided a thorough methodological discussion about using elite in-depth interviews to answer this project's research questions, it should be noted that simply outlining the "how" is only one half of the equation when conducting any meaningful research. Thus, the fifth and sixth chapters of this dissertation will be devoted to the other half of the equation: the "what." They will perform the essential task of documenting the results from the interviewing outlined in Chapter IV. However, prior to examining the extent to which the flow of influence and innovation between commercial and political marketers is bidirectional and operating as a feedback loop rather than merely a unidirectional flow from commercial to political marketers as is commonly assumed, it is important to briefly refresh the reader's memory with the three questions for which answers are being sought.

This dissertation was driven by three research questions: First, to what extent is political marketing influencing the practice of commercial marketing? Second, how have changes in marketing strategies and technology impacted both political and commercial marketing? Third, what are the likely consequences of the relationship between political marketing and commercial marketing? These research questions were kept in mind when conducting the 33 telephone interviews (21 Canadian and 12 international) which cumulatively represent 20 hours and 39 minutes of conversations with the men and women who are best suited to provide evidence for or against the sought bidirectional flow of influence and innovation between commercial and political marketers. 
Remembering my research questions, the fifth and sixth chapters are organized according to the two aforementioned conduits (marketing and technology) that exemplify the potential bidirectional flow of influence and innovation between commercial and political marketers. This chapter focuses on the marketing conduit while the next chapter focuses on the technology conduit. Within each of the conduits, the decision was made to organize the analysis by the key themes revealed while I transitioned from open to focused coding rather than by the demographic traits of the interviewees themselves which were discussed in the previous chapter. The thinking was that a more intricate and richer analysis could be woven by using the themes that arose from the interviews rather than just the demographic traits of the interviewees as the guiding light for these two crucial chapters. Furthermore, as was pointed out in Chapter IV, separating commercial marketers from political marketers proved harder than expected since the boundaries between them were less clear than was anticipated. We should also take this opportunity for revisiting a disclaimer that appeared in the previous chapter: that an unpolished and authentic representation of the interviewees' perspectives was a key consideration in this study and, therefore, the interviewees spoke in their own words - profanities and all.

Writing a dissertation is a daunting task and it is easy to drown in the data that has been collected, data which requires organization, analysis and, ultimately, expression. To avoid that fate, this chapter proceeds in the following manner: First, my analysis commences with an unforeseen discussion that stemmed from the comments of numerous interviewees and which offers an important consideration that should be kept in mind since it concerns the fit — or lack thereof — of the terminology that defines the broader discipline in which this project is situated. Second, the respondents' thoughts on 
relationship marketing are revealed. Third, the trifecta of speed, risk, and opportunity that characterize the current marketing environment is discussed. Fourth, the notion of neutrality in both commercial and political marketing is interpreted with an eye towards whether or not neutral marketing is still the name of the game. Fifth, consumer citizenship and the long-standing practice of corporate social responsibility are catalogued and contextualized. Sixth, and finally, the increasingly contentious and divisive subject of tribal marketing is taken on and analyzed as a bridge to the following chapter since, as a tactic, it is often viewed as being enabled and accentuated by the databased microtargeting strategies that have become the bread and butter of most nationallevel marketing campaigns. And, of course, the technology conduit is the subject matter of Chapter VI.

\section{What's in a Name?}

Perhaps the most suitable starting point for laying out the results of a project intended to examine the extent to which the flow of influence and innovation between commercial and political marketing could be characterized as a bidirectional feedback loop rather than simply a unidirectional flow from commercial to political marketers would be to examine the respondents' thoughts on the suitability (or lack thereof) of the term political marketing itself. Surprisingly, there were some very different opinions on this matter.

The question that served as the catalyst for those differing opinions simply asked: What comes to mind when you hear the term "political marketing?" Numerous respondents held that the term is an ill-fitting descriptor for the type of work they practice. For example, when asked what the term means to him, Interviewee $\# 24$, the 
founder and president of a California-based research firm specializing in elections and public policy and which represents non-profit, government, media, special interest, and corporate clients, curtly and concisely responds: “Someone who doesn't know how politics works" (Interviewee \#24, personal communication, December $27^{\text {th }}, 2018$ ). Similarly, Interviewee $\# 25$, the president of an American data analytics targeting firm and former campaign manager, states that, "Well, it's a term that nobody in politics ever uses, for starters. So, what comes to mind is someone who doesn't work in politics" (Interviewee $\# 25$, personal communication, January $15^{\text {th }}, 2019$ ). Interviewee $\# 29$, a partner in a Democrat-aligned boutique digital consulting firm who has an extensive history of developing and running the digital and social media strategies for various upballot and down-ballot races across the U.S., explains that, to her, "The term political marketing sounds like somebody's trying to sell me something (laughs), like some kind of marketing — because that's just not a term that we use. Political marketing — (laughs) what?" (Interviewee $\# 29$, personal communication, January $\left.29^{\text {th }}, 2019\right)$. And, finally, Interviewee \#5, a well-known Canadian Conservative political strategist, pollster and researcher, states that, "I mean, it strikes me as a very academic term. It's $[\ldots]$ never a term that I would use in everyday life" (Interviewee \#5, personal communication, October $\left.12^{\text {th }}, 2018\right)$. But why is this the case? Why, to paraphrase numerous respondents, is the disciplinary label for the field of inquiry itself so out of touch? To flesh out an answer to this important but vexing question requires that we return to the responses that were just provided and that we dig a little deeper.

Returning to Interviewee $\# 25$ is a logical starting point for that purpose. Again, Interviewee \#25 states that, "Well, it's a term that nobody in politics ever uses, for 
starters. So, what comes to mind is someone who doesn't work in politics" (Interviewee $\# 25$, personal communication, January $15^{\text {th }}, 2019$ ). He elaborates on that comment by explaining that,

Yeah. Yeah, yeah. But overall political marketing, to me, means [...] marketing using political tools $[\ldots]$ or another way to say it is marketing for things in the political sector. Political messaging, political advocacy, political electioneering would be one, advocacy work. Yeah. I mean, I would never use the word political marketing if I'm talking to somebody in my business. Yeah. Political messaging is probably the best way to say it. (Interviewee \#25, personal communication, January $15^{\text {th }}, 2019$ )

Interviewee \#5 who, again, says that "I mean, it [political marketing] strikes me as a very academic term. It's $[\ldots]$ never a term that I would use in everyday life" also offers an interesting perspective when we look a little closer at what he says next:

I guess [...] it's almost the marketing perspective that I disagree with. I don't see a distinction between, I guess what some people would describe as traditional marketing activities and communications, like political communications and marketing [...] I guess I just see it all together. I don't see the distinction between what I guess some people call marketing activities and others would say is a communication, like giving a speech or something like that. I don't see any division between them. (Interviewee \#5, personal communication, October $12^{\text {th }}$, 2018)

In other words, to him, marketing and communication are fluid concepts that blend together as do the practice of those concepts between the political and the commercial realms.

As stated earlier, when asked what comes to mind when hearing the term “political marketing," Interviewee \#24 replies: "Someone who doesn't know how politics works" (Interviewee \#24, personal communication, December $27^{\text {th }}, 2018$ ). While that response may seem brash at first glance, when he elaborates on what he means it becomes much more nuanced. For example, he states that, 
On the pure politics side, it's campaigning. It's electioneering. It's voter contact. Those are the words that we use. I mean I don't know. I suspect a lot of people would say academia is out of touch with reality in a lot of ways. And I mean I heard - just over this holiday break, I've heard several college students that I've spent some time with explain that the classes that they're taking have no realworld application. Like their marketing classes have no discussion of social media, right? So, it's a lag or whatever, right? When you teach from a textbook [...] you're always going to have a lag behind what reality is. (Interviewee \#24, personal communication, December $27^{\text {th }}, 2018$ )

In essence, as he sees it, it is not solely the line between marketing and communication, on the one hand, and the implementation of those concepts in the political and commercial ecosystems on the other hand, that is more grey than black and white. A clinical yet informed perspective of what political marketing means to its practitioners, regardless of the label used to describe their profession, should not be devoid of the skills needed to thrive in that profession.

Other interviewees held that political marketing was anything but an ill-fitting descriptor for the type of work they practiced and that the label was certainly not "out of touch" academic jargon. Interviewee \#11, an executive at a Canadian public affairs firm and a political practitioner who has ample experience with communications and government relations on behalf of the New Democratic Party (NDP), offers the clearest such response when he reasons that, “Oh, I would strongly disagree. I don't believe the term to be exclusively the domain of the academics" (Interviewee \#11, personal communication, October $31^{\text {st }}$, 2018). He expands upon his answer by explaining that,

In my years involved in federal campaigns, and running the [...] federal New Democratic Party's campaign, we used the term in our daily lexicon in the office all the time. And I think it precisely captures what it is that we do. What political parties do, I should say. (Interviewee \#11, personal communication, October $31^{\text {st }}$, 2018) 
Additional interviewees offered more neutral responses, such as Interviewee \#10, a Democratic pollster, market researcher and strategic communications consultant, who states that, when asked what comes to mind when hearing the term political marketing, "You know, not much comes to mind, because I actually don't really hear that term all that much. Look, I guess I would [...] I think what you're referring to would be more like political targeting" (Interviewee \#10, personal communication, October $30^{\text {th }}, 2018$ ). In essence, she reasons that, due to its omnipresent impact on contemporary campaigning, targeting (i.e. the concept and practice of microtargeting or segmentation which was introduced and outlined in Chapters II and III) is a more suitable term for what scholars and journalists typically label as political marketing.

Interviewee \#31, a Texan public affairs and communications consultant with experience in crafting tailored messaging and strategies for political campaigns, businesses as well as for advocacy groups, approaches the question from a different angle. For example, as he puts it himself: "What comes to mind when I hear the term political marketing? That's a little bit hard to answer. Partly I think because I'm kind of steeped into it" (Interviewee \#31, personal communication, January $\left.30^{\text {th }}, 2019\right)$. He adds that,

I don't think that [...] I don't have a quick and easy answer, unfortunately. For me, it is a sort of complex system of [...] a complex system intended to [...] or, yeah, that's used to promote, I would say, people, organizations, and ideas. Yeah. So this is actually a really interesting question for me. As a political consultant, I often talk to my clients about what we do and how we're going to work with them in terms of commercial marketing. And [...] I don't just mean using the language of commercial marketing. What I do is I really explain it as I say, think of what we are doing as marketing. And I tell them, we use the same tools and the same strategies, but we adopt them to our specific market. And I say just what I told you a minute ago. There's no kind of magic here. What we're doing is we're marketing, but instead of selling shoes, instead of selling cars we're selling 
leaders, and we're selling ideas. (Interviewee \#31, personal communication, January $30^{\text {th }}, 2019$ )

But selling leaders and ideas is no small feat — especially in the hyper-mediated, hyperpartisan and hyper-paced landscape in which political campaigns are currently operating.

The latter of these three facts is expressly dealt with by Interviewee \#33, a hybrid marketer, principal strategist at a Texas-based strategic communications consultancy and former creative advertising director for several recent Republican presidential candidates, when he states that, in reflecting on the term political marketing,

Non sequitur is the first term that comes to mind. Two words that just don't necessarily go together. And yeah. I'm being a little facetious. But it [political marketing] certainly exists, but to me, marketing is a longer-term concept. CocaCola markets, right? They're around for 100 years whereas a political campaign is a thing that is born, lives, grows up, runs, and dies in 18 months. (Interviewee \#33, personal communication, February $4^{\text {th }}, 2019$ )

It should be noted here that this notion of the differences in the speed at which marketing in the political and the commercial realms is conducted, and the implications that speed has for the campaigns run, will be revisited throughout this dissertation. Furthermore, regardless of whether or not there is consensus on the fit (or lack thereof of) the term "political marketing," there was generally a consensus about the importance of relationship marketing in both political and commercial marketing campaigns, a subject matter to which we must now turn.

\section{Relationship Marketing Redux}

Very few major purchases are decided upon without conducting research, regardless of whether we are speaking about big ticket commercial purchases like a new car or home, or big ticket political purchases like voting in a federal election or joining a political party. Quite often, the research done to that end is not conducted in isolation. 
Instead it is influenced by our interpersonal relationships and social networks which consist of people we personally trust and respect or, at the very least, we consider knowledgeable sources of information able to guide our judgment. Recognizing these factors, I opened the door to discussing the concept and practice of relationship marketing (the basic tenets of which were outlined in Chapter II) with the interviewees in this sample by way of a two-part question. That two-part question was presented in the following manner: first, I asked, "What comes to mind when you hear the term 'relationship marketing?"”; second, I asked, "Do you think there's a difference in terms of how relationship marketing is interpreted in the commercial versus the political context? Or are they interchangeable?"

Not surprisingly, the interviewees' responses varied drastically given the diverse expertise and experiences that each interviewee brought to our discussion. Some simply had not heard about the concept or practice while others expressed intimate and acute knowledge of it. Similar to earlier sentiments expressed by a handful of interviewees on the poor fit of the disciplinary term "political marketing," some thought that the term "relationship marketing" was somewhat out of date, out of touch and too academic, as is expressed by Interviewee \#9, a Conservative political advisor, media commentator and head of an Ottawa-based opinion research and public affairs consultancy, who colorfully remarks "Holy fuck! [emphasis in original] Do people not talk to anybody anymore?" (Interviewee \#9, personal communication, October $30^{\text {th }}, 2018$ ). While the name may be off the mark, he adds that the practice of relationship marketing is omnipresent in contemporary marketing in both the commercial and political varieties. For instance, he says that, "Look, I mean, that's everywhere," but it usually goes by another name: 
“'Stakeholder Relations' is how it's often described in politics” (Interviewee \#9, personal communication, October $\left.30^{\text {th }}, 2018\right)$. In other words, interestingly, here we have another instance where a political marketing practitioner expresses concern that the terminology used by scholars is out-of-touch or out-of-step with the terminology used by practitioners on the ground. Interviewee $\# 25$ was less adamant about the saturation of the practice of relationship marketing, offering yet another label for the practice. When asked "What comes to mind when you hear the term 'relationship marketing?"' he responds that,

I know of it because I mean, I'm in sales. So, I have a good sense for what you're talking about. But I don't necessarily hear much of it in [...] it wouldn't be a term you'd use a lot of if you're a political professional. (Interviewee \#25, personal communication, January $15^{\text {th }}, 2019$ )

In his opinion, "peer-to-peer messaging is probably the appropriate phrase" for the practice (Interviewee \#25, personal communication, January $15^{\text {th }}, 2019$ ).

Regardless of whether we use the label of relationship marketing, stakeholder relations, or peer-to-peer messaging, the essential components of the practice are the same and they are concisely captured by Interviewee \#9 who states that, "It's a lot easier to have an understanding, [and to] persuade somebody, if you have some relationship with them that allows you to have a channel where there's some trust" (Interviewee \#9, personal communication, October $\left.30^{\text {th }}, 2018\right)$. Interviewee $\# 13$, a Canadian market and opinion researcher and communications strategist who is also a Principal at a government relations and strategic communications firm with a global footprint, has a similar perspective on the practice of relationship marketing by noting that, "To me, it's just about developing with someone; connecting with them on a $[\ldots]$ well, connecting with people. That's how you're going to market to them: by creating that connection - the sticky factor" (Interviewee \#13, personal communication, November $7^{\text {th }}, 2018$ ). 
Interviewee \#31 adds more to this discussion about the "sticky" nature of relationship marketing:

It's you're going to listen to your friends more than you're going to listen to a stranger, right? What they say is going to be stickier. It's going to have more impact. So, one of the things that we do [...] I mean, we do this in lobbying, right, where a lot of times your client wants to know which decision-maker you spoke with. And while that's important, what is too often missed is that you often get a lot more mileage out of talking to their staffs, talking to their legislative directors, because those are the people who are credibly [...] who they consider credible resources, and they're informing their decisions. So, with relationship marketing in politics, we look a lot to influence not only the specific, say, voters or constituents that we're looking to influence but their friends as well. And they're the people with whom they have trusted relationships so that we can build off of that. (Interviewee \#31, personal communication, January $30^{\text {th }}, 2019$ )

To put it more simply, as does Interviewee \#31, relationship marketing is essentially about "Leveraging third-party relationships in order to get credible" (Interviewee \#31, personal communication, January $30^{\text {th }}, 2019$ )

Essentially, leveraging relationships - whether using existing ones or attempting to craft new ones for future leveraging - is the name of the game in relationship marketing. This thinking is reflected in the initial thoughts on relationship marketing relayed by numerous additional respondents. For example, when asked his first thoughts upon hearing the phrase relationship marketing, Interviewee \#3, the CEO of the public affairs wing of a global market research firm as well as a political and social researcher, commentator and author, quickly responds,

Oh, well that's the old loyalty marketing type of program in which, what you're trying to do is build a relationship with your clients. So, if you take a look at anybody who's in the customer satisfaction client [indistinguishable] business, it really developed around them. At least in [...] my experience. (Interviewee \#3, personal communication, October $1^{\text {st }}, 2018$ )

Interviewee \#21, the co-founder and chief operating officer of an American digital and data consultancy, former director of digital strategy at the Republican National 
Committee (RNC) and a former media executive with three decades of experience under his belt, also offers a similar point of view on the practice of relationship marketing. According to him, "It's the one to one marketing. Tracking an individual who cares about a topic, cause, or issue that based on that marketing will either make a donation, conduct an activity online, and or go to the voting booth" (Interviewee \#21, personal communication, November $\left.23^{\text {rd }}, 2018\right)$. Interviewee \#30, a Washington, D.C.-based political marketer, digital advertising strategist and Vice President of Political Sales at a data-driven marketing firm that has a global presence, echoes this perspective, but with greater detail, by expressing the belief that,

Well, what comes to mind is just actually engaging with consumers on a one-toone basis and listening to what they have to say, and speaking back to them in a way that you would in a relationship: you would listen to their concerns, instead of just kind of blasting them with an idea and hoping that a certain percent of people it works for. (Interviewee \#30, personal communication, January $30^{\text {th }}$, 2019)

Interviewee \#27, a seasoned Republican political consultant and strategist, gives us an example of the "one-to-one basis" of relationship marketing in political marketing by noting that,

It means, okay, [inaudible] Candidate $X$, can we talk you into opening up your contact list and talk you into sending an email to all of the people on your contact list saying, 'Hey, take a look at Candidate $X$ because, I've got to tell you, I love this guy.' That's what relationship marketing is to me. Others may have a different idea of what it means. That's what it means to me. (Interviewee \#27, personal communication, January $24^{\text {th }}, 2019$ )

Other respondents were less quick and less certain in their responses. Interviewee \#2, a veteran Canadian political and market researcher and former Director of Research at a Toronto-based Canadian public affairs, government relations and crisis management firms, was one such individual. When asked about relationship marketing, he responds, 
Hmm [...] relationship [...] well, I think that means developing a relationship with the consumer probably across a number of categories so that, if they like $X$, they are more inclined to like $Y$. So, they can build those kinds of relationships and then probably use that across different types of marketers, so they'll share that. I have no idea if that's accurate, but that's how [...] I mean, I think in relationship marketing, if it is that, if it's doing things like developing ways to maintain contact with particular consumers, to build reward systems, that kind of thing, I think that type of thing will definitely continue. (Interviewee \#2, personal communication, September $24^{\text {th }}, 2018$ )

Interviewee \#6, a Canadian political pollster and researcher who often appears on Canadian national TV broadcasts to synthesize the pulse of the country, offers a similar sense of unfamiliarity with the concept yet, as he fleshes out his answer, it becomes evident that he too is familiar with the concept but not with the relationship marketing label that it has often been given. As he puts it himself:

I don't know. Again, I've never really heard that before. But I think it would be the kind of thing where, once a party has been able to make contact with you, or get your email address or that kind of thing, which always seems to be their main focus (laughs), and then to maintain that relationship, you know? (Interviewee \#6, personal communication, October $17^{\text {th }}, 2019$ )

Furthermore, he channels his inquisitive nature as a researcher by explaining the relentless nature of Canadian political parties' use of relationship marketing by way of an example:

I sign up for party [...] I sign up as like a person who is interested in a party. I sign up for all of them, so that you get all these things. And you're just bombarded with them. And they just continue to keep this relationship with you, I guess. You know, some of them, I often get some from the NDP like, 'We see that you haven't donated to us once this year, so we really want you [to] by the end of the month.' They really $[\ldots]$ try to get you with those kinds of things. I can see that that would be what the relationship is trying to [...] maintain. (Interviewee \#6, personal communication, October $17^{\text {th }}, 2019$ )

When speaking of relationship marketing, Interviewee \#17, a hybrid marketer who sharpened his teeth developing and running the digital operations for the Conservative Party of Canada where he pioneered their usage of email marketing and 
digital fundraising tactics prior to opening up his own digital marketing agency that caters to both a political and commercial clientele, offers us some important considerations to be kept in mind, building off of his definition of the concept itself. For example, as he puts it,

Relationship Marketing? Well, I mean, that's basically what we're [...] what political parties should be doing. It's, you know, trying to build meaningful relationships with people. And I don't think the parties are there. You know, a lot of their list-building and targeting is you know, 'Please give me money. Please get out and vote. Please do this. Please do that.' People aren't actually getting much return. (Interviewee \#17, personal communication, November $12^{\text {th }}, 2018$ )

In essence, he introduces us to two points. The first is that, when discussing the practice of relationship marketing in the context of political marketing, when the varnish is stripped away, the reason for relationship fostering and leveraging is usually to increase fundraising returns and not to foster any authentic kind of relationship with the voter. Second, relationship marketing in the political marketing context benefits the political apparatus far more than the voter. Both of these side effects of relationship marketing in the political marketing context will be fleshed out a little later in this chapter. Interviewee \#10 also offers us an interpretation of relationship marketing that touches on the importance of fundraising and of moving voters towards the voting booth when she states that,

I think of people leveraging [...] of companies using peoples' personal relationships to utilize them to market [...] I don't know; I mean, it's definitely used in the political context. Well, that's how people convince others to register to vote, like you do, you know, bring your friends to the polls. Or you do house parties to introduce people to candidates and for fundraising. So, it's pretty commonplace. (Interviewee \#10, personal communication, October $30^{\text {th }}, 2018$ )

Interviewee \#4, an NDP strategist, political columnist and commentator, walks us through his interpretation of relationship marketing and how the practice of relationship 
marketing as a technique has evolved in conjunction with ongoing advancements in communications technology in the political marketers' toolbox. He initiates that discussion by stating that, "Well, relationship marketing, to me, and maybe I've got this wrong, but relationship marketing to me would mean somebody who has [indistinguishable] a previous relationship to leverage your advance" (Interviewee \#4, personal communication, October $\left.11^{\text {th }}, 2018\right)$. And, as he sees it,

Well, it [relationship marketing] works on so many different levels, right? I mean [...] well, in a way, that stuff has always happened: 'Why am I voting for Jim? Well, I'm voting for Jim because Jane knows Jim; and Jane is a really good person; and I know her; and I trust Jane and I trust Jane's judgment, so I think Jim is probably good, and I'm going to vote for that person.' That's nothing new. That's very normal. But now we've taken it into a really abstract thing where I am [...] you know, 'I like Ontario Proud,' or 'I like Rebel Media, and Rebel Media likes so and so, and so I like so and so. And so and so doesn't actually do anything for me, but I have an affiliation, I have a relationship there.' So, you know, I think it's carrying the idea of affiliation into [...] just a logical conclusion. I mean when you have [...] you know, when you have partisan parts of news outlets, that's partisan, but ones with very clear opinions or orientations as opposed to being the classic newsgathering source with you know, multipartisan analysis and discussion, you know, once you move away from that model, so that now, if you watch Fox, you're like this, and if you watch CNN, you're like that, you read this magazine, you are this kind of person, and if you read that kind of magazine, you are that kind of person, so all the subscriber lists, all the [...], you know, the cable subscriptions are all part of a value chain to the politicians because we're self-affiliating. So, you know, Jane is CNN. You know, Clinton is [...] I like CNN, and I watch it, I like the commentators, right? So, again, I don't think it's particularly healthy, but that is the way it is going at this time. (Interviewee \#4, personal communication, October $11^{\text {th }}, 2018$ )

Interviewee \#19, the Associate Principal at a Canadian public affairs, government relations and crisis management firm and a former NDP communications consultant with extensive experience in media relations, crisis communication and campaign management, also speaks of relationship marketing and its ongoing evolution. However, unlike Interviewee \#4, she does not couch that evolutionary discussion in terms of the irrefutable impact of new technologies and the potential roles they are playing in fanning 
the flames of tribal marketing (tribal marketing being a matter to be unpacked later on in this very chapter) or the crafting of a kind of echo chamber (a matter that will be discussed both later in this chapter as well as in the following chapter). Instead, her discussion sees a generational ebb and flow as the modus operandi of the ongoing evolution of relationship marketing. She begins that discussion by simply stating that "it's changing" (Interviewee \#19, personal communication, November $\left.16^{\text {th }}, 2018\right)$. She elaborates on how it is changing by using her own personal experience and explaining that,

When I first had a bank account, it was Royal Bank, because my parents banked with the Royal Bank. Same. I voted New Democrat, because my parents voted New Democrat. And, I think that, well there's still a lot of that out there, that younger people are more willing to [...] there's more variety of choices (both on products; it's not just like Coca Cola versus Pepsi), you know what I mean? And it's the same in terms of the media you consume and thereby your political opinions. You know, I think that kind of, that breadth of variety means that the challenge to keep a brand loyalty - whether that's at the kind of corporate side or the political side - becomes more challenging. Yeah. And there's also, in addition to kind of your parents and your friends and stuff like that, there's also regional distinctions in both obviously the marketing and the political side of like, not just, 'I vote this way because my parents do,' but 'This is kind of the way we do as a community, as a province,' or whatever. (Interviewee \#19, personal communication, November $16^{\text {th }}, 2018$ )

In essence, here, Interviewee \#19 posits that younger consumers are less likely to be as intransigent as older consumers in their brand loyalty and also less likely to have their brand loyalty established via familial relationships and geography — two organic types of relationship marketing that are crafted not by marketers themselves but by the consumers. Instead, in her opinion, younger consumers are more likely to have fickle brand loyalty tendencies largely due to the fact that they grew up in an environment characterized by greater choice - both consumer and political. 
Interviewee \#17 takes this discussion on the relationship between the scope and scale of consumer choices and relationship marketing even further. He holds that there is an inverse relationship between the scope and scale of consumer choices an individual has and the importance of relationship marketing as a technique or practice. Concerning relationship marketing, he claims that,

I think in the commercial context, I think most businesses care a little bit more. You know, like, $[\ldots]$ if you're a voter, and you're considering who to vote for, and you've got an issue that you care about, but the Conservatives, and the Liberals, and the NDP, they don't want to talk about it, they don't care about it, well, guess what? You're not going anywhere else. There's nowhere else to go. Right? Whereas, if you're looking for a new shoe, and you care about $X, Y$, and $Z$ in your shoes, and you know, Nike and Adidas aren't doing it for you, well, guess what? There's literally hundreds of other companies that will sell you a shoe, right? So, I think there is a big difference in the amount that people care. Again, part of this also goes down to professionalization, right? There's nobody who works at the parties - most of them - whose job it is to answer emails or respond to Facebook messages or things like that. Some of them do it. I know the Conservative Party has like a support desk that's actually really well-staffed and they generally get back to people. You know, it's tough to answer everyone. In some questions, truly, there's nothing that you can say to these people to make them happy, right? So, they do a good job of it. But not everyone does. And, for a lot of people, it's a write off. Whereas, I think if you're a business, you can't afford to just write people off. (Interviewee \#17, personal communication, November $12^{\text {th }}, 2018$ )

In other words, as he sees it, the more choices a consumer has, the greater the importance of relationship marketing for the marketer. Since, generally speaking, there are so few viable (i.e. electable) political parties, he holds that relationship marketing is less of a concern for political marketers than it is for commercial marketers. With that in mind, it makes sense to pivot our investigation from the first to the second portion of the two-part question framing the discussion of relationship marketing which asked: "Do you think there's a difference in terms of how relationship marketing is interpreted in the commercial versus the political context? Or are they interchangeable?" 
To begin unraveling the respondents' answers to that question requires acknowledging how effective and important relationship marketing is as a marketing technique. Interviewee $\# 28$, the managing partner of a Democrat-aligned targeting firm and a former Chief Technology Officer of the Presidential Inaugural Committee, provides us with such an acknowledgement in stating that,

When executed correctly, it is a very powerful way to talk to potential voters. Anytime you can use a personal connection to a voter, as opposed to an anonymous campaign message, it's going to resonate a lot more with the target. (Interviewee \#28, personal communication, January $28^{\text {th }}, 2019$ )

Interviewee \#1, the president of the Canadian public affairs division of a global market research firm and a communications strategist with experience in policy development, agrees and his remarks highlight the irrefutable importance of relationship marketing when he says that, "And, just purely from a personal standpoint, if you're not going to have a personal relationship with me, then I won't have one with you" (Interviewee \#1, personal communication, September $\left.12^{\text {th }}, 2018\right)$. Interviewee $\# 23$, a Canadian political strategist who has practiced his craft at both the national and provincial level for decades, and who is the president of an Alberta-headquartered digital marketing and strategy consultancy, helps us begin to get at whether or not there is a difference in terms of how relationship marketing is interpreted in the commercial versus the political context. He does so by way of a detailed discussion of what relationship marketing means to him and how he pitches the practice to commercial clients after having practiced it in the political trenches for quite some time:

To be honest, relationship marketing is what I tend to try and sell corporately: Relationship marketing in politics; so, what I've taken now is relationship marketing, I've tried to boil down into the construct of what is a social network. And so social networks for me are the building blocks of all society. And going back to my dishwasher example, if your dishwasher breaks down, you talk to the 
people within your social network about what brand they own, and what they're going to buy. And if your mother-in-law has a top loading cutlery tray, how does it impact your decisions around buying the dishwasher? Well, what's your relationship with your mother-in-law. If your relationship with your mother-inlaw is you know, such that, you know, it's a good relationship, then maybe you buy it then. But if it's not good, then maybe you just let it go. So that for me is relationship marketing, but I call it building on social networks. In politics, it works a little differently, but at the same time, it's pretty much the same. You pick up the telephone, it's election day, and you call somebody, your friend who knows who to vote for all the time, and you say who am I voting for, and they tell you who to vote for. And that social network model dictates the voting outcome. So, it's kind of similar, but I don't like calling it relationship modeling or marketing. (Interviewee \#23, personal communication, December $5^{\text {th }}$, 2018)

When asked about whether or not there was a difference between relationship marketing in the political marketing or the commercial marketing professions, Interviewee \#20, the General Manager of an Ottawa-based media agency and a commercial marketer with over twenty years of experience in the fast changing world of content creation in both the marketing and advertising realms, concisely responds that, "I would think they're interchangeable" (Interviewee \#20, personal communication, November $\left.19^{\text {th }}, 2018\right)$. She, however, was the only one of the thirty-three respondents who held that opinion. Each of the other respondents who were aware of relationship marketing and what the practice entails held that there were indeed some distinctions between how the concept is interpreted, and practiced, in the political marketing and commercial marketing contexts.

Interviewee \#16, the founder and president of a well-known Toronto-based advertising agency, commences our dissection of a number of the key distinctions in the practice of relationship marketing in the political, as opposed to the commercial, marketing realm. He does so by stating that, "I think the primary difference is what's the purpose of the relationship, right?" (Interviewee \#16, personal communication, 
November $\left.8^{\text {th }}, 2018\right)$. He walks us through some of the hallmarks of that difference by explaining that,

So, it stems from the fact that, in a commercial context, the relationship is really about share of wallet and frequency. So, in the political context, we don't need you to vote more than once. Right? And so, there isn't that kind of relationship building effort to try to say, 'I need more of your votes and I need them more often. I need them more between [indistinguishable].' Right? Whereas, in the commercial context, [if] you're a big Tim Hortons fan, I just need you to come more at lunch than just for coffee. And so, you're constantly trying to manipulate the relationship to greater [...] for a greater share of wallet. That's a fundamental difference, in terms of how you manage a relationship. And then, of course, that leads to the tools that you use. So, you know, in commercial relationships, you incentivize behavior. In political communication, you can't incentivize behavior. I mean, except through the policy. You know, 'If you vote for us, your taxes will go down.' But you can't say, 'Vote for us and get a buy one, get one free.' Or, 'Vote for us and bring your kids along and they can vote, too.' There aren't tools that are comparable, in terms of relationship management. Whereas, you've got loyalty programs on the commercial side that earn points with every transaction and allow you to win contests, and all of those kinds of things that are added to the relationship. And then, of course, there's differential recognition components as well. Like, think of airline loyalty programs and the way that the best customers are given preferred treatment. The closest you can get to that in politics is a very tiny amount can (which is like preferred donors) get a little more access. But that's a sketchy area to begin with. Laurier Clubs for people who have donated a thousand dollars a year or whatever. But, for the most part, you don't have differential; you don't have marketing that's targeted at people because they are better, they are more Liberal than other people. And, as I said earlier, it tends to be the inverse: the marketing dollars are spent on swing voters. I mean, we've gone into elections where we've literally said we're going to spend our entire budget against $7 \%$ of the population. And so, that's a phenomenon that doesn't exist in [commercial marketing] because it's not a zero-sum game in commercial. It doesn't exist in the commercial realm. We have made strategies for clients all the time who say, 'If we could get one more purchase out of our existing customer, we wouldn't have to get any new customers at all.' (Interviewee \#16, personal communication, November $8^{\text {th }}, 2018$ )

With these substantial differences between relationship marketing in the commercial versus the political realms in mind, Interviewee \#16 goes so far as to say that, "The two realms are so antithetical that they just can't coexist in terms of how they transfer the learning and the CRM [Customer Relationship Management]" (Interviewee \#16, personal 
communication, November $\left.8^{\text {th }}, 2018\right)$. Interviewee $\# 3$ also posits that relationship marketing is anything but interchangeable between commercial and political marketing. According to him, "They're completely different" (Interviewee \#3, personal communication, October $\left.1^{\text {st }}, 2018\right)$. He elaborates on why this is the case by reasoning that,

I don't think relationship marketing works in the political world. It might if you're somebody who's like a municipal politician, in which your relationships with people are transactional. That's when it would work. And, [in] the commercial world, for example, if you're an American Express client, they have a relationship with you based on everything from all of the way they treat you as a customer, and the way that they deal with your transactions, and the way they deal with your billing and everything else, all the way through to the offers that they make to you as part of your client relationship with them. So, it's not what happens in politics; what happens in politics is not relationship marketing, as I understand it. It's a different kind of relationship. You don't have a transactional relationship [in politics]. (Interviewee \#3, personal communication, October $1^{\text {st }}$, 2018)

Interviewee \#28 certainly does not think that relationship marketing is interchangeable between the commercial and the political realms, but he does not go so far as to say that their concepts or practices are incompatible. Instead, he offers a more moderate position on the matter when he notes that,

Yeah. I think it's a little bit different, because of the ask, ultimately. With political, you're talking to your friends or your neighbors about why you support someone and how that's going to make your life better. When you're talking about which detergent to use, I feel like that's an entirely different (laughs) and, maybe, that's a bad analogy, but the stakes are so much lower there. (Interviewee $\# 28$, personal communication, January $28^{\text {th }}, 2019$ )

In essence, Interviewee $\# 28$ is reasoning that the concept and practice of relationship marketing is not antithetical between the two realms. More accurately, it is the significance of the end goal of relationship marketing as practiced by political marketers (i.e. winning over voters for a candidate and party) or commercial marketers (i.e. attracting purchasers to a product or a service) which represents the main difference 
between the relationship marketing practiced in either ecosystem. A similar perspective is offered by Interviewee \#13. For instance, she explains that,

I think the only difference I can think of is [...] I guess, when I'm thinking of a product, I'm not sure I get that, what's the word? 'Visceral.' It's like the other side of a coin in a commercial context. I don't feel like I get that as pronounced as I do in a political context. I'm either going to develop that relationship and be warm with that message, or I'm going to be repelled. And I see that differently than I would a commercial product. I'm trying to think of a commercial product that $[\ldots]$ something they've messaged. I might disagree with you trying to sell me sugary drinks, but I'm not viscerally affected by it, as I am by the political messaging and marketing, anyway. (Interviewee \#13, personal communication, November $7^{\text {th }}, 2018$ )

Interviewee \#25 who, as was pointed out earlier, holds that, "peer-to-peer messaging is probably the appropriate phrase" for what we tend to think of as relationship marketing adds a little more to this discussion on how the contrasting end goals of relationship marketing in the political and commercial contexts represent a substantial difference between its practice in the two realms (Interviewee \#25, personal communication, January $\left.15^{\text {th }}, 2019\right)$. He does so by musing that, "I haven't seen much peer-to-peer work in the commercial space, now that I think about it" (Interviewee \#25, personal communication, January $\left.15^{\text {th }}, 2019\right)$. Why is that likely the case? He quickly gives us an answer to this question by remarking that,

Yeah. I mean, well, I guess it's harder to be excited about selling a bag of chips than a candidate. I don't know. I mean, yeah. Yeah. I'm trying to think of a consumer brand that is trying to get people so excited. I'm never going to email my 20 friends and tell them to try these veggie chips. [But] I may say, 'It's $5: 26 \mathrm{pm}$. Don't forget to vote, please.' (Interviewee \#25, personal communication, January $15^{\text {th }}, 2019$ )

Here Interviewee \#25 highlights the fact that relationship marketing has an inherently human and social aspect to it which is dependent upon opinion leaders or, to use today's buzzword, influencers. And that opens the door to a more granular discussion of other 
important differences between the practice of relationship marketing in the political and commercial marketing contexts.

As Interviewee \#1 reminds us, one of the key questions faced by marketers (commercial or political) is this: "[If] more and more of our media is created by our personal relationships with people, then how do you tap into that?" (Interviewee \#1, personal communication, September $\left.12^{\text {th }}, 2018\right)$. Good question. With that in mind, he states that, "So there is relationship marketing; there is, you know, using [...] I want to say thought leaders, but influencers of social media to sort of go talk about your thing, your products" (Interviewee $\# 1$, personal communication, September 12 $\left.{ }^{\text {th }}, 2018\right)$. In the words of Interviewee \#20, that process works in the following manner: "So, [you send] your best message to your best stakeholder and it's the relationship that develops with that influencer or, you know, with that delegated person" (Interviewee \#20, personal communication, November $\left.19^{\text {th }}, 2018\right)$. But this is easier said than done. As Interviewee \#16 puts it:

You know, the use of influencer marketing is a big phenomenon in brand-building [and] it's non-existent in politics. Right? You don't pay an influencer to put, you know, Justin Trudeau's picture on his or her Instagram feed. Whereas, you know, we pay people all the time to take a picture of themselves drinking a Corona. (Interviewee \#16, personal communication, November $8^{\text {th }}, 2018$ )

In other words, here Interviewee \#16 gives us a concrete example of one of the different ramifications of relationship marketing in commercial versus political marketing, thereby drawing attention to the fact that the marketing strategies and techniques practiced in commercial marketing cannot simply be superimposed onto political campaigning. There are fundamental differences between the two realms; and the way that relationship marketing is practiced is one such difference. 
While it may be true that the kind of relationship marketing practiced by social media influencers who act as paid or unpaid unofficial spokespersons for products in the commercial marketing realm may be absent in the political marketing realm for obvious legal reasons, the argument could still be made that, when discussing relationship marketing in the political marketing trade, there are indeed influencers or (to use more academic language) opinion leaders in abundance in politicking. Unlike their commercial marketing counterparts, they may not, of course, be receiving a financial payment for their unofficial lobbying, but they are still lobbying those within their social network.

Interviewee \#24 sets the stage for that discussion and also draws our attention to the fact that influencers are not new. They existed long before social media platforms like Instagram popularized the concept and turned the act of influencing others' choices (by persuasive or recognizable individuals) into a lucrative profession in and of itself. In other words, regarding the case of influencers, social media platforms merely monetized the inherent ability possessed by some to practice the art of friendly persuasion among their peers. As Interviewee $\# 24$ puts it,

Well, I mean every business has a CRM. And they're trying to - and this goes back to that kind of share and engagement component. This idea that it's not just campaign talking to voter. It's voter talking to voter and identifying who those voters are as far as influencers. (Interviewee \#24, personal communication, December $27^{\text {th }}, 2018$ )

He also makes the important point that being an influencer is not dependent upon technology. He cites a political marketing example that is as old as the act of campaigning itself in saying that, "I mean just to give you an indication of a very early kind of use of this - and it's kind of an old school thing that isn't used very much anymore. The coffee, right?" (Interviewee \#24, personal communication, December $27^{\text {th }}$, 
2018). He walks us through the process of this informal, non-technology dependent form of being an influencer and also how it has evolved and become more technology dependent by explaining that,

So, 50 years ago, 25 years ago, one of the key components of any campaign for even Congress, but definitely more local, is the coffee, right? You identify the 25 neighborhoods where you want to meet people. You identify a friendly in that neighborhood that will host a coffee at their house at 7 o'clock on a Thursday night. You mail postcards to the 5,000 people surrounding them in that neighborhood or, depending on how densely populated it is, right, or maybe 500, depending on what you're doing. And you invite those people to a coffee. You know most of them aren't going to show up. But you have [...] it's a postcard from Sally Sue to her neighbor saying, 'Hey, I live here. I'm supporting Joe Smith for Congress. He's coming to my house for coffee on Thursday night.' [It's] very low tech. Today you can have people in the database tagged for all kinds of things including who they relate to and who they would be good at influencing. (Interviewee \#24, personal communication, December $27^{\text {th }}, 2018$ )

In terms of the link between databases and relationship marketing, Interviewee

\#11 makes an important point: what relationship marketing means and how it is practiced

"depends on the level of engagement" (Interviewee \#11, personal communication,

October $31^{\text {st }}$, 2018). He elaborates on this by explaining that,

You see, like, people who are long-time members of a party (donors, supporters, people who get the mail from the party monthly, people who go to meetings on an occasional basis), they have a deep relationship with that party. And, for many people, it's lifelong. So, for them, you know relationship marketing, like when, you know, the leader of the party or the president of the party sends you an email or a letter (on a mass basis, of course), you know, you've got an intimate relationship with that party (because you've been donating, you've been going to meetings, you've been doing it for years). I don't have that same relationship with a product. But, again, most Canadians don't have that relationship with a political party. We're talking maybe $2 \%$ of the population I think are even members of a political party. So, that's, for the other $98 \%$ of the country, they would have very little relationship with that party. They may have fond experiences in the past, right? I get that all the time. People come up to me and say, 'Oh, Jack Layton. He was so great. I voted for him.' And they've probably voted for two other parties since the 2011 Election - which is fine, but there's not much of a relationship between the individual and the party, per se. (Interviewee \#11, personal communication, October $31^{\text {st }}$, 2018) 
Interviewee \#11 also makes the important point that this is not strictly a political marketing phenomenon. The same holds true for relationship marketing in the commercial context. As he says it himself:

And the same is true, I mean, different levels of engagement / different product, right? You know, I lease a car. That car company sends me stuff all the time. I feel [like] part of their family, because they mail me, they phone me, they want to keep me in their [fold], you know, the next time I get a car, they want me to stay with that brand of car, you know? But I have no relationship to my soda (laughs) or, you know, underarm deodorant, for example. Well, yeah, the bigger ticket items, because they have the ability to [...] they know where I live, right? So, because, you know, you've got to register your car, so they have data on me. Whereas, I bought Degree underarm deodorant, [and] the guys at Degree don't know that I just bought that. They know that they moved 50 units last week at the No Frills, but they don't know that [John Doe] at 161 Glendale was one of those guys. They don't have data on me. So, they can't develop that relationship. But the car company can! [emphasis in original]. (Interviewee \#11, personal communication, October $31^{\text {st }}, 2018$ )

But the level of engagement in relationship marketing varies based upon the circumstances of the particular campaign being run and, of course, on whether or not that campaign is of the political or commercial marketing variety. Even so, Interviewee \#6 reminds us that, in his eyes at least, those variances are not absolute when he notes that, "I would think there's a lot that's similar" (Interviewee \#6, personal communication, October $\left.17^{\text {th }}, 2018\right)$. Returning to Interviewee $\# 24$ helps illuminate how relationship marketing can be similar in commercial and political marketing by stating that,

I mean whether it's relationship marketing, or account-based marketing, or whatever it is, on the business side, there's kind of this I'd call it more automation, marketing automation essentially. If I'm trying to sell a product and I've identified someone who's got some interest, I'm going to have an account manager who's going to be on that person. They're going to be on some sort of regular schedule of emailing them, and sending them a note, and reaching out to them in kind of regular fashion in order to develop that relationship that gets them to the point where they buy. Similarly, you could kind of look at a campaign in that way. It's just not talked about in that way, but that's essentially what we're trying to do. We're trying to talk to people in the 12 different ways we know how to reach 
them with a message that we expect is going to be of interest to them. (Interviewee \#24, personal communication, December $27^{\text {th }}$, 2018)

In essence, here we are reminded of the fact that both political and commercial marketers practice the craft of relationship marketing and that the end goal is the same for both types of marketers: to foster an affinity between the brand/product and the voter/consumer to heighten the odds of a vote/sale. However, the challenges they face while working towards that end goal tend to vary between the two realms.

Interviewee \#12, a Canadian political and corporate strategist, pollster, and campaign manager who has worked in conjunction with the Liberal Party of Canada and its candidates for quite some time, gives us his definition of relationship marketing as well as an important example of a key difference in the practice of relationship marketing between the political and commercial marketing contexts when he states that, to him, relationship marketing is

Dialogue between the marketer and the consumer. [And, when it comes to relationship marketing,] I think that you require a lot more consistency with political marketing than you do with consumer marketing, because your political consumer is being constantly exposed to negative information about your brand in a way that your commercial company is not. A commercial consumer is not. And, so, if you are not constantly in their face counteracting what they hear about you everywhere else, you'll lose them. I mean, you can go through life thinking that your brand - like your consumer brand - is perfect. Nothing may ever happen to change your mind about that. Right? But, you know, I mean your government is regularly going to disappoint you (laughs). (Interviewee \#12, personal communication, November $1^{\text {st }}, 2018$ )

Interviewee $\# 32$, a political activist, blogger, pollster and consultant who has provided his services to numerous campaigns both in his native New Zealand and also in the United Kingdom, does something similar but highlights a different distinction between relationship marketing in the two realms while also offering an important consideration to keep in mind when he explains that, 
So, it's [relationship marketing] not necessarily about selling a product or a service, but it's about selling really the company or the brand. It is, because, in the political context, that's all you're selling - effectively. It's about selling the brand, about selling the company. You might be selling individual politicians, too. You're [...] yes, of course, you want people to vote for you, and during the campaign there's more of a focus on actually getting out there and doing it. In commercial marketing, you have some companies who will do marketing that's got no relationship marketing; it's simply: people like our product; here's what the price is; here's where you can get it. But, even the companies that do do relationship marketing, that can't be all you do. There's no point in everyone saying you have a great brand, and then they don't actually buy anything off you. Unlike in politics, where, actually, that brand is all-important, because, if you get the brand, that effectively becomes the sale. (Interviewee \#32, personal communication, January $31^{\text {st }}$, 2019)

In other words, masterfully conducted relationship marketing is no consolation prize for the lack of making a sale. Relationship marketing is only useful if it increases the likelihood of a sale.

Interviewee \#6 also draws our attention to an additional important difference between relationship marketing in the political and commercial marketing environments when he notes that,

If you're someone who always buys a Ford, you're not going to buy a Ford every year or two. But $[\ldots]$ just maintaining that loyalty is important. But, for a political party, they probably want to hit you up for a couple hundred bucks a couple times a year every year. And then, during an election campaign, if they can, try to get you to be a volunteer and to [...] make sure you go vote [...and] I think they'd be a lot more dependent on maintaining that, 'cause they need to. They need it every four years, and they also need it throughout to keep the money coming in. (Interviewee \#6, personal communication, October $17^{\text {th }}, 2018$ )

Here, Interviewee \#6 gets at a key difference in the use of relationship marketing as practiced by both political and commercial marketers: while both commercial and political relationship marketing campaigns strive to maintain contact with consumers/voters on an ongoing and constant basis, political marketers typically aim to 
extract money from the recipient more frequently than do commercial marketers especially commercial marketers selling big ticket items.

Why is this the case? As was hinted at earlier, many of the commercial brands that have the resources (i.e. the data, funds, talent, expertise, and desire) to practice relationship marketing are selling cars, homes, luxury and lifestyle goods, all of which are typically expensive and therefore unlikely to be purchased on a rolling basis. In contrast, political campaigns and parties generally have fewer resources on hand at any given time and therefore always need to keep an eye on acquiring more. However, as Interviewee \#30 aptly points out, albeit with a hint of cynicism: "They say they do it [relationship marketing] in politics, and they don't. And they do in the commercial world. But, you know, it's hard to do on a limited budget and with limited time. Again, in politics $[\ldots]$ politics is a very risk averse business" (Interviewee \#30, personal communication, January $\left.30^{\text {th }}, 2019\right)$. We will turn our attention to examining risk aversion in both the commercial and political marketing contexts a little later in this chapter. However, in the meantime, it is worth picking up on Interviewee \#30's earlier comment on political marketers that, regarding relationship marketing, "They say they do it in politics, and they don't" (Interviewee \#30, personal communication, January $30^{\text {th }}$, 2019).

This line of reasoning is also voiced by Interviewee \#33 who says, "Relationship marketing? That's another great old marketing term. I think that's something that political campaigns think they do but they really don't" (Interviewee \#33, personal communication, February $\left.4^{\text {th }}, 2019\right)$. Below, he elaborates on what he means by this 
while, at the same time, questioning the intention, depth, and shelf life of any relationship marketing strategy being practiced by political marketers:

I think political campaigns and candidates, in general, all think they're a little bit more famous and a little bit more loved than they really are. And so, are you really having a relationship? It's kind of like an election, it is a relationship, but it's kind of not very deep, right? So, I think if you like a person, you're more likely to vote for that person. So, there's that sort of relationship, right? Whereas if I bought an Audi, right, then that's a completely different relationship. And they send me a magazine every two months and a little letter and a note. And so, I mean, there is a long-term relationship there, which is kind of funny because in politics, when you cast that vote for somebody, they're going to be with you for 4 years or 6 years or 2 years. It's very similar to buying a car [...] and I think political campaigns do frankly an appalling job of that. (Interviewee \#33, personal communication, February $4^{\text {th }}, 2019$ )

Here Interviewee \#33 makes the point that commercial relationship marketing campaigns are rightfully envisioned as long-term strategies of customer cultivation and retention and that, while political relationship marketing campaigns should be envisioned and practiced in the same manner, to his mind they generally are not. What he says goes back to Interviewee \#17's comment earlier in this chapter, where he reasoned that the more choices a consumer has, the more important relationship marketing is for the marketer since customer retention is less certain (Interviewee \#17, personal communication, November $\left.12^{\text {th }}, 2018\right)$. And, because there are generally more candidates than are ultimately viable (i.e. electable) in any given electoral cycle, political marketers take customer retention for granted and therefore pay less attention to executing effective relationship marketing strategies. However, in the opinion of Interviewee \#33, there are two additional reasons for political marketers' disconnect with or neglect of relationship marketing — depending upon how you label the lost opportunity. For example, he posits that, 
I think people win, and then you never hear from them again until it's time for them to run again. I think because number one, money. And I think number two, candidates trick themselves into thinking they're doing it because they'll send out, 'Well, here's my newsletter, my once a quarter newsletter from the office. And I'm doing a lot of constituent services, right, and helping Mrs. O'Leary with her pothole problem or whatever it is.' So, I think candidates think they're doing that but they're not. And I think from the voter perception, it's like, 'Hey, we never hear from these cats until they need our vote.' (Interviewee \#33, personal communication, February $4^{\text {th }}, 2019$ )

To sum up our discussion of relationship marketing, the vast majority of interviewees, whether commercial or political marketers, and whether they were Canadian or not, upheld the importance of relationship marketing in any effective marketing campaign. However, many interviewees made the crucial point that there are substantial differences between the way that relationship marketing is put into practice in commercial versus political marketing. More specifically, it was revealed that the end goal of relationship marketing for political marketers and commercial marketers represents perhaps the most pronounced difference between the way that relationship marketing is practiced in the two realms. Additionally, the level of engagement coupled with the depth and longevity of the kind of relationship marketing strategies practiced was another important difference between commercial and political marketers. It is a subject that serves as the perfect point to pivot to our discussion of speed, especially since speed and longevity are related to one another.

\section{Speed, Risk, \& Opportunity}

As mentioned in Chapter III, speed as a force and as a consequence of increasingly technology-dependent campaigning — whether of the commercial or political marketing variety — presents a challenge to marketers which will only increase in the years ahead. This section examines how speed manifests itself in both the 
commercial and political marketing environments, focusing on how political marketers appear to have greater familiarity with and ease in harnessing speed for the purpose of crafting effective marketing. It thereby highlights a concrete instance wherein political marketers are out-innovating their commercial counterparts and also adding a new dimension to the long-standing and groundbreaking political marketing framework developed by Jennifer Lees Marshment and others.

Channeling the words of James Carville, the architect of Bill Clinton's successful 1992 presidential campaign, Interviewee \#9 kickstarts our discussion on speed and its impact upon marketing campaigns by stating that: "Well, like on the highway, speed can kill, because there is an expectation, I think in this world in which we live, that responses are more quickly provided" (Interviewee \#9, personal communication, October $30^{\text {th }}$, 2018). He contextualizes this initial response by explaining that,

So, you've got to kind of understand that expectation. You also have to be judicious and not making the mistake of rushing the response. But, yes, speed is absolutely a factor in all so-called news cycles. And people would run campaigns around, you know [...] how to put something in the 6 o'clock news, [how to] put something in a newspaper versus a television story. That's all screwed up now. It's also about speed: just getting it out there now. People want to get information out there so that it can dominate the agenda - whether that be for ten minutes or twenty. And agenda domination is also about speed. So, speed has many layers to it. (Interviewee \#9, personal communication, October $30^{\text {th }}, 2018$ )

In his estimation, "agenda domination" is much more difficult in the current communication and marketing environment because social media has greased the proverbial gears and increased the speed of both message dissemination and the expectation of message response or rebuttal.

A similar perspective is voiced by Interviewee $\# 19$ when she states that, "Speed kills. [...] That was the first thing told to me when I stared working in political 
communications, and it has only become more and more true every single day" (Interviewee \#19, personal communication, November $16^{\text {th }}, 2018$ ). With this in mind, she adds that, nowadays,

You can't wait fifteen minutes to kill a shitty story. [By then,] it's already too late. $100 \%$ Because, when something [is] out there, you can't put the toothpaste back in the tube. When you turn away from your computer, or when you go to the can [emphasis in original] and come back five minutes later and some story's broken, it's already out there. You know what I mean? And, it's not like [...] you know, you don't have time to call a journalist back and spin them [...] it's already out there. (Interviewee \#19, personal communication, November $16^{\text {th }}, 2018$ )

Interviewee \#8 sums up the situation with speed thus far when he states that,

I think with social media, now [...] the expectation on the part of consumers is that brands will respond much more quickly, not just to specific inquiries or engagement, but to developments in the broader [...] the broader ecosphere, for lack of a better term. So that is something that is probably relatively new. (Interviewee \#8, October $26^{\text {th }}, 2018$ )

In essence, with the increased speed of the news cycle via the proliferation of social media platforms, consumers are expecting more attention and accountability from the brands they interact with — regardless of whether those brands are political or commercial in nature. And this speed-centric shortening of the consumer-to-brand feedback loop is drastically amplifying the already existing pressures and difficulties with which marketers have long had to contend.

To make the impact of technology-induced speed upon campaigning patently clear, Interviewee \#27 provides us with a graphic, hyperbolic and political example of how this dynamic creates a terrain that is very delicate and difficult for marketers to navigate by remarking that,

Oh, speed? It's everything. You have to $[\ldots]$ when you're in $[\ldots]$ a competitive race, you must have someone who is monitoring social media and trends, has your name on Google Alert and any other way so that they instantly know if you're being hit because that could spiral out of control within a very, very short period 
of time. [...] Some are using Twitter to respond to this and put stuff down, but you can find, in a very short period of time, your candidate's head is on the sidewalk and blood spurting out of their aorta if you are not monitoring what's happening on social media. (Interviewee \#27, personal communication, January $24^{\text {th }}, 2019$ )

While the pressures and difficulties that speed has posed for marketers are certainly not recent developments, Interviewee \#27 highlights how they have intensified relatively recently:

And it's a 24/7 kind of thing. There is no peace and quiet anymore. [It] used to be that we had three times in the news cycle when: it was the morning news, the midday news, and the evening news. And now the cycle is $24 / 7$ because of social media, which is why candidates are spending more money because they have to have people to monitor this stuff. (Interviewee \#27, personal communication, January $24^{\text {th }}, 2019$ )

Or, as Interviewee \#4 puts it: "The news cycle — in terms of politics - I've seen that as being the major change in the last decade" (Interviewee \#4, personal communication, October $\left.11^{\text {th }}, 2018\right)$. He then explains why this is the case: "You know, you don't counter somebody's attack tomorrow. Somebody attacks you today, and you've got to attack them back today, because [...] print media runs once a day, but social media, but electronic media runs, you know, 24/7” (Interviewee \#4, personal communication, October $\left.11^{\text {th }}, 2018\right)$. With this ever-accelerating news cycle in mind, he adds that,

I think the day when a political party watches, and you watch your opponent on TV doing a presser at 10am or whatever, and they make whatever attack and your quick response team has to decide whether they're going to respond and what way they're going to respond to it, and then the [...] you know, you can put out a press release and hand it to the folks who are in the press gallery or in the bus, and that's all fantastic, but also mobilizing your social media base to carry a counterattack is part of the strategy. And that's something you want to unleash as soon as you can to whatever, you know, whatever level of power you can put behind it. If nobody hears your counterattack, it doesn't matter. (Interviewee \#4, personal communication, October $11^{\text {th }}, 2018$ ) 
This line of reasoning is echoed by Interviewee \#26, who remarks that, "You have to get out in front before somebody else gets you. And it continues to speed up as a result of that" (Interviewee \#26, personal communication, January 23 $3^{\text {rd }}, 2019$ ).

Interviewee \#8, the Chief Strategist at a nationally-known Canadian political and market research firm, is also in agreement on this matter, as is evinced when he states that, "I would say the days when you could, you know, conduct the project and then deliver a report six to eight weeks later are long gone" (Interviewee \#8, personal communication, October $\left.26^{\text {th }}, 2018\right)$. But why are those days long gone? Well, he walks us through his answer to this question by offering us a response that views the catalyst for this change as part technological and part philosophical:

And it's partly because clients are much more sophisticated in their own consumption and use of some of these market research tools and they want the data right away. But, also, you know, the pace of the market has accelerated. I think it's cultural first. I think the culture has accelerated. And I think the technology has accelerated alongside that. And, you know, they're interwoven; it would be impossible to separate out the acceleration of the culture from the acceleration of technology. (Interviewee \#8, personal communication, October $\left.26^{\text {th }}, 2018\right)$

Interviewee \#7 is keenly aware of the impact of speed upon campaigning and reflects upon that matter philosophically as well. For instance, he remarks that,

I think speed is super important. I think things moves so fast. I think that knowledge is higher than ever and understanding is lower than ever. Everyone [...] we all know a lot more than we ever knew before. And our understanding and our exposure - even to other points of view - is lower than it's ever been before. (Interviewee \#7, personal communication, October $25^{\text {th }}, 2018$ )

A similar, yet more nuanced, perspective is given by Interviewee \#1 when he claims that,

It's not a speed issue; it's an awareness issue. Far more people are their own media filter now. [...] So, in the past, you had to wait 'til the CBC news, or CTV, or you had to wait 'til the news kicked in, whether it was noon or $6 \mathrm{pm}$, you know? (Interviewee \#1, personal communication, September 12 ${ }^{\text {th }}, 2018$ ) 
Both Interviewee \#1 and Interviewee \#7 provide some serious food for thought by claiming that speed is spurring superficial comprehension of events in addition to a lower likelihood that consumers will come into contact with others who hold opinions and have perspectives that are different from their own. To put it another way, he reasons that one of the side effects of speed is the continuing growth of the so-called echo chamber which will be examined later in this chapter when discussing the notions of tribal marketing as well as in the following chapter when discussing how the increasing integration of microtargeting strategies contributes to the matter at hand.

While the focus of the impact of speed on the news cycle in this dissertation largely concerns its implications for both commercial and political marketers, any discussion of the news cycle would not be complete without including its implications for journalists themselves — albeit only briefly. Interviewee $\# 6$ begins that discussion when he states that, "I mean no one's really on deadlines anymore" (Interviewee \#6, personal communication, October $\left.17^{\text {th }}, 2018\right)$. But that does not mean that things have slowed down for journalists. Quite the opposite. As he explains it:

You're not trying to get the 5 o'clock paper. But you're just trying to get it out as fast as you can, you want to be up-to-date, you don't want to be overtaken by new information. So, there is that kind of pressure. (Interviewee \#6, personal communication, October $17^{\text {th }}, 2018$ )

Interviewee \#1 elaborates upon this when he states that, "I feel so sorry for journalists (laughs) who used to have a day to put together a story. Now if they aren't ahead of the story by tweeting out what they've heard, they're, you know, considered out of the loop" (Interviewee \#1, personal communication, September 12 $2^{\text {th }}, 2018$ ). Furthermore, as he sees it, "The whole process of journalism has gone from sort of doing investigative [reporting...] even over the course of the day, down to just, you know, what can we glean 
from what we've heard?" (Interviewee \#1, personal communication, September $12^{\text {th }}$, 2018). In his estimation, this has serious consequences since, "they're [i.e. journalists] not getting both sides of the story. They don't have time to search for both sides of the story" (Interviewee \#1, personal communication, September 12 ${ }^{\text {th }}$ 2018). A substantial consequence of this compression of time is that, "Obviously, the pace of media has changed the pace of decision making" (Interviewee \#1, personal communication, September $\left.12^{\text {th }}, 2018\right)$.

Interviewee \#26, the President of a California-based and Democrat-affiliated political communications strategy shop that specializes in four of the key pillars of marketing (consulting and communication, digital advertising and campaigning, rapid response and crisis management, and media buying and planning) also notes the irrefutable importance of speed in both the act of campaigning and the coverage of that act when he says that,

Speed is incredibly important. It is - yes. It's defined by that, plus the level to which news and communications has sped up in general. It started off with the 24hour news, back in the late $80 \mathrm{~s}$ and early $90 \mathrm{~s}$, and now has accelerated with Twitter and Facebook. (Interviewee \#26, personal communication, January $23^{\text {rd }}$, 2019)

Briefly returning to Interviewee $\# 1$ highlights how much the norms of the mediascape have changed in such a short time span when he notes that, "you know, there was a time when media were criticized for running tweets across the bottom of news stories [and now] news announcements are made via Twitter, stock market announcements are made via Twitter, $[\ldots]$ we're negotiating NAFTA on Twitter" (Interviewee \#1, personal communication, September $12^{\text {th }}, 2018$ ). But even in this 24 -hour news cycle replete with the potential for individuals to gain near real time updates on current events via platforms 
like Twitter and Facebook, as well as the ratcheting up of the pressure that this puts on journalists struggling to stay afloat, according to Interviewee \#32, that all-important journalism staple known as the evening news is still crucial — albeit it for reasons other than we might have anticipated. For example, he explains how,

Well, it's a 24-hour news cycle. Everyone says that now. But, people watch the 6 o'clock news to see how something's been reported, but not to find out about it. This means that the politicians are always aiming for speed in response. If something breaks, you often now get MPs tweeting out a response within minutes. Where, previously, it would have been, 'Oh, yeah [the] filing deadline. We have to get something to TV by $4 \mathrm{pm}$ and then we have to get something to the newspapers by 8pm for their overnight edition.' But, yeah, it's all instant now, basically. And, again, if we actually go back to the social media stuff, people even will start piling onto politicians and demanding answers from them on social media and, so, sometimes they'll be responding literally within minutes then. (Interviewee \#32, personal communication, January $31^{\text {st }}, 2019$ )

Thus, while speed may have eliminated balance in the working conditions of journalists, while it may have reduced the objectivity and depth of the news coverage available to the average consumer, and while it may have shortened the time frame in which campaigners (both political and commercial) must develop and deliver counterattacks to any threat posed by the now truly 24-hour news cycle, speed has not killed off older forms of media. It has merely repurposed them.

When asked about the importance of speed in political campaigning and whether or not it has changed campaigning through the proliferation of faster communications technologies and networks, Interviewee \#17 responds in a nonchalant manner: "Yes and no" (Interviewee \#17, personal communication, November $\left.12^{\text {th }}, 2018\right)$. He expands upon this terse response by offering an important dose of context:

I mean, political campaigns have always had to react quickly to what's going on. But, I think it's definitely a little bit faster now, in terms of you know, instead of hours, you could be looking at minutes. Right? And, you know, a good example is, look at any of these recent sexual assault or misconduct allegations that have 
been put against the Ontario PCs in the past week. You know, you look at these things and you think, five years ago, okay, there probably would have been an investigation and some sort of finding of guilt before something happened, right? (Interviewee $\# 17$, personal communication, November $12^{\text {th }}, 2018$ )

And why is this the case? According to him, it is a combination of the relentless pace at which the news cycle now moves and of the pre-emptive action that it prompts in the "sink or swim" environment in which political marketers operate. For example, he reasons that,

Today, you know, people don't want to deal with the updates machine. They don't want to deal with the negative news stories. They know they're not waiting for the newspaper to print in the morning. They're just going to have a story out five minutes after it happens. They have to react quickly and, you know, you saw [Tony Clement,] a senior cabinet minister, a senior advisor get turfed in a matter of minutes, basically. As soon as this happened. So, you know, things happen a lot quicker. And, I wouldn't say this is the case in the example I just used, but a lot of times people overreact or make kind of rash decisions because they're so desperate to respond to the breaking news. (Interviewee \#17, personal communication, November $12^{\text {th }}, 2018$ )

And, of course, commercial marketing campaigns are not immune to this increasing source of pressure, as Interviewee \#27 reminds us:

Well, for the same reason, the people who are in charge of protecting the brands of companies, the smart companies have people whose job it is to catch this stuff the minute it starts to take off. They have to. Can you imagine the effect on United Airlines if a passenger gets off and tweets that, 'They just killed my dog. The dog froze to death because they stuck it in a cold part of the plane down there with the bags'? That's a black eye on United. And that will quickly pile on. It can be amplified very, very quickly on a variety of platforms. Well, it's lightning speed now compared to what it used to be. A passenger that went through that 20 years ago would have to write a letter to United, and no one would know they did it. Now [laughter], they just put it on Instagram with a picture of their dead dog, and it's all over the place within minutes. (Interviewee \#27, personal communication, January $24^{\text {th }}, 2019$ )

Sticking with the airline example, albeit using a less graphic Canadian equivalent, Interviewee $\# 9$ offers us his own take on the impact of speed in the current commercial marketing context: 
I mean, take the average airline traveler now. If they have a crappy experience, right away, they're out tweeting and, most often, if you fire at Air Canada, 'Why am I stuck on runway for four hours at Pearson? What are you doing for me? Are you gonna fix it?' Boom! Air Canada has somebody sitting there who responds on Twitter, so that you can manage that particular story before it becomes bigger or creates a greater organic movement that you have to respond [to]. The same in politics, you know? [...] If somebody hasn't responded in five minutes, that's not acceptable. (Interviewee \#9, personal communication, October $30^{\text {th }}, 2018$ )

However, as we will see shortly, more often than not, the pace at which the marketers in a given realm (i.e. commercial versus political) rise to the occasion often varies.

Interviewee \#23 helps us return to the broader issue of the impact of speed upon marketing campaigns and how it has increased. He does so by stating that, quite simply, "I think speed kills in politics. You're either moving quickly or you're dead" (Interviewee $\# 23$, personal communication, December $\left.5^{\text {th }}, 2018\right)$. He then proceeds to contextualize his thoughts on this matter by reflecting that:

When I started off, we had the 24-hour news cycle, and we had rapid response teams that met in the morning, and we would issue a press release by two in the afternoon. You know, like the idea of that now is just laughable. [For example,] in 2010, we put out [a] rebuttal of our competitor's platform in four hours. You know, like that's the modeling now, that speed, and this is probably where I find my greatest frustration, trying to cross over to corporate (Interviewee \#23, personal communication, December $5^{\text {th }}, 2018$ )

Here Interviewee $\# 23$ also introduces us to the differing levels of familiarity with speed that can be seen when comparing and contrasting political and commercial marketers that was alluded to earlier. He elaborates on this by explaining that,

We move so fast in politics. Right? And if so-and-so has said something, the war room gets it, we turn it around, and we push it out. Like it just fucking happens. In corporate, I mean, we write something, give it to the client, [the] client reviews it, hands it back to us, and asks for revisions, we revise it, give it back to them, they give it back to us for more revisions, we give it back to them, they float it up to their leadership team, the leadership team has questions, so we answer them, and then maybe we get a presentation to the leadership team, by which time I've lost interest. Whatever happened, whatever was instigating our communications struggle, is over. (Interviewee \#23, personal communication, December $5^{\text {th }}, 2018$ ) 
Interviewee \#31 also illuminates a difference in the interpretation of (and the comfort with) speed that can be witnessed when comparing commercial and political marketing operations. For instance, he claims that,

Well, I think speed is less of a factor because on the commercial side, the organizations, while they may have goals, earnings, reports, things like this, they're more predictable. And they have an indefinite timeline, right? So, one thing that's sort of unique about politics — and I've explained this to people before - is it's really like running a small business, only it's a small business that is only [...] you have to start it up and tear it down in 9 to 12 months. (Interviewee \#31, personal communication, January $30^{\text {th }}, 2019$ )

Despite the large body of scholarly literature on the "permanent campaign" in contemporary politicking regarding fundraising, polling, media monitoring, spinning, etc., very few would honestly classify political campaigns as having the "indefinite timeline" enjoyed by many commercial marketing exercises. In fact, numerous respondents in this project argued that the exact opposite is true: political campaigns especially here in Canada - have very abridged timelines. As Interviewee \#10 explains, "I think it's slower [commercial marketing]. Because there's not necessarily an end date, right? With all political campaigns, there's an end date" (Interviewee \#10, personal communication, October $30^{\text {th }}, 2018$ ). Of course, when speaking of political campaigning, that end date is none other than Election Day. Because of that omnipresent terminal end date, "Clients expect things to be done faster and responses [to come] faster and you to be always on call and, you know, I mean things have sped up" (Interviewee \#10, personal communication, October $30^{\text {th }}, 2018$ ). As Interviewee $\# 18$, a Canadian researcher and author who has written extensively on the subject of politics and political marketing, aptly puts it: "It's [speed] everything now. Again, it's everything. And it's probably not useful. I think they have more time. What's plain to me is that consumer marketers have 
more time than political marketers to do branding" (Interviewee \#18, personal communication, November $\left.14^{\text {th }}, 2018\right)$.

The short "from cradle to grave" timeline of political marketing campaigns in conjunction with the terminal end date is clearly on the mind of Interviewee \#22, a Principal at a Canadian public affairs, government relations and crisis management firm, and a former Conservative Party of Canada political consultant, when he states that, as regards political campaigning in Canada, "you only have thirty or sixty days to [...] make your case" (Interviewee \#22, personal communication, November $27^{\text {th }}, 2018$ ). This certainly constitutes a major difference between political and commercial marketing. He elaborates on this major difference by explaining that,

And, so, I think that, you know, you don't necessarily have a way, in the corporate world — perhaps that gap between you know Christmas and [...] maybe that lead up to Christmas, or something like that - for certain types of marketers where there may be like a huge part of their year that depends on having a strong fourth-quarter, or having a strong December in sales or something like that. (Interviewee \#22, personal communication, November $27^{\text {th }}, 2018$ )

In other words, that combination of the greatly abridged timeline of political campaigns and their irrefutable end date is a noteworthy distinguishing feature between political and commercial marketing. Interviewee \#25 illuminates how this is related to the greater notion of speed:

The pressure in political is, is it a match in terms of timing and spending your money? You are, by design, supposed to be bankrupt on election day. If you finished your campaign with money in the bank, you messed up. So, if you're selling toilet paper or Q-Tips, if you need to push it back a week, it's generally okay with a few exceptions like Christmas, holiday shopping (Interviewee \#25, personal communication, January $15^{\text {th }}, 2019$ )

With that being the case, Interviewee \#31 states that, when it comes to the relentlessness of speed, "The difference is I think the longer that you are in the industry, 
you get better at managing it" (Interviewee \#31, personal communication, January $30^{\text {th }}$, 2019). To his mind (and also that of numerous additional interviewees), political marketers are better at managing speed and using it to their advantage than are their commercial marketing counterparts. For example, he explains that,

Speed is the name of the game. Nothing happens slowly in politics. Everything needs to be done last week. [...] I think it's always been the case, but I also think - and some of it is because of the nature of political campaigns and political work. There are a lot of $[\ldots]$ you have to be able to adjust on the fly because things happen that are completely outside of your control, and you're going to have to respond to them. (Interviewee \#31, personal communication, January $30^{\text {th }}$, 2019)

Consequently, "in the political environment, you don't always have the luxury of saying like, "Well, we can push back and we'll get this done in a week" (Interviewee \#31, personal communication, January $\left.30^{\text {th }}, 2019\right)$. Or, as Interviewee \#7 puts it:

Politics always seems urgent. It may not be, but it certainly seems that way. Like, I don't know where you are in Ottawa but, like, drive down to Langevin tonight, or whatever we call it now, and at 11 o'clock there will be lights on in the building because there will be people working. There won't be a lot of that at Proctor \& Gamble tonight. (Interviewee \#7, personal communication, October $\left.25^{\text {th }}, 2018\right)$

Fair enough. In other words, given the compressed time frames of political campaigns coupled with the compressed news cycle, political marketers are more inclined to burn the midnight oil than are their commercial counterparts. In this light,

Generally speaking, [commercial marketing is] less deliberate. Unless they're in a crisis. Look, if there's a [...] you know, if God forbid, you know, you had, you know, some sort of cataclysm from a consumer product, they leap into action really, really quickly. But, generally speaking, it's like 'who cares if we deal with this today? We can deal with it tomorrow.' (Interviewee \#7, personal communication, October $25^{\text {th }}, 2018$ )

This line of reasoning closely resembles what Interviewee \#26 holds when he states that, in commercial marketing, speed is obviously present and accounted for, but, 
It's to a much lesser extent [i.e. corporate]. I mean, it's slower. I mean if I introduce - the biggest danger with that is leaks. It's letting the design of the iPhone get out before the iPhone's been announced. But the pace at which the iPhone is going to be announced is generally going - it's stuck to a much more rigid and plotted out timeline. And so, unless you're dealing with a crisis like an exploding phone, or something like that, or an airline crash, as a general rule, it's going to move at a much more deliberate pace. (Interviewee \#26, personal communication, January $23^{\text {rd }}, 2019$ )

To put it differently, according to Interviewee \#21 and also Interviewee \#26, unless there's a consumer crisis that implicates the brand or product being marketed, consumer marketing moves at a much slower pace than does political marketing. However, as we will discuss a little later in this chapter, there is a great deal of variance in this pattern.

Returning to the greater matter at hand, Interviewee \#28 is in agreement on the subject of speed. For instance, when it comes to political campaigning, he notes how "Time is the single most important asset of any campaign" (Interviewee \#28, personal communication, January $\left.28^{\text {th }}, 2019\right)$. As such, he adds that,

And, so, you have to operate in the most expedient way humanly possible. And, that's something that you just do not have the same pressures in the corporate or brand world. It is entirely [emphasis in original] night and day. We see that every time where we're working with different vendor partners: we're asking for a lot more a lot faster than anyone in the commercial world, because you don't have the same constraint. [In commercial marketing] I just don't think there's the same urgency. You know, brands are taking pictures, you know, revenue projections, and outlooks that are many years into the future, where a political campaign is trying to win this [emphasis in original] year. [They're] just totally different event parameters. (Interviewee \#28, personal communication, January $28^{\text {th }}, 2019$ )

Basically, in marketing, speed and urgency go hand in hand - and this is much more the case in political marketing than in the commercial variety. As Interviewee \#32 explains, "I think, actually, a company needs to generally be a bit more considered about what's our brand? So, I think the speed is definitely less [than in politics]" (Interviewee \#32, personal communication, January $\left.31^{\text {st }}, 2019\right)$. 
As Interviewee \#33 views it, "Speed [...] has always been a big issue in political campaigns, and speed kills" (Interviewee \#33, personal communication, February $4^{\text {th }}$, 2019). Taking this into consideration, he reasons that, "And I think when there's an issue that comes out, it goes from zero to being a big problem in really a matter of a couple of hours" (Interviewee \#33, personal communication, February $4^{\text {th }}, 2019$ ). But, for him, the issue is somewhat more complicated - there is more to it than just speed alone. For example, he argues that,

I think it's speed plus stickiness. If you have a lot of things that will bubble up and, frankly, nobody cares and it'll go away [...] So if it's just speed, you can endure. You can batten down the hatches and the bad story comes and if it doesn't really get a lot of traction for another couple of days, it can also be gone in 24 hours. (Interviewee $\# 33$, personal communication, February $4^{\text {th }}, 2019$ )

In other words, as Interviewee $\# 33$ sees it, speed alone is not problematic for marketers. The sheer volume of news stories coupled with the public's increasing fickleness and shrinking attention span often allow potentially damaging stories to extinguish themselves. But, if the story strikes a nerve thereby achieving "stickiness," all bets are off. Under those circumstances, technology-induced speed allows bad and sticky news to spread exponentially fast and with crippling effects.

Interviewee \#26 also thoroughly discusses the matter of speed, its imbalanced impact upon commercial and political marketing, and, crucially, his thoughts on why this imbalance persists. He begins that discussion by identifying that,

Well, commercial marketers tend to move very slowly in comparison. So, there is definitely less speed. If things happen, whether it's a brand crisis, or somebody says something wrong, or the market needs to move because some great opportunity has been created [...] And commercial advertising agencies are not universally, but often - slow in their development of marketing techniques and marketing responses, and that sort of thing. Whereas political moves at lightspeed, comparatively. (Interviewee \#26, personal communication, December $\left.27^{\text {th }}, 2018\right)$ 
One of the main reasons for this imbalance was hinted at earlier by Interviewee \#23 and is picked up here again by Interviewee $\# 26$ : the very different organizational structure and chain of command between typical commercial marketing campaigns, on the one hand, and typical political campaigns on the other hand. For instance, Interviewee \#26 explains that,

Well, it's a combination of corporate processes [...and] I think some of it is just the complexity of a corporate approvals process compared to a political team that's much faster-moving. And also, the creative processes for the development of commercial advertising are just generally slower because they take their time thinking about it, and they test ideas back and forth with an internal advertising agency, and there's a much [...] it's not just a larger group of people, but it's also a more thought-out process than political advertising, which tends to be done quite quickly. And that's not to say that, at a presidential level, that there isn't a big team. But most political advertisements are very small groups of consultants working very, very fast. (Interviewee \#26, personal communication, December $\left.27^{\text {th }}, 2018\right)$

Interviewee \#23 helps us flesh out some of the differences in the organizational structures between commercial and political marketing and their impact upon the speed at which the two realms move by noting how "Politics is all fast, and this other stuff is just so slow. [...] Yeah, I think the bureaucracy, I also think that again, the control structures are very different" (Interviewee $\# 23$, personal communication, December $5^{\text {th }}, 2018$ ). With a keen sense of opportunity to capitalize on the political marketer's experience in contending with speed and to export that knowledge and expertise to the commercial marketing world, he explains how

Our thinking was that the stuff that we built for politics would be, I mean, I thought the corporations would buy right into it. But they're just so fucking slow [emphasis in original], they're just so slow. Oh, they're slow, oh my god [emphasis in original]. There's nothing slower than the corporation. (Interviewee \#23, personal communication, December $5^{\text {th }}, 2018$ ) 
Interviewee \#25 is also quick to catalogue the lack of speed that characterizes commercial marketing. To that end, he states that, "Commercial is certainly slow" (Interviewee \#25, personal communication, January $\left.15^{\text {th }}, 2019\right)$. He elaborates on this by explaining that,

The commercial space makes us laugh. Every time we get an urgent order from a commercial client, urgent means something very different to commercial versus political clients. Urgent with a political client means you've got one or two hours that you're watching [and] anything can go. Urgent in my commercial space is typically, 'Can I please have it this week or early next week [laughter]?' That's one thing that commercial clients can learn from political clients is that you don't need a week to make an easy decision. (Interviewee \#25, personal communication, January $15^{\text {th }}, 2019$ )

A similar perspective is voiced by Interviewee \#16. For example, he explains how,

[A key] lesson I tell my clients is, nothing needs to take as long as it does. What we show them is that, through our political work, we can work in real time. We can adapt in hours and days. I mean, we've had situations where you've had national television commercials go from necessity to on air in less than twentyfour hours. And, yet, I work with clients who can take like a full year developing a single ad. And, so, you know, when I talk about it, I explain to them [that] you can't talk about a sense of urgency without acknowledging the tolerance for risk. And, so, what slows the process down is an intolerance for risk. (Interviewee \#16, personal communication, November $8^{\text {th }}, 2018$ )

That "intolerance for risk," which manifests itself much more visibly in the commercial marketing realm (and which some would say has metastasized throughout the commercial marketing ecosystem) is an important matter to which we must now direct our attention. This is especially important since it is accentuated by the increased speed of the environment in which marketing campaigns must be run. Interviewee \#16 helps us do so by explaining that,

Why it [i.e. the marketing campaign] speeds up in politics is not that people want to be riskier in politics - you know how risk averse politicians are when they speak. It's an understanding that the risk is necessary, because there's no time to be more cautious, right? This thing is [...] typically you can find the dynamic of a campaign (say the five-week campaign) [...well] it might be over by day eleven. There isn't an opportunity to have sober second thought and reflect. And that's why, you know, people capitalize on other people's mistakes. Because risks are 
taken. But there's no other way to do it, because it's a short time frame. (Interviewee \#16, personal communication, November $8^{\text {th }}, 2018$ )

In other words, urgency and risk go hand in hand; and, furthermore, with risk comes opportunity. With that in mind, Interviewee \#16 notes how,

What I try to say to brand [i.e. commercial] marketers is: try to understand that you guys are worried excessively about risk. And so, things are taking far too long, and you're losing opportunity in the marketplace to capitalize on maybe the silence of your competitor, or the outdated innovation of your competitor's product, whatever it happens to be, or a consumer choice trend you could be capitalizing on - this happens all the time. You know, big companies lumber forward and then stare in amazement that some trend just sort of seemingly out of nowhere blew up and took half their market share. It's like, 'No, no, we saw that three years ago, but you studied it for three years as opposed to acting on it.' You know, that's one of the lessons that I think consumer brands really need to learn from politics. They could adopt a much more precise planning framework. I think it's just laziness, to be honest. (Interviewee \#16, personal communication, November $8^{\text {th }}, 2018$ )

Unlike Interviewee \#16, Interviewee \#33 associates the commercial marketer's

risk aversion not with laziness but with fear. For instance, he states that, "The commercial side is a little more afraid of speed" (Interviewee \#33, personal communication, February $\left.4^{\text {th }}, 2019\right)$. With that established, he reasons that,

In a political campaign, a big political campaign, maybe we do $10 \mathrm{TV}$ commercials and 150 different digital ads and lots of different messages and lots of different stuff, and we push a lot of things out there. Whereas on the commercial side, there's more thought given [and] it's a little more risk averse. They're not going to do as much. Well, because they've got a lot more at stake. I mean, they've got a long-term brand to build and they're [...] like, when Target does its Christmas campaign, they start on it [in] June and they work on it. And at the beginning of Christmas season, they run their Christmas campaign, and they hope it works, whereas in a political race, you put stuff out there, and if it's not working, you have got to change immediately. Yeah. And [on] the political side, the political campaigns are built to react to that feedback loop and are willing to react to that feedback loop including throwing everything out. Whereas that ain't going to happen at Target. (Interviewee \#33, personal communication, February $\left.4^{\text {th }}, 2019\right)$ 
According to Interviewee \#33, commercial marketers are more risk averse and are therefore less comfortable with the ingrained speed of the news cycle and the subsequent speed at which successful marketing campaigns must typically be run. This could be the case because brand building — and brand maintenance for that matter — run deeper and take a much longer-term cultivation process in commercial marketing than in political marketing. For instance, many of the most successful commercial brands have existed for decades, unlike political candidates who often must adjust their "brand" after each election cycle. No matter how you want to characterize it, the "win or lose," the "black or white," or the "zero sum" nature of political marketing encourages flexibility which reflects a willingness to take risks and to adjust the brand in ways that would be untenable in commercial marketing.

Interviewee \#23 highlights this fluidity of political marketing by explaining that, when something is not working on the campaign trail, evasive action is required. As he puts it himself:

So, in politics, we'd adjust. Like we wouldn't just keep fucking trying to get people to say it, to agree with our value. We would adjust because we need to win. [...] We would adjust to their values. I mean, it's very difficult to change a person's values. (Interviewee \#23, personal communication, December $5^{\text {th }}, 2018$ )

Interviewee $\# 2$ offers a similar vantage point when he explains that,

I think you have to be quick; you have to be able to shift very quickly if you find that a particular strategy is not yielding what you anticipated it would yield. I think you have to be much more nimble on tracking consumer behavior and consumer sort of likes and dislikes. I don't know that they [...] I don't know that, to be honest, $[\ldots]$ whether or not they change that quickly, but I think there's a perception that they can. And in the political context, certainly they can. You have to be on top of that, and I think that requires significant speed. You need to be able to determine whether or not things are changing and what impact that's having in terms of something like voter intention. (Interviewee \#2, personal communication, September $24^{\text {th }}, 2018$ ) 
Interviewee \#6 also discusses the ability of political marketers to take evasive action, but he does so by contextualizing his thoughts by way of the ultra-fast news cycle that was discussed earlier in this chapter. For example, he states that, "I think the news cycle is a lot shorter than it used to be. So, if you can change the channel pretty quickly, that can be pretty effective. So, being able to do that is important" (Interviewee \#6, personal communication, October $\left.17^{\text {th }}, 2018\right)$. However, the argument could be made that this fluidity and nimbleness, while generally in abundance in political marketing, is harder to achieve in commercial marketing — at least with well-established and long-standing commercial brands. Interviewee \#13 neatly sums up the discussion on the relationship between successful marketing and fluidity while simultaneously highlighting the difficulty which that relationship brings to the table when she states that, "Everything has to shift and change at every given point based on every different factor that has influenced the new decision you just took [...] Whether it's the public, whether it's your candidate, everything. It's constantly in motion" (Interviewee \#13, personal communication, November $\left.7^{\text {th }}, 2018\right)$. That can prove to be a daunting task.

Interviewee \#7 helps us bring the discussion back to the relationship between speed and risk-aversion when he states that, "I think speed is super important and I think successful people in politics are people who don't cavil over decisions, but just make them" (Interviewee \#7, personal communication, October $25^{\text {th }}, 2018$ ). He offers us a differing opinion or, at the very least, an important caveat to keep in mind: that risk aversion exists in political marketing too. But, in his opinion, the most skillful political marketers or the political marketers who "are good at it" (it being their trade) are not hamstrung by taking risks and making fast decisions. For instance, he states that, 
I think it's [...] I think the willingness to make a call is something that most people in politics do not have and those who I think are good at it are willing just to make them [...] Look, they don't wait for the perfect decision; they're willing to make the $70 \%$ decision. Shorter timeline. More urgency. And, frankly, just a willingness to make the call. (Interviewee \#7, personal communication, October $\left.25^{\text {th }}, 2018\right)$

Interviewee \#12 laments the impact that the unrelenting speed at which political campaigns are currently being run as well as the greater likelihood of political marketers to take more risks than their commercial marketing counterparts (thereby being more decisive and nimbler in their thinking and subsequent branding) has had upon the crafting of the creative content which can be seen as representing the pitch to voters. With these factors in mind, he states that, “There's risk involved because there's obviously less consideration given to each message than there would have been in the other scenario. And it's been the death of production values" (Interviewee \#12, personal communication, November $1^{\text {st }}$ 2018). And he too sees the compressed time frame of political marketing campaigns (in contrast to the extended and often indefinite time frame of many commercial marketing campaigns) as the reason for the "death of production values" (Interviewee \#12, personal communication, November $1^{\text {st }} 2018$ ). Furthermore, because of that reality, he firmly states that "Well, the time frame of campaigns and the conclusion of campaigns is obviously the fundamental difference between consumer marketing and political marketing, right?" (Interviewee \#12, personal communication, November $1^{\text {st }}$ 2018). That said, it is important to point out a certain type of disconnect that is related to the "death of production values" noted by interviewee \#12.

Interviewee \#31 helps us with that task. He points out the fact that speed and substance do not always go hand in hand in the practice of marketing - either commercial or political. For example, he states that, 
I think that today there is another factor, which is with all of this technology, a lot of people [...] they know that the technology is there, and they know what it can do, but they don't really know what it takes to get it done, right? (Interviewee \#31, personal communication, January $30^{\text {th }}, 2019$ )

Technology may speed up the delivery or distribution of the final pitch (e.g. the marketing strategy and deliverables such as the advertisements and promotional material for consumer outreach that cumulatively make up the final pitch to consumers), but it cannot speed up the creative thought process required to develop the pitch from start to finish. However, unfortunately, expectations have not kept pace with reality. As Interviewee \#31 explains,

So, the[se] words [are] just kind of like the bane of my existence because I have people say, 'Well, can't you just do this?' And they don't understand [that] well, it's going to take some time [...] Yeah, they say, 'We can get this campaign, right?' or 'Can't you just get some ads up?' And they don't understand [that] we've got to get the creative done. We have to get the landing pages ready. We have to get [...] there's a lot of work that goes into [it...] you're not just pushing a button. (Interviewee \#31, personal communication, January $30^{\text {th }}, 2019$ )

Again, technology has increased the speed of the news cycle (as discussed earlier in this chapter), the speed of message/content delivery, and also the speed of client expectations, but it has not increased the speed at which ideas and marketing strategies — whether political or commercial - are formulated and finessed. It should also be noted that this oversight (or this intellectual blind spot) is not only to be found in increasingly anxious and impatient clients. It can also afflict those within the political marketing world despite the fact that its practitioners are more accustomed to managing speed than are their commercial counterparts. For example, Interviewee \#31 notes how,

I think political campaigns and the people sort of running them at the decisionmaker level, a lot of times because they don't understand the timelines that are involved in getting those complicated tasks, complex tasks, done, have unrealistic expectations for how quickly things can get out the door. (Interviewee \#31, personal communication, January $30^{\text {th }}, 2019$ ) 
Here he is reminding us that commercial marketing clients do not hold a monopoly on unrealistic expectations.

Interviewee $\# 1$ helps us sum up the systemic impact of speed upon marketing both commercial and political — by stating that, "That's the biggest thing: the speed at which decisions are made, and that's not just on the political side. That's up in the $\mathrm{C}$ Suites of business as well" (Interviewee \#1, personal communication, September $12^{\text {th }}$, 2018). He expands upon this by noting how, "Where it used to be things took time and were considered, there's no time to consider anymore. I think decisions are made on the go, because that's the way media works now" (Interviewee \#1, personal communication, September $\left.12^{\text {th }}, 2018\right)$. With that in mind, he also posits that this acceleration is not solely the result of an ever-accelerating news cycle courtesy of new communications technologies, but that it is also the result of a growing need for instant gratification and an impatience that has permeated Western society. For instance, he argues that,

Well, the expectation of clients is [...] yeah, the expectation of clients is, you know, can we have it yesterday? And that's changed, right? But I think that's a general expectation for everything, right? The expectations of pizza delivery is faster. The expectations of $[\ldots]$ you know, in a world in where you can $[\ldots]$ go this afternoon online and order things from Amazon and there's a pretty good chance it shows up tomorrow: hard goods [...] when hard goods can move that fast, there's an expectation that advice and soft goods like [...] I don't want to say data is a soft good, but there's an expectation that, if you can't move data that fast, then what's wrong with you, right? (Interviewee \#1, personal communication, September $12^{\text {th }}, 2018$ )

In other words, expectations have been completely realigned by the increased transportation (of hard goods) and transmission (of soft goods) facilitated by communications technologies. To his mind, this is all the more true for soft goods (i.e. data, marketing strategies, advertising campaigns, etc.) since, according to many an 
impatient client, you should be able to move light goods faster than heavy goods. But, of course, as Interviewee \#1 was alluding to, there is an obvious difference between packaging hard goods up in a box and sending them on the road via same-day shipping and crafting creative content, testing it, and then distributing it to a client. One task is clearly more complicated than the other. Yet he thinks that this fact is seldom taken into consideration anymore. The goalposts of client expectations are no longer planted where they once were.

Interviewee \#3 offers a similar perspective on the shifting goalposts of client expectations when he states that, "The expectation is now [and] the satisfaction has to be instantaneous" (Interviewee \#3, personal communication, October $1^{\text {st }}, 2018$ ). Importantly, he adds that expectations of speed are all the more heightened here in Canada, "given that we have short election campaigns" by comparison to our neighbors south of the border (Interviewee \#3, personal communication, October $1^{\text {st }}, 2018$ ). Interviewee \#11 reminds us that the expectation is not just for expediency, but also for quality. For instance, he states that, "There's no question that speed [and] that the desire for speed has increased over time. There's no question" (Interviewee \#11, personal communication, October $\left.31^{\text {st }}, 2018\right)$. He then adds that, "And now, with the tools that we have, there is an expectation that things are not only fast, but they're very good" (Interviewee \#11, personal communication, October $31^{\text {st }}, 2018$ ).

Interviewee $\# 25$ offers a more nuanced perspective on the matter. According to him, when it comes to speed, "It's pretty constant [...] Very predictable. [...] It's pretty much been the same for a few decades" (Interviewee \#25, personal communication, January $\left.15^{\text {th }}, 2019\right)$. In other words, there has always been a desire and a need to move 
quickly and move with great speed, should a marketing campaign have any chance of being successful. That is nothing new. However, what he sees as new is the extent to which speed has become all-pervasive and also the necessity of keeping up with the speed of the competition. For example, he explains that,

I think what you're getting at is speed at which media is delivered. So, obviously, the expectation for media delivery in 2018 is same-day, next-day. The expectation for media delivery in 1996 might've been three, four, five, six days. So, it's not [just that] the money moves fast. It's the actual getting TV spots to TV station or mail delivery, would typically take longer. Is the need greater? Is that the question? Some of it. I mean, the need is because the other guy's doing it. And if the other side can get an ad cut and aired at least on pre-roll same day or overnight, then the other side's got to do it too. (Interviewee \#25, personal communication, January $15^{\text {th }}, 2019$ )

Interviewee \#22 offers a similar point of view, but his is focused primarily on political marketers and Canadian political marketers in particular. With regard to speed, he reasons that,

I think it's the most important thing of all. I think that parties will also [...the] parties will move as fast as they possibly can afford, because, especially in the Canadian system, where [...] you don't have unlimited budgets, if you can be a little bit faster, that's the only other way you might have to get [...] an advantage. (Interviewee \#22, personal communication, November $27^{\text {th }}, 2018$ ).

Keeping your head above water in the increasingly fast-paced world of political marketing — and, to a lesser extent, commercial marketing — can often come with a steep price tag, but it need not always be the case. Interviewee \#30 explains how this can be so:

Keep in mind the platforms that are most real-time are also the lowest cost. So, they appeal greatly to people on a political budget. You know, if I only have $\$ 5,000,000$ to spend, then I can put a tweet out and get some traction out of it, or at least get it picked up by the news, which then is where a lot of eyeballs are for political $[\ldots]$ the political branding side, then, you know, that's something I'm going to take advantage of quickly. Whereas, you know, a tweet from Oreo isn't something that, you know, people outside the brand really follow aggressively. However, when done creatively, it can kind of break through and sort of have an 
impact broadly on the base of their existing customers. (Interviewee \#30, personal communication, January $30^{\text {th }}, 2019$ )

Even so, numerous interviewees were of the opinion that commercial marketers are more hesitant to adjust their marketing campaign style than are their political marketing brethren and to utilize the tools needed to adapt to the increasing speed with which campaigns must be run. In that vein, Interviewee \#11 posits that, "I would submit that the speed is less important than getting it right [in commercial]. Whereas, in politics, because of the tight timelines, speed is a necessity" (Interviewee \#11, personal communication, October $31^{\text {st }}$, 2018).

Interviewee $\# 17$ provides us with an important consideration that also relates to the matter of speed in campaigning and the differences between commercial and political practitioners. For example, he says that, "Again, I mean, if you look at, you know, what $[\ldots]$ so, one of the big differences between commercial marketing and political marketing too is the focus on advertising, right?" (Interviewee \#17, personal communication, November $\left.12^{\text {th }}, 2018\right)$. He unpacks this intriguing claim by explaining that,

[In] political advertising, I would say, there's less focus on advertising than there should be $[\ldots]$ with the political stuff. Whereas commercial is almost entirely advertising. I mean you've got, I would say, politicians rely a little bit more heavily on their social media and their own personal brands than businesses would. So, there's definitely a difference there. So, you think about like a big ad campaign that a business might run. There's months of planning that go into those things, right? So, I still say they're a little bit slower [commercial], but I think there's lots of businesses who are doing a really good job responding to current events very quickly on social media, and usually get to build brand awareness... You know, there's lots of examples, like when the power went out at the Super Bowl (I think that was a year or two ago), there were some really clever ads that came out on social media. I think Oreo did one. They can be really clever on social media, too. Absolutely. But, I do think the focus is more on the advertising for those guys. (Interviewee \#17, personal communication, November $12^{\text {th }}, 2018$ ) 
In other words, political marketers are not the only ones able to develop an advertisement spontaneously. However, generally speaking, advertisement creation is a more methodical and premeditated process for commercial marketers than it is for political marketers. Interviewee \#16 neatly sums things up for us at this point when he says that,

But, advertising works is obviously one of the lessons for consumer marketers. Investment intensity matters; adaptability matters; speed to market matters. These are things that politics has demonstrated are different [and] that consumer marketers could adapt to their business more effectively. (Interviewee \#16, personal communication November $8^{\text {th }}, 2018$ )

In addition to differing timelines and their implications for contending with speed,

perceptions of risk are vastly different in terms of commercial or political marketing.

Interviewee \#11 was asked the following question: How do you think speed factors into commercial marketing? His answer reaffirmed this fact when he responded that,

They're not working under the same time pressures as elections. They're also [...] and I think that there's more caution because, to make a mistake at a high level, like a high brand product placement, just a bad ad that just really, you know, I'm thinking like, you know the Pepsi ad, the one with the protestors and the tear gas [and] Selena Gomez [it was actually Kendall Jenner] came out with a Pepsi. That was a real hit [to Pepsi] and it didn't decimate Pepsi, but it was a hit. And I think that, in an election, you can't run the ball; you've got to throw. You've got to go for the yards, because you've got only a few weeks, and you've got so many things on the line that, if something's not working, you've got to mix it up and you've got to mix it up quickly. Whereas, if your sales for the last two quarters of your diet soft drink are softening, you don't have to make really fast decisions to turn that around within a few days. You've got a little bit more time, I would assume, in the commercial [sector] to turn things around. (Interviewee \#11, personal communication, October $31^{\text {st }}, 2018$ )

As referenced above, for fear of a public backlash (as in the Kendall Jenner Pepsi advertisement) or of alienating a segment of the potential market, commercial brands are usually more risk averse than are their political counterparts. Also, since commercial brands have often been cultivated over much longer time frames than have political brands (at least those of individual politicians themselves), they take more neutral 
marketing strategies than do political brands. The investigation of this matter now allows us to shift gears to yet another area where political marketers have more experience and expertise than do their commercial counterparts: neutrality, or the lack thereof.

\section{The End of Neutrality?}

There's an old saying that you either stand for something, or you stand for nothing. Voters have long expected the former from their elected representatives; but what about consumers of commercial products? To steer interviewees towards revealing their thoughts on this matter, the following question was asked: Do you think that commercial advertising of brands in a fashion that appears to abandon political brand neutrality (e.g. Nike's Colin Kaepernick campaign or Gillette's recent \#MeToo campaign) in favor of taking firm political stances on "hot button" political issues will become more common, or will it still remain the exception that proves the rule?

Interviewee \#24 opens that discussion for us when he responds "Let's look at [it] this way: I think that was an extraordinary move [i.e. Nike's Colin Kaepernick advertising campaign]. And I think you're going to see more extraordinary moves by corporations" (Interviewee \#24, personal communication, December $27^{\text {th }}, 2018$ ). Yet he cautions, "But I still think it's going to be the exception. Does that make sense? [...] Yeah. I think we'll still be shocked every time we see it, but we'll be seeing it more often" (Interviewee $\# 24$, personal communication, December $27^{\text {th }}, 2018$ ). Interviewee $\# 26$ is clearly in agreement by stating that, "I think it'll be the exception" (Interviewee \#26, personal communication, January $\left.23^{\text {rd }}, 2019\right)$. Asking him a probing question about why he thinks that is the case gives him the opportunity to thoughtfully expand upon his answer. He begins that process by concisely stating that the main reason that he thinks 
most commercial brands will remain neutral in their marketing campaigns for the foreseeable future is their "risk aversion" (Interviewee \#26, personal communication, January $\left.23^{\text {rd }}, 2019\right)$. He then offers an important consideration:

Yeah. And also, I don't generally think that the public wants constant political communications. They, generally speaking, don't like political communications. And so, for a brand to [...] there's a certain point where commercial advertising serves as relief from politics [laughter]. And so, I think that large companies understand that. And there are exceptions to where somebody in an advertising agency thinks they can really get everybody talking about Gillette for a week. And that was very, very smart. Very smart [emphasis in original]. But that's only going to work once in a while. If Nike came out with the same ad, essentially, next week, there would be a collective yawn. (Interviewee \#26, personal communication, January $23^{\text {rd }}, 2019$ )

To put it another way, as he sees it, commercial marketing is most likely to remain neutral due to inherent corporate risk aversion to the fact that many consumers have political communication fatigue, and to consumers' having a distaste for repetition despite the widespread understanding among marketers that repetition works because repetition leads to remembrance.

Interviewee \#32 helps investigate how risk aversion can be a consideration for commercial marketers when weighing the pros and cons of pursuing a desired marketing strategy by stating that, when it comes to abandoning political brand neutrality,

I think it's the exception because, generally, if you get too political, you risk alienating a decent proportion of your support base. Now, if you're a very, very [emphasis in original] big brand without hugely effective competition, or huge brand loyalty, you can therefore afford to do that. (Interviewee \#32, personal communication, January $31^{\text {st }}, 2019$ )

Interviewee \#31 offers some substantial food for thought on this marketing approach and, in particular, on the case of Nike's Colin Kaepernick advertising campaign when he states that, 
I read an interesting article talking about the Nike campaign, in particular, that I thought brought up a pretty salient point, which was that for all of the focus about the politics of this from U.S. domestic perspective, it was kind of missing the point that Nike is a global brand, and that actually the U.S. market is only a fraction of their overall customer base. And so, if they are alienating a fraction of a fraction, but they are building customer loyalty outside of the U.S. with these other fractions, then it makes it an overall economically wise decision. So, I don't think that $[. .$.$] I know we all like to think that the companies that have marketing$ campaigns that resonate with our own values are good and that the ones that don't are bad. But I think it's - especially when you're talking about big multinational corporations - it's a lot more complicated than that. (Interviewee \#31, personal communication, January $30^{\text {th }}, 2019$ )

Of that there is no doubt. In fact, one could argue that there are very few companies that have the reach, recognition, and penetration that Nike enjoys the world over.

Interviewee \#21 also discusses risk aversion and the danger of potentially alienating consumers should commercial marketers abandon their long-standing practice of producing politically neutral product advertising campaigns when he states that,

Oh, I don't know. But, I mean, Nike's always been progressive with their marketing. So, it didn't totally surprise me. But on that topic, they did make a decision that they were going to potentially risk alienating a huge portion of the population. That was a huge bold move. I mean, progressive marketing is one thing. Political progressive marketing is a totally different one. (Interviewee \#21, personal communication, November $23^{\text {rd }}, 2018$ )

How true. Interviewee $\# 27$ provides us with a more detailed explanation of this delicate dance and he does so by way of a contemporary analogy. For instance, he explains that, regarding politically-charged commercial marketing campaigns,

I think they're experimenting with that now, but the jury is out. It's a dangerous thing for them to do - unless they pre-determine [...] well, because when you do that, you are losing customers that might otherwise buy your product. So now, you are mixing political views with who buys your razors [or whatever product you're selling]. You make the mistake on that end, and suddenly, you're losing customers because they don't like you getting in bed with a particular political view. So, if you're going to do that, you better be sure of what you're doing and why because that is fraught with risk. It's like going to church and having a minister who usually recites scripture, suddenly decide that he's going to go on an 
anti-Trump rant. It's bound to piss off somebody in the congregation. (Interviewee $\# 27$, personal communication, January $24^{\text {th }}, 2019$ )

Even so, and troublesome or not, Interviewee \#2 maintains that this is the direction in which things appear to be going. For instance, he states that,

Yeah. I think that probably will happen, at least for a while [...] I think we've seen evidence of that over the last several years where companies that sell consumer goods or consumer services align themselves with particular issues. So, they're not neutral on [...] you know, things like Nike's recent association with Kaepernick. You know, I think they'll take a stand because that will be beneficial to them, but I'm not sure that it helps them ultimately. There's a long debate over things like Corporate Social Responsibility. Does that actually help? (Interviewee $\# 2$, personal communication, September $24^{\text {th }}, 2018$ )

The closing question is both thoughtful and significant but it cannot realistically be answered here. That said, we will unpack the interviewees' thoughts on the concept of Corporate Social Responsibility and Consumer Citizenship a little later on in this chapter. But, for now, let us continue to examine the greater notion of neutrality.

On that matter, Interviewee \#2 acts as his own devil's advocate when he states that, "Maybe it is increasingly important, but I think the notion of neutrality is something that companies can continue to take without having an impact on whether or not they are considered as sources for consumer products" (Interviewee \#2, personal communication, September $\left.24^{\text {th }}, 2018\right)$. Consequently, he adds that, "I just think it's such a difficult thing to disaggregate, right? And do consumers make decisions that are that sophisticated? I'm not so sure" (Interviewee \#2, personal communication, September $24^{\text {th }}, 2018$ ). He explains his rationale here by way of an example:

If I buy Nike is it because I'm saying I like the stand they've taken on the NFL? I'm not sure. I think I say, 'I don't care if I buy Nike or ASICS, but [...] Yeah. And I [...] completely concede I may be an outlier here on that. But I've also seen lots of data that suggests that people will say they are influenced by those things, and they're not. So, I think it depends on the strength of the linkage to perhaps a particular issue, but [...] I don't know. I don't know how effective those will be 
and I don't know whether or not neutrality from a corporate perspective is necessarily in danger. (Interviewee \#2, personal communication, September $24^{\text {th }}$, 2018).

Interviewee \#8 voices a similar perspective when he states that,

The idea of brands taking a position on an issue [...] again, I think you're right: we are seeing more and more of that. I don't know that it's required that they take a position on an issue per se, or anything. I mean, I can see why [...] why brand marketers would want to do that, given the attitudes and beliefs and preferences of millennials, and, you know, Gen $Z$ in particular. But is it going to be a requirement? I don't know. (Interviewee \#8, personal communication, October $\left.26^{\text {th }}, 2018\right)$

Put differently, there is a great deal of variance in the approaches that commercial marketers take to their advertising strategies and, either way, we as researchers as well as commercial marketers themselves may be overthinking the possible considerations that consumers take into account when deciding to make a purchase or not.

Interviewee \#23 offers an important consideration by shining light upon reluctant marketers in both the commercial and political practice. He begins that discussion in the following manner: "Based on my experience, what I'm seeing is a commitment to status quo marketing. And again, the difference is, so why don't politicians fall into the status quo marketing problem?” (Interviewee \#23, personal communication, December $5^{\text {th }}$, 2018). Wasting no time, he quickly responds to his own question by stating that, "And they do - they do all over the place, and you can see them when they do it, they fall into status quo marketing and then they get defeated" (Interviewee \#23, personal communication, December $\left.5^{\text {th }}, 2018\right)$. Further, in his opinion,

It's so black and white with us [political marketers]. We can lose 51 to 49 , and we've lost, and we have to change. Whereas you're with a corporation, and you slide $2 \%$ market share, and no one gives a shit. So, the consequences are so much higher for us, and that forces us into innovative strategies, whereas the corporate marketer doesn't have the same pressure, so they find themselves in the status quo model. Or the pressures are you know, minimal increase. Like I have to take 
politicians from single digits to victory. You have to innovate, you have to think differently. Whereas someone else is thinking, you know if I can get a $2 \%$ market share gain, that'd be pretty impressive. Yeah, and I've really struggled with it, because it's hard to kind of, you know, jump in and convince people they should do different things, and the person is like yeah, but if I do that, will I lose? Well you might, you know, you might, I don't think so, but you might. (Interviewee \#23, personal communication, December $5^{\text {th }}, 2018$ )

In other words, here Interviewee $\# 23$ offers us an important caveat that, while political marketers may often be more open-minded than their commercial marketing counterparts, not all of them are when it comes to the flexibility and "outside the box" thinking that is often required to successfully bring a marketing campaign from start to finish. Just as importantly, if the candidate that the political marketer represents is not willing to be open-minded in their thinking, it does not matter how neutral their political marketing team is, since the buck stops with the candidate. Interviewee $\# 20$ also expresses a similar perspective when stating that, regarding commercial brands and their marketers, "I don't know. I mean, I think they're still neutral. I mean, they have brand neutrality. You know, I think it's par for the course" (Interviewee \#20, personal communication, November $\left.19^{\text {th }}, 2018\right)$. She elaborates on this by explaining that,

Like, I don't think, with those brands, like I mean, they have opportunities with digital media to you know, heighten how they work, and you know, maybe have trendier messaging and move faster through their ad funnel. But, beyond that, I think they just evolve as advertising evolves. (Interviewee \#20, personal communication, November $19^{\text {th }}, 2018$ )

Interviewee \#13 goes in a different direction, noting that, "I don't think anyone's shying away anymore from letting their position be known" (Interviewee \#13, personal communication, November $\left.7^{\text {th }}, 2018\right)$. Additionally, she adds that, "Whether it's personality, a company, a politician, you know, anybody. Everybody knows now where you stand on things. It's not hidden as much as it used to be" (Interviewee \#13, personal 
communication, November $\left.7^{\text {th }}, 2018\right)$. Interviewee $\# 1$ takes a less wholesale approach to the matter by reasoning that, "Well, I think some brands are going to have to become less neutral" (Interviewee $\# 1$, personal communication, September $12^{\text {th }}, 2018$ ). Yet he reminds us that,

I think it's different for every brand, it's different for every company, right? But I think some are going to choose sides because the public are going to expect them to choose sides. And I think some are going to be fine being neutral, but they're going to have to appeal $[\ldots]$ their appeal is going to have to be more than their product. And I think, in politics, it's going to be the same thing, right? You know [...] the appeal has to be more than what you say, and it will continue down this path of increasingly polarized politics where you're on one side or the other, you're going to see that they're going to have to have defined ways to go beyond what's in your policy hamper to define themselves. They already do. (Interviewee $\# 1$, personal communication, September $12^{\text {th }}, 2018$ )

In his opinion, abandoning the commercial marketers' long-standing standard operating procedure of brand neutrality is no sure thing, but there will likely be more momentum to do so. As he sees it, this is largely a sign of the times in which we are now living. Numerous additional interviewees feel the same. Interviewee \#11 is one such individual. For example, he argues that,

One could make the observation that, in the era of Trump, who is a very polarizing figure $[\ldots]$ and he has ushered in $[\ldots]$ now he is not the cause of all the division. He is a symptom of it. And, so, he didn't start it. But he is certainly a product of it. But his acceleration of the divisions that are going on, forcing people to choose sides, that is: are you with us or against us? (Interviewee \#11, personal communication, October $31^{\text {st }}$, 2018)

Furthermore, he adds that, "I would make the prediction that, things like that will become more frequent as brands double down and attempt to identify that audience, right?" (Interviewee \#11, personal communication, October 31 $\left.1^{\text {st }}, 2018\right)$. Interviewee \#12 admits a similar perspective when he reasons that,

I think the thing [i.e. non-neutral commercial marketing] has accelerated dramatically post-Trump, because America is polarized so starkly in the post- 
Trump era that people feel like they are choosing sides every day and almost every consumer decision that they make feels like you're taking a side. And so, I think it's really accelerated, but I don't think it started with Trump. I mean, Nike has been playing around the edges of that for a while. And, you know, Starbucks always set out to represent a certain mentality to a certain group of people. Right? Yeah. Exactly. So, that always constrained what they could do and what they could be associated $[\ldots]$ what standard they would be held to, right? If you're Starbucks, you're going to come under more scrutiny about how you treat your employees than if you're Second Cup. (Interviewee \#12, personal communication, November $1^{\text {st }}, 2018$ )

Interviewee $\# 25$ thinks this is not only typical for the times in which we live, but that it is also the logical progression of doing business today. Additionally, he helps us shift gears towards discussing the variables behind a commercial marketer's weighing whether or not to venture down the road less traveled of non-neutral commercial marketing. For instance, he states that,

I noticed that many companies are really becom[ing] more active [politically]. I'd like to think it's because they're good people, but I think it's really just a marketing tool. I think as the electorate becomes more polarized and easily sort of picked apart, it makes sense for a company based in Texas to be pro-Republican, pro-oil, pro-Anwar ruling. And it makes sense for a company who's based in San Francisco or New York City to do things that are supportive of Me Too and other things. [...] Yeah. I mean, I think it's great that they're becoming more politically active. But [I] promise you it's not just because it's the right thing to do. Yeah. I mean, it's a calculation that they all have to make. (Interviewee \#25, personal communication, January $15^{\text {th }}, 2019$ )

Interviewee \#31 offers some substantial food for thought on this marketing approach and, in particular, on the likely arithmetic that went into Nike's thinking before it launched its powerful but controversial Colin Kaepernick advertising campaign by explaining that,

I think it depends on [...] I think it depends on the circumstance. And I think it depends on the economic model that the decision is based on. I don't think that Nike or anybody else is making decisions to have these sort of political valueladen marketing campaigns without first doing the research to determine whether or not that's going to have a positive impact benefit for shareholders. (Interviewee $\# 31$, personal communication, January $30^{\text {th }}, 2019$ ) 
Or, as Interviewee \#29 shrewdly puts it: "Well, I mean, these are for-profit companies that have to answer to their shareholders. So, they only do it if it makes them money" (Interviewee \#29, personal communication, January $\left.29^{\text {th }}, 2019\right)$. Indeed.

As far as embracing politically-charged commercial advertising goes, it is all about achieving a balance between the aforementioned risk and the potential reward for cashing in on current market trends and public sentiments. Interviewee \#19 points this out when she says that, "I think it depends on the political climate at the time. And, well, (laughs) it depends on if it's profitable for them or not. Right?" (Interviewee \#19, personal communication, January $\left.29^{\text {th }}, 2019\right)$. She takes this argument further by explaining that,

Like, I mean they made [...] obviously Nike made a very savvy calculation. Their stock price went up. I hadn't considered [... I mean] I had always considered Nike as a piece of shit (laughs) sweatshop and so did all of my Lefty friends. But, all of a sudden, you have all these kinds of Progressives that are on my Facebook and my timeline singing the praises of Nike, right? And, as much as taking a stand, it was a massive political rebrand for them. Are we going to see more or less of that? I mean, probably a little bit more, as we go into an increasingly polarized political, class, and societal environment, you know?

(Interviewee \#19, personal communication, January $29^{\text {th }}, 2019$ )

Interviewee \#22 also addresses this important subject matter when he states that, "I think that brands are increasingly willing to $[\ldots]$ to take publicly, to take public political stances, more so than in the past" (Interviewee \#22, personal communication, November $\left.27^{\text {th }}, 2018\right)$. And, when pressed about why he thinks this is the case, he responds that,

I think that's true I mean, I think it could be perhaps it'd be easier to do the math, to figure out whether it would benefit you. It'd be easier to think that, you know, you might be able to kind of make a calculation that, if it angers certain customers, they might still be likely to maybe still buy your product, and it makes some people very happy, and they will be more likely, and it's just a math decision, and it's easier to make those math decisions. (Interviewee \#22, personal communication, November $27^{\text {th }}, 2018$ ) 
Interviewee \#30 offers a similar argument when he posits that, "Well, I think [with] Colin Kaepernick, you know, potentially, they made a calculation, right? [...] That there weren't a lot of Trump voters buying Nike shoes (laughs). Right?" (Interviewee $\# 30$, personal communication, January $\left.30^{\text {th }}, 2019\right)$. Interviewee $\# 17$ is also of the same mindset, as is evinced when he states that, "And, you know, I've been a huge fan of the Colin Kaepernick campaign. I thought it was amazing. But, at the same time, like, you know, Nike made a ton of money off it. Right?" (Interviewee \#17, personal communication, November $\left.12^{\text {th }}, 2018\right)$. He takes this argument further in explaining that,

They know who their market is, right? You know, if it was all, you know, white suburban dads buying their shoes, I don't think that campaign happens. But, that's not who buys their shoes. So, they're able to do that type of campaign. So, that's actually a good example of, you know, in political terms, 'activating your base,' right? Like, getting people fired up about something. I know I went onto Nike that day and I was like, 'I wonder if I should buy something?' Just because I'm very supportive of Colin and what he did. And, you know, it was a real motivating thing for me. And I think it was for a lot of people too. (Interviewee \#17, personal communication, November $12^{\text {th }}, 2018$ )

Activating your base is a subject that we will flesh out more fully in the following section, where the respondents' thoughts on the notion of tribal marketing will be examined. However, in the meantime, more attention needs to be given to both Nike's successful Colin Kaepernick campaign and Gillette's less successful \#MeToo/toxic masculinity campaign.

Interviewee $\# 9$ provides us with an important consideration before embarking upon that discussion when he states that, when marketers craft any given campaign, it is important to remember that, "Different demos [demographic groups] look at different values and different things" (Interviewee \#9, personal communication, October $30^{\text {th }}$, 2018). Therefore, when crafting a marketing campaign, the astute marketer - whether 
commercial or political - must remember that the success or failure of a campaign often "depends on the demography of the people you're trying to sell to" (Interviewee \#9, personal communication, October $\left.30^{\text {th }}, 2018\right)$. He then gives us an example of a particular demographic group that increasingly gets its fair share of scrutiny in both academic literature and the popular media as of late: Millennials. For instance, he maintains that, "Millennials look at different values" (Interviewee \#9, personal communication, October $30^{\text {th }}, 2018$ ).

Interviewee \#33 helps paint a picture of how, given their substantial clout (in terms of population and also purchasing power), Millennials impact the thinking and strategizing of large brands such as Nike and the politically-charged advertising campaigns that those brands have recently been producing. For example,

I think when you've got a brand like Nike [...] that they're kind of - I'm not really sure what their motivation was to do that, but I think it's sort of - I guess they did okay with it. I think that it was fine. I don't know if it really helped them or hurt them in the long term. It'll be interesting to see. I bet it probably helps them. Gillette, I think they took a lot of flak for that ad, which I think was unnecessary. In the case of both of them, they're not doing it because there's this warm spot in their hearts that they want to do it. I mean, the motivation is to build the business. And so, this kind of goes back to what I was saying about the longer-term point of view. So, if you want to [...] in both cases, if it's a MeToo thing or the Nike Colin Kaepernick thing, they were talking to people who are 35 and under. And so, what they want to do is go, 'Hey, look. These are brands obviously [...] Gillette's been around for 100 years. Nike's been around since the 1970s. So, these are brands that have constantly got to pull new people into the fold.' (Interviewee \#33, personal communication, February $4^{\text {th }}, 2019$ )

Consequently, the thinking amongst marketers follows this reasoning: "I think really this is a message that we think resonates with people that we want to get on our side, so here we go [...] We'll prosecute ourselves with that message if we have to - whatever it takes" (Interviewee \#33, personal communication, February $4^{\text {th }}, 2019$ ). He sums up the situation by stating that, 
I'm not saying that their heart's not in the right place. I'm not saying they didn't mean it well. But ultimately, they're not running a non-profit over there. They want to make money and they need another generation in the business. (Interviewee \#33, personal communication, February $4^{\text {th }}, 2019$ )

But growing your base can prove to be quite a challenge - especially in the increasingly polarized times in which we live today.

Interviewee \#9 helps us draw this section to a close and helps open up the interviewees' thoughts on the growing importance of the provocative matter of tribal marketing when he states that, "If you're Nike, [...] with Colin Kaepernick taking a stand [...] I mean, there may be a corporate philosophy that backs it, but it doesn't hurt either, because you're going against a political force that isn't necessarily popular with your consumer base" (Interviewee \#9, personal communication, October $30^{\text {th }}, 2018$ ). And, more and more, that consumer base is of vital importance. With this in mind, Interviewee \#32 says that,

I'll be really interested to see not the sales figures, you know, they might not release them for the next six months, but a couple of years down the track, how Nike and Gillette have done. Because, certainly there's been quite ferocious backlash to what they've done. And, the questions I have are: does that last beyond a couple of months? And, at the end of the day, do people at the store still find that it gives them a better shave, or are you really not going to buy Nike shoes just because the company's pissed you off? Most people say they're the best shoes you can buy if you're a runner. So, does the negative impact of going political last? (Interviewee \#32, personal communication, January $31^{\text {st }}, 2019$ )

However, the other side of the coin should also be considered. Considering that flipside, he asks the following important questions:

And what are the benefits of the positive feedback with the people who agree with that [and] think, 'Wow!' This is a calculated risk. But, the risk is probably on the upside to a degree, because if you can [emphasis in original] get that loyalty brand, that is what politics is about. [In] politics, the people you want are those who will stick with you through thin and think and will always vote for you even if you annoy them. So, and what they're trying to do is build their political brand, but the potential market share you're losing, and how much of that, and 
how long does it last for? (Interviewee \#32, personal communication, January $\left.31^{\text {st }}, 2019\right)$

In essence, most interviewees, regardless of whether they are commercial marketers or political marketers, and regardless of whether they practice in Canada or elsewhere, maintained that commercial marketing will likely generally remain neutral due to inherent corporate risk aversion. They posited that abandoning the commercial marketers' long-standing status quo of brand neutrality will likely not become the new normal, but there will likely be more momentum to do so. And, in instances where commercial marketers are open to abandoning brand neutrality (given their formidable experience with such matters), political marketers can serve as skilled guides to navigating that treacherous terrain. In sum, when thinking about $\mathrm{H} 4$ which hypothesized that politics is seeping into more areas of contemporary life and that, consequently, commercial marketing is becoming less value-neutral, the findings appear to be murky.

\section{Consumer Citizenship \& Corporate Social Responsibility}

Consumer Citizenship, a concept that was introduced in Chapter I and was examined in Chapter II, should be discussed prior to examining tribal marketing since it was brought up with the interviewees, and since it could also be thought of as the light side of non-neutral marketing practices whereas tribal marketing could be viewed as the dark side of such marketing practices. The following question was posed to probe the interviewees' thoughts on this subject: What comes to mind when you hear the term "consumer citizen"? Interestingly, the majority of the interviewees were not familiar

with the term and responses from those familiar with the concept varied drastically. A number of the respondents expressed a certain sense of cynicism with the term. Interviewee \#19 offers our point of entry into this discussion when she states that, "Oh, 
jeez $[\ldots]$ I guess $[\ldots]$ we're all consumer citizens, to be honest. But, you know, what comes to mind? Kind of a useless buzzword to be honest" (Interviewee \#19, personal communication, November $\left.16^{\text {th }}, 2018\right)$. Interviewee $\# 9$ amplifies this perspective when he responds that,

(Laughs) Great. More bullshit. But, yeah, it's just [...] we buy shit all the time. So, politically, we do the same thing. And we're trained in certain ways: where we look, how we seek validation, and, so, the consumer overlaying of citizen[s] is reflective of how our consumer purchasing patterns reflect how we engage in our citizenship [...our] responsibilities of citizenship. (Interviewee \#9, personal communication, October $30^{\text {th }}, 2018$ )

Interviewee \#33 begins his discussion of this matter in a similar manner by stating that the term "Sounds a little bullshitty" (Interviewee \#33, personal communication, February $\left.4^{\text {th }}, 2019\right)$. However, after that pithy remark, he offers a valuable insight into what the term means to him and also into how he thinks it may be particularly problematic in the current political environment:

But I do think if it means what I think it means, I think it could be real. And right now, certainly in our country, you've got a lot of people who are, 'I'm Democrat and I'm going to vote for a Democrat no matter what, and they're Democrat even if he's dead, I'm going to vote for him.' And the same thing on the Republican side. So, I think people are off in their corners. And then there's very few swing voters, so as political consultants, where we're trying to find new voters to bring over to our guy or fighting over this very, very [emphasis in original] small number of swing voters. I think that changes as we go on. So, I just don't know that a consumer citizen frankly exists at the moment. I think that's a charming idea, but it comes and goes, right? I mean, I think you see cycles where I think [...] like 2008. I think with Obama or with Reagan in 1980, I think you had people who were going, 'Well, damn the party. I love this guy and I'm going to vote for him.' At the moment, I don't think it exists. (Interviewee \#33, personal communication, February $4^{\text {th }}, 2019$ )

Some may say that this happened in the 2016 U.S. presidential election when Donald Trump secured the keys to the White House by winning over numerous segments of long- 
standing Democratic voters (most notably the so-called Reagan Democrats), but it will be interesting to see if this happens again in 2020.

As an important aside, Interviewee \#18 offers us a significant consideration about consumer citizenship that should be kept in mind going forward. While it may not be painted with the brush of cynicism, it is steeped in lament. For example, when asked the same interview question as all of the respondents (What comes to mind when you hear the term "consumer citizen"?), she responds,

A reality - sometimes an unfortunate one. Because, I go back to the idea of Consumer Citizen as somebody who has wants and needs. And consumerism is about short-term wants - often. And citizenship is about long-term needs. And, ideally, we can be a blend of all of those. (Interviewee \#18, personal communication, November $14^{\text {th }}, 2018$ )

However, many - myself included — would argue that we appear to be having great difficulty attaining that blend.

Others chose not to couch their thoughts of consumer citizenship in cynicism. For instance, Interviewee \#7, a partner and founder of a Toronto-based government relations, strategic communications, research and digital campaign consultancy, and a long-time Conservative political strategist, gave a very stripped down and literal interpretation to the subject, stating that, "I would assume that means looking at voters [emphasis in original] from the standpoint of consumer habits" (Interviewee \#7, personal communication, October $25^{\text {th }}, 2018$ ). Interviewee $\# 14$, a long-standing public affairs and policy researcher and Principal at a Canadian government relations, strategic communications, public policy research and analysis firm, offers us a more nuanced perspective on the concept by stating that the term consumer citizen "reminds me of 
Susan Delacourt's book, Shopping for Votes" (Interviewee \#14, personal communication, November $\left.7^{\text {th }}, 2018\right)$. He expands upon this by explaining that,

Well, it makes me think one of two ways [...] a Consumer Citizen is like a marketer [who] wants a consumer, right? Like a consumer of running shoes? They want to have their market share as high as possible within the consumers of [emphasis in original] running shoes, right? The running shoe consumer. So, I thought about it as that designation. But, I also think of it as a citizen themselves making a consumer choice about, you know, where to donate, or who to help and that kind of thing. But, I actually think that one is extremely elastic and the other isn't. Like, people don't tend to change who they donate to from one year to another. Right. So, you might think of yourself as a consumer citizen, and making choices about who to vote for but, really, that's - unfortunately, I think - a minority of voters. And, the other way around is, parties are definitely trying to, you know, build up and maintain their market share among citizen consumers. (Interviewee \#14, personal communication, November $7^{\text {th }}, 2018$ )

In essence, for him, consumer citizenship — whether commercial or political in nature is about both consumer acquisition and retention.

Interviewee \#3 also offers a nuanced and insightful position on the subject of consumer citizenship. When asked about the term, he quickly responds that, "Oh, we talk a lot about it" (Interviewee \#3, personal communication, October $1^{\text {st }}, 2018$ ). He expands upon his answer by expressing the belief that the term consumer citizen is based upon a false dichotomy:

The reason for that is the idea that there's a private sector and there's a public sector is completely destroyed, or has been destroyed completely [...] There's no such thing as private anymore. And, so everything is somehow imbued with political aspects these days. When you can't turn on an awards show on television [...] you know, on Sundays, you can't turn on a football game without somebody doing something that is political now. You can't go to a sport $[. .$.$] you can't$ watch a sporting event in Canada like a hockey game where there not doing a tribute to the troops, or they're recognizing whatever. It's all become extremely political. And becoming more so every day. (Interviewee \#3, personal communication, October $1^{\text {st }}$, 2018) 
That view — that the political is bleeding over into more and more facets of modern life - was shared by numerous respondents throughout the interviewing process of this dissertation.

Interviewee \#17 frames his discussion of consumer citizenship in a light which is closely aligned to much of the academic literature on the subject matter (as seen in Chapter $I$ and $I I$ ) when he states that,

Consumer Citizen? I mean, not much. I guess you're sort of referring to, you know, people being able to make their own choices about where they shop, what they buy and, you know, the idea that people will make choices on products based on things that don't necessarily have to do with product quality, but could have to do with, you know, is the company environmentally friendly? Is the company sourcing their materials ethically? Things like that, right? (Interviewee \#17, personal communication, November $12^{\text {th }}, 2018$ )

A close perspective is voiced by Interviewee $\# 31$ when he notes that, "Consumer citizens I would expect to be people who make consumer choices based on their perception of how the political positions or values of specific companies mesh with their own" (Interviewee \#31, personal communication, January $30^{\text {th }}, 2019$ ).

While, as noted earlier, more interviewees were unfamiliar with the term consumer citizen than was expected, most interviewees were familiar with the notion of Corporate Social Responsibility (C.S.R.), which also deals with — to use the words of Interviewee \#31 - the "perceptions" and "values" behind consumption. However, it traditionally does so from the marketers' perspective more so than that of the actual consumer. In other words, Consumer Citizenship is more the consumers' domain whereas Corporate Social Responsibility is more the marketers' domain.

Interviewee \#14 begins our discussion of this matter when he states that, "I think C.S.R. (Corporate Social Responsibility) campaigns, rather, have long been valued by 
marketers as an element to support the brand; or, as an element to create as favorable a regulatory acceptance as is possible" (Interviewee \#14, personal communication, November $\left.7^{\text {th }}, 2018\right)$. He elaborates on this by explaining his understanding of the essentials of the practice of C.S.R. when he explains that,

I think it's long been the case that industries and companies sometimes identify that it would be valuable for them to "give back" in a way that is strategically aligned with the objectives they want to accomplish. So, I don't think that's changed. I think that there are probably times and issues that are, you know, that make the level of activity wax and wane, and sometimes, you know, it becomes table stakes, like, you know, Esso or Enbridge, they have got to spend on, you know, charities, corporate social responsibility to try to have their reputation be [...] less dirty (laughs). (Interviewee \#14, personal communication, November $\left.7^{\text {th }}, 2018\right)$

Interviewee \#25 states that, "Yeah, I mean, that's [C.S.R.] definitely a thing that [...] I mean, we hear about it" (Interviewee \#25, personal communication, January $15^{\text {th }}, 2019$ ). He adds that, "I mean [...] I hear about it as much in the political space" (Interviewee $\# 25$, personal communication, January $\left.15^{\text {th }}, 2019\right)$. However, speaking strictly about the American political context (given where he is located), he explains how he sees most of those discussions about C.S.R. playing out:

I mean, in the political space, I'll hear almost exclusively on the Democratic side. Different jobs will, I mean, as basic as, "Make sure to recycle," and, "buy local, and, "make sure they have a diverse workforce," things like that. But a lot of political shops are very small, one, two, three people. It might be two guys with cell phones and a check book. You know? So, there's not a lot of [...] there's not necessarily a big footprint, to begin with. (Interviewee \#25, personal communication, January $15^{\text {th }}, 2019$ )

Here, Interviewee $\# 25$ references a recurring point that numerous interviewees mentioned and which should be dealt with before going any further: the footprint (a.k.a. the size) of most political marketing practices. 
While the literature referenced earlier on in this project highlighted the fact that political marketing is a bigger business in the United States than it is here in Canada, the fact is that, on both sides of the border, political marketing consultancies and practices are often small operations in terms of both personnel and brick and mortar presence. This is particularly true in Canada given the less substantial amounts of money involved in our elections, our shorter electoral time frames, and the fewer elected offices in Canada compared to the United States. And this reveals something that was referred to by a number of interviewees: something they referenced as the "briefcase business" nature of political marketing — especially in Canada.

Interviewee \#3 is the respondent who introduces that particular phrase to the lexicon of this study when he states that, "Well, I think, particularly in Canada, the political marketing business, the campaign business, is pretty much a briefcase business" (Interviewee \#3, personal communication, October $1^{\text {st }}, 2018$ ). He fleshes out his thinking by explaining that,

You're not $[\ldots]$ they're not really serious companies that are doing this type of work. They tend to be all very small. They have other types of businesses that keep them going in terms of revenue. So, they don't really have the means to work on big campaigns the way that, say for example, commercial marketers do. (Interviewee \#3, personal communication, October $1^{\text {st }}, 2018$ )

Because of these Canadian financial constraints, he reasons that there is an opportunity for political marketers to learn a substantial lesson from their commercial counterparts, as is demonstrated when he states that,

I think one of the big things that they can learn from commercial marketers is [...] is looking at programs that have big budgets in which they don't have the normal limitations that somebody working in a political campaign would have in terms of money and assets $[\ldots]$ and trying to take a look at how people who do have the money and assets do what they do. (Interviewee \#3, personal communication, October $\left.1^{\text {st }}, 2018\right)$ 
But transferring those lessons learned back to political marketing campaigns in Canada can be a challenge. As Interviewee $\# 23$ puts it:

I mean, you have to make your money somewhere else, and then you drop in. Right, so you either work in the States and come back, I mean, very few do that too. Most of us are working real, quote unquote marketing jobs, and then we just get dragged into the odd campaign. (Interviewee \#23, personal communication, December $5^{\text {th }}, 2018$ )

Returning to Interviewee \#3 helps us keep this discussion of the briefcase nature of political marketing in Canada in perspective. From his standpoint, this is not a uniquely Canadian phenomenon. For example, he notes that, "I think it's fairly typical around the world" (Interviewee \#3, personal communication, October $1^{\text {st }}, 2018$ ). He then walks us through why this is the case: "And the reason is that there's really $[\ldots]$ the one we tend to compare ourselves to is the U.S., which is not really a good representation of how political consulting or campaigning works around the world" (Interviewee \#3, personal communication, October $\left.1^{\text {st }}, 2018\right)$. For instance,

They don't limit what you can raise and they don't limit what you can spend, which means that you can have multi-million-dollar campaigns. I mean, everything that we do in Canada runs on a shoestring. It's mostly still a volunteer type of activity. And, as far as a [...] the people who make a living doing it, they're $[\ldots]$ the living that they make (laughs) is not what I would consider to be $[\ldots]$ it's not the kind of thing that you would consider to be anything more than a somewhat compensated for hobby. (Interviewee \#3, personal communication, October $\left.1^{\text {st }}, 2018\right)$

Interviewee \#16 concurs with the briefcase nature assessment of political marketing in Canada and with the fact that Canadian practitioners typically compare themselves to their American counterparts when, at least in terms of the scope and scale of their operations, there are no grounds for such a comparison. He drives this point home by way of a vivid example from the recent past: 
You can't survive off it here, right? Whereas, in the U.S., we didn't really appreciate the magnitude of difference that we're talking about until we did the Trudeau campaign in 2015. And, you know, somebody suggested we enter it into sort of a political advertising awards show that they run in the U.S., in the international category. And we ended up winning the "Best International Political Campaign.” I think we beat out, you know, Netanyahu's campaign or something that year. And, we won the international award. So, we sent a couple of people down to, I don't know, South Carolina or wherever the awards show was. And when I asked them [the agency representatives sent down to represent the firm], I said, "What other agencies were there?" [and] they said, "Oh, there were like hundreds of agencies, but you wouldn't have heard of any of them." Like, literally, hundreds of agencies and consultancies who-full-time-do, you know, state-level, and Senate-level, federal, and municipal election campaign work for thousands, and thousands of candidates. And they're all extraordinarily wellfunded. So, it's a true profession there. And here it's not. So, that's the big difference. (Interviewee \#16, personal communication, November $8^{\text {th }}, 2018$ )

With that important consideration having been discussed, we can draw to a close our examination of the respondents' thoughts on the matter of C.S.R. itself. Interviewee \#2 helps to do so when he asks the following question: "There's a long debate over things like Corporate Social Responsibility. Does that actually help?” (Interviewee \#2, personal communication, September $\left.24^{\text {th }}, 2019\right)$. He quickly proceeds to answer his own question by saying that,

So, you know, if you're an oil company, you have to have some sort of a position on environmental issues [...] But I'm not sure — and I may be an outlier here I've never been particularly convinced that those are effective strategies for selling consumer goods. Because I don't think ultimately [...] well, I don't know. I don't know. Maybe it is increasingly important, but, I think the notion of neutrality is something that companies can continue to take without having an impact on whether or not they are considered as sources for consumer products. (Interviewee \#2, personal communication, September $24^{\text {th }}, 2019$ )

Interviewee \#12 also expresses some important sober second thought on the now ubiquitous practice of C.S.R. when he states that,

I think Corporate Social Responsibility is going to become passé pretty quickly. Because it's inadequate. It's insufficient for what peoples' demands of business are now. Which is to be more inherently responsible, not just have a department that dispenses some cash to mitigate the shittiness of what you do, but to actually 
be better in the first place. (Interviewee \#12, personal communication, November $\left.1^{\text {st }}, 2018\right)$

In sum, building off of the previous section's discussion of neutrality or the lack thereof, notions of consumer citizenship and corporate social responsibility are becoming more relevant and prevalent due to the fact that politics is increasingly seeping into more facets of life than was the case in the past. In such an environment, the perceptions and values driving consumption are becoming ever more important considerations. The interviewees relied upon here generally reflected both these positions. That said, many interviewees expressed a substantial amount of cynicism when reflecting upon the motivation for both consumer citizenship and corporate social responsibility. The thinking went that consumer citizenship tends to happen on the consumers' end and Corporate Social Responsibility happens more on the marketers' end. Additionally, respondents held that consumer citizenship and Corporate Social Responsibility represent the light side of non-neutral marketing practices while tribal marketing represents the dark side of such marketing practices. With that dichotomy being established, we must now turn to tribal marketing.

\section{Talking Tribal Marketing}

To gauge the respondents' thoughts on the increasingly topical but controversial subject of tribal marketing, a two-part question was posed. The first part of that question asked: What comes to mind when you hear the term "consumer tribe" or "brand tribe?" If something came to mind, the second part of that question was then asked: Do you think that there's a similarity between how that term is interpreted in the commercial context versus the political context? Needless to say, if nothing came to mind when the first part

of the question was asked, the second part was not asked. Perhaps unsurprisingly, the 
diverse cross-section of interviewees resulted in a wide range of opinions on the topic of tribal marketing. Accordingly, for both organizational and logical reasons, we will examine the first part of the two-part question prior to the second.

While a number of interviewees were unfamiliar with the terms consumer tribe or brand tribe, or with the notion of tribal marketing in general, most had some familiarity with the broader concept itself. Nonetheless, the varied professional and geographic backgrounds of the interviewees ensured a wide array of diverse opinions and perspectives on the subject matter. Some, like Interviewee \#24, express a hint of cynicism when discussing the topic. For example, when asked the initial question about tribal marketing, he responds, "I don't really know. I mean I think that's kind of like a buzzword" (Interviewee $\# 24$, personal communication, December $27^{\text {th }}, 2019$ ). He contextualizes his response by adding that,

Now keep in mind, as a pollster, I always want to put people in a box so [...] as people, right, I mean it's human nature for us to want to put people in a box, right? So, if I can easily, say, put you in one place and put your neighbor in another place, it's great. But I think that's just kind of a buzzword. (Interviewee \#24, personal communication, December $27^{\text {th }}, 2019$ )

By wanting to "put people in a box" as a pollster, Interviewee \#24 is referring to the allimportant task of quantifying individuals for the purpose of crafting surgical microtargeting voter outreach strategies, a subject matter that was introduced in in the previous chapters of this dissertation and which will be interpreted through the eyes of the interviewees in great detail in the following chapter.

Interviewee \#9 also cynically colors his initial thoughts on tribal marketing, as is evinced when he states that the first thing that comes to mind "would be trying to sell books. Or, I guess, Ted Talks these days, or podcasts" (Interviewee \#9, personal 
communication, October $\left.30^{\text {th }}, 2018\right)$. But he is quick to transition from cynicism to historical contextualization when he explains that,

You can call it whatever you want, be it a tribe, because that suggests there are, you know, different behaviors that are unique to that body that you want to be aware of if you're communicating with them or trying to move them. But, yeah, there's always been descriptions, and the lairing of the description and the word used to capture those descriptions depends on who's writing them and how they're seeing people organize. So, it's $[\ldots]$ yes, I've heard those terms, or versions of those terms for years [emphasis in original]. And people have always looked to people in collectives. So, that's just the term of the days, I suspect. (Interviewee \#9, personal communication, October $30^{\text {th }}, 2018$ )

In other words, from his vantage point, the terms may change but the tactics remain the same. Interviewee \#22 also sees the label of tribal marketing as a new term for an old tactic when he notes that, "I think that that's kind of another kind of way of companies using the concept of like, a customer persona, or it's kind of like their target markets for like an old-fashioned word would be that" (Interviewee \#22, personal communication, November $\left.27^{\text {th }}, 2018\right)$. With this in mind, he adds that, "I think it's [tribal marketing] a different way of visualizing that" (Interviewee \#22, personal communication, November $\left.27^{\text {th }}, 2018\right)$.

Similar to both Interviewee \#24 and Interviewee \#9, Interviewee \#26 also frames his initial thoughts about tribal marketing in a cynical fashion. For example, "So my first thought, what comes to mind, is I think it's a dumb term" (Interviewee \#26, personal communication, January $\left.23^{\text {rd }}, 2019\right)$. Yet, he too pivots from this perspective when he fleshes out his thinking:

But outside of that, I think about data and how data is used to divide people into various tribal categories. And I think it's more a symptom of the use of data rather than [...the] very few people [who] would consider themselves [...] maybe in their cars, they're tribal-aligned. But in politics, there are people that call themselves Progressives, or people that call themselves Democrats, and I suppose you could look at them as tribal in that sense. But I don't really ever hear people 
using those terms in politics as much. (Interviewee \#26, personal communication, January $23^{\text {rd }}, 2019$ )

But not every interviewee who had heard of tribal marketing, brand tribes or consumer tribes thought that those terms were generally not utilized by political practitioners. Interviewee \#11 is one such individual who holds that contrasting view. For example, he recounts that, "up in Ottawa, when I was there - and people use that term down here [in Toronto] too — but $[\ldots]$ people from other political parties [would] say [...] 'But do people in your tribe do X, Y, or Z?"” (Interviewee \#11, personal communication, October $31^{\text {st }}$, 2018). With that established, we can backtrack and unpack his thoughts on what tribal marketing means to him. He offers a terse definition when he states that, "Well, that's the group of people who are loyal to a particular brand or party $[\ldots]$ it's the grouping of loyal supporters" (Interviewee \#11, personal communication, October $31^{\text {st }}$, 2018).

Interviewee \#15, a Senior Consultant at a Canadian government relations, public affairs and opinion research firm, and the former Director of Market Research in the Prime Minister's Office (PMO), offers a similar definition, both in terms of content and language use, when she notes that, for her, a consumer tribe or a brand tribe constitutes "A group of people who have a loyalty $[\ldots]$ as well as $[\ldots]$ a tendency to either purchase or vote a certain way" (Interviewee \#15, personal communication, November $7^{\text {th }}, 2018$ ). Loyalty is also an essential ingredient for tribal marketing according to Interviewee $\# 6$, as is evident when he defines the term in the following manner:

People who have a loyalty with a particular brand and they always buy it, because they've always bought it - and, you know, and I can personally probably think of a number of brands that I always flock to even though I don't really think about it, or know why. But, yeah, that's what I would think of. (Interviewee \#6, personal communication, October $17^{\text {th }}, 2018$ ) 
Interviewee \#28 also considers the importance of loyalty in establishing his thoughts on the practice of tribal marketing. For instance, he claims that, "what comes to mind would be people who are loyal to a specific group $[\ldots]$ or have a shared quality and you're trying to have your marketing resonate towards that cohort and also influence each other inside of that group" (Interviewee \#28, personal communication, January $28^{\text {th }}, 2019$ ). Here, Interviewee \#28 makes the important point that, as far as he is concerned, tribal marketing is not solely defined by a sense of loyalty. It is also defined by influence between marketer and consumer on the one hand, and consumer and consumer (a.k.a. relationship marketing) on the other hand. Put differently, for him as a marketer, you want members of your tribe to organically recruit their peers into your tribe on an ongoing basis.

This line of reasoning is incorporated into Interviewee \#8's thoughts on tribal marketing as well, as can be seen when he remarks: "Well, that implies a cohort of consumers who coalesce around (from an attitudinal perspective and preference perspective) who coalesce around a certain brand that they are favorable towards, and likely are promoters or proselytizers [of]" (Interviewee \#8, personal communication, October $\left.26^{\text {th }}, 2018\right)$. He elaborates on his thinking by explaining that,

Well, not a formal brand ambassador [...] but a brand tribe to me is the equivalent of super fans. And, they're worth their weight in gold, because they will disseminate typically positive messages and perspectives on a given brand, because they really believe in it. It's authentic. Yeah. And real. (Interviewee \#8, personal communication, October $26^{\text {th }}, 2018$ )

But, as will be discussed a little later in this section when comparing how tribal marketing is envisioned in the commercial marketing versus the political marketing context, there is a dark side to the notions of authenticity that tribal marketing can foster 
among individuals. And, because notions of authenticity, loyalty, and organic relationship marketing associated with effective tribal marketing can be extremely strong, as Interviewee \#21 reminds us, "I think every commercial marketer wants to create that tribe. That's why they all have their charitable giving arms or various non-profit wings, whatever corporate social responsibility" (Interviewee \#21, personal communication, November $\left.23^{\text {rd }}, 2018\right)$. That said, he is quick to point out that not all such efforts are equal in their depth and breadth, which can be seen clearly when he reasons that, "I think a lot of that $[\ldots]$ I think a lot of that is the feel-good stuff. I don't mean to disparage the commitment. But I don't think Pepsi or Coke are building a tribe like Beto O'Rourke is" (Interviewee $\# 21$, personal communication, November $23^{\text {rd }}, 2018$ ). Even so, he notes that,

I think that there are progressive brands that are. And they're brands that $[\ldots]$ it kind of gets back to that whole thing I said earlier about the generational evolution of consumer market or consumer purchasing habits [...which, for example] is, look at these products that are helping you save energy in your home. So, you're protecting the environment, whether it's a Nest [thermostat] to manage your home temperature when you're not there. I don't think Nest creates a tribe. But that kind of smart home [...] in the smart home marketplace that is creating energy efficiency, I think that's a tribal vertical market. (Interviewee \#21, personal communication, November $23^{\text {rd }}, 2018$ ).

A key phrase that Interviewee \#21 mentions here, "generational evolution of consumer market or consumer purchasing habits" warrants further consideration when unpacking the interviewees' initial thoughts on the subject of tribal marketing. Interviewee \#13 injects an important thought into that discussion when she reminds us that, "it's not just about marketing. It's also about reaching people the way they communicate and digest and ingest information now" (Interviewee \#13, personal communication, November $7^{\text {th }}, 2018$ ). She adds more to her thinking in explaining that, 
"People aren't getting information the same way they used to. And, so, you need to adapt to get your message out" (Interviewee \#13, personal communication, November $7^{\text {th }}$, 2018). Interviewee \#14 echoes this sentiment and highlights just how quickly the political marketing landscape shifts when he notes that, "I think we should also not probably lose sight of the fact that there's no stability in this. Like, and not much history. So, the way people communicate now is ridiculously different from like two elections ago" (Interviewee \#14, personal communication, November $7^{\text {th }}, 2018$ ). And, not all age groups communicate in the same fashion. With this in mind, Interviewee \#31 posits that,

Well, I mean, that's [tribal marketing] really just adjusting and crafting your messages to be audience specific. It's about being culturally competent. So, if you want to talk to a group of 18-to-25-year-olds, you're probably going to talk to them about an issue in language both visual and written or oral that is going to be different somehow than the language, visual, oral, or written that you're communicating with people who are 55 to 60 . (Interviewee \#31, personal communication, January $30^{\text {th }}, 2019$ )

Interviewee \#27 sees eye to eye with Interviewee \#31 on the topic of tribal marketing, as is clearly evinced when he offers us his thoughts on the term:

Okay, here's tribal marketing: Candidate $X$ figures out, midway through a campaign, that the people most receptive to her message are people who are between the ages of 18 and 32 who are single. Okay, now we know in this demographic that, for whatever reason, we're doing really well with that group, and that we can isolate that group on Facebook or some other social media, but we know where they are, or we know what their interests are, or we know how to get on their news feed, "So let us spread the word to people who may not yet be registered to vote but still can register to vote, that she is extremely popular with this group and why so that we can goad them into voting." (Interviewee \#27, personal communication, January $24^{\text {th }}, 2019$ )

As was just referenced by Interviewee \#14, Interviewee \#27 also thinks that the tectonic electoral plates that tribal marketing stands upon have shifted drastically in a very short amount of time, as is clear when he remarks that, 
This is a recent phenomenon in the United States, but in the mid-term elections in 2018, voter turnout was up 30 and $40 \%$ in a lot of places, and a lot of those people had never voted before. A lot of those people may have only voted once in the past 10 years in primaries, but they were motivated to do so by this tribal networking that goes on, which is very easy to do with Facebook. Yeah. If you ask me how to do tribal marketing of Wrigley Spearmint Gum, I would say, "You need to talk to somebody else. I don't know." But I'm sure they know who it is and however they define it [...] I'm sure the people at Wrigley's know who likes their gum. (Interviewee \#27, personal communication, January $24^{\text {th }}, 2019$ )

Just as important as recognizing the fact that the electoral landscape is quickly and continually changing, and that these changes tend to foster tribal marketing, numerous interviewees in this sample thought that data-based microtargeting (or segmentation) and tribal marketing go hand in hand, with some even going so far as to say that such targeting practices promote tribal marketing - for better or for worse. Interviewee \#2 begins that discussion for us when he states that, "Oh (laughs), Consumer Tribe? I assume that's [...] I assume that's some kind of segmentation of consumers by either a combination of attitudinal demographic data or some other form that would mean they are like-minded in some way" (Interviewee \#2, personal communication, September $\left.24^{\text {th }}, 2018\right)$. When it comes to tribal marketing, segmentation is also on the mind of Interviewee \#32, as is undeniably witnessed when he is asked What comes to mind when you hear the term "consumer tribe" or "brand tribe?" and he promptly and unequivocally responds: "Well, segmentation, basically" (Interviewee \#32, personal communication, January $\left.31^{\text {st }}, 2019\right)$. He offers more insight into his thinking when he explains that, for him, tribal marketing entails

Doing something that's going to appeal to that specific tribe or, well, demographics aren't quite the right word, because, often, it's attitudes and values - not just your demographics. But, yeah, you know [...] segmentation is effectively what comes to mind there. And trying to get your product, or service, or company, identified with that tribe. (Interviewee \#32, personal communication, January $31^{\text {st }}, 2019$ ) 
Interviewee $\# 5$ examines the matter at hand from a more hypothetical perspective, but ultimately arrives at the same conclusion. For instance, he states that, "You know, it's [...] it's obviously about building a[n] understanding [of] behavior into groups. That people who $[\ldots]$ people who, you know, shop at one store, buy one sort of thing are likely to buy another sort of thing" (Interviewee $\# 5$, personal communication, October $12^{\text {th }}$, 2018). He then makes an important point that, in his opinion, the expectations of tribal marketing and the realities of it may not be perfectly aligned. Or, as he puts it himself:

From a marketing perspective, the Holy Grail is to be able to market to people individually $[\ldots]$ That's the dream; whether it's political or commercial. The [...] reality is that, in most cases, the goal is to group people into tribes, or groups, or whatever you want to call them, "segments" (and how many you have depends on the quality of your data), and then you market to that segment. So, again, you know, $[\ldots]$ it's better to market to a segment that you know [...] you divide everybody into four segments and it's better [...] you'll have better success marketing slightly different products or messages to each of those four segments than just treating everybody exactly the same. But it's better to have 400 segments than 4. (Interviewee \#5, personal communication, October $12^{\text {th }}, 2018$ )

In essence, the less is more approach does not apply when it comes to the microtargeting (or segmentation) that effective tribal marketing strategies rely upon.

Interviewee \#30 also sees tribal marketing through the lens of microtargeting which he refers to a "clustering." For example, he reasons that, "I mean, I think of that as $[\ldots]$ that's just a new name for clustering. That's just a new name for getting people $[\ldots]$ for putting people into groups and trying to figure out how to best address those groups" (Interviewee \#30, personal communication, January $30^{\text {th }}, 2019$ ). A complimentary contextualization of tribal marketing is voiced by Interviewee $\# 25$ when he states that,

I've heard $[$ of ...] tribal marketing a little bit. Breaking large groups into manageable sizes. Yeah. So yeah. There's been a lot of breaking groups into different personas. That's a thing that people do a lot of. I use different personas 
for targeting all the time. (Interviewee \#25, personal communication, January $\left.15^{\text {th }}, 2019\right)$

But the "different personas" (to use the words of Interviewee \#25) or the different microtargeting or segmentation strategies that are increasing the appeal, presence, and penetration of tribal marketing do not come without consequences.

Interviewee \#3 commences the commentary upon some of these critical consequences when he states that, "We're writing a lot about that [tribal marketing] these days and it's really a reflection of the fact that the middle has dropped out of politics and people are more and more identified with, I would say, better defined types of positions" (Interviewee \#3, personal communication, October $1^{\text {st }}$, 2018). He paints a more detailed picture of how this is so when he explains that,

So, in the United States, it's a great way of looking at, you know, what a Democrat is today versus what a Republican is today. You know, all of the sort of images, signals, and the credibility of the spokespeople and all the rest of it is very differentiated. And it's not quite that way in Canada, but it's moving that way. (Interviewee \#3, personal communication, October $1^{\text {st }}, 2018$ )

A more pessimistic perspective is voiced by Interviewee \#14 when he notes that,

Well, the use of the term tribe, I think of more politically. And, it's a really dark term, in my view now, because [...] because tribes tend to involve people doing things out of a sense of loyalty and emotional commitment that sometimes go against what your rational or moral compass would normally tell you to do. (Interviewee \#14, personal communication, November $7^{\text {th }}, 2018$ ).

He elaborates on his position when he argues that,

Like, there's no point in having tribal loyalty if you're not going to ask people to do something they're uncomfortable with. [It's] more the [...] emotional brain that, you know, you can develop and leverage [with] a tribe, and exploit it, or serve it, or both. But when you create a tribe, the idea of tribalism is: "I' $m$ in this one, not that one; that one is not us." And that is divisive by nature and problematic in politics. (Interviewee \#14, personal communication, November $7^{\text {th }}$, 2018). 
And, with this in mind, he reveals what he envisions as the logical conclusion for the kind of "emotional brain" appeals that tribal marketing fosters when he explains that,

So, what's happening a lot with tribal behavior in politics is [...] that people now end up instead of picking a tribe that fits their values and aims, they end up shaping their values and aims as a result of the tribe they're in. Like, "If that's what the tribe needs me to say, that climate change isn't really happening, well, fuck that, climate change isn't really happening." Right? And then, as soon as that leader says, "Actually, we do believe in climate change," well then everybody in that tribe is like, "Yeah. We've always fuckin' believed in climate change. We've always just thought these solutions were wacky." What the fuck? That's Orwellian! Yeah. That's why I think of tribes being really unhelpful. (Interviewee \#14, personal communication, November $7^{\text {th }}, 2018$ )

Orwellian or not, tribal marketing is becoming a more recognizable, commonplace, and effective way of marketing. Interviewee \#13 is clearly in agreement as is evident when she states that, "I think tribes are incredibly important in marketing. And I think that that tactic or logic is incredibly persuasive" (Interviewee \#13, personal communication, November $\left.7^{\text {th }}, 2018\right)$. Looking back at the recent past, she remarks that, "From [the] political context, it's how Trump won. He knew how to mobilize his tribe" (Interviewee \#13, personal communication, November $7^{\text {th }}$ ，2018). Interestingly, Interviewee $\# 13$ offers a dose of self-reflexivity when she admits that,

From a marketing perspective, I totally ascribe to tribes, and I know I'm influenced by them, so, if for your purposes, it is still separate from our emotional feelings to the word, to a connection to the word, it is incredibly important and powerful and it works. I would not diminish the power of that rallying. (Interviewee \#13, personal communication, November $7^{\text {th }}, 2018$ )

Like others in this study, she points out that, "It does have a negative, it can have a negative connotation" (Interviewee \#13, personal communication, November $7^{\text {th }}, 2018$ ). Interviewee \#4 proceeds to illuminate why that negative connotation exists:

Well, [...] it relates to the same idea, right? [i.e. Consumer Tribe and Brand Tribe] That we've....and, I think, you know, here's where it's disturbing to me: it's that, where we take the idea of pride, then we've given away rationality. 
Right? Because we're not interested in having a discussion and learning anything more; we're interested in who's wearing a red jersey and who's wearing a blue jersey an who's wearing an orange jersey. That's it. There's nothing more to it. It's tribal. It's tribal. It's about identity. (Interviewee \#4, personal communication, October $11^{\text {th }}, 2018$ )

Be that as it may, Interviewee \#13 notes that, "But, it's not all negative for me. For me, it means similarities, rallying and the like, you know, having a shared something with someone else. You know, it could be commercial, it could be politics, it could be whatever" (Interviewee \#13, personal communication, November $7^{\text {th }}, 2018$ ).

With the respondents' initial thoughts on tribal marketing examined, we can now turn our attention to the second part of the interview question aimed at that particular matter which asked: Do you think that there's a similarity between how that term is interpreted in the commercial context versus the political context? Interviewee \#15 offers a point of entry into the variety of answers provided by the respondents on this subject when she argues that,

I think there are probably some broad similarities. Well, they're probably measured in somewhat the same way. But I imagine the political one is much deeper and likely a lot more [...] I mean, do you have an affiliation or a brand tribe to a bar of soap? I imagine who you're voting for is a lot more fundamental to who you are as a person. (Interviewee \#15, personal communication, November $7^{\text {th }}, 2018$ )

Interviewee \#3 has a similar position on the topic of tribal marketing, as is shown when he explains that, "I think what's happening is that the tribalism is much better reflected in the world of politics than it is in the world of commercial activities. But, increasingly, the political is seeping into the commercial" (Interviewee \#3, personal communication, October $\left.1^{\text {st }}, 2018\right)$. He then provides us with a couple of interesting examples of this overlap: 
Take a look at the new Nike advertising campaign [the Colin Kaepernick campaign]. Or take a look at, when it's done poorly, what Pepsi tried to do with one of the Jenners, with her street protest advertisement. Yeah. So, most of the emotions [...] the you know, the sort of big battles of the world are taking place around this idea of what is the say, for example, the American tribe? Or, you know, what is a real French person? Or a real Italian? Or a real Swede? What is that? What does it mean to be Swedish now? So, the tribalism is that sort of in and out kind of position. It's leaking into the commercial world because, increasingly, the products and services that you buy are a reflection of the tribe you're a member of. And you see some of that in Canada, right? So, Tim Hortons [...] Stephen Harper [...] would go to Tim Hortons [...] and would accuse everybody who went to Starbucks as being unCanadian. He never actually said that the signal was sent. That's the political leaking into the commercial, not so much the commercial leaking into the political. (Interviewee \#3, personal communication, October $\left.1^{\text {st }}, 2018\right)$

Here he echoes a phenomenon that was examined earlier in this chapter (the increasing overlap between the political and the commercial facets of life) and also two recent and vivid examples of politically-charged advertising campaigns conducted by commercial marketers which broke the long-standing mold of politically neutral commercial marketing (Nike's Colin Kaepernick campaign and Pepsi's Kendall Jenner campaign).

In the words of Interviewee \#4, "They seem to me kind of the same thing [tribal marketing in the commercial context as opposed to the political context]. It's kind of still an appeal to identity" (Interviewee \#4, personal communication, October $11^{\text {th }}, 2018$ ). Furthermore, as he sees it,

It's self-affirmation in some way of it - whether it's because I'm driving a Ford, or because I'm voting Republican. It's not a rational [...] it's not like, here are the features and benefits of a Ford [...Or] here's the platform of Doug Ford - he didn't have a platform. [It's] more visceral. Yeah, it's about the identity thing, right? (Interviewee \#4, personal communication, October $11^{\text {th }}, 2018$ )

That "identity thing" is where tribal marketing thrives: in the visceral, the emotional, the unrelentingly human need to fit in somewhere and to be a part of something. With this in mind, a number of respondents likened tribal marketing to the intense bonding that is 
present among hardcore sports fans. And rightly so, because, as Interviewee \#33 says: "politics is a little like sports for the un-athletic" (Interviewee \#33, personal communication, February $\left.4^{\text {th }}, 2019\right)$. He expands upon this notion when he reasons that,

And so, you got your New England Patriots fans and you got your Los Angeles Rams fans, and they're Patriots fans all the time. But when something happens, you just spark them a little and they become rabid Patriots fans. So, the same thing with Democrats and Republicans and conservatives and liberals. They're always there, and if you can give them a reason to get excited — an interesting person to follow, an interesting issue to get fired up about - then you're just lighting that match and it's ready to go off. (Interviewee \#33, personal communication, February $4^{\text {th }}, 2019$ )

A complimentary contextualization of tribal marketing is voiced by Interviewee \#11 when he puts it this way:

Certainly, sports teams come to mind. That level of relationship. Fans, which is why, you know, that's the term: fanatics. Fans are very tribe oriented. They behave in a certain way: they gather, they cheer, they go through experiences together, good times, bad times. (Interviewee \#11, personal communication, October $31^{\text {st }}, 2018$ )

That intense tribal marketing which is part and parcel of political marketing is increasingly appearing in the realm of commercial marketing as well. As Interviewee \#17 puts it himself: "Well, I mean certainly there's a little bit of tribalism in consumer marketing" (Interviewee \#17, personal communication, November $12^{\text {th }}, 2018$ ). Using an example, he then walks us through how he sees tribalism working in the commercial marketing world.

You know, there's a lot of people who were Nike or Adidas 'til they die, right? Or Xbox or PlayStation. And people will defend their brand. And, you know, I used to remember when the first ever Xbox came out, I remember being online and being excited to get one and people were just having these crazy [emphasis in original] online [discussions] about which one's better. It's like, neither of them is even out yet. You know? So, definitely, you know, it happens in the commercial world. But, it's nothing compared to political, right? Like, you've got people who have - quite frankly - no idea what they're talking about (laughs) so many times, and they will just [...] it's like a life or death thing, right? Like they will go 
to war for the side that they've picked. And, you know, I think we're seeing some of the worst of that in the United States right now. We're seeing the very negative things that can happen with that. So, you know, I would say political tribalism is mostly a negative thing. It's a lot worse than you would see in consumer commercial. (Interviewee \#17, personal communication, November $12^{\text {th }}, 2018$ )

Why is this the case? As was hinted at earlier, the stakes are typically lower and emotions usually do not usually run as high when it's a matter of commercial brands as opposed to political brands (be they the parties or the individual politicians themselves). Interviewee \#16 is on the same page, as can be seen when he explains that,

Well, I mean, people in the commercial context talk about tribalism all the time, in the sense is that we're trying to find something, common values, common interests, shared interests that binds people together that we can use to create real strong engagement and then, ultimately, evangelicalism, where they can go out and brag about their adherence to Starbucks or whatever to their friends and try to widen the circle. I think tribalism in the political context has a different meaning. And it's gone to a fairly dark place in the last few years, in the sense that it's about polarity and it's about divisiveness and, you know, competing visions. I don't think that people who are tribal in the sense of, they really, really love Starbucks really, really hate people who go to Tim Hortons. It doesn't have the same connotations in the commercial context that I think it does in political. (Interviewee \#16, personal communication, November $8^{\text {th }}, 2018$ )

Returning to the crux of the latter part of the discussion on tribal marketing entails

fleshing out whether or not the interviewees thought that that term is used in a similar fashion in both the commercial marketing and political marketing realms. Interviewee \#32 helps us navigate back towards such a discussion when he notes that, "I don't think they are interchangeable" (Interviewee \#32, personal communication, January $31^{\text {st }}$, 2019). He elaborates on his thinking by explaining that,

I think there's some common overlap[s], but I don't think that how you segment a commercial one of the tribes are necessarily the same for politics, because there can be brand loyalties and appeal that cross some political thresholds. Political tribes are probably a bit more [...] not permanent, but harder to dent. I don't think people change political tribes so much, but I think, [with] commercial tribes, people can change more often. (Interviewee \#32, personal communication, January $\left.31^{\text {st }}, 2019\right)$. 
He then walks us through a particularly Canadian example that exemplifies how commercial tribes typically ebb and flow much more freely than do political tribes. For instance, he recounts how,

I mean, just as an example, I mean, if you look at most countries, unless they do really badly, most political parties keep 30 to $40 \%$ of the vote. Bad elections: 30 ; good elections: $40-45$. The great thing I always recall was [...] was it twelve years ago? It might be longer now. Research in Motion (RIM), which manufactured the BlackBerry, and Apple had almost equal share prices. Today, Apple share prices are a hundred times the price of RIM. BlackBerry's [...] been destroyed. At the time [emphasis in original] when the BlackBerry was out, it had a tribe. It was business people. No [emphasis in original] business person [...] it was a sign that you were in business. People didn't have them just for fun. It was the sort of business sign, like a Rolex watch is for rich people. And, everyone had them. So, there was a very strong BlackBerry tribe. [Then] the iPhone came along and [...] everyone had an iPhone. Twelve-year-olds now get an iPhone. So, there's an example of how you can have massive change with your commercial tribes, but less-so with political tribes. Not totally. There are some political parties that do go extinct, but I do think that the history is that most political parties over 40 or 50 years have actually maintained reasonable levels of support within their terrain. (Interviewee \#32, personal communication, January $31^{\text {st }}, 2019$ )

Yet even though political tribes are generally more stable than their commercial counterparts, they face challenges that were not as acute even in the relatively recent past. Interviewee $\# 6$ walks us through the challenges of the terrain faced by political marketers when attempting to craft and maintain their tribe(s) as he notes that, "And I think that parties are banking on it a lot. But it's increasingly difficult, because there used to be a lot more identification people had with parties" (Interviewee \#6, personal communication, October $\left.17^{\text {th }}, 2018\right)$. For example, as he explains it,

They were Liberals, they were Conservatives, and they always were. But you're seeing that really, really down in Canada, and you're seeing that in a couple of recent provincial elections [...] people who have voted for one party or another for perhaps all of their lives - are now shopping around. So, that loyalty is even harder than $[\ldots]$ it is much harder to maintain than it used to be [here] in Canada. Whereas, in the United States, you still see, you know, partisanship is still very, very entrenched. Whereas here, here you wouldn't really think about it too much 
if your daughter or your son married someone who was from a different party. You wouldn't; it really wouldn't be something you'd think about too much. Whereas, in the United States, they've done polls on it and, you know, there's been people who say, you know, they would be upset if their child married a Republican or a Democrat - it's much further entrenched there than it is here. (Interviewee \#6, personal communication, October 17 $7^{\text {th }}, 2018$ ).

Interviewee $\# 1$ offers an important consideration for us by stating that, "I think [that] even though people are polarized, tribes will change, right? I think that there's less of a relationship in politics. There's less ownership. We expect less of them" (Interviewee \#1, personal communication, September $\left.12^{\text {th }}, 2018\right)$. Interestingly, Interviewee $\# 1$ also provides us with an opinion on the ebb and flow of tribal marketing that contradicts that just provided by Interviewee $\# 32$ when he reasons that, "I think the cult of politics will shift more rapidly than the cult of products" (Interviewee \#1, personal communication, September 12 $\left.2^{\text {th }}, 2018\right)$.

Shifting from the matter of tribe stability back to whether or not tribal marketing is interchangeable between the commercial marketing and political marketing contexts, Interviewee \#8 argues that, "I would say they're probably pretty close to equivalent. Your party membership would be your brand tribe, in many respects $[\ldots]$ your campaign team, your workers, and yeah, elements of your base" (Interviewee \#8, personal communication, October $\left.30^{\text {th }}, 2019\right)$. Interviewee $\# 23$ takes a different approach to this subject by beginning his response by way of an example, but arrives at the same conclusion, as is clear when he states that, when it comes to tribal marketing, "I think of Apple immediately" (Interviewee \#23, personal communication, December $\left.5^{\text {th }}, 2018\right)$. He reveals his rationale by explaining that,

We have these brands, tribes where people become early adopters. Well, Apple is the easiest to kind of jump all over. And those early adopters become defining. And I think that in politics, it's a little bit different, in that it's simpler. I guess 
maybe it's the same. It's a simple metric that says this is who I belong to. This is what I am. (Interviewee \#23, personal communication, December $5^{\text {th }}, 2018$ )

However, he makes an important point when discussing such tribalism, that being that,

In corporate tribalism, you actually tend to know more. Whereas in political tribalism, you don't know very much. You know who your team is, right. So political tribalism has more to do with like cheering for a sports team than it does with, you know, my team's the Conservatives. Go Conservatives go. Whatever the Conservatives say, I believe in. And it's hard to move away from that tribalism, in the same way that, you know, the Flames scored nine goals, yeah, go Flames! (Interviewee \#23, personal communication, December $5^{\text {th }}, 2018$ )

Interviewee \#5 also holds that tribal marketing is interpreted similarly between the

commercial and political marketing contexts when he notes that, "I think it's called different things, but I think any political party that knows what they're doing has a very good understanding of who their target voters are and what the buttons to push on them are" (Interviewee \#5, personal communication, October $12^{\text {th }}, 2018$ ). Interviewee \#33 concurs, arguing that pushing the buttons of tribe members can be an easily accomplished and immensely effective tactic:

Well, look, every brand would love to have a tribe. And it's a really difficult thing to do and I've heard people say tribal marketing, I heard people say spreaders of the Gospel of a particular brand, and Apple is a great example of that. Apple fan people and they love that brand, love, love, love it [emphasis in original] and then will buy practically anything they put out. So, any marketer would love to do that. Whereas in politics, it almost feels like it's a little easier to generate that. It's like, in other words, it's always just lying a couple of millimeters below the surface and you just have to go and just spark it up a little. (Interviewee \#33, personal communication, February $4^{\text {th }}, 2019$ )

In essence, here Interviewee \#33 expresses a line of thinking that was voiced by a number of respondents earlier in this chapter, and which can be used to sum up much of our discussion on tribal marketing: that both commercial marketers and political marketers strive to craft consumer tribes or brand tribes, but that it is typically easier to do so and to mobilize those tribes in the political context than in the commercial context. That finding 
is closely in line with what was hypothesized in $\mathrm{H}_{2}$ : political marketers are better suited than commercial marketers to craft and mobilize tribes due to political marketers' longstanding experience with mobilizing the small but energetic segments of the populace needed to win elections.

To pivot to the following chapter which examines the technology conduit of influence and how the use of technology is another area in which the potential bidirectional flow of influence and innovation between commercial and political marketers can be witnessed, Interviewee \#17 offers some serious food for thought on the claim that data-based microtargeting strategies fuel tribal marketing for good or for bad:

I think, at some point, people have to be accountable for their own actions, right? So, certainly, political parties are guilty of, you know trying to fire up their supporters and targeting them on these volatile issues, you know, immigration (in the United States) is the obvious example, right? Getting people all inflamed about this. When really, I think the issues that they're usually talking about are tinkering at the margins, right? Nobody's actually suggesting any huge changes. But they just use these examples to rile each other up on both sides. It's really inflammatory; and it's really bad for any sort of meaningful discourse. (Interviewee \#17, personal communication, November 12 $2^{\text {th }}, 2018$ )

In sum, this rather lengthy chapter played the important task of laying out the respondents' thoughts on a number of specific marketing strategies and tactics which, from my perspective, could be seen as areas that showcase the bidirectional feedback loop of influence between commercial and political marketers and which hint at the likelihood that political practitioners are ahead of their commercial counterparts regarding certain matters in the art of marketing. 


\section{VI \\ Technology Conduit Findings}

This chapter picks up where the previous results chapter left off. That previous chapter examined the so-called Marketing Conduit of Influence and dealt with the interviewees' thoughts on a few marketing strategies and tactics that are indicative of a bidirectional feedback loop of influence between commercial and political marketers in opposition to the unidirectional flow of influence from commercial to political marketers which is a hallmark of the lion's share of existing scholarly literature on the subject of political marketing. This new chapter examines the Technology Conduit of Influence and pays particular attention to a number of technology-dependent practices and tactics that also highlight instances wherein political marketers are influencing the thinking and practices of commercial marketers rather than the other way around.

The structure of the chapter accomplishes that task as follows. First, attention is directed towards the increasingly important process of microtargeting and, specifically, to how political marketers are out-innovating their commercial marketing counterparts on this matter. Second, the focus shifts to how, when it comes to targeting, political marketers are often able to do more with less than are their commercial marketing colleagues. Put differently, political marketers practice targeting with a greater sense of discipline and efficacy than do commercial marketers. Third, the impact of speed as a force for marketers to contend with (and its amplification by technology) is examined, paying particular attention to the subject of targeting and to how political marketers are more accustomed to contending with speed than are commercial marketers. Fourth, consideration is given to the "dark side" of targeting and the technology that it relies upon with emphasis upon the appropriateness of fit for the particular campaign being run, 
on privacy, and on how the use of technology primarily for targeting purposes may be having an adverse effect on voter loyalty thus creating voter apathy.

\section{The Ebb \& Flow of Microtargeting}

As discussed in great detail in Chapter III, microtargeting is an essential component of the current incarnation of data-driven political campaigning and, as such, it represented a substantial portion of the discussion in the interviews that this dissertation relies upon for its primary research component. Relatively early on in the journey from open to focused coding, it became clear that both commercial and political marketers practice the use of microtargeting, or "targeting" as most interviewees referred to it. However, the way and the extent to which they do so varies - a fact that will be unpacked shortly.

While most interviewees were quick to point out that what can be thought of as microtargeting began life in the realm of commercial marketing before being imported into political marketing, the majority of interviewees in my sample thought that political marketers were ahead of their commercial counterparts in the practice of targeting. Put differently, it was felt that political marketers are practicing more sophisticated targeting. Interviewee \#2 offers a concise but revealing point of entry into this discussion in claiming that, "Political marketers have been very good at using demographics and attitudinal research in targeting messages and I think commercial marketers have perhaps learned that to some extent from them" (Interviewee \#2, personal communication, September $\left.24^{\text {th }}, 2018\right)$. Interviewee $\# 25$ adds that, "If I had to give you one place where

political is really beating commercial, it's on the one-to-one targeting level, because it's 
vital in political and nice to have in commercial" (Interviewee \#25, personal communication, January $\left.15^{\text {th }}, 2019\right)$.

To use the words of Interviewee \#25, the reason that one-to-one targeting (a.k.a. microtargeting) is "vital" in political marketing but merely "nice to have" in commercial marketing has to do with the availability and role of money in the two different realms a distinction that will be thoroughly discussed shortly. But, before embarking upon that discussion, we need to devote more attention and time to the essential argument that, when it comes to targeting, political marketers are ahead of their commercial counterparts. Interviewee \#28 helps with that matter by explaining that,

We generally have a better sense of our customers or our voters, and we do everything we possibly can to reach them during that period of time. So, there's a lot less of general advertising and more trying to find very specific groups of people, in politics and doing everything you can to reach them. (Interviewee \#28, personal communication, January $28^{\text {th }}, 2019$ )

Interviewee \#23 paints a much more vivid picture of this matter and draws our attention to the art of the pitch in stating that,

I make my living selling this to corporations, right? So, when I go in and try and sell micro-targeting to corporations, holy fuck [emphasis in original] they shit themselves. They absolutely shit themselves. And they were so afraid they were going to be caught doing something that was political, that they wouldn't do it. Now, when I repackaged it, and changed the name, you know, targeted communications or whatever the hell I turned it to, doesn't really matter, but then they would start to buy in. But they were hyper, they were very skeptical of these political techniques, and being caught doing something that was seen to be political. So, I think that what happened is, and on top of that, there isn't a marketer in the world that doesn't want to believe that their ideas are completely unique and original. (Interviewee \#23, personal communication, December $5^{\text {th }}, 2018$ )

The risk aversion in commercial marketing that was discussed earlier in Chapter $V$ clearly rears its head again here and is dissected by Interviewee \#23 as he walks us through how his typical meetings aimed at repackaging and selling microtargeting to corporate commercial clients would go: 
And I fly into Toronto, and I start talking to them about micro-targeting, and the woman who ran their MARCOMS (marketing communications team), said this is what we've been doing for years. And I'm looking at what they're doing, and I'm like, you guys don't have a data system to save your fucking lives. You don't have a big data structure, you don't have, like you call it micro-targeting, you can call it targeting, but what you're doing is you're using big, broad demographics, and targeting a big demographic. Which is true, that has been done forever. What was new was targeting the psychographic model, right? How people will respond to a specific piece of information. And that was pioneered entirely in politics and brought over. (Interviewee \#23, personal communication, December $5^{\text {th }}, 2018$ )

A similar — yet arguably less emphatic — perspective is voiced by Interviewee \#17. For example, he notes how, "I think, you know, there's a lot of good stuff that comes out of political campaigns. One of them is the relentless focus on data, that I think a lot of businesses are slowly starting to get onboard with" (Interviewee \#17, personal communication, November $\left.12^{\text {th }}, 2018\right)$. He shines some much needed light on how the use of microtargeting is one such strategy that businesses are "slowly starting to get onboard with" by explaining that,

I think there's a lot of companies who have figured this out. But, there are still, you know, 90 to $95 \%$ of businesses who want to do Facebook advertising and have no idea what they're doing. And they're doing stuff like, you know, hitting "boost" on a post, and thinking that's going to get them Facebook advertising, or get them results from Facebook advertising. When, really, there's so much more to it. (Interviewee $\# 17$, personal communication, November $12^{\text {th }}, 2018$ )

He expands upon this by likening many commercial marketers and the clients that they represent to stumbling around in the proverbial dark which characterizes the post-mass marketing world that we are now arguably living in and which was described in Chapter II. For instance,

They don't know how to target audiences; they don't know how to set up a proper sales file; they don't know how to, you know, actually find people who are going to get sales. They don't know how to make sales online [...] It's all just like broadcast. So, I think the people who know how to do this have a huge advantage. We've seen some examples of that, you know, like Dollar Shave Club, and Harry's, for example, who have absolutely cut into Gillette and all these other huge companies who have dominated the razor market forever [...] These guys came in and would, 
you know, [with] a little bit of viral marketing and really good digital advertising, just caused a huge headache for Gillette [...] Gillette's still fighting back, right? Like, they've got their own razor program now, but there's so many people who have never made the switch back. [...] So, you know, I think - especially if you're a small or medium sized business - you can be extremely successful if you use this stuff properly. (Interviewee \#17, personal communication, November $12^{\text {th }}, 2018$ )

Turning our attention back to Interviewee $\# 25$ adds further depth to this conversation and, in particular, to how political marketers are likely ahead of their commercial marketing counterparts in terms of the alchemy, science, or art of microtargeting. For example, as he puts it himself:

I think maybe the most common belief [is] that [...] political, in many ways, is seen to be kind of following commercials. But I think there's one specific place, actually, where it really does excel. That is where you're targeting a specific dataset of individuals and not relying on look-alike modeling. And the reason is that if you're selling Q-Tips, it doesn't really matter if you're talking to-- well, look-alikes are perfectly fine. But if you're selling a candidate or an issue, it really does make a difference if the person is a likely voter or not a likely voter, and the two look alike. A likely voter looks just like a not-likely voter. So unlikely voters are often worthless to me. And I spend a lot of time [...] people in my space spend a lot of time figuring out how to cut those two universes apart and only talk to the people that matter based on their voter file. (Interviewee \#25, personal communication, January $15^{\text {th }}, 2019$ )

Much of this stems from the fact that voters are hard to identify - a fact that is compounded in an era that is increasingly characterized by "secret voters" or "silent voters" who choose not to vote for the candidate for whom they told pollsters, colleagues, friends, and family members that they would vote (Bedard 2017; Ellis, 2018; Zito \& Todd, 2018). Interviewee \#2 shines some light upon these secret/silent voters and why they are more likely to be found within the political polling rather than the market research context by explaining that,

You know, I think, if you're asking people about do they like Coke, or do they like Pepsi, that's a pretty straightforward question. But, it's very difficult when you have substantial changes in the electoral process and in things like the rise of populist leaders like a Trump, where people will may not want to admit that 
they're going to vote for him and then vote for him. (Interviewee \#2, personal communication, September $24^{\text {th }}, 2018$ )

But consumers are hard to identify too. For example, as Interviewee \#23 puts it:

And in terms of corporations, I don't think most corporations even know who buys their product $[\ldots]$ and even the retailer, I mean, we give them our postal code, or we give them our credit card information or whatever, but I'm not sure it's tracked the way we would track it. (Interviewee \#23, personal communication, December $5^{\text {th }}, 2018$ )

At this early point in the discussion of the so-called technology conduit, Interviewee \#23 also gives us an important distinction that should be kept in mind before diving deeper into the more specific technology-centric examples of how the flow of influence and innovation between commercial and political marketers is operating as a bidirectional feedback loop. That distinction or, more accurately, that dividing line (regardless of whether or not it is easily drawn) is between what he calls "Visible Technology" and "Invisible Technology." To contextualize that discussion, the distinction came out of a very wide-sweeping open-ended question wherein I simply asked: "What role do you think technology is playing in political campaigning?" With that on the table, Interviewee $\# 23$ responded "Oh, huge roles." But that is not where our interest lies. Instead, it lies with what he said next.

There's visible technology, and then there's invisible technology. So, the visible technology, the stuff that we're doing right now with, using Facebook, targeting communications, targeting ads, everything is moved from television to digital. We're seeing it time and time and time again. And so that visible piece is very big. The invisible stuff, the data stuff that's going on, like what's happening with databasing, predictive, you know, artificial intelligence, and how we're now modeling how decisions [that] are being made, how we're predicting specific outcomes, all of that is invisible to the general user, but it is massive. Like in technology, you have a team of data scientists now, working with you to make sure that, you know, everything kind of goes the way you want it to. (Interviewee $\# 23$, personal communication, December $5^{\text {th }}, 2018$ ) 
With this in mind, one could argue that the "visible technology" is only visible in the sense that an iceberg is visible in that a small portion of it can be seen on the surface of the water by the naked eye, but the rest of it - the more substantial and significant portion of it - lies submerged beneath the surface and thereby out of sight. For example, while many voters and potential voters are aware that political parties are utilizing mainstream social media platforms like Facebook, Instagram, and Twitter (a.k.a. the "Big Three") for numerous aspects of political campaigning ranging from advertising to voter outreach and everything in between, they don't see the scope and scale of those efforts. Nor do voters grasp what is truly entailed — despite the fact that the widespread media coverage of Cambridge Analytica's illicit data scraping and other tactics in the 2016 U.S. presidential election placed the relationship between political campaigns and social media platforms on the public's radar. Furthermore, the Big Three social media companies (and many of the smaller players as well for that matter) operate by the black box logic of revealing as little of their innerworkings as possible to the general public, be that anything algorithm-related or concerning the methods and organizational structure that they instill to manage the means to those ends (Ghonim \& Rashbass, 2017; Leetaru, 2019; Rogers, 2019). Additionally, when it comes to objectively quantifying what is really and truly, in the words of Interviewee $\# 23$, "invisible to the general user," there is ample wiggle room and very little uniformity in any honest answer to that question.

With these facts in mind, I thought it was necessary to slip a strategic probing question into the discussion with Interviewee \#23 to flesh out more detail on the distinction between visible technology and invisible technology. Consequently, I asked: "And do you think both the invisible and the visible use of technology you're describing 
[...do] you think it's given the same proportion of importance on the commercial versus the political side? Or is one given more importance than the other, if you're looking across those two realms?" After a sober pause, he responded in the following manner:

Again, I can only go with what I've seen. I'd love to be able to see into how, like a large grocery store, is using their data sections. But you know, what I could see when I was working with others was they weren't using the data. Like if I had access to every purchase that a person had made in the last, you know, 20, 30 years, I'd be using it so much differently than they were using it. I mean, they were using it predictively, to sell the products, but they're not using it as predictively as we would have. Like they're not digging into it the same way we would have. Like modeling the values and understanding what was behind it all. (Interviewee \#23, personal communication, December $5^{\text {th }}, 2018$ )

In other words, in the eyes of Interviewee \#23, commercial marketers have not been extracting the full potential of the possible insights provided by the data that they have been acquiring for decades. In this vein, he adds that, "they're just looking for more, they're not looking to understand it, they're looking just to sell. And I think that's kind of a difference. We were always looking to understand" (Interviewee \#23, personal communication, December $\left.5^{\text {th }}, 2018\right)$.

With that "difference" or perhaps more appropriately that disconnect in mind, Interviewee \#23 provides us with another striking example of the lack of interaction between commercial marketers and political marketers that Interviewee \#16 spoke of earlier and which, unfortunately, can be seen as characterizing much of the marketing landscape. For instance, he maintains that,

I think the commercial markets, I mean, I've gone to the commercial marketing segments, and maybe what they're better at is branding things. Like they came up with way better language, I went to a commercial digital conference after we'd been doing digital for years, and they came up with way better language around what they were doing, you know, predictive modeling, can't remember what they were called, but I spent half of the conference going, I don't know what the hell they were talking about. But when I looked at what they were doing, we'd been doing it for years. And not only had we been doing it for years, but we continued to push. (Interviewee \#23, personal communication, December $5^{\text {th }}, 2018$ ) 
However, this particular passage tacitly offers a reminder that, while the lexicon of commercial marketing and political marketing may not be totally interchangeable, the strategies they use may be close to it and, when it comes to microtarget modeling, the political marketers have the edge.

Interviewee \#33 helps illuminate how, in relation to microtargeting, political marketers have the edge over their commercial marketing brethren. For instance, he explains that,

The one other thing I would say that the commercial people want to learn from the political people $[\ldots]$ is the data targeting that we use. And the fact that we start with a voter list is always very helpful. But the fact that they [political marketers] are identifying their potential customers by name, $[\ldots]$ is an incredible benefit because then you can go get them [...] we handle data ruthlessly [and] I think they [commercial marketers] envy [that]. (Interviewee \#33, personal communication, February $4^{\text {th }}, 2019$ )

Similar to the detailed conversation offered courtesy of Interviewee \#16 when discussing relationship marketing in the earlier marketing conduit, here Interviewee \#33 highlights the fact that, under most circumstances, the majority of commercial marketers do not know their customers by name, especially when selling smaller ticket (i.e. lower-priced) items. As in that earlier discussion, the reason for this is that smaller ticket items do not generate the same quantity of paperwork and therefore the same volume of data as when acquiring bigger ticket items like a house or a car — and that, of course, severely limits commercial marketers' ability to microtarget. But is it the case in politics?

As is hinted at by Interviewee \#33, political marketers have access to a voter file that includes granular data about such issues as who is registered to vote and who voted in past elections, which can be combined with commercially purchased data recording 
individual consumer purchases and preferences. Interviewee \#28 highlights the fundamental importance of the voter file by taking a step back and moving from the general to the specific. But first the general, which is that, quite simply, "Technology is really the foundation of essentially everything that's happening in politics" (Interviewee \#28, personal communication, January $\left.28^{\text {th }}, 2019\right)$. He then transitions to the specific by explaining that,

What you're looking at [...] technology and data, looking at them together, because everything that campaigns do is based off of the voter file and real-world actions and reactions to the voting outcomes [...] And building this in-depth picture of the electorate and figuring out who you need to talk to in order to win elections. So, for decades, at this point, everything has been centered around utilizing the voter file in the most appropriate manner to reach the exact voters you need to win your election. And, that's just so unbelievably central to every campaign, because it's out there, up-and-down ballot, and it's not just all the uproar that we've heard after Cambridge Analytica and people being concerned about how data is being used in the digital world. This is the same voter file that is powering direct mail, phone calls, all the way down to the individual canvassers who are knocking on peoples' doors asking you know, if you support this candidate or not. (Interviewee \#28, personal communication, January $28^{\text {th }}, 2019$ )

Interviewee \#31 helps clarify why the voter file is so essential in political campaigning and how it is used therein:

I think at this point, any serious marketer is not going to be operating without a certain suite of technologies. And there are different brands or different companies that are providing them, but everybody I think that is serious is going to have a CRM [Customer Relationship Management system]. Everybody who's serious is going to have relationships with different data vendors. I mean, this is another area where as political marketers, we have our own primary data sources that we go to like voter files. But we measure [...] we marry those up with commercial marketing databases in order to build out profiles and do audience modeling and audience targeting. (Interviewee \#31, personal communication, January $30^{\text {th }}, 2019$ )

Returning to Interviewee \#28 helps flesh out this discussion by way of an example. For instance, as he puts it:

On the political side, I mean, you're just looking at how you can influence specific groups of people, and you have so many different sections that you're looking at 
that are modelled out on top of the voter file. You know, whether it is a group of people who care deeply about women's health issues, or environmental issues, or anything like that [...] so, looking at that cohort and what messages would resonate to them, and producing different creative specifically for them versus for the general population. (Interviewee \#28, personal communication, January $28^{\text {th }}, 2019$ )

Again, as with the majority of the discussion thus far in the technology conduit concerning the interplay between political marketers and commercial marketers, microtargeting is the modus operandi. The voter file, and the data that it consists of, is the means to that end.

In keeping with a key finding at this point, Interviewee \#24 offers the opinion that political marketers can teach commercial marketers a thing or two about data-driven microtargeting. For example, as he puts it:

Taking some of the hyperlocal targeting that we do in campaigning, from a geographic standpoint and from a demographic standpoint, and injecting that into the market, the business side, can certainly be something that can be had. Right now, I suspect on the business side, it's more of a [...] they take a more global approach, right. They've traditionally been buying TV ads for a DMA [Designated Market Area], right. So, no one in politics, I mean unless you're running for governor or something, buys TV ads by DMA. You're now in a very hyperlocal cable TV, digital targeting kind of a universe. And those big concepts ads are farther and farther and fewer between. (Interviewee \#24, personal communication, December $27^{\text {th }}, 2018$ )

That said, Interviewee \#30, a long-time Washington-based Republican political marketer and digital advertising specialist, offers us an important reminder regardless of how granular the data on hand is and how intricately it is used: "But, again, I think there is a stubborn sort of resistance to accepting that reality might exist outside the voter file" (Interviewee \#30, personal communication, January $30^{\text {th }}, 2019$ ). The most vivid example of that "stubborn resistance" is Hillary Clinton's ill-fated 2016 presidential campaign and its overreliance on data-based microtargeting at the expense of retail campaigning which was discussed earlier in Chapter III. Furthermore, we must acknowledge the undeniable 
fact that, due to stricter privacy laws on this side of the $49^{\text {th }}$ Parallel, the practice of microtargeting is more fertile in the United States than in Canada. Consequently, Canadian voter files contain far fewer metrics or data points than their American counterparts - a fact that will be discussed at length later in this chapter.

\section{Discipline \& Efficacy of Targeting}

Nonetheless, the commercial marketers' "envy" of the data and its use by political marketers that was referenced by Interviewee \#33 exists here in Canada as well. Much of it hinges upon what Interviewee \#7, a former Conservative Party of Canada strategist and hybrid marketer, deems political marketing's "efficacy of [the] dollar" (Interviewee \#7, personal communication, October $\left.25^{\text {th }}, 2018\right)$. Essentially, that efficacy of the dollar refers to the fact that political marketers generally have to stretch the reach of a dollar further than their commercial marketing counterparts who have much larger budgets for their campaigns. And, as Interviewee \#7 explains more thoroughly, the efficacy of the dollar is particularly acute in the Canadian context since,

The solution in the United States is always just more artillery, right? Get more money, and spend more money and, by the way, spend it this way. In Canada, it's [...] how do you manage scarcity? I only have a dollar. How am I spending my dollar? In America, the answer is: go and get a second dollar. (Interviewee \#7, personal communication, October $25^{\text {th }}, 2018$ )

Interviewee \#23 reminds us of the importance of money in crafting and curating the data that microtargeting relies upon by stating that, "it's a constant investment, and when you constrain the money in politics, as we've done in Canada, you don't have enough money to constantly stay on top of your data structure" (Interviewee \#23, personal communication, December $\left.5^{\text {th }}, 2018\right)$. This all important - and often overlooked - 
issue of data maintenance and the difficulties it raises will be discussed a little later in this chapter.

The importance of money as a key factor in determining the effectiveness of the use of data-based microtargeting is clearly and concisely captured by Interviewee \#10 when she states that, in relation to targeting and the use of technology, "It all revolves around the amount of money available" (Interviewee \#10, personal communication, October $\left.30^{\text {th }}, 2018\right)$. Interviewee $\# 33$ offers a similar perspective in claiming that, "let's be honest, I mean, a political campaign doesn't run on issues; a political campaign runs on money" (Interviewee \#33, personal communication, February $4^{\text {th }}, 2019$ ).

In essence, less money available for targeting potential voters (or customers, if we're talking commercial marketing) means that marketers have to put more emphasis on learning who their potential supporters are and therefore must work to derive more granular data and, equally as importantly, they must seek to gain more meaningful insights from the data they do acquire - which is no easy task. Returning to Interviewee \#33 sheds some much needed light upon this matter when it is explained that,

Campaigns $[\ldots]$ and traditional clients are willing to put more money into data crunching. But I think the big disconnect is you've got your data management and your data crunching, and I think there's a promise of insights from that data [...] But getting those insights from that data is I think where people are selling snake oil and also there's a great misunderstanding as to what we're really getting for our funds. (Interviewee \#33, personal communication, February $4^{\text {th }}, 2019$ )

Interviewee $\# 23$ offers a look at the flipside of the coin: big commercial brands that consistently have more money on hand for advertising, overhead, payroll, research, testing, and any of the other necessary building blocks of a marketing campaign but which may have a contrarian outlook on the need for targeting. In so doing, he offers us the example of Procter \& Gamble, the Ohio-based consumer goods company whose 
brands and products cover everything from personal hygiene to beauty and family care.

He reminds us to keep a sense of perspective when recalling the beyond the norm (for commercial marketing), politically-charged advertising campaigns recently utilized by Nike and Apple, which were discussed in the preceding chapter, as well as the use of technology to that end. For instance, he maintains that,

I think you're dealing with the exceptional companies. I mean, Nike's always been exceptional. Nike, Apple, you can probably count them on one hand. But where's General Electric? You know, where's, what other major consumer brands can we point to? Procter \& Gamble. Procter \& Gamble isn't creating any new ground; I mean, they're using the tools, but they were very slow to move to digital. (Interviewee \#23, personal communication, December $5^{\text {th }}, 2018$ )

But where do the aforementioned discipline and efficacy of targeting and the purported advantage that political marketers have over their commercial marketing counterparts on that front come into the picture?

But even now, Procter \& Gamble are still one of the big ones, [and] they totally rejected targeted marketing, and now they're going specifically back towards big exposure campaigns. Well, that's what you can do when you've got all the fucking money. The rest of us have to actually focus on people who might want to buy our product. And Procter \& Gamble, I bet there's a Procter \& Gamble in every person's house in North America, if not, you know, so it's just a different model. (Interviewee \#23, personal communication, December $5^{\text {th }}, 2018$ )

Again, money is the link. Its abundance, or its paucity, is often a key factor in determining the extent to which microtargeting is utilized. More money reduces the need to specifically focus targeting solely on those most likely to be receptive to a given message. More money also can allow for the possibility of a message's not resonating or (in the language of numerous interviewees) not "sticking," to be little more than the cost of doing business. However, when you are campaigning on a tighter budget, the fallout from a message's not sticking is much more damaging since there is simply less money to spend on targeting another group in the hope that it will be more receptive to the 
message. In other words, when you have less money to spend in your campaign, you have fewer opportunities to lather, rinse, and repeat your targeting and thus your messaging.

There are, of course, exceptions to this rule. The troubled 2016 Hillary Clinton presidential campaign that we have referred to a number of times throughout this dissertation is the most obvious example that comes to mind. There was no shortage of money on hand in that particular campaign. However, the Clinton campaign spent a great deal of its money in a very different — and ultimately less effective - manner than did the Trump campaign. They spent too much money microtargeting likely voters via TV advertisements and the more traditional advertising mediums, whereas the Trump campaign spent more of its campaign war chest on microtargeting via digital advertising as well as on on-the-ground retail campaigning which kept the ear of the candidate closer to the very voters needed to win the presidency (Halpern, 2017; Allen \& Parnes, 2017; Zito \& Todd, 2018). Furthermore, with that controversial presidential campaign now nearly four years behind us, it is safe to say that, given the anti-incumbent anti-status quo sentiment permeating much of the American electoral landscape at that time, the coronation of an establishment candidate like Hillary Clinton was, in hind sight, clearly a losing proposition.

In sum, money cannot be considered the sole incentive for using microtargeting and practicing it with the greatest sense of discipline and efficacy. Just as important a consideration as the amount of money in a particular campaign is the nature (and ramifications) of political campaigning itself. Much of this has been analyzed in the previous chapter, so it only warrants a mention in passing here. Included in the discussion were the so-called "Briefcase Business" nature of political campaigning and consulting in 
Canada, the zero-sum nature of political marketing compared to commercial marketing, the issue of risk aversion, and the terminal end date associated with political marketing (which is largely absent in commercial marketing), to name but a few.

For the sake of brevity and to minimize the amount of repetition in this dissertation, I will now briefly revisit the zero-sum nature of political marketing since, in addition to money, it was referenced by numerous interviewees as a very visceral motivation for the political marketers' greater discipline and innovative use of technology for the purposes of targeting potential voters in comparison with that seen in the commercial sector. Interviewee $\# 5$ captures the core of this matter by stating that, "It's a zero-sum game, in politics, [and] there's a tendency, I think, a greater discipline in focusing on the people who are truly accessible to you, that is not perhaps as true in commercial marketing" (Interviewee $\# 5$, personal communication, October $12^{\text {th }}, 2018$ ). Interviewee \#16 adds greater detail to this discussion while, at the same time, shining light upon an important difference between political marketers and commercial marketers. For example, he explains that,

In politics target segment prioritization is more disciplined. We still, in advertising in the consumer side, rely very heavily on demographics, [we] rely very heavily on large segments of the population - and it's largely because we work with a lot of mass brands [...] There is this sort of general, like, if she's a soccer mom, this is the minivan for her. Where in politics, it's much more disciplined, and it's literally down to the riding level and one-to-one communication, and past voting behavior and so on. (Interviewee \#16, personal communication, November $8^{\text {th }}, 2018$ )

In essence, the data utilized to craft targeted communication with potential voters can be seen as more detailed and more granular than that utilized by commercial marketers — at least here in Canada. The reason for this Canadian-specific caveat will be addressed later 
in this chapter when considering the differing interpretations of the relationship between data and privacy in the United States versus in Canada.

Interviewee \#16 picks up where he left off and offers us an important but infrequently noted difference between political marketers and commercial marketers by claiming that,

There are those who will argue with me that in CRM marketing and other forms of digital and direct communication, brands are doing the same thing. But, that is generally focused on customer retention. It's not generally focused on acquisition. Whereas, in politics, target segment prioritization is very disciplined for the purpose of acquisition. Retention is almost assumed. If you voted Liberal the last three elections, we're not going to spend a lot of money against you. So, when I say it's more priority and more discipline, it's also because it's more acquisition oriented. (Interviewee \#16, personal communication, November $8^{\text {th }}, 2018$ )

In this era characterized by fickle consumers operating in an ecosystem littered with numerous brand choices for what is essentially the same product or service being sold by their competitors, targeted communication in commercial marketing is often driven by the modus operandi of keeping an existing clientele loyal and thereby not having it slip away to a competing brand - a matter discussed extensively with regards to relationship marketing and tribal marketing in Chapter $V$. In political marketing, however, the modus operandi is expanding the size of one's potential voter pool and then mobilizing that new voter pool in conjunction with one's existing voter pool (i.e. the base) that is already on hand. And, more often than not in political campaigning, the balance of resources whether time, money, or personnel — is directed towards the former (acquisition) rather than the latter (retention).

But, here too, there are exceptions that should be kept in mind. First, the highly polarized political landscape in which most political campaigning currently occurs often appears to be tilted towards mere retention by way of catering solely to one's base of 
supporters — a setback that will be discussed in the aptly titled "Dark Side of Targeting" portion of this chapter. Second, when campaigning for office, one must acknowledge that the line between minimizing the resources spent on retaining existing supporters for the sake of expanding one's supporter pool can easily degenerate into taking those existing supporters for granted - a lesson the 2016 Hillary Clinton campaigned learned the hard way.

The argument could be made that the most significant element of political campaigning which spurs the need to use technology for the purposes of microtargeting with the most discipline and efficiency possible is the speed at which campaigns are run. It is a speed which, at the risk of sounding like a technological determinist, is largely caused by an ever-shortening news cycle, a heightened sense of immediacy due to the proliferation of social media news delivery services like Twitter, and a growing dependency on the technologies required to assemble, run and maintain the microtargeting models in which political marketing campaigns place an inordinate amount of faith. With efficiency in mind and with the results on display thus far, we can see that support for $\mathrm{H}_{3}$, which projected that political marketers are better at conducting data-based microtargeting strategies — and doing so on tighter budgets than are commercial marketers - is starting to take shape.

Before directly addressing speed and its implications, we should take this moment to recap the main points made thus far in this chapter. First, the argument that the increasingly data-driven practice of microtargeting is being practiced more substantially and more intricately by political marketers than by commercial marketers was made. Second, I argued that that more substantial and more intricate microtargeting is bolstered 
by the fact that political marketers typically practice targeting tactics more efficiently and with a greater sense of discipline than do their commercial marketing counterparts. The political marketer's doing more with less targeting approach is largely a necessity dictated by the less well financially lubricated and shorter "from conception to completion" time frame in which political marketing campaigns are run. Both of these points are indicative of the broader bidirectional flow of influence that this study is searching for.

\section{The Impact of Speed on Targeting \& Beyond}

Furthermore, and prior to examining the technology-facilitated side effects of speed on campaigning in general and targeting in particular, it is important to illuminate a less frequently discussed but equally as important component of any discussion on speed in campaigning regardless of whether that campaigning is commercial or political in nature: the time frame in which the money a campaign has must be spent. Simply put, it is about the intensity of the marketing executed by a political campaign compared to a commercial campaign. On this matter, Interviewee \#16 concisely states that, when it comes to comparing and contrasting commercial or political marketing, "The intensity of the marketing is dramatically different" (Interviewee \#16, personal communication, November $\left.8^{\text {th }}, 2018\right)$. He catalogues why that is the case by explaining that,

There are very few consumer advertising brands that will advertise a spend level comparable to what a political party will spend in a very, very [emphasis in original] abbreviated timeframe. And they won't produce nearly as much content in that short timeframe. So, there are categories that, you know, are impulse categories and need to be on air all the time. They've got to be at highways, like McDonald's is a good example of fast food. It still doesn't come close to what a political party will put out there during an election campaign. And, so, that intensity of marketing over a short period of time is a dramatic difference. (Interviewee \#16, personal communication, November $8^{\text {th }}, 2018$ ) 
He then gives us an example from his own work experience, noting how,

You know, when I talk to consumer brands about how much spending we did for the Liberal Party, they're like, 'God, I wish I had resources like that.' Right? Because they have to spend [...] they might have half a million dollars to spend over fifty-two weeks. And political parties will be spending millions per week. So, you know, it's just [...] the order of magnitude is massive. And, you know, and the media investment can differ. I think [...] well, it's really what I just said, in terms of the, you know, the investment being concentrated heavily during a short period of time. (Interviewee \#16, personal communication, November $8^{\text {th }}$, 2018)

To put this another way, the total volume of money that a political marketing campaign may have on hand is often drastically less than the total volume of money a commercial marketing campaign may have available for a particular campaign. However, given the compressed time frame in which political campaigns are organized, run, won, lost, and dissolved, compared to their commercial counterparts political marketing campaigns have the necessity (or luxury, depending on your perspective) of bombarding potential voters with a much higher volume of messaging over a much shorter period of time than does the typical commercial marketing campaign.

Since speed was discussed at length in the previous chapter with respect to its differing interpretations and implications for political or commercial marketers and as to which of the two has the competitive edge in adapting to the unrelenting speed that characterizes campaigning in the twenty-first century, the discussion here will be brief and will focus solely on the link between speed and technology. Interviewee \#33 initiates that discussion by stating that, quite simply, "Every cycle gets faster from the technology" (Interviewee \#33, personal communication, February $4^{\text {th }}, 2019$ ). He gives us an example of this evolution in speed by adding that,

We've gone from a week to produce a TV commercial to we've got to do one today [inaudible] the polling today if we need to. And then the dealing with like 
you said the things that pop up from social messaging or an unforeseen problem. (Interviewee \#33, personal communication, February $4^{\text {th }}, 2019$ )

Here he echoes the comments of a number of other interviewees who also spoke about the impact of the shortened time frame (courtesy of new technologies) upon crafting creative, a subject matter examined in Chapter $V$.

Interviewee \#10 frames this discussion of the increasingly close-knit relationship between technology and speed by stating that, regarding political marketing, "Everything is very fast. It's very fast. [And] I think it's definitely increased. I mean, it's increased because of technology" (Interviewee \#10, personal communication, October $30^{\text {th }}, 2018$ ). Interviewee $\# 26$ adds more to this conversation by explaining that,

Speed is incredibly important. It is [...] yes. It's [campaigning] defined by that, plus the level to which news and communications has sped up in general. It started off with the 24-hour news, back in the late 80 s and early 90 s, and now has accelerated with Twitter and Facebook. (Interviewee \#26, personal communication, January $23^{\text {rd }}$, 2019)

Harkening back to the discussion that was had in the preceding chapter, Interviewee \#29 notes how, "Well, speed is important because the news cycle moves so quickly. Sure. Because now, with social media, the news never stops" (Interviewee \#29, personal communication, January $29^{\text {th }}, 2019$ ).

As discussed earlier, while this undoubtedly creates immense pressure on marketers, it also creates great opportunity - if one is able to strike while the iron is hot. As Interviewee \#2 put it, with the host of web-based communications technologies that are undeniably tools of the marketing trade (be that commercial or political), "The ability to respond quickly — and now I'm thinking about this in terms of marketing, right? has increased dramatically with the advent of technologies" (Interviewee \#2, personal communication, September $\left.24^{\text {th }}, 2018\right)$. Interviewee $\# 17$ draws our attention to some of 
the opportunities for marketers that technology-enabled speed presents by explaining that,

But, you know, social media has made a big difference. You know, we talked about the speed at which things happen. So that's obviously one example. I would say the ability to do testing (A/B testing) and test messages, [and] float trial balloons $[. .$.$] you know, these are things that you used to do by saying something$ stupid to a reporter and hoping that they would say it and then like waiting a week to see what the editorials say about it. Right? (Laughs) Now you can go and run an ad set for say, you know, twenty-four hours and get meaningful results. So, that's interesting as well. Definitely on the CRM side, the database side, the degree to which we can track supporters and actually interact with them in a meaningful way has grown. (Interviewee \#17, personal communication, November $12^{\text {th }}, 2018$ )

In essence, with the discussion of speed in both this and the previous chapter, a picture of political marketers besting their commercial marketing colleagues by way of outinnovating their commercial counterparts under the increasingly time-sensitive constraints of the current environment in which marketing campaigns are executed is becoming ever clearer. Consequently, support for $\mathrm{H}_{1}$ which, as seen in Chapter III, posits that political marketers are more comfortable than are commercial marketers with the speed at which successful marketing campaigns must be run is firming up.

Prior to shifting away from the light side of microtargeting and commencing our necessary discussion of the dark side of targeting, it is worthwhile to take a moment to summarize the key findings made in the technology conduit thus far. First, most interviewees felt that political marketers are practicing more sophisticated targeting than their commercial brethren. Second, the shorter time frames in which political marketing campaigns are run and the higher intensity of those campaigns require political marketers to develop and execute leaner and meaner marketing campaigns than their commercial counterparts. In essence, political marketers have long had to do more with less than have 
commercial counterparts — and they have had to do it faster than commercial marketers. These are important attributes that should not be overlooked.

\section{The Dark Side of Targeting}

No discussion of microtargeting can be focused solely on the attributes of the operation itself or on the elegance with which the craft is applied by both commercial and political marketers. There are consequences to everything in life, and microtargeting is no exception to this rule. Therefore, in the spirit of balance and transparency, this section sheds light upon what could be labeled the dark side of targeting — targeting itself being a practice which is anything but transparent in nature due to the secrecy with which most commercial and political marketers alike ply their craft and also due to the fact that much of the inherent practice of targeting (no matter its granularity and efficacy) happens well out of sight of the average voter or consumer.

\section{Silver Bullet Wishful Thinking}

It is important to point out that microtargeting is not a sure thing, nor is it even required in every political race without exception. It may be a useful tool in the modern political campaigner's toolbox, but sometimes it is a tool that may not fit the particular electoral landscape in which a given race is being run.

Microtargeting is undeniably important in marketing (be it commercial or political in nature) and a large number of the respondents in this study hold the belief that political marketers are currently practicing more advanced targeting than are their commercial counterparts. Yet Interviewee \#29, a seasoned American progressive political activist, digital strategist, and Democratic political consultant offers us an important consideration to be borne in mind when thinking about targeting in the political context. It is simply 
this: there is no "one size fits all" approach to microtargeting and, sometimes, it may not fit at all. For example, when speaking about the role of microtargeting in the context of the recent 2018 U.S. Congressional midterm elections, she remarks that, "Well, the larger races do that [microtargeting]. But, [in] the wave election, like we just had, what happens on the edges doesn't really matter so much" (Interviewee \#29, personal communication, January $\left.29^{\text {th }}, 2019\right)$. In essence, Interviewee $\# 29$ reminds us that microtargeting cannot change the fundamentals of an election or its momentum. Instead, microtargeting works best when the elections are closely contested (Baldwin-Philippi, 2017; Munroe \& Munroe, 2017).

When the fundamentals of an election are flawed — such as when a candidate is inherently unpopular - and when a candidate or party has the electoral momentum due to either a particularly visceral socio-political landscape in which that specific race is being run, or when voters are operating with the intention of replacing the status quo no matter what the consequences, microtargeting cannot prevent the inevitable. Interviewee \#5 offers a similar and concise perspective in positing that: "Technology is not going to make a bad idea good, right? And bad technology is not going to make a good idea bad, right?" (Interviewee \#5, personal communication, October $12^{\text {th }}, 2018$ ). He expands upon this train of thought by offering some much needed historical context to the discussion of the role of technology in marketing - microtargeting included:

You need a good idea, and that's foremost and more important than anything. And $[\ldots]$ technology just allows you to communicate or transmit that idea to the people that you need to. And [...] marketing's always been pretty good at that: from the first commercial radio broadcasts at the end of the 1920s, into television really exploding in the late ' $40 \mathrm{~s}$ and early ' $50 \mathrm{~s}$, and now with the Internet. You know, if you go back and look at the pictures of London in the mid-1800s, you'll see the horse drawn omnibuses covered in placards for different brands. So, [...] technology isn't...I don't think it changes things. I think it just [gives you] 
different ways of reaching people you need to. (Interviewee \#5, personal communication, October $12^{\text {th }}, 2018$ )

The more things change, the more they stay the same! In a nutshell, technology is relative and it cannot escape the context in which it is used.

Interviewee \#5 also offers us more bird's-eye level historical context when speaking of the role of technology in political campaigning and the speed at which it is adopted in the commercial versus the political contexts. For example,

I think, traditionally, political campaigns [...] have historically been a little slower to adopt technological changes. A little slower, but not a lot. And I think nowadays (especially in the States), [with] a large class of professional political consultants that stuff gets adopted and managed even faster. (Interviewee \#5, personal communication, October $12^{\text {th }}, 2018$ )

Adoption speed aside, speaking from a front row seat, Interviewee $\# 5$ is persistent on the fact that political campaigning is about two things in particular. The first is the candidate him or herself, as was mentioned earlier. The second is the message that the candidate is pitching to the public. However, it is extremely difficult to separate one from the other. Technology cannot change this. In fact, from Interviewee \#5's perspective, it does just the opposite.

The whole core of any and all political campaigns is to get your message to the voters who need to hear it, and that can be the same message to everybody, or it can be a specific message for a specific group of voters (either geographically or demographically). Technology just allows you to do that. It's just the medium. (Interviewee \#5, personal communication, October $12^{\text {th }}, 2018$ )

Interviewee $\# 29$ reminds us that microtargeting and technology in general are not necessarily the golden ticket to a winning marketing campaign, although political marketers are more adept at the matter, but she was not the only interviewee to hold such a view. Interviewee $\# 21$ is one such dissenting voice. "But database sophistication, I think, is where political marketing still hasn't caught up to the creme de la creme of 
commercial marketing" is how he opens up his dissenting opinion (Interviewee \#21, personal communication, November $\left.23^{\text {rd }}, 2018\right)$.

Remembering that targeting relies upon databases, we can now turn our attention to unravelling the details of the evidence provided by Interviewee \#21 and how, in his opinion, the inherent ebb and flow of personnel in political marketing likely places political marketers at a severe handicap in comparison with their commercial competitors when it comes to targeting:

You see tactics deployed that are emblematic of more sophisticated marketing but they don't, by and large - and if you researched any of my past work, you'll know that this is kind of my raison d'etre - in the political technology world is that there's not a lot of continuity in the political organizations. (Interviewee \#21, personal communication, November $23^{\text {rd }}, 2018$ )

He gives us more details by way of a comparison between upper echelon commercial marketing and upper echelon political marketing campaigns. For example,

Well, if you look at a large corporate entity, like a Coca-Cola - just to take one off the top of my head. There are a class of those, right, the Fortune 500, the Fortune 50. They've got time, money, longevity, infrastructure. And the executive turnover isn't as frequent and product stays the same. I mean, in the political organization the party is the same, but the candidate is different. And the candidate tends to control the party. So, they bring in - just as an example, my predecessor, I kind of reinvented what they were doing. And then my successor, who I appointed - I mean, I recommended him and he ended up getting accepted for the job. But he kind of evolved my work. But then the Romney campaign comes in, they take over and do their own thing. Then the Trump crew comes and they take over, do their own thing. And the one consistency through all that different turnover was the data because that's the bread and butter in terms of the database marketing. But then what I think you find is the technical sophistication ebbs and flows or the strategy ebbs and flows. And so, the constant is the data, but the tactics change. (Interviewee \#21, personal communication, November $23^{\text {rd }}$, 2018)

In other words, the infrastructure, personnel, and institutional knowledge that comes from a low turnover rate of personnel is generally lacking in upper echelon (i.e. national) political marketing campaigns, a fact that wreaks havoc on efforts to create continuity in 
virtually all aspects of political campaigning — databased microtargeting included. And, the havoc caused by that lack of continuity is more pronounced the further down-ballot one descends.

Interviewee \#16 also draws attention to the lack of continuity that is characteristic of political marketing by focusing more on the candidate himself or herself than on the personnel organizing, running, and steering the proverbial campaign ship. Using a number of national-level Canadian examples, he explains that,

So, given your branding, the main difference is that the party brand and the personal brand of the party leader must co-exist. And that's a fundamental difference that you don't see in consumer marketing. With Tide detergent, you don't have the Tide detergent brand and then sort of, you know, the person behind the Tide detergent brand that you have to deal with their brand separately. In political branding, you have to think about, what is the Liberal Party? What is the Conservative brand? What is the NDP brand? And, at the same time, what is the brand of Thomas Mulcair? What is the brand of Andrew Scheer? Whatever, whoever is leading the party at a particular time, they have a personal brand that has to co-exist with and reflect and, initially reinforce the party brand. And that's why you see so often in the narrative that goes on about polling and so on [...] you hear phrases about, you know, running ahead or behind the party. So, you know, and you don't have that [...] that's not a phenomenon that exists in consumer marketing. So, I think it's an important distinction. And it forces a lot of strategic thought about where you're going to invest. Are you going to make the party brand halo the individual who now leads the party and, you know, this person is going to be what you expect of a Liberal leader? Or, are you going to say, forget everything you know about the Liberal Party, we've got a new leader and he's remaking the party in his image? (Interviewee \#16, personal communication, November $8^{\text {th }}, 2018$ )

With these challenges in mind, Interviewee \#21 posits that, "Database sophistication, I think, is where political marketing still hasn't caught up to the creme de la creme of commercial marketing" (Interviewee \#21, personal communication, November $23^{\text {rd }}$, 2018).

In his opinion, one of the main reasons why that is the case is turnover and the subsequent reinventing of the wheel that goes along with it. As he puts it, "Database 
marketing is the lowest hanging fruit in terms of sophistication" (Interviewee \#21, personal communication, November $\left.23^{\text {rd }}, 2018\right)$. He explains why this is the case while also illuminating the general cyclical pattern of organizational and staff turnover by noting that,

But you see at the campaign level, the Obama campaign was doing some sophisticated work. The work I was doing, I think, was a little bit more evolved than traditional databases. And what Parscale, Brad Parscale, has done with the Trump campaign, I think, was more akin to advancements in database marketing. But the political establishments, the party organizations every two to four years they've got new management. So, it tends to be a lot of creating new efforts every two to four years. (Interviewee \#21, personal communication, November $23^{\text {rd }}$, 2018)

But there is more to it than just that. For example, he points out that,

And so that's within the political apparatus themselves. Outside of that, you've got the consultant fees and they kind of are evolving. But not at the degree that they could because they don't have, I think, the scale to put the investment into it. (Interviewee \#21, personal communication, November $23^{\text {rd }}, 2018$ )

It is now time to turn our attention, in the following section, to the use of digital consultants and to the role they play in innovative data-based targeting strategies, not to mention the many other actors and forces vying for a role in the increasingly data-driven practice of political campaigning.

While conducting the interviews, the question that launched that discussion asked: are political parties or third-party vendors better suited to develop, test, implement, and maintain new campaign technologies? The lion's share of the respondents maintained that it was the third-party vendors who had the innovative edge in that regard. Interviewee \#31 offers us an unequivocal and clear point of entry into that discussion by stating that,

Third-party vendors. No question. Because political parties are ultimately political, and they are making decisions that often are informed by factors that are 
exclusive to the goal of a particular product. Having third-party vendors develop technologies-- number one, just through competition, competition for market share, you're going to have innovation that is not coming from political parties. A political party, when they do it, basically what you're doing is you're getting into monopoly-type economics. And you tend to run into those same types of challenges, both as far as internal politics, but also as far as a lack of kind of incentive to innovate. (Interviewee \#31, personal communication, January $30^{\text {th }}$, 2019)

In other words, he opens up this discussion by first indicating that, in his view, third-party vendors are undeniably ahead of political parties when it comes to crafting the technologies needed for contemporary campaigning and then went on to say that much of the reasoning for this is that competition breeds innovation. Since political parties operate in a relatively competition-free environment, it is not surprising that they are not exactly innovating on this front.

Interviewee \#23 offers a similar perspective by explaining that, when it comes to who is promoting the use of new technology on the political campaign trail,

I'd say it's proving to be campaign vendors. Yeah, I think that, you know, if you take a look at the big data structures that exist right now, they're almost all created and maintained by third parties. Yeah, that's exactly what I was thinking about, NationBuilder, but even if you go down into the States and you look at the professional consultants down there, they're all managing, it's being managed that way, through third parties. And then we just kind of import it. Like the Liberals are using essentially a version of it, from an American firm, you know, everybody steals from everybody. I think it's because it's just expensive to innovate. So, entrepreneurs, everything becomes a bureaucracy. And entrepreneurs thrive outside of those bureaucracies. So even political entities are bureaucracies. So, getting those political entities into, to innovate in data structures, first of all, you have to pay a full-time data guy, and then, what we're all afraid of in this moment, because we all went through an evolution of it, is that you build something on your own, and then the guy who built it for you leaves, or holds you hostage. So now we tend to go to the companies. (Interviewee \#23, personal communication, December $5^{\text {th }}, 2018$ )

Essentially, Interviewee \#23 reminds us that innovation is not inexpensive and that political parties often do not have the financial resources needed to innovate in this 
particular capacity - especially here in Canada. Interviewee \#19 concurs. She too holds that third-party vendors have the advantage over political parties and that, once again, money is the primary reason for this. For instance, she states that, when it is about innovative technology and its implementation in political campaigning,

I think third-parties. Well, [...] we've ended the per-vote subsidy; across Canada there's the restrictions on the amount of money that can be raised; political parties just don't have the money to do it. Just like designing the stuff, let alone even buying it is crazy [emphasis in original] expensive, right? (Interviewee \#19, personal communication, November $16^{\text {th }}, 2018$ )

Interviewee \#22 adds an even greater level of detail to the discussion of the expensive nature of integrating technology into a political marketing campaign especially a Canadian one. He does so by not only speaking about the finances but also about the security and ownership of that expensively acquired technology and the data that it relies upon. For instance, he says that

It's extremely [emphasis in original] expensive to maintain a national database in Canada, because, I mean, you take any given year: $10 \%$ of the population moves, passes away, changes in some way, shape, or form; you have home phone databases that are less useful every year, as people abandon that; you have the Canada Post database that, again, it's hard to keep track of people and it's an extremely expensive subscription to maintain. And then you have all the uses since, if someone were to maintain that for a party, there would be [...] that would have a cost to it that a party would normally have been doing internally, right? And, so, can they afford (based on the limited amount of money that Canadian parties raise. Which isn't very much as a percentage [compared to] what American parties raise.) [...] can any party afford to basically outsource operations like that and then, do they own that information? Can it be used by somebody else? Would there be legal issues if identifications or other types of data that were gained from one use case were being used by another? I think parties prefer to in-house databasing, because I think it's a data security issue, and it's a data privacy issue for them. (Interviewee $\# 22$, November $27^{\text {th }}, 2018$ )

Fundamentally, a database (the necessary foundation upon which virtually all ancillary digital-campaigning products and services are built) is inherently characterized by inconsistency. Unfortunately, wading through inconsistency in an attempt to massage it 
into consistency - consistency being the calling card of any meaningful pattern recognition for the purposes of crafting strategic communication - costs a significant amount of money. And, that is to say nothing about the cost of securing the data in the databases themselves given the increasingly hackable world of today where political campaigns have fallen victim to hacking, most notably in the United States, but elsewhere as well.

While financial concerns can certainly limit innovative thinking, before walking through some of the other constraints that arise when considering technology in the political market, we must address the fact that, although most of the interviewees wholeheartedly felt that third-party vendors were out-innovating political parties in developing and integrating new technologies into the practice of campaigning, there were some more nuanced perspectives that came out of the interviewing. Most of those dealt with the act of integrating new technologies rather than the act of innovative inception.

Interviewee \#33 initiates the discussion of nuance in relation to innovation in campaigning technology. For instance, when asked that same question (i.e. are political parties or third-party vendors better suited to develop, test, implement, and maintain new campaign technologies?), he simply states that, "This is a cop-out answer, but it's got to be a little bit of both" (Interviewee \#33, personal communication, February $4^{\text {th }}, 2019$ ). He expands upon the symbiotic relationship between political parties and third-party vendors on the issue of innovation by explaining that, "The parties surely don't have the technology to develop them. But the parties know how to use them" (Interviewee \#33, personal communication, February $\left.4^{\text {th }}, 2019\right)$. It takes two to tango. He gives us a number of examples to help paint a picture of why this is the case. For example, 
And I mean, so the parties have gone from the olden days of clipboards with names and addresses on it up through very high-tech door-knocking systems with tablets running videos that are customized to the person who's at the door. So I think while that it's really got to be a partnership and I think what happens - stop me if I veer off the topic — is you have people come all the time that go, 'Oh, I've got this cool app or I've got this cool tool and this would be so great for you,' but they don't really understand what we've got to do. So, they have an app solving a problem that we don't really have. So, I think we need amazing technology, but the parties and the campaigns are the ones who can use it and evaluate it and getting back to the app people to tweak it. (Interviewee \#33, personal communication, February $4^{\text {th }}, 2019$ )

Put another way, third-party vendors may be the better technology innovators but they need the political parties and political marketers running campaigns to guide them in determining the most useful areas for improvement and problem solving through technological application.

Interviewee \#30 floats the possibility of another important relationship when it comes to developing technologies for the purpose of political campaigning, one that does not focus solely on a partnership between third-party vendors on the one hand and political parties and political marketers on the other. Instead, it is a relationship between three parties: first, political parties and political marketers; second, the third-party tech vendors (whether boutique services/agencies, individual digital consultants, or large-scale service providers) which often develop the technology campaigning services and apps adopted by political campaigns that can afford to make such a purchase; and third, the big tech companies that provide the infrastructure, base-level code, or operating systems that the services or products supplied by third-party vendors are built upon. As he puts it,

I think it has to be [...] in terms of development and testing, you know, it has to be sort of a shared effort. And you need partnerships on the outside, because they don't have the bandwidth or the resources — frankly — to do the kind of testing that's required [to] develop that kind of infrastructure and [that] sort of intelligence. I was thinking partnerships with vendors and tech companies. I think the problem [...] I think there are some small, some privately-held companies that 
are doing really great work in that area. But, I think the $[\ldots]$ political revenue is so small for what they're doing [...] there's some unicorns out there that are doing some work in the kind of real-time signal and data world that could be well-suited to helping political campaigns and committees but, of course, the political campaigns and committees have to buy it first. (Interviewee \#30, personal communication, January $30^{\text {th }}, 2019$ )

On the matter of buying technology, Interviewee \#33 adds that,

Well, the role of data and the desire for data is the same across the board. Then it gets down to how much can you spend to get the data and then how much should you spend to utilize that data? So, if my campaign is big enough to afford a paid door-knocking service and I've got a great data package and I know to knock on this house but not these two houses, that's a great way for me to utilize that data; but it all costs money. So if I'm running in a city council race, right, and I've got $\$ 15,000$, that's the best data set I'm going to get is [inaudible] the voter file from last time because that's really all I can afford [...] And to crunch these [...] when you get into a $[\ldots]$ if you get into a statewide race and even in a small state, you're still looking at hundreds of thousands of records to manage. (Interviewee \#33, personal communication, February $4^{\text {th }}, 2019$ )

Once again, money and institutional knowledge seem to be two of the largest factors in determining how far technology is integrated into any given political marketing campaign.

As regards innovative thinking about technology in the context of political marketing, money and a lack of institutional knowledge as well as limited up to date technological infrastructure from personnel turnover may be setbacks that befall political marketers far more than third-party tech vendors — but there are other setbacks that political marketers face too. Interviewee \#24 explains that an additional potent setback is the combination of two often, but not always, conjoined forces: a generational divide and a capability divide. He opens up this discussion by stating that, "So, look I think the barrier is more legacy thinking than it is money" (Interviewee \#24, personal communication, December $\left.27^{\text {th }}, 2018\right)$. He elaborates by explaining that, 
If you're running a campaign, even if you're spending $\$ 10,000$ on campaigning for county commissioner in some Podunk kind of a place, you're still getting a mail list from somewhere on who to send your mail to. You're still printing out a precinct list of who to walk door to door to. So that same vendor, unless they're as backwards as you're thinking it is, is going to have some other offering. They're going to have a [...] they're going to at least be able to send you the Excel file. Look, you're going to get an Excel file, right? So why wouldn't you then load that into a texting platform and text people, right? So, it's not necessarily a money thing. It's a capability. It's an understanding. It's also maybe a relevancy, right? I'm not going to send back a fuck you don't text me ever again text because I'm technologically involved, right, and I live in Orange County, California, where everything is technology, and it's just whatever. But if you text someone in some other part of the country where they've never gotten a political text before, you may backfire, quite frankly. So, I think it's less of a financial thing and more of an understanding, capability, interest, that sort of thing. (Interviewee \#24, personal communication, December $27^{\text {th }}, 2018$ )

In other words, one needs both the technical knowledge and the willingness (i.e. the lack of risk aversion) to put that knowledge to use on the campaign trail while still being cognizant of the idiosyncrasies of the particular electoral landscape (which can include geography, economic, demographic, etc.) in which a race is being run. As Interviewee \#27 points out, there is often a generational divide on that matter.

And this is where I see it; the great innovation that we have begun to see over the last three years has come from younger people getting into the business who grew up with technology. I did not. Everything I know about technology, I've had to learn in the last eight years; but the kids who grew up with it who understand the power of social media and technology in ways that I've had to learn in recent times, and because they grew up with it, they have a stronger appreciation of its capacity to move people. And that's where the innovation is coming from for some of the candidates now emerging in the political marketplace who are under the age of 35 who come in as absolute and total masters at social media. And people my age $[\ldots]$ are looking at some of the stuff that they're doing, and we're saying, 'Shazam, the way we used to do things in the early years, 20 or 30 years ago, is way outdated.' (Interviewee $\# 27$, personal communication, January $24^{\text {th }}$, 2019)

In essence, like a number of the other respondents in my sample, such as Interviewee \#19 who, although only in her forties, claimed that, "In a way, I've almost aged out (laughs) now" (Interviewee $\# 19$, personal communication, November $16^{\text {th }}, 2018$ ), 
Interviewee $\# 27$ holds that younger political marketers generally have a much higher knowledge and comfort level than older political marketers with the digital campaigning technologies and platforms that are proving to be the most effective tools in the current political marketers' toolbox.

Interviewee \#27 elaborates on the importance of integrating new technology into the political marketer's toolbox and how the willingness and capability to do so is more often than not found with the younger, rather than the older, practitioners. For instance, he states that,

The smart people keep up with this, but I see them on candidates, too. I had a candidate, not long ago that I called him, and I say, 'Not for nothing, but your opponent is all over the Internet with Internet ads.' And he said, 'Oh, that's a waste of money. I'm not wasting money on that.' And the worst mistake I made in his campaign is that I didn't argue with him. He lost by three votes to a newcomer who knew how to do this stuff-the stuff that he poo-pooed. (Interviewee \#27, personal communication, January $24^{\text {th }}, 2019$ )

He takes this discussion further by way of another recent example of a federal campaign that he ran, which highlights the relationship between new technologies, legacy thinking, older political marketers and the candidates they represent as well as the willingness to consider altering the status quo in favor of new ways of conducting the business of political campaigning by utilizing new technologies and strategies to these ends. But first he prefaces that example by stating that, "If you're not tech-savvy or if you don't have somebody tech-savvy on your staff or in your consulting team, you're going to get left behind" (Interviewee \#27, personal communication, January $24^{\text {th }}, 2019$ ). Onto the example,

So here is, typically, a campaign, let's say, in a suburban district 10 years ago; you did cable advertising, you did persuasion mail, you did robocalls, you did yard signs, and the Internet was a foreign country. Today, my attitude is, 'We start on 
Facebook and we end there, and everything else that we do emanates from there.' And two years ago, I had a client call me and the mission was this, 'We want you back - I'd done it four years before- [...] we've learned a lot from you. We already know how to do a lot of what you taught us, but we want you around just to tell us if we're headed in the wrong direction. So, here's a nice contract for you. Just tell us if we're going in the wrong direction.' So, they sent me the budget, and in the budget was $\$ 100,000$ for cable television and a pittance for social media. And I called him, and I said, 'This $\$ 100$ grand you have in cable, cut it out. Cut it. Put it all into internet and Facebook ads.' And they said, 'You're nuts.' And I said, 'No, I'm not. The world changed in the four years since you were elected to office, and if you don't do this, you'll get your clock cleaned.' (Interviewee \#27, personal communication, January $24^{\text {th }}, 2019$ )

They took his advice to heart and ultimately won their re-election race. However, he notes that that is not always the way things go. For example, he states that, at the same time as he was advising that particular client, "I noticed a candidate also running for reelection right across the river had that same discussion" but, in that instance, the client went a different direction: embracing the status quo rather than the new technology tools that are becoming ever more important in political marketing today (Interviewee \#27, personal communication, January $\left.24^{\text {th }}, 2019\right)$. The candidate simply said, "“No; cable TV has worked for us in the past, and that's what we're going to do again.' And he went down in flames" (Interviewee \#27, personal communication, January $24^{\text {th }}, 2019$ ).

While there is often a generational divide on the willingness to integrate new technologies into the act of political campaigning, Interviewee \#24 reminds us that the generational divide may not be as distinct as we often imagine it to be. When speaking about that divide, he claims that, "Yeah. I think to some degree, [it's] generational" but it is more gray than black or white (Interviewee \#24, personal communication, December $\left.27^{\text {th }}, 2018\right)$. For example, he states that,

I mean, well, one thing I'll caveat though, and I think it's really important [...and] we see this all the time [...] when we do research $[\ldots]$ we do it in multi-modes. We talk to people [with] landlines because there's still half of Americans that 
[have] landlines. (Interviewee $\# 24$, personal communication, December $27^{\text {th }}$, 2018)

In essence, when considering the integration of new technologies into the practice of political marketing, we must remember that, quite often, the integration can be gray rather than black or white since, with few exceptions, new technologies layer on top of other existing technologies rather than outright eliminating their predecessors. Furthermore, while it may be true that younger individuals are more likely to integrate new technology into their routines, employment, entertainment and interactions than are older individuals, there are always exceptions. As Interviewee \#24, puts it himself:

And we also basically always have an online component. And we explain to people that Grandma's on Facebook. A lot of people, well, their clients kind of think that we're just talking to millennials. Well, no. Grandma's on Facebook. At 10 o'clock at night she's looking at what her friends are up to. And then she clicks over, and she sees in her Gmail an email for a survey and clicks through the survey, and completes it. And then she goes to bed, right, at 11 o'clock. (Interviewee \#24, personal communication, December $27^{\text {th }}, 2018$ )

Essentially, Interviewee $\# 24$ correctly points out the obvious, but often overlooked, fact that we cannot identify younger individuals as the sole users of new technologies. To do so would miss a valuable market segment (if we are talking about commercial marketing) or a valuable target segment (if we are talking about political marketing). He notes that smart marketers, whether commercial or political, have already noted this fact and are adjusting their strategies accordingly. He provides us with a concrete commercial example that reflects this thinking when he states that,

There's a product in the States and probably in Canada, too, called GrandPad. And it's basically an Android device that they've put a platform on that essentially gives you all the capability of text, call, and Facetime, but in this kind of closed network. And it's all on self-service. So literally, Grandma opens up the box and presses, and it's already configured, and she can talk to her grandkids. And there's no share pictures, right. And there's no connection. There's no signing up to WiFi. There's none of that friction, right. And I always kind of [...] I kind of talk 
about it with friends. I'm like, 'How long does this market exist for?' Right? I mean if you're 40, maybe there's a 40-year-old in America that can't sign onto WiFi or get a smartphone. But there's no 35-year-old. There's no 20 -year-old. So maybe there's like 20, 30 years of this to go, maybe? I don't know. It's kind of like [...] but I guess it's a market. And it's not that big of a friction to get into the market. So okay. (Interviewee \#24, personal communication, December $27^{\text {th }}$, 2018)

In other words, the use of new technology is cutting across all age demographics in the American and Canadian political and commercial marketing landscape examined by this dissertation. However, the speed at which it cuts into or, more appropriately, absorbs into that landscape varies between younger and older individuals. It may be true that younger individuals absorb technology faster, but it would be off the mark to dismiss the fact that older individuals are absorbing it too, albeit at a generally slower pace than do younger individuals. As Interviewee \#24 sums it up himself: "So, I guess the point is that there's definitely some people out there who are clueless on technology. But it's not just a generational" (Interviewee \#24, personal communication, December $27^{\text {th }}, 2018$ ).

Regarding the link between third-party vendors and innovation and the money that fuels the relationship between the two, Interviewee \#20 steers the discussion back to a subject that was examined earlier: turnover. However, she sees it in a different and optimistic light.

So, $[\ldots]$ obviously there is turnover and that relates to money, that relates to age. If a campaign is successful, people go work in party offices or work for elected officials [...] the four-year cycle is long and, unlike America, we don't have midterms, so you know, the professionalization of politics is indeed here. But it's not at the same scale as our American colleagues. So, yeah, obviously turnover is a huge - I would say it's a huge concern - but, obviously, people manage to deal with it and do okay. I think technology done right prevents the turnover from being a negative thing, because you should have something. (Interviewee $\# 20$, personal communication, November $19^{\text {th }}, 2018$ ) 
To her mind, that "something" is a combination of fresh perspectives, courtesy of new personnel, and also greater efficiencies via newer technologies. However, she still maintains that this is a complicated relationship. As she puts it,

Now, that being said, technology has changed rapidly between the 2011 campaign, to 2015, to 2019. I think that part of the struggle is indeed technology changes so fast, and political campaigns in Canada have incredible turnover. How do campaigns keep up? So, I think it is hard, but third-party vendors, you know, there's that gray. (Interviewee \#20, personal communication, November $19^{\text {th }}$, 2018)

According to her, third-party vendors can be painted gray since, if you are running a political campaign and you are going to hire a third-party vendor to provide services to help your campaign run more efficiently, "it has to be a really trustworthy vendor" and, as the old saying goes: good help is hard to find (Interviewee \#20, personal communication, November $\left.19^{\text {th }}, 2018\right)$.

Interviewee \#25 helps highlight the gray nature of third-party political vendors and why good help is indeed hard to find. He frames that explanation by way of what could be classified as an inverted pyramid of technology in political marketing. Unlike in journalism where the inverted pyramid refers to structuring a news story with the most important information (i.e. the who, what, where, when, why, and how) at the outset of a story with all subsequent information descending in importance the further away one gets from the first sentence of the story, in political marketing the inverted pyramid has a totally different meaning. It deals with technology and its use in up-ballot races (which represents the top of the pyramid) as opposed to down-ballot races (which represents the bottom of the pyramid). More specifically, the higher profile (i.e. the more up-ballot) a race, the greater the potential use of technology and granular data for campaigning purposes. As Interviewee \#25 explains, 
If you're at the federal level, you're at the top of your game. I mean, you're doing all the things that are available to you. When you start getting down-ballot (it's somewhere around second-tier congressional race and lower), all the tools that you might consider, start disappearing. And some of it is cost. Some of it is just manpower or lack of understanding of the vendor space. (Interviewee \#25, personal communication, January $15^{\text {th }}, 2019$ )

In his eyes, the further down-ballot the race, the greater the likelihood of choosing the wrong vendor - should you even have enough money on hand to purchases the services of a third-party tech vendor to begin with. For example, he explains that,

So, in some cases, if you don't have the resources to really evaluate, it's easy to pick the wrong vendor. So, we see a lot of people at lower levels of the campaign world just picking crappy vendors and not knowing. And there's an entire industry of people in the political space that earn their living from "dumb money". Yeah, there's people that just earn their living from local races that would never stand a chance of getting anything at an upper level where they're more heavily evaluated. (Interviewee \#25, personal communication, January $15^{\text {th }}, 2019$ )

In other words, Interviewee $\# 25$ pulls back the curtain on what one could classify as the underbelly of third-party tech vendors: those who make a living selling products and services that are neither necessary nor appropriate for the kind of race a particular political candidate is running - hence the term "dumb money." While it may be bad form to double-dip, something Interviewee \#33 said earlier on in this chapter rings true and remains incredibly relevant when talking "dumb money":

Campaigns $[\ldots]$ and traditional clients are willing to put more money into data crunching. But I think the big disconnect is you've got your data management and your data crunching, and I think there's a promise of insights from that data [...] But getting those insights from that data is I think where people are selling snake oil and also there's a great misunderstanding as to what we're really getting for our funds. (Interviewee \#33, personal communication, February $4^{\text {th }}, 2019$ )

Essentially, one could go so far as to say that the kind of third-party vendor profiting from certain candidates' good will, enthusiasm, and desire to embrace digital data-based campaigning - regardless of whether or not doing so will reap them any meaningful 
rewards in the context of the race that they are running — can at best be seen as selling snake oil and at worst as being inherently predatory.

But, of course, not all third-party tech vendors can be painted with that brush and, in political campaigning, it takes more than one bad apple to spoil the whole barrel. Interviewee \#25 recognizes this fact and offers an honest and self-reflexive assessment of the situation by stating that, regarding third-party vendors and political parties on the matter of digital campaigning,

Well, both of them have fatal flaws. Let's start with that. The fatal flaw among vendors like myself is that I'm driven by profit. The fatal flaw among political parties is that those decisions are often made with other biases whether to reward political friends, to enhance the career prospects of the person making the decision, all kinds of things. So, I've seen bad out of both. There's longer institutional knowledge - well, there's turnover in both places. I mean, the reality is that there's vipers in both hands. (Interviewee \#25, personal communication, January $15^{\text {th }}, 2019$ )

In other words, he reminds us that human nature resists change and that there are only so many personality types, regardless of which particular profession one practices.

Stepping away from discussions of human nature and "dumb money," Interviewee \#28 helps us pivot back to the key point of the discussion that was had over the past few pages: is it the political parties or third-party vendors that have the upper hand in innovating new campaign technologies? He does so by speaking about the matter from a somewhat philosophical perspective which also picks up on the earlier discussion on turnover. To that end, he states that,

Ultimately, a campaign is an ethereal being. It disappears after the election day, and all the staff scatters, so it's very hard to get institutional knowledge. You really have to have an external resource — whether it be a vendor or a political party - that's able to provide continuity to make sure the best tools, and best technology are available to the campaigns. And the only sort of caveat to that would be incredibly [emphasis in original] well-funded things like presidential campaigns (where you can do a lot of this in-house). But, even with that, you still 
need the historical knowledge and you need to have a lot of assistance from thirdparties. I think, historically, you've seen the vendors have been better at providing this continuity than the political parties themselves. (Interviewee \#28, personal communication, January $28^{\text {th }}, 2019$ )

As noted earlier, turnover is one of the key reasons that third-party vendors are better suited for pushing the innovative envelope on the development and utilization of new campaign technology. Bearing that in mind, Interviewee \#31 offers a nuanced perspective on this issue by saying that, "I think that the question has to be, what's the cause of the turnover, right?" (Interviewee \#31, personal communication, January $30^{\text {th }}$, 2019). He then reminds us that, "And there's going to be turnover in the private sector too. But again, I think this goes back to in political parties and political organizations. Ultimately, they're political" (Interviewee \#31, personal communication, January $30^{\text {th }}$, 2019). As referenced earlier, part of being political means a generally smaller from conception to death (i.e. start to finish) budget for a political marketing campaign in comparison to a commercial marketing campaign. With that in mind, Interviewee \#31 remarks that,

I can speak better on the Democratic side, but a lot of times, there's a lot of [...] there's a disproportionate amount of ego, and a disproportionately low amount of pay. On the Democratic, on the more progressive, whatever you want to call it side, there's a lot of - and I speak from experience here-being paid and doing it for the cause, which is great until you have a mortgage and kids. (Interviewee $\# 31$, personal communication, January $30^{\text {th }}, 2019$ )

Fair enough. But as Interviewee \#26 explains, turnover can help spur innovative thinking.

For example, he states that,

I think the innovative thinking is probably coming from consultants that have crossover with the commercial end. So, the people that are having more exposure. And, in some cases, the vendors for political consulting which often work both in commercial and political realms, are the ones that are pushing the more creative ideas and tools to political consultants because they have exposure to that (Interviewee \#26, personal communication, January $23^{\text {rd }}, 2019$ ) 
In essence, he posits that it is the digital political consultants who practice their trade within a feedback loop that constitutes interacting with both political and commercial clients who are more likely to think outside of the proverbial box and, therefore, to push the development of new campaign technologies further than their colleagues who lack such a bidirectional feedback loop. But why is this the case? According to Interviewee $\# 26$, it is because,

Well, the people that run the parties are not [...] well, first of all, there's not enough technology people within them. And those that are, are transient and tend to move about quite a lot. So, there isn't really a stable [...] a vendor has a more stable developmental process than the party does. (Interviewee \#26, personal communication, January $23^{\text {rd }}, 2019$ )

Yet political parties still play an essential role when it comes to new technology on the campaign trail. As was hinted at earlier, much of it concerns the integration of said technology rather than the development of it from the ground up. For instance, Interviewee \#27 speaks of how the parties

Can help their candidates become tech-savvy if they're candidates are not $[\ldots]$ They can provide the infrastructure. They can provide the tools. They can provide some of the data and the analytic information so that someone knows how to easily use it. But at the end of it, there's no substitute for the person who is on the ground with the candidate who understands their passions, what moves them, what touches them, what they really sincerely want to do for their jurisdiction, who understands their story. And that person needs someone who can take that passion and that energy of theirs and translate it into a video or a campaign message that actually touches and moves people (Interviewee \#27, personal communication, January $28^{\text {th }}, 2019$ )

In other words, we must remember that technology, regardless of whether or not it is developed, tested, implemented, and maintained by either third-party digital vendors or political parties themselves is not the driving force of any given political campaign — no matter if that race is an up-ballot or a down-ballot race. The candidate and the narrative 
that the candidate and the team pitch to the voting public constitute the driving force of a political campaign. Technology is only utilized to spread a candidate's narrative more efficiently to reach potential or probable voters. At the end of the day, all political campaigns start and finish with the candidate. Technology is no silver bullet.

\section{Privacy Problems — or the Lack Thereof?}

Over the course of the last fifteen years or so, political campaigning has become increasingly reliant upon data regardless of whether or not voters know that more and more of their online and offline activities are being catalogued by the national political parties, and regardless of whether such data-dependent campaigning is necessary (or even fruitful) from the campaign's perspective (Hersh, 2015; Kreiss, 2016; Munroe \& Munroe, 2017). With this in mind, Interviewee \#26 states that,

The cost of targeting has exceeded its benefits, in many cases. And I think you can make some arguments, for example, that in the 2016 presidential election, there was too much microtargeting: the Clinton campaign had spent too much time microtargeting because the data said these people or that people were the most effective. And their algorithms told them that this would work or that would work best. And in the end, what happened was they didn't take a wholesale approach to their marketing and left out all types of people that became very important when their assumptions were wrong. And so, $[\ldots]$ the eternal campaign dilemma with microtargeting is do you go wide and thin, or small and powerful, as a function of frequency? And if you get that decision wrong, you're going to lose. (Interviewee \#26, personal communication, January $23^{\text {rd }}, 2019$ )

In other words, a wholesale reliance upon data-dependent campaigning without first having some sober second thought about the necessity for a data-dependent microtargeting strategy, given the electoral landscape in which a particular campaign is being run, can lead political marketers into the all too familiar trap of being unable to see the forest for the trees. 
And then there is the matter of privacy. The relationship between data and privacy, regardless of whether or not we are referring to the commercial or political marketing context, is anything but uniform. It varies by state, province, and country. Not surprisingly, although Canada and the United States are consistent on many matters, the legal boundaries on the use of data (not to mention what constitutes privacy or its breach) are an area not characterized by cross-border consistency (Hersh, 2015; Munroe \& Munroe, 2017). A comprehensive study of that subject matter alone could easily be the topic of a new dissertation, or even a whole career's worth of scholarly investigation. At this junction, this dissertation can merely acknowledge that the interplay between data and privacy is a complex and convoluted matter. Yet it is one that any discussion of microtargeting (for political or commercial ends) must pay homage to since data is the back bone of any microtargeting campaign.

As was pointed out earlier in this chapter, Canadian voter files are thinner than are their American counterparts due to the stricter privacy laws here in Canada (Hersh, 2015; Munroe \& Munroe, 2017). This fact was clearly reflected in this dissertation's field work. Interviewee \#7 hints at a consequence of this reality by stating that, "Well, that's also [...] why there's more political marketing development in the United States. You just can't buy data here.” (Interviewee \#7, personal communication, October $25^{\text {th }}, 2018$ ). With this Canadian political data drought in mind, he pithily remarks that, "I applaud anyone who's trying to figure out a better way to build [...] a mouse trap, but, you know, there should be some understanding of the actual limitations that exist in this marketspace" (Interviewee \#7, personal communication, October $25^{\text {th }}, 2018$ ). In Canada, the limitations placed upon the accessibility and use of data in the political marketplace 
are substantial. Interviewee \#7 takes us further into why this is the case by using Relationship Marketing (a concept and practice that was discussed in earlier chapters) as his canvas, a canvas that is painted by data, whether easily obtained or not. That process, he explains, is "about tying other relationships to voting profiles and behaviors" (Interviewee $\# 7$, personal communication, October $25^{\text {th }}, 2018$ ). In his eyes,

There's only so much you can do with that. But you can do psychographic research. But, again, that's just research. What you're missing is the hard data points on things like —which you're prohibited from having in this country, because of privacy [...] — I can't call VISA and buy aggregated data for VISA, let alone individual data [...] Whereas in America, I can do both. (Interviewee \#7, personal communication, October $25^{\text {th }}, 2018$ )

Numerous other interviewees held similar views on the role of data in political marketing in the U.S. and Canada and on the different conception and regulations of privacy that exist in both countries. For instance, Interviewee \#8 claimed that,

Well, I think [...] you know, the U.S. has been there for a long time [...] with their voter records and different privacy laws [...] permit that. And, so, their campaigns are heavily data-driven. Our campaigns are becoming increasingly data-driven in Canada and in other parts of the world, but, you know, the data that you can get in the U.S. is on an individual voter [...] and then model. It just outstrips anything. (Interviewee \#8, personal communication, October $26^{\text {th }}, 2018$ )

Similarly, Interviewee \#22 explains why and how the data that is available to American political operatives "outstrips" what is available to their Canadian counterparts:

There's predictive tools. There's the ability to [...] I mean, in the States, there's a lot more tools available, because the privacy rules allow you to use services like, you know, Experian, Axiom, to essentially target people using third-party data. In Canada, we have such a restriction on third-party data that I'm not sure that a lot of marketers are able to do what they can do in the States. (Interviewee \#22, personal communication, November $27^{\text {th }}, 2018$ )

Interviewee \#23 highlights one of the cross border peculiarities of what privacy entails when comparing and contrasting Canada and the U.S. As he puts it: 
Down in the States, we have much less stringent privacy laws, that must be even more so, of course [...] Like you're not allowed to call a cell phone down there [...] because a cell phone for some reason has been determined to be private. But I can totally target your personal cable box, and specifically send you a specific type of advertisement. Like it's a weird kind of freedom of speech [...] it's just weird [...] They draw their lines pretty weird now. I guess we may draw our lines pretty weird too, but they're our lines, so I guess we feel more comfortable with them. (Interviewee \#23, personal communication, December $5^{\text {th }}, 2018$ )

With this is in mind, one could argue that privacy is a fluid concept that varies from one jurisdiction to another and that it could be said that what constitutes privacy is undergoing a process of evolution or redefinition. Interviewee $\# 19$, is one such individual. Her spirited response below indicates why:

I think (laughs) the concept of privacy is changing all-to-fucking-gether [emphasis in original]. Do you know what I mean? And, also, that's kind of [...] I think it's less-so to privacy rights and more about money [...] You know, because of like, what does privacy mean in these days? Frankly, you're either just open to the world, or you might as well just fucking go off the grid and move into the woods, right? (laughs) That's the way I look at it. I never dick around with my privacy settings or anything like that. Like, I just, if somebody want to see my stuff, they're going to, you know? (Interviewee \#19, personal communication, November $16^{\text {th }}, 2018$ )

In her eyes, resistance is futile. And, it is safe to say that today few of us would be willing to return to Walden Pond as American author and poet Henry David Thoreau immortalized in his seminal 1854 book Walden; or Life in the Woods which critiqued modernity in a world that was far less complicated than is ours today. That said, whether resistance to the shrinking definition and scope of what constitutes privacy truly is futile will remain to be seen in the years to come.

\section{Buyer Beware: Side Effects of Targeting \& Technology at Large}

As a wise man once said: for every action, there is an equal and opposite reaction.

The use of technology in the practice of marketing (whether political or commercial) and, 
more specifically, the use of microtargeting is no exception to this rule. Interviewee \#11

opens the door to such an examination by explaining that,

The ability to identify audience, and segment that audience, and tailor your messaging to that audience, has all been to the benefit of both commercial as well as political marketers. And it has allowed us to do it in a pretty sophisticated way, so we can tailor a very narrow casted messaging that we know that a particular component of the audience wants to hear, [and] send that message. Now, the downside of that has been-whether it's a symptom of, or a cause of - $[\ldots]$ one of the other trends that has developed in concert with the technological advancements, has been the absence of long-term voter. (Interviewee \#11, personal communication, October $31^{\text {st }}, 2018$ )

In particular, he points out that the act of microtargeting and the data that it relies upon

has played a role in replacing the constant long-term voter with a more fickle elector who has limited interest in, affinity with or loyalty for any given political party. He unpacks this statement by detailing how,

So, in previous generations, it was more common for those that came before us to stick with their vote, regardless of the candidate or the issues in each election. It was based on religion; it was based on geography; it was based on ethnic [...] ethnicities; or it could be a combination thereof, right? And those loyalties have fallen by the wayside in recent years. Well, I don't know what the catalyst was. Either people are increasingly seeing little variation in their options [...] No, you know, no solid preference. Or, the parties have done a good job using technology in marketing. And this is where I was going to close the loop there on the point. Which is, because voters are in perpetual shopping mode, so to speak [...] where they're not loyal to their previous vote, political parties must [...] it's not just about going after the next voter; it's also about holding onto your existing voters because, if they're mobile, and your competitors are seeking them out, trying to get them over to you, you not only have to go after the next tier of voter, you have to hold your own voters. And, so, you're actually doing a hold, as well as a reach for the next tier of voters; and so, technology, that's one of the reasons why we're in perpetual campaign mode. This is why we're perpetually marketing towards people. So, why is it important to constantly feed your base? It's because they could leave you at any moment. Or the fear is that they could leave you at any moment. And, so you must constantly feed and water your own supporters - all the time. (Interviewee \#11, personal communication, October $31^{\text {st }}, 2018$ )

The latter part of this lengthy quote establishes an important link between the disappearing long-term voter and the practice of relationship marketing and tribal 
marketing - two phenomena which were extensively examined in Chapter II and Chapter V. Furthermore, Interviewee \#11 reminds us that, in a political marketing environment characterized by the ever-increasing use of technology for the purpose of microtargeting, money once again is an important consideration. This is especially the case in Canada where voters are moving away from the aforementioned loyalty, affinity, or consistent interest in a political party. As he puts it himself,

You also need to raise money, because we've regulated the laws that allow...only individuals can now donate to political parties in Canada... And so, therefore, the individual supporter has now become more and more important. And technology has allowed us to constantly stay in touch with those people, [to] feed and water them with information (segmented information) that they like, right? (Interviewee $\# 11$, personal communication, October $31^{\text {st }}, 2018$ )

Another less beneficial side effect of targeting and the technology that it relies

upon has to do with shared media experiences and the intake (if any) of diverse media perspectives. Once again, Interviewee \#11 sets the stage for that discussion.

Now, at the same time, I would say to you that, while the tools have aided in identifying, persuading, and motivating audiences, [...] some certain tools, like Facebook and Twitter, have become, you know, controversial because, you know, they're limited in their abilities. But it also, you know, we also run the risk, as we segment more and more, the audience is [...] we also carve people out of a more general conversation, right? That is, people used to get their news from, you know, Knowlton Nash and newspapers. And, you know, I would get the same news as you, if we watched the same newscast every night - even though we lived in different parts of the country. Well, now, with the tools that we have at our disposal (things like Facebook, things like Twitter), you can segment out certain audiences, where they're getting their news from Facebook, and they're only getting their news from sources that they themselves have selected. So, there's a lot of...you know, echo chamber. (Interviewee \#11, personal communication, October $31^{\text {st }}, 2018$ )

In other words, compared to the media landscape of decades past where there were fewer sources and channels of news distribution, the average individual was generally forced to interact with perspectives that he may not have shared since the news organizations 
needed to cater to individuals with a variety of different views or ideologies on limited bandwidth. For example, when there were only three cable TV networks in the United States (NBC, CBS, and ABC), news coverage had to offer a diversity of perspectives on any story covered to provide viewers of very different outlooks with what they felt was relevant information for them in the broadcast. Failing that, at the very least, the news coverage needed to be neutral in the perspective provided (Bennett, 2012; Cacciotto, 2017; Cornfield, 2017; Serazio, 2015). The same could generally be said of radio and print (Bennett, 2012; Serazio, 2015). However, there was more opportunity to narrowcast on radio and, especially, in print since it was financially possible to develop and narrowcast content for specifically tailored audiences through amateur radio and printing, neither of which could be replicated in the limited channel universe that characterized much of the second half of the twentieth century (Bennett, 2012; Cornfield, 2017; Serazio, 2015). But cable TV, satellite TV, the Internet itself and then the plethora of social media websites, services and podcasts that use the Internet as both their content gathering and distribution service have changed the past forever.

And so we have the birth of the media echo chamber wherein, in the words of Interviewee \#11, "Once the audience has [...] chosen their sources of information, it becomes very difficult for others to penetrate that person" (Interviewee \#11, personal communication, October $31^{\text {st }}, 2018$ ). He provides us with a very detailed and sweeping perspective on the echo chamber by noting how,

It's very much like in the States, where the country is self-selecting where people move to, in order to live around people of like mind, right? So, Democrats are moving to the cities, Philadelphia, you know, those kinds of places. Republicans are moving to certain states and living in certain cities to be away from those who don't share their values. Or, those that watch Fox do it to confirm their bias; those that watch MSNBC do the exact same thing to confirm their own bias. And so, 
they go to bed at night knowing that they're right, because the world has reinforced their bias through the information that they have elected to choose. (Interviewee \#11, personal communication, October $31^{\text {st }}, 2018$ )

With that in mind, he steps back and offers us a self-reflexive assessment of the key challenge posed by a world where the new normal includes microtargeting/segmentation through digital algorithms that are provided by newsfeeds on social media (most notably those on Facebook and Twitter). In that respect, he states that,

That's one of the challenges that political marketing has going forward: that, as we segment more and more, and as we tailor our messages more and more to the individual level, we break away that ability to have a broader conversation or be persuaded with new information from other sources. (Interviewee \#11, personal communication, October $31^{\text {st }}, 2018$ )

Interviewee $\# 19$ also notes the presence of the current political marketing environment's tendency to gravitate towards the creation of such echo chambers, and she does so by highlighting their effectiveness - for both good and bad. The example she cites is that of Ford Nation Live, the campaign website and press release repository which featured press releases carefully and cleverly crafted to appear more like news stories than traditional political campaign press releases (Blackwell, 2018; Bryden, 2019). The Ford Nation Live website was created and run by then Ontario Premier candidate Doug Ford and, to a much lesser extent, the Progressive Conservative Party of Ontario. Building on the foundation of the popular but short-lived (i.e. single episode) TV show Ford Nation which aired on the now defunct Sun News Network and then later on YouTube, Doug Ford's Ford Nation Live website sought to achieve two goals. The first was to raise funds for his ultimately successful premiership campaign, allowing him to deliver content (i.e. his message and his platform) directly to his likely supporters and thereby to bypass traditional media outlets and distribution channels that he and his 
campaign thought would be naturally predisposed to skew his campaign's message in a manner that would benefit the incumbent Ontario Premier and Leader of the Ontario Liberal Party, Kathleen Wynne. The second was, of course, to bring the fight directly to Kathleen Wynne and the long-governing Liberals, but to do so on his own terms and with his own trademark brashness and sense of panache (Blackwell, 2018; Bryden, 2019; Wise, 2018). With that background established, Interviewee \#19 comments on the effectiveness of the political echo chamber effect by stating that:

And then you look at Ford Nation News or whatever, right? And that's, you know, I don't give a shit. New Democrats can talk about how slimy and disingenuous it is, but it fuckin' works. Really, really, really well [emphasis in original]. It's great. So, I mean, the idea that you no longer need the traditional media to communicate to the public is, I think, the most kind of significant overarching [example] of how technology has changed things. (Interviewee \#19, personal communication, November $16^{\text {th }}, 2018$ )

When asked a broad question about the role that marketing as a concept and as a practice is currently playing in political campaigning, Interviewee \#4 takes a cynical stab at the question by responding in a manner that, similar to that of Interviewee \#11 and Interviewee \#19 hints at the increasing prevalence of technology-enabled (via microtargeting) echo chambers:

Well (long pause) they're playing the role of telling politicians how to win without $[\ldots]$ pursuing an agenda, or having a platform, but by stimulating or exciting micro groups and getting them impassioned. That's kind of the way I see things going. I see things, you know, this is very much, you know, kind of the Ford "Ontario Proud" kind of model. (Interviewee \#4, personal communication, October $11^{\text {th }}, 2018$ )

Here Interviewee \#4 refers to Ontario Proud, a notorious Canadian conservative-aligned advocacy group and advertiser that began as merely another politically-charged Facebook page but which is now a brick and mortar business which makes use of advanced digital marketing and microtargeting techniques to aid conservative Canadian candidates and 
causes. Ontario Proud is widely (but unofficially) credited with playing a decisive role in organizing and mobilizing a significant portion of the effort to remove Kathleen Wynne's Liberals from power (Bryden, 2018; Crawley, 2018; Syed, 2018).

With Ontario Proud in mind, Interviewee \#4 states that the most innovative thinking about political campaigning is "probably happening on the far right" (Interviewee \#4, personal communication, October $11^{\text {th }}, 2018$ ). Referencing groups like Ontario Proud, he adds that,

We're seeing this use of narrative tied to data analytics, tied to market segmentation, tied to think tanks, tied to opinion columnists, and it's overall a, you know, a big push on the right. That's the way things seem right now. The most innovative things. And those things, I don't like, but they're the most innovative things I can think of. (Interviewee \#4, personal communication, October $11^{\text {th }}, 2018$ )

He sheds light on the type of innovative work these politically-oriented advocacy groups and digital marketing firms are practicing by explaining that,

Well, you know, they're doing market segmentation, and they're using analytics of peoples' Facebook and other social media accounts that they're using and all that stuff. Well, you know, there's [...] different levels in political campaigning: [...] at the street level, you've got, obviously, data, datasets of voters with whatever historic voter information political parties have gotten. And there's different levels of sophistication on that stuff. And then it just becomes an issue of how much the political parties can buy and analyze to add demographics and psychographic groupings on top of that and then narrowcast messages to them. (Interviewee \#4, personal communication, October $11^{\text {th }}, 2018$ )

Additionally, Interviewee \#4 draws our attention to the rather clandestine nature in which much of this market segmentation is occurring. For example, he states that, with social media-based digital advertising relying upon data-heavy microtargeting strategies, "you can be running ads for days and days to a specific market segment that shows up only in peoples' Google, or their Facebook, or their etc., etc." (Interviewee \#4, personal communication, October $\left.11^{\text {th }}, 2018\right)$. He adds that, 
Define your platform. And, you can be running those ads for a long time before your opponents even understand those ads are having resonance and being run and doing damage, so, you know, unlike the past, where, you know, you did radio ads, or TV ads, as soon as they came out, everybody went 'Oh my God. It's a terrible ad. We've got to counter that,' this is more sneak attacks. So, it's a narrowcasting idea. And, so, the technology has made that possible and the technology has also allowed the analysis to be done so that you can relate the group to the concern and then speak back to it. (Interviewee \#4, personal communication, October $11^{\text {th }}, 2018$ )

He takes this discussion one step further by walking us through an example of how, in his words, "You never see the attack coming" in a political marketing environment characterized by microtargeted digital marketing that uses social media as its conduit (Interviewee \#4, personal communication, October $11^{\text {th }}, 2018$ ). Sticking with his claim that the most innovative thinking about political campaigning is unfortunately happening on the fringe of the political spectrum and, in particular, on the far right, he explains that,

Because we can send out Facebook ads that are really vile and nasty to people who are Soldiers of Odin [the anti-immigrant and arguably neo-Nazi activist group], and they go, 'Wow! I really like that Trump guy, because he's speaking my language.' And they get all revved [up], and the rest of the population never knows. They never see it. (Interviewee \#4, personal communication, October 11 ${ }^{\text {th }}$, 2018)

The reason that such advertising is generally invisible to all but the intended recipient is that the content in that targeted advertising is increasingly in the form of one of the most granular, focused, and controversial data-based microtargeting practices: dark posting. Maxwell Gollin (2018) explains the essentials of dark posting when he notes that,

Dark posts are targeted ads on social media. Unlike boosted or organic posts, though, they don't appear on your timeline. They also don't show up in the feeds of your followers. Instead, they show up as sponsored content in the feeds of users you're specifically targeting [...] They're not formally on your page. Effectively, they only exist for the targeted users that see them. (Gollin, 2018)

With data-driven microtargeting and the broader systemic integration of technology into the life blood of virtually any political marketing campaign able to pay 
for such a treatment, having addressed the aforementioned side effects that may result from doing so, Interviewee \#21 cautions us about one other noteworthy potential side effect: party fracturing. As he explains, "But what I'm getting at is that I think with the fractures that are occurring within the parties, technology and datafications are going to facilitate a third-party movement a little bit more rapidly than we thought about previously" (Interviewee \#21, personal communication, November $23^{\text {rd }}, 2018$ ). Speaking from his perspective as a long-standing Republican digital strategist, he expands upon this nuanced point of view by adding that,

I think that $[\ldots]$ people's fundamental principles aren't going to be found in the traditional parties, the Republican or the Democratic Party. I think you're going to start to see people siphoning off and creating these new party movements. Just like the online voting, it's more of a long-term play. But you're going to start to see more of a third-party effort afoot. (Interviewee \#21, personal communication, November $23^{\text {rd }}, 2018$ )

One could argue that we are already seeing this happen in the United States with the grassroots libertarian and fiscally conservative Tea Party movement of the 2010 Congressional midterms and, more recently, with the ongoing internal party divide that the Democrats are facing at the congressional, senatorial, and presidential primary levels, where they are grappling with the recent resurgence of "Democratic Socialism." This new movement is also occurring in Canada, most notably with Maxime Bernier's recently formed People's Party of Canada which bears a striking philosophical resemblance to the Tea Party movement.

To sum up this discussion on the side effects of targeting and the increasing use of technology writ large in marketing, especially in political marketing, the following comments by two interviewees in my sample are particularly relevant. The first is courtesy of Interviewee \#26 who states that, 
As the role and breadth of data has expanded, the levels to which one can microtarget and the data market has expanded, the ability to microtarget has exponentially increased, and that has become a major part - to the point where it's potentially detrimental to campaigns. (Interviewee \#26, personal communication, January $23^{\text {rd }}, 2019$ )

The second is courtesy of Interviewee \#4 who aptly points out that, in the not so distant past,

Political marketing never had social media and the ability to narrowcast in this way. So, that part is hugely different. Campaigns need now to find out how people can, you know, use Facebook affiliations and keywords to place ads and understand how to navigate that system. I mean, a campaign won't be successful without those people. That didn't even exist two election cycles ago. That barely existed [in] the last [Canadian federal] election cycle (2015). (Interviewee \#4, personal communication, October $11^{\text {th }}, 2018$ ).

Furthermore, he reminds us that, in terms of microtargeting and the data that it relies upon, "The idea of psycho and demographical overlaces is nothing new. That goes back a long time. But now it's like the ability to put it into effect has become [...] weaponized" (Interviewee \#4, personal communication, October $11^{\text {th }}, 2018$ ). 


\section{VII \\ An Ending}

To begin the process of drawing this dissertation to a close requires revisiting the reasoning behind why it was undertaken in the first place. This study was launched for the purpose of re-examining the long-standing relationship between politics and marketing and to review the basic tenets of a discipline known in academia as political marketing including the pattern of influence on which it is predicated. Looking back to the beginning of Chapter I, Susan Delacourt (2013) shone light upon the pattern of influence in question by noting that, "The marketing world would come up with efforts to reach customers better; then, the American political world would borrow and adapt those lessons; and finally, Canadians would import the techniques north of the forty-ninth parallel” (p. 262). That pattern of influence has generally been thought of as the hallmark of political marketing as a discipline. On this subject, Jennifer Lees-Marshment (2001a), perhaps the most influential scholar on the subject of political marketing and also a seminal player in laying the foundation for the formal discipline itself, concisely states that, "Political marketing is about political organisations adapting business marketing concepts and techniques to help them achieve their goals" (p. 22). It is about political marketers adopting the tactics and strategies of commercial marketers for the act of political campaigning and, ultimately, governing.

But nothing is static, not even academia. With this in mind, I chose to examine whether or not that well documented pattern of influence still holds true or if it is shifting. Essentially, I set out to explore the possibility that the flow of influence and innovation between commercial and political marketers is bidirectional and operating as a feedback 
loop rather than merely as a unidirectional flow from commercial to political marketers, the latter being what the vast majority of the literature posits.

Recognizing that it would be impossible to have an exhaustive analysis that definitively deals with all aspects of a discipline as broad as political marketing in one single study, I chose to limit my search for evidence of that bidirectional feedback loop of influence and innovation between commercial and political marketers to two areas serving as an example or, as I referred to them throughout this dissertation, two conduits of influence: marketing and technology.

To obtain the requisite data for such an analysis, 33 elite in-depth interviews were conducted via telephone between September 2018 and February 2019 with a wide array of industry-leading Canadian and American political marketers, commercial marketers, public opinion researchers, pollsters, journalists, political strategists, and strategic communications consultants. The interviews constituted a cumulative 20 hours and 39 minutes of primary research with individuals who, given the high stakes and the cutthroat competitiveness of the work that they do, are typically hesitant to speak to outsiders about their craft. With that data in hand, attention can now be turned to the key findings and instances of the sought for bidirectional feedback loop of influence and innovation between commercial and political marketers. Proceeding chronologically, let us begin that discussion with the results relating to the marketing conduit.

\section{Marketing Conduit Conclusions}

The first key finding or conclusion that falls within the scope of the marketing conduit is that: 
Political marketers appear to have greater experience, comfort, and ability in harnessing speed for the purpose of crafting effective marketing than do their commercial marketing counterparts.

Simply put, political marketers are out-innovating their commercial colleagues under the increasingly time-sensitive constraints that are an inescapable reality of marketing in the current hyper-mediated ecosystem where marketing campaigns - whether political or commercial in nature - are run. Or, to recap what Interviewee \#26 said earlier in Chapter $V$, in political marketing, "You have to get out in front before somebody else gets you" (Interviewee \#26, personal communication, January $23^{\text {rd }}, 2019$ ). This is less so in commercial marketing. While, as noted earlier, this finding offers a clear example of the sought for bidirectional feedback loop of influence wherein political marketers have the upper hand in contending with speed and the challenges it poses for marketers, it also adds a missing element to the definitive political marketing framework developed by Jennifer Lees Marshment and others. In addition, this finding adds further support to the findings of Sasha Issenberg (2012), Clive Veroni (2014), Daniel Kreiss (2016), Bruce I. Newman (2016), and Michael Serazio (2017), amongst others.

As was discussed extensively in Chapter $V$, due to the increased speed of the news cycle courtesy of the proliferation of social media platforms, consumers are expecting more attention and accountability from both the commercial and the political brands with which they interact. Consequently, the shortening of the consumer-to-brand feedback loop caused by the increased speed of the news cycle and by greater consumer expectations has created an environment which is more amenable to the political marketer than it is to the commercial marketer. This is because the former has always had 
to contend with the speed of the news cycle and tight timelines, be they filing deadlines for journalists or the all-important terminal end date known as Election Day. In essence, political marketers are better at managing speed and at using it to their advantage than are commercial marketers - a key point. As an example of the very different interpretations of speed between the commercial and political marketing realms, without a consumer crisis that implicates the brand or product being marketed, consumer marketers move at a much more leisurely pace than do political marketers. This more leisurely pace applies to virtually all components of the way that commercial marketers craft a marketing campaign, whether or not it involves the more methodical and premeditated creative content development process, the more extensive and time-consuming testing of their creative content, or the typically slower rollout of their creative content than is the case on the political side of the aisle.

Related to this is the fact that commercial marketers are more risk averse and less comfortable with the inherent speed of the news cycle and the speed at which marketing campaigns must now be run (should they hope to be successful) than are political marketers. A portion of the commercial marketer's discomfort with speed stems from the reality that both brand building and brand maintenance are much longer running processes than are witnessed in the world of political marketing. Generally speaking, commercial marketers have a much more pronounced intolerance for risk than do political marketers and are less likely to realize that urgency, risk, and opportunity are all connected. Furthermore, the aforementioned terminal end date of Election Day spurs political marketers to be flexible, self-reflexive, nimble, and open to taking risks or even 
to redefining what their brand stands for in ways that are not likely feasible in commercial marketing.

In essence, in today's environment, corporations which are used to the more leisurely pace and the more risk-averse status quo of the relatively recent past and which cannot react to the unforeseen in an expedient manner are increasingly prone to suffering very negative (and very expensive) consequences. For recent examples of this fact one needs only to think of Boeing's sclerotic response to the reliability issues surrounding the now still grounded 737 Max 8 jet and the massive fines applied to Johnson \& Johnson as well as Purdue Pharma for their role in the ongoing opioid crisis — and these are just a few of the most visible instances making headlines this year alone. Put differently, when it comes to contending with speed and risk, commercial marketers should prioritize learning from their political counterparts.

The second key finding or conclusion of this dissertation is that:

The political is bleeding over into more facets of modern life, and this is advantageous to political marketers more so than to commercial marketers since, by their very nature, political marketers - unlike their commercial marketing counterparts - have always had to craft marketing campaigns that are not valueneutral.

As referenced in Chapter $V$, while most interviewees thought that the wholesale likelihood of commercial marketers' reversing their long-standing tendency of upholding brand neutrality in favor of politically-charged commercial marketing campaigns similar to Nike's recent Colin Kaepernick campaign and Gillette's recent \#MeToo/toxic masculinity campaign may not become the new norm any time soon (for reasons of risk 
aversion and the fear of turning off potential customers), there will likely be more momentum to at least experiment with such politically-oriented campaigns in the future. And, should commercial marketers embark upon that experimental path, political marketers have the most valuable expertise to offer. This key deduction adds further insight into the research conducted by Clive Veroni (2014), Margaret Scammell (2015), Robert Busby and Sue Cronshaw (2015), and Michael Serazio (2015).

The third key conclusion within the marketing conduit is that:

Political marketing is a "briefcase business"-especially here in Canada and, therefore, political marketers are more resourceful and efficient marketers who are better at doing more with less than are their commercial marketing colleagues.

As was discussed in Chapter $V$, political marketing can often be thought of as a briefcase business in the sense that many political marketing operations are quite small, often consisting of sole proprietor businesses or consultancies. They run campaigns on shoestring budgets and therefore have to stretch each marketing dollar of the campaign as far as possible. This is particularly true in Canada where the political markets are smaller, less active and less well funded than is the case in the United States where sole proprietor political consultancies co-exist with an abundance of large-scale full-time political consultancies - a situation that is all but impossible here. This important reality check of a finding echoes the thinking of Donald A. Gross and Robert K. Goidel (2003), Eitan D. Hersh (2015), Daniel Kreiss (2016), Daniel Kreiss, Regina G. Lawrence, and Shannon C. McGregor (2018) to name but a few.

The fourth key finding or conclusion in the area of the marketing conduit is that: 
Tribal marketing is becoming a more recognizable, commonplace and effective way of marketing, and political marketers who are more familiar with this practice are better at building and mobilizing tribes than are commercial marketers.

Given that selling politicians and policies has always been a more visceral undertaking than selling commercial products, it is hardly surprising that a deep-seated psychological marketing practice such as tribal marketing would be more familiar territory for political marketers than for commercial marketers and that the practice itself would be more amenable to the world of politics. Again, the stakes are usually not as high — and the emotions are usually not as strong - when addressing commercial brands as opposed to political brands. Even so, tribal marketing is beginning to appear in commercial marketing more frequently than it used to. Why is this the case? An increasingly polarized consumer society which is beginning to mirror an irrefutably polarized political society as well as the savvy commercial marketer's recognition that building a tribe around one's product can be immensely beneficial for business are just two reasons for the growing presence of tribal marketing in the commercial marketing arena. Further, as was described in Chapter $V$, while both political marketers and commercial marketers often attempt to craft consumer tribes or brand tribes, it is often easier to craft and to mobilize those tribes in the political context than in the commercial context. In addition, as was discussed earlier, the electoral landscape is continually changing — increasingly more quickly than in the past — and these changes tend to foster tribal marketing. In fact, many of the interviewees in this sample thought that data-based microtargeting (or segmentation) and tribal marketing are correlated, with some positing that such targeting 
practices promote tribal marketing. This crucial conclusion bolsters support for the work of Bernard Cova and Veronique Cova (2002), Douglas Atkin (2004), Clive Veroni (2014), Robert Busby and Sue Cronshaw (2015), Michael Serazio (2017), and Jhih-Syuan and Itai Himelboim (2018).

\section{Technology Conduit Conclusions}

Using tribal marketing and its connection with the data-based and technologydependent microtargeting practices utilized in both commercial and political marketing as our pivoting point, we can now address the key findings or conclusions that fall under the umbrella of the technology conduit. The first is that:

Political marketers are ahead of commercial marketers in the practice of microtargeting and they are practicing more sophisticated microtargeting than are commercial marketers.

While the lion's share of interviewees rightfully indicated that what can be thought of as microtargeting may have originated in the commercial marketing world prior to its adoption by political marketers, most thought that political marketers currently have the edge over their commercial marketing counterparts on that crucially important element of any serious large-scale contemporary marketing campaign.

This edge (or advantage) enjoyed by political marketers stems from the fact that the data utilized to craft targeted communication with potential voters can be seen as more granular than that which commercial marketers have available for the purposes of crafting targeted communication with their potential customers. As noted earlier, unlike political marketers, commercial marketers have not been extracting the full potential of the possible insights provided by the data that they have been accumulating for a quite 
some time. More often than not, commercial marketers do not know their customers by name, especially when selling smaller ticket (i.e. lower-priced) goods. This is especially true since smaller ticket items do not generate the same quantity of paperwork and therefore the same quantity of data as is generated when acquiring bigger ticket items. Not surprisingly, that fact severely limits commercial marketers' ability to microtarget.

However, because of much stricter privacy laws here in Canada, the use of microtargeting is less advanced in Canada than it is in the United States. Therefore, as a result of this inescapable reality, the voter files used by Canadian political marketers have substantially less data points or metrics than those used by American political marketers. This same privacy-induced data diet applies to Canadian commercial marketers as well when we compare them to their American counterparts.

Aside from varying privacy laws, money is another important consideration in establishing the effectiveness of the use of data-based microtargeting in any given political or commercial marketing campaign. The less money available for targeting potential voters or customers, the harder it generally is to acquire granular data and to massage that granular data into predictive insights that can be used for the purposes of crafting effective communications that increase the likelihood of moving a voter or a customer to a purchasing position — be that voting for a particular candidate or party in the case of political marketing, or buying a certain product or service in the case of commercial marketing. But money and its use for the purpose of developing microtargeting strategies cannot overcome the circumstances in which a campaign is being run. For instance, it cannot make a fundamentally flawed candidate or product any more popular by itself. To put it another way, microtargeting is neither a sure thing, nor is 
it even required in every single political or commercial marketing campaign. It may be a useful tool in the modern marketer's toolbox without regard to the arena (commercial or political) in which that market operates, but occasionally it is a tool that may not fit the particular environment in which a specific campaign is being waged. As stated in Chapter $V$, if we are talking about political marketing, microtargeting cannot change the fundamentals of an election nor its momentum. Furthermore, microtargeting as a tool is most effective in closely contested races given that technology is relative and it cannot escape the context in which it is used. In essence, my first key finding within the technology conduit is complimentary to the research of Sasha Issenberg (2012), Clive Veroni (2014), Eitan D. Hersh (2015), and Daniel Kreiss (2016), in particular.

The second key finding or conclusion within the scope of the technology conduit is that:

Political marketers practice targeting with a greater sense of discipline and efficacy than do commercial marketers.

This important point is similar to the "briefcase business" key finding that was identified as part of the marketing conduit and discussed earlier in this chapter as well as in Chapter $V$. There are factors that are often part and parcel of the practice of political marketing including having less money on hand throughout the duration of a campaign than is generally the case in commercial marketing campaigns, and often being hamstrung by the stricter privacy laws in Canada that can curtail the type of data on hand as well as how that data is used for targeting purposes - which mean that political marketers have to be more disciplined in the targeting that they practice. In other words, they have to run a lean and mean targeting machine compared to commercial marketers. This is further 
accentuated by the fact that the political marketers must develop and execute a marketing campaign much faster than is the case for commercial marketers. It may well be said that speed can be considered the most important element of political campaigning which promotes the use of technology for the purposes of microtargeting with the most discipline and efficiency possible. This important point adds support to the work of Sasha Issenberg (2012), Clive Veroni (2014), Marco M. Cacciotto (2017), Daniel Kreiss and Adam J. Saffer (2017).

The third key finding or conclusion within the scope of the technology conduit is that:

Third-party political marketing technology vendors (i.e. digital political consultants) who practice their trade within a feedback loop which includes interacting with both political and commercial clients are more likely to push the development of new campaign technologies further than are their colleagues who lack such a bidirectional feedback loop — be they either political or commercial marketers.

Furthermore, while political parties still play an important role in the development of new campaign technologies, their role is not best suited to the actual development of such technologies. Instead, the role of political parties is one of defining the problems that could benefit from future technology developments as well as implementing and maintaining the new campaign technologies developed by third-party technology vendors. As was discussed in Chapter VI, third-party vendors may be the better technology innovators but they need the political parties and political marketers running campaigns to guide them in determining the most useful areas for improvement, for 
problem solving through technological application and also in providing the most effective application process for the technologies they develop. Unfortunately, as was also highlighted in Chapter VI, efforts to create continuity in virtually all aspects of political campaigning (infrastructure, personnel and institutional knowledge) can be crippled by the transient nature of political marketing and the high turnover rates of personnel in the staffing of political parties and campaigns. And, quite simply, that lack of continuity is more noticeable the further down-ballot one descends. In sum, this noteworthy finding is aligned with the thinking espoused by Donald A. Gross and Robert K. Goidel (2003), Eitan D. Hersh (2015), Daniel Kreiss (2016), Daniel Kreiss and Shannon C. McGregor (2018), Daniel Kreiss, Regina G. Lawrence, and Shannon C. McGregor (2018), in particular.

With these key findings that highlight the sought for bidirectional flow of influence between commercial and political marketers within the scope of both the marketing conduit and the technology conduit now illuminated, we can now turn our attention to four important questions that should be addressed before we can answer this study's research questions in earnest. The first such question asks: Why is the pattern of influence and innovation in the marketing landscape shifting? While arriving at a comprehensive answer to this question within the final pages of a dissertation is unrealistic (in fact, such a subject matter could easily be the focus of a subsequent substantial piece of scholarly work, a topic that will be discussed shortly), the evidence revealed by the interviewees in this dissertation allows for a preliminary answer to this important question which, in time, could be fleshed out more fully. For example, changes in the confines of what constitutes acceptable terrain for marketers to tackle and changes 
in technology coupled with shifts in the expectations, sophistication, tempo, and patience of target audiences have all played a role in shifting the long-standing pattern of influence and innovation in marketing to one where commercial marketers no longer have a monopoly on the best practices of the alchemy of effective marketing. Regarding the act of marketing itself, political marketers have the upper hand on a number of matters ranging from "doing more with less" than their commercial equivalents (but doing so more expediently), to crafting and activating tribes, to having a more pragmatic approach to risk aversion and, finally, to developing the non-value neutral marketing strategies that are becoming more commonplace in our increasingly polarized world. When thinking about the technology that marketing strategies and marketers themselves rely upon, political marketers also have a number of important advantages over their commercial marketing colleagues. Perhaps the most notable advantage is political marketers' more intricate and efficient practice of data-based microtargeting and "outside of the box" thinking spurred by the financial and manpower constraints that are typically more substantial in the political than in the corporate realm and, of course, by the everincreasing speed at which technology moves.

In fact, speaking of constraints, we should take this opportunity to address something that was revealed courtesy of the interviewees in both Chapters V and VI (and mentioned therein). It is the disparity between the realities of political marketing in Canada and the U.S. which can aptly and concisely be summed up as follows: first and foremost, the data used to craft intricate microtargeting strategies and their appeal to key audiences is less granular, less detailed, less plentiful, and less easily obtained in Canada due to stricter privacy laws and to the more restrictive data acquisition laws north of the 
$49^{\text {th }}$ Parallel. Second, the "from cradle to grave" time span in which elections are called, run, and subsequently won or lost is much shorter in Canada than in the U.S. Third, Canadian political campaigns (regardless of which level of government they are for) have much smaller and tighter budgets than their American counterparts due to, amongst other things, the more stringent campaign finance laws in the Canadian electoral landscape. Fourth, generally as a result of the two previous distinctions, political campaigns in Canada typically have less manpower on hand than do their American equivalents.

The second important question to ask and address at this juncture is the following: how do the findings of this study update or challenge what we already know or think about political marketing? Again, much of the scholarly thinking about political marketing is encapsulated by the political marketing framework developed by Jennifer Lees Marshment and others in the late 1990s and early 2000s. The general line of reasoning is that political marketing borrows and adapts for the political world the thinking, strategies, techniques, and tools of commercial marketing. To put it another way, when it comes to marketing effectively, commercial marketers are the innovators and the influencers. They craft the tools and tactics of the marketing trade but political marketers apply the fruits of commercial marketers' labor to the act of political campaigning. By its very nature, this dissertation offers a more nuanced picture of the interplay of influence and innovation since it is predicated on examining whether or not this pattern is the sole pattern of influence and innovation characterizing the current state of political marketing. Essentially, this study updates and challenges the existing literature on the subject of political marketing by revealing that the flow of influence and innovation between commercial and political marketers can best be thought of as a 
bidirectional feedback loop with two-way traffic between commercial marketers and political marketers instead of as a unidirectional feedback loop with one-way traffic from commercial to political marketers. In other words, it posits that there are numerous instances where political marketers are out-innovating their commercial counterparts - a clear contrast to much of the existing body of literature on the subject of political marketing.

The third question that should be dealt with at this point is one that is necessary but difficult - if we are to be honest — for most researchers to discuss. That question is: what are some of the shortcomings or limitations of this study? First, one such limitation was the fact that, despite numerous efforts to gain the insight of practitioners from both the commercial marketing and political marketing professions in one of the largest political marketing playing fields (most notably the United Kingdom), the intervieweegenerated data was limited to solely Canadian and American respondents (with the exception of course of the one non-North American respondent, the native New Zealander who is referred to as Interviewee \#32). Consequently, this project provided a very Anglo North American-centric perspective on the political marketing profession. Based upon that setback, the results of this study cannot be generalized beyond the scope of the Canadian and American contexts. Similarly, and secondly, since the key areas in which evidence for the bidirectional flow of influence and innovation was limited to that of marketing and technology, it would be unwise and inappropriate to attempt to generalize the findings of this study to other areas of influence and innovation beyond the scope of the aforementioned marketing and technology conduits. Third, another limitation of this study is one that befalls any study utilizing a research method that is 
dependent upon gatekeepers: response rates and representativeness. As was discussed in Chapter $I V$, there were ultimately 33 respondents or interviewees who participated in this study. They were a combination of pure political marketers and hybrid marketers, the latter being a label which was developed to describe individuals who practice marketing in both the political and the commercial realms. There was a dearth of pure commercial marketers represented in this study, but it was not for lack of trying.

The fourth question to address before returning to and ultimately answering the research questions themselves flows naturally out of the previous question. It asks: what are some avenues for future research that could expand upon this study? Naturally, further research on the bidirectional flow of influence and innovation in political marketing could pick up where this study left off. Doing so could include searching for evidence of the bidirectional flow in a non-Anglo North American context by securing interviews with qualified individuals in countries outside of Canada and the United States. But, again, the same problems of accessibility that befell this study would likely befall such a subsequent study. Not surprisingly, another avenue for future research would be to branch out beyond the two conduits of influence to which the results from this study were limited. Finally, further research could utilize a research method other than the elite in-depth interviews used here. However, given the fact that adequately cataloguing and mapping the flow of influence and innovation between the commercial marketing and political marketing ecosystems requires speaking with the influencers and innovators who operate in those environments, other research methods may not be very fruitful. 


\section{Returning to the Research Questions One Last Time}

In the closing pages of this dissertation, it is now time to return to the three research questions that launched this study in the first place. They asked: First, to what extent is political marketing influencing the practice of commercial marketing? Second, how have changes in marketing strategies and technology impacted both political and commercial marketing? Third, what are the likely consequences of the relationship between political marketing and commercial marketing? Let us tackle these research questions chronologically.

First, we can conclude that political marketing is undeniably influencing the practice of commercial marketing and it is doing so in a number of different ways. In the hypermediated, hyperpolarized and increasingly fast-moving ecosystem in which either commercial or political marketing campaigns must be conducted, political marketers have distinct advantages over their traditional commercial marketing colleagues. Political marketers have more experience, comfort, and ability in harnessing speed for the purpose of crafting effective marketing than do their commercial marketing counterparts. Political marketers are more attuned to practicing effective non-value-neutral marketing than are their commercial marketing peers — an increasingly important consideration since the political is bleeding over into ever more facets of modern life, including commercial marketing. Political marketers are more resourceful and efficient marketers and are better at doing more with less than are their commercial marketing colleagues. Tribal marketing is becoming a more recognizable, commonplace and effective way of marketing, and political marketers are more familiar with this practice and are better at building and mobilizing tribes than are commercial marketers. Also, political marketers are running 
more sophisticated, more disciplined and more efficient mictrotargeting practices than are their commercial marketing counterparts.

Second, in terms of how changes in marketing strategies and technology have impacted both political and commercial marketing, we can reason that, in this moment characterized by speed, urgency, data-based microtargeting, tribal marketing, and valuebased brand positioning (to name but a few crucial elements of analysis discussed in this dissertation), these forces have undeniably impacted both commercial and political marketers - but not in the same manner and not to the same extent. With this in mind, we can conclude that these forces impacted political marketers earlier and more noticeably than they did commercial marketers and that, based upon this fact as well as the necessity that it poses, political marketers have had more experience and have developed greater expertise in crafting and producing effective marketing campaigns to address these matters than have commercial marketers.

Third, political marketing and commercial marketing are becoming increasingly interlinked, both in terms of the marketing strategies and the tactics that they utilize as well as the challenges that they must confront and, ultimately, overcome. However, there are a number of serious consequences that can be seen as the side effects of that increasing interaction between the two different marketing realms and which could become more pronounced in the years ahead. These include (but are not limited to): further political polarization; an ever-growing media echo chamber which further precludes any possible type of shared media experience; an increasingly fickle voter and consumer population; an increasingly problematic interpretation of what privacy constitutes and how it factors into technology-dependent marketing — if at all. 
With the key findings from both the marketing conduit and the technology conduit outlined and the research questions answered, we can now determine which of the four testable hypotheses were supported and which were challenged. Let us proceed chronologically.

- $\mathrm{H}_{1}$ : Political marketers are more comfortable than are commercial marketers with the speed at which successful marketing campaigns must be run.

As was revealed in the results on display in Chapter V and Chapter VI and, of course, the key findings recapped in this concluding chapter, this hypothesis $\left(\mathrm{H}_{1}\right)$ was supported.

- $\mathrm{H}_{2}$ : Political marketers are better suited than are commercial marketers to craft and mobilize tribes due to political marketers' longstanding experience with mobilizing the small, but energetic, segments of the populace needed to win elections.

The results in Chapter V and Chapter VI and as well as the key findings from this chapter also allowed us to infer support for this hypothesis $\left(\mathrm{H}_{2}\right)$.

- $\mathrm{H}_{3}$ : Political marketers are better at conducting data-based microtargeting strategies and doing so on tighter budgets than are commercial marketers.

Similarly, the data catalogued and dissected in Chapter VI and also the key findings in this concluding chapter provide support for this third hypothesis $\left(\mathrm{H}_{3}\right)$.

- $\mathrm{H}_{4}$ : Politics is seeping into more areas of contemporary life and, consequently, commercial marketing is becoming less value-neutral.

The fourth and final hypothesis $\left(\mathrm{H}_{4}\right)$ was less clear-cut and therefore more nuanced. While the results illuminated in Chapter V as well as the key findings here in Chapter VII indicate that politics is increasingly infiltrating more aspects of modern life - and that 
this is more advantageous to political marketers since they have always had to craft marketing campaigns that are not value-neutral — most interviewees thought that, although non value-neutral commercial marketing may not become the new norm any time soon (due to corporate risk aversion and a fear of turning off potential customers), there will likely be a greater impetus to potentially experiment with such politicallyoriented commercial marketing campaigns in the future.

In drawing this project to a close, with regard to the influence and innovation needed to mount successful marketing campaigns in the current day and age, unlike as may be commonly assumed, commercial marketers do not hold a monopoly. In essence, this dissertation searched for evidence of a bidirectional feedback loop of influence and innovation between commercial and political marketers which, if found, could add a more nuanced understanding of the long-standing status quo in academic literature and popular thinking on the matter of political marketing. Figure 1, which can be seen on the following page, serves the purpose of visually representing the sought for feedback loop.

Despite the fact that no pure commercial marketers were represented in this study's sample (since all interview requests sent to such candidates were denied), after a substantial amount of secondary and primary research focused upon two conduits of influence or areas that exemplify the possibility that the flow of influence and innovation between commercial and political marketers is bidirectional and is operating as a feedback loop rather than merely a unidirectional flow from commercial to political marketers (those being marketing and technology), we can conclude that political marketers are indeed ahead of their commercial counterparts on certain matters in the exercise of their profession. 
Figure 1. Two-Way Flow of Influence \& Innovation Flowchart

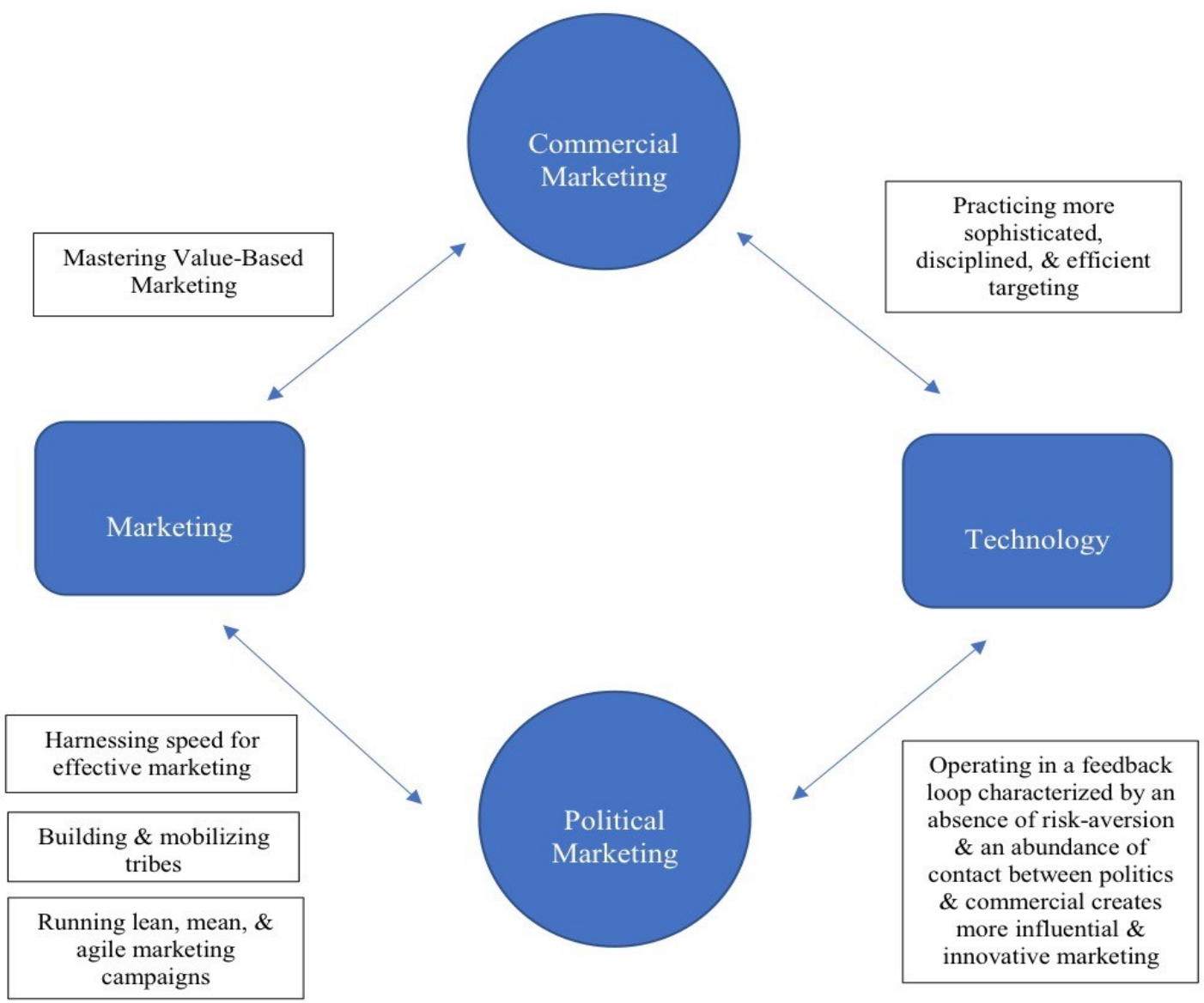

But what is the cost of this claim? And what are the consequences of this finding?

While such questions cannot be answered exhaustively in the closing pages of a dissertation (in fact, answers of that sort could easily populate an entire dissertation), it is nonetheless important to address them here. This is especially true since, as was mentioned earlier in both Chapter I and Chapter II, it is not atypical for scholarly discussions of political marketing to include accusations of political marketing's having a malignant effect upon democracy. That effect is characterized as, amongst other things, polluting the envisioned purity of democratic governance with what many have viewed (rightly or wrongly) as being the cynical and short-term uses and instant gratifications 
typically associated with consumer marketing. And that is to say nothing of grandiose discussions of the public sphere as well as the obvious differences between commercial marketing and political marketing.

To begin this concise but crucial discussion, let us turn our attention to one of the most frequent accusations found in almost every scholarly reflection upon the impact of political marketing and which, based on its omnipresence, we can use to pivot towards a discussion of not just the possible consequences of the proliferation of political marketing but, more importantly, the consequences of the bidirectional feedback loop of influence and innovation that this dissertation searched for. The accusation is that marketing in politics cheapens the political process and the process of elective governance by applying the supposedly superficial modus operandi of consumerism replete with some of its worst side effects (most notably short-term thinking, instant gratification, and style over substance) to the act of political campaigning and, should a campaign be successful, to the act of governing. Such lines of reasoning are voiced by the likes of Terence H. Qualter (1991), Zygmunt Bauman (2005), and Joe Klein (2006). But, as Thierry Giasson, Jennifer Lees-Marshment, and Alex Marland (2012) remind us, "Political marketing is said to have both positive and negative implications for democracy. The actual democratic outcome of the process depends on the way that political organizations choose to use the tools and concepts offers" (p. 250). Stephan C. Henneberg, Margaret Scammell, and Nicholas J. O'Shaughnessy (2009) shine light upon an important positive implication of political marketing when they state that the "relationship building approach of political marketing could well provide a basis for more meaningful interactions between voters and institutions" (p. 166). Similar arguments are voiced by 
Declan P. Bannon (2005), Helene P. M. Johansen (2005), Stephan C. Henneberg and Nicholas J. O’Shaughnessy (2009), and Thierry Giasson, Jennifer Lees-Marshment, and Alex Marland (2012).

The key findings from both the marketing conduit and the technology conduit (which were summarized earlier in this concluding chapter) highlighted how, with a discerning eye, contrary to common belief and also to much of academic literature, the flow of influence and innovation between commercial and political marketers can be seen as a bidirectional feedback loop rather than merely a unidirectional feedback loop flowing from commercial to political marketers. An inescapable consequence of this is that the line between commercial marketing and political marketing is blurring to the extent where it is no longer truly visible. Or, as numerous interviewees in this project posited, the political is bleeding over into the commercial more and more. One could argue that consumers are being forced to take sides on political issues through the very products they purchase - or refuse to purchase. To use the current vernacular, increasingly, consumers are obliged to find their tribe or their lane and to stay in it at all costs. This is familiar territory for political marketers but much less so for commercial marketers. Furthermore, the increasing proliferation of microtargeting strategies and the hyper-fragmentation that it creates continues to offer opportunities by way of allowing marketers (whether political or commercial) to find, communicate with, and mobilize individuals who are receptive to a marketer's pitch — be that purchasing a product or a service or voting for a certain candidate. However, these strategies have been known to increase the ideological polarization that can be seen as scuttling any potential for reasoned and deliberative discussions on an ever-growing number of subject matters. 
In essence, the practice of marketing and the influence and innovation it relies upon is changing. And, as Winston Churchill famously remarked in 1925, a full fifteen years prior to his becoming the Prime Minister of the United Kingdom, "There is nothing wrong in change, if it is in the right direction" (Churchill, 2009, p. 27). However, defining what constitutes change in the "right direction" and how it can be applied to the current state of marketing remains a difficult and frustrating task that will ultimately remain unresolved for quite some time, if not indefinitely. With that in mind, it is poetically fitting to note that, when Churchill made his comments in 1925, another well known individual by the name of Francis Scott Fitzgerald (2001), in concluding The Great Gatsby, perhaps one of the most seminal American novels of all time, wrote that, "So we beat on, boats against the current, borne back ceaselessly into the past" (p. 115). 


\section{Bibliography}

Allen, J., \& Parnes, A. (2017). Shattered: Inside Hillary Clinton's Doomed Campaign. New York, NY: Crown.

Arnhold, U. (2010). User Generated Branding: Integrating User Generated Content into Brand Management. Bremen, Germany: Gabler Verlag.

Atkin, D. (2004). The Culting of Brands: When Customers Become True Believers. New York, NY: Portfolio

Babbie, E. (2005). The Basics of Social Research (3 ${ }^{\text {rd }}$ ed.). Belmont, CA: Thompson Wadsworth.

Bannon, D. P. (2005). Relationship Marketing and the Political Process. Journal of Political Marketing, 4(2), 85-102.

Barbook, R., \& Cameron, A. (1996). The Californian Ideology. Science as Culture, 6(1), 44-72.

Barksdale, H.C., \& Darden, B. (1971). Marketers' Attitude Toward the Marketing Concept. Journal of Marketing, 35(4), 29-36.

Bauerlein, M. (2009). The Dumbest Generation: How the Digital Age Stupefies Young Americans and Jeopardizes Our Future [Or, Don't Trust Anyone Under 30]. New York, NY: Jeremy P. Tarcher/Penguin.

Bauman, Z. (2005). Liquid Life. Cambridge, U.K.: Polity.

Berg, B. L. (2009). Qualitative Research Methods for the Social Sciences ( $7^{\text {th }}$ ed.). Boston, MA: Allyn \& Bacon.

Berger, A. A. (2011). Media and Communication Research Methods: An Introduction to Qualitative and Quantitative Approaches ( $2^{\text {nd }}$ ed.). Thousand Oaks, CA: SAGE Publications Inc.

Bennett, W. L. (2012). News: The Politics of Illusion ( $9^{\text {th }}$ ed.). Boston, MA: Longman.

Bird, A. (1994). Careers as Repositories of Knowledge: A New Perspective on Boundaryless Careers. Journal of Organizational Behaviour, 15(4), 325-344.

Birnbaum, J. H. (2000). The Money Men: The Real Story of Fund-raising's Influence on Political Power in America. New York, NY: Crown Publishers.

Breen, T.H. (2004). The Marketplace of Revolution: How Consumer Politics Shaped American Independence. New York, NY: Oxford University Press. 
Bryman, A \& Teevan, J. J. (2005). Social Research Methods: Canadian Edition. Don Mills, ON: Oxford University Press.

Busby, R., \& Cronshaw, S. (2015). Political Branding: The Tea Party and its Use of Participation Branding. Journal of Political Marketing, 14(1/2), 96-110.

Butler, P., \& Harris, P. (2009). Considerations on the Evolution of Political Marketing Theory. Marketing Theory, 9(2), 149-164.

Cacciotto, M. M. (2017). Is Political Consulting Going Digital? Journal of Political Marketing, 16(1), 50-69.

Carey, J. W. (1989). Technology and Ideology: The Case of the Telegraph. In J. W. Carey, Communication as Culture: Essays on Media and Society (pp. 201-30). Boston, MA: Unwin Hyman, Inc.

Carey, J. W. \& Quirk, J. J. (1989). The Mythos of the Electronic Revolution. In J. W. Carey, Communication as Culture: Essays on Media and Society (pp. 113- 41). Boston, MA: Unwin Hyman, Inc.

Carlson, W. B. (2001). The Telephone as Political Instrument: Gardiner Hubbard and the Formation of the Middle Class in America, 1875-1880. In M. T. Allen \& G. Hecht (Eds.), Technologies of Power: Essays in Honor of Thomas Parke Hughes and Agatha Chipley Hughes (pp. 25-56). Cambridge, MA: The MIT Press.

Chua, A. (2018). Political Tribes: Group Instinct and the Fate of Nations. New York, NY: Penguin Press.

Churchill, W. (1925/2009). Churchill's Wit: The Definitive Collection. R. M. Langworth (Ed.). London, U.K.: Ebury Press.

Copeland, D. A. (2003). The Antebellum Era: Primary Documents on Events from 1820 to 1860. Westport, CT: Greenwood Press.

Cormack, P. (2012). Double-Double: Branding, Tim Hortons, and the Public Sphere. In A. Marland, T. Giasson, \& J. Lees-Marshment (Eds.), Political Marketing in Canada (pp. 209-23). Vancouver, BC: UBC Press.

Cornfield, M. (2017). Empowering the Party-Crasher: Donald J. Trump, the First 2016 GOP Presidential Debate, and the Twitter Marketplace for Political Campaigns. Journal of Political Marketing, 16(3/4), 212-243.

Cova, B. (1997). Relationship Marketing: A View from the South. In T. Meenaghan (Ed.), New and Emerging Paradigms, AMA Special Conference, University College Dublin, June, pp. 657-72. 
Cova, B., \& Cova, V. (2002). Tribal Marketing: The Tribalisation of Society and its Impact on the Conduct of Marketing. European Journal of Marketing, 36(5/6), 595-620.

Cova, B., Kozinets, R. V., \& Shankar, A. (2007). Tribes, Inc.: The New World of Tribalism. In B. Cova, R. V. Kozinets, \& A. Shankar (Eds.), Consumer Tribes (pp. 3-25). Oxford, U.K.: Butterworth-Heinemann.

Craig, D. B. (2005). Fireside Politics: Radio and Poltical Culture in the United States, 1920-1940. Baltimore, MD: The Johns Hopkins University Press.

Czitrom, D. J. (1982). Media and the American Mind: From Morse to McLuhan. Chapel Hill, NC: The University of North Carolina Press.

Delacourt, S. (2013). Shopping for Votes: How Politicians Choose Us and How We Choose Them. Madeira Park, BC: Douglas and McIntyre Ltd.

Dermody, J., \& Scullion, R. (2001). Perceptions of Negative Political Advertising: Meaningful or Menacing? An Empirical Study of the 1997 British General Election. International Journal of Advertising, 19(2), 201-225.

Dermody, J., \& Scullion, R. (2003). Facing the Future: Young People's Awareness of the 2001 British General Election Advertising Campaigns. Journal of Public Affairs, $3(2), 152-165$.

De Sola Pool, I. (1983). Forecasting the Telephone: A Retrospective Technology Assessment. Norwood, NJ: Praeger

De Vaan, M., Stark, D., \& Vedres, B. (2015). Game Changer: The Topology of Creativity. American Journal of Sociology, 120(4), 1144-1194.

Dufresne, Y. \& Marland, A. (2012). The Canadian Political Market and the Rules of the Game. In A. Marland, T. Giasson, \& J. Lees-Marshment (Eds.), Political Marketing in Canada (pp. 22-38). Vancouver, BC: UBC Press.

Elder, E., \& Phillips, J. B. (2017). Appeals to the Hispanic Demographic: Targeting through Facebook Autoplay Videos by the Clinton Campaign During the 2015/2016 Presidential Primaries. Journal of Political Marketing, 16(3/4), 319342.

Ferguson, N. (2017). The Square and the Tower: Networks and Power, from the Freemasons to Facebook. New York, NY: Penguin Press.

Fitzgerald, F. S. (2001). The Great Gatsby. Ware, Hertfordshire, U.K.: Wordsworth Classics. 
Giasson, T., Lees-Marshment, J., \& Marland, A. (2012). Introducing Political Marketing. In A. Marland, T. Giasson \& J. Lees-Marshment (Eds.), Political Marketing in Canada (pp. 3-21). Vancouver, B.C.: UBC Press.

Goldberg, J. (2018). Suicide of the West: How the Rebirth of Tribalism, Populism, Nationalism, and Identity Politics Is Destroying American Democracy. New York, NY: Crown Forum.

Goldstein, K. (2002). Getting in the Door: Sampling and Completing Elite Interviews. PS: Political Science \& Politics, 35(4), 669-672.

Gollin, M. (2018, November 13). What are Dark Posts on Social Media? We Shed Some Light on Dark Posts for Facebook, Instagram, Twitter, and LinkedIn. FALCON.IO. Retrieved from: https://www.falcon.io/insights-hub/topics/socialmedia-strategy/what-are-dark-posts-on-social-media-2018/

Green, J. (2017). Devil's Bargain: Steve Bannon, Donald Trump, and the Nationalist Uprising. New York, NY: Penguin Books.

Green, J., \& Issenberg, S. (2016, October 27). Inside the Trump Bunker, With Days to Go. Bloomberg Businessweek. Retrieved from: https://www.bloomberg.com/news/articles/2016-10-27/inside-the-trump-bunkerwith-12-days-to-go

Green, M. (2002). Selling Out: How Big Corporate Money Buys Elections, Rams Through Legislation, and Betrays Our Democracy. New York, NY: Regan Books.

Gross, D. A. \& Goidel, R. K. (2003). The States of Campaign Finance Reform. Columbus, OH: The Ohio State University Press.

Halpern, S. (2017, June 8). How He Used Facebook to Win. The New York Review of Books. Retrieved from: http://www.nybooks.com/articles/2017/06/08/how-trumpused-facebook-to-win/

Hanson, E. C. (2008). The Information Revolution and World Politics. Lanham, MD.: Rowman \& Littlefield Publishing Group, Inc.

Harding, J. (2008). Alpha Dogs: The Americans Who Turned Political Spin into a Global Business. New York, NY: Farrar, Straus and Giroux.

Hayles, K. N. (2012). How We Think: Digital Media and Contemporary Technogenesis. Chicago, IL: The University of Chicago Press.

Heaney, M. T., Newman, M. E., \& Sylvester, D. E. (2011). Campaigning in the Internet Age. In Stephen C. Craig \& David B. Hills (Eds.), The Electoral Challenge (2 ${ }^{\text {nd }}$ ed.). Washington, DC.: CQ Press. 
Henneberg, S.C., Scammell, M., \& O’Shaughnessy, N.J. (2009). Political Marketing Management and Theories of Democracy. Marketing Theory, 9(2), 165-188.

Henneberg, S.C., Scammell, M., \& O'Shaughnessy, N.J. (2009). Political Relationship Marketing: Some Micro/Macro Thoughts. Journal of Marketing Management (1/2), 5-29.

Hersh, E. D. (2015). Hacking the Electorate: How Campaigns Perceive Voters. Cambridge, UK: Cambridge University Press.

Hersh, E. D. (2018, May 16). Cambridge Analytica and Data Privacy [U.S. Senate Judiciary Committee Testimony]. Washington, D.C.

Holt, D. (2002). Why Do Brands Cause Trouble? A Dialectical Theory of Consumer Culture and Branding. Journal of Consumer Research, 29(1), 70-90.

Houchin Winfield, B. (1990). FDR and the News Media. Urbana, IL: University of Illinois Press.

Issenberg, S. (2012). The Victory Lab: The Secret Science of Winning Campaigns. New York, NY: Crown Publishers.

Jiwani, F.N., \& Krawchenko, T. (2014). Public Policy, Access to Government, and Qualitative Research Practices: Conducting Research within a Culture of Information Control. Canadian Public Policy, 40(1), 57-66.

Johansen, H. P. M. (2005). Political Marketing: More Persuasive Techniques, an Organizational Perspective. Journal of Political Marketing, 4(4), 85-105.

John, R. (2010). Network Nation: Inventing American Telecommunications. Cambridge, MA: The Belknap Press of Harvard University Press.

Kary, T. (2018, May 18). Cambridge Analytica Files U.S. Bankruptcy After Data Scandal. Bloomberg. Retrieved from: https://www.bloomberg.com/news/articles/2018-05-18/cambridge-analytica-filesu-s-bankruptcy-after-data-scandal

Keller, K.L. (2002). Branding and Brand Equity. In B.A. Weitz \& R. Wensley (Eds.), Handbook of Marketing. Thousand Oaks, CA: Sage.

Kittler, F. (2010). Optical Media: Berlin Lectures 1999. (A. Evans, Trans.). Cambridge, U.K.: Polity Press. (Original work published 2002)

Klein, J. (2006). Politics Lost. New York, N.Y.: Doubleday.

Klein, N. (2000). No Logo. New York, NY: Picador. 
Kohli, A. K., \& Jaworski, B. J. (1990). Market Orientation: The Construct, Research Propositions, and Managerial Implications. Journal of Marketing, 54(2), 1-18.

Knuckey, J., \& Lees-Marshment, J. (2005). American Political Marketing: George W. Bush and the Republican Party. In D. Lilleker \& J. Lees-Marshment (Eds.), Political Marketing: A Comparative Perspective (pp. 39-58). Manchester, U.K.: Manchester University Press.

Kraska, T. (2013). Finding the Needle in the Big Data Systems Haystack. IEEE Internet Computing, 17(1), 84-6.

Kreiss, D. (2016). Prototype Politics: Technology-Intensive Campaigning and the Data of Democracy. New York, N.Y.: Oxford University Press.

Kreiss, D., \& Jasinski, C. (2016). The Tech Industry Meets Presidential Politics: Explaining the Democratic Party's Technological Advantage in Electoral Campaigning, 2004-2012. Political Communication, 33(4), 544-562.

Kreiss, D., Lawrence, R. G., \& McGregor, S. C. (2018). In Their Own Words: Political Practitioner Accounts of Candidates, Audiences, Affordances, Genres, and Timing in Strategic Social Media Use. Political Communication, 35(1), 8-31.

Kreiss, D., \& McGregor, S. C. (2018). Technology Firms Shape Political Communication: The Work of Microsoft, Facebook, Twitter, and Google With Campaigns During the 2016 U.S. Presidential Cycle. Political Communication, 35(2), 155-177.

Kreiss, D., \& Saffer, A. J. (2017). Networks and Innovation in the Production of Communication: Explaining Innovations in U.S. Electoral Campaigning from 2004 to 2012. Journal of Communication, 67(4), 521-544.

Lafferty, B. A., \& Hult, G. T. M. (2001). A Synthesis of Contemporary Market Orientation Perspectives. European Journal of Marketing, 35(1/2), 92-109.

Lasswell, H. D. (1938). Propaganda Technique in the World War. New York, N.Y.: Peter Smith.

Lees-Marshment, J. (2001a). Political Marketing and British Political Parties: The Party's Just Begun. Manchester, U.K.: Manchester University Press.

Lees-Marshment, J. (2001b). The Marriage of Politics and Marketing. Political Studies, 49(4), 692-713.

Lees-Marshment, J. (2001c). The Product, Sales and Market-Oriented Party: How Labour Learnt to Market the Product, Not Just the Presentation. European Journal of Marketing, 35(9/10), 1074-1084. 
Lees-Marshment, J. (2004). The Political Marketing Revolution: Transforming the Government of the UK. Manchester, U.K.: Manchester University Press.

Lees-Marshment, J. (2009). Marketing After the Election: The Potential and Limitations of Maintaining a Market Orientation in Government. Canadian Journal of Communication, 34(2), 205-27.

Lees-Marshment, J. (2012). The Impact of Market Research on Political Decisions and Leadership: Practitioners' Perspectives. In A. Marland, T. Giasson \& J. LeesMarshment (Eds.), Political Marketing in Canada (pp. 91-106). Vancouver, B.C.: UBC Press.

Lees-Marshment, J. (2013). Welcome to Political Marketing: Training to be Delivered for the Graduate Programme in Political Management at Carleton University. Auckland, New Zealand: Jennifer Lees-Marshment.

Lees-Marshment, J., Conley. B.M., \& Cosgrove, K. (2014). Marketing US Politics. In J. Lees-Marshment, B.M. Conley, \& K. Cosgrove (Eds.), Political Marketing in the United States (pp. 1-25). New York, NY: Routledge.

Leslie, L. Z. (2010). Communication Research Methods in Postmodern Culture: A Revisionist Approach. Boston, MA: Allyn \& Bacon.

Levine, L. W., \& Levine, C. R. (2010). The Fireside Conversations: America Responds to FDR During the Great Depression. Berkeley, CA: University of California Press.

Lilleker, D.G. (2003). Interviewing the Political Elite: Navigating a Potential Minefield. Politics, 23(3), 207-214.

Lilleker, D.G. (2005). Local Campaign Management: Winning Votes or Wasting Resources? Journal of Marketing Management, 21(9/10), 979-1003.

Lin, J.S., \& Himelboim, I. (2018). Political Brand Communities as Social Network Clusters: Winning and Trailing Candidates in the GOP 2016 Primary Elections. Journal of Political Marketing, 18(1-2), 119-147.

Lubrano, A. (1997). The Telegraph: How Technology Innovation Caused Social Change. New York, NY: Garland Publishing, Inc.

Marland, A. (2003). Marketing Political Soap: A Political Marketing View of Selling Candidates Like Soap, of Electioneering as a Ritual, and of Electoral Military Analogies. Journal of Public Affairs, 3(2), 103-15. 
Marland, A., \& Esselment, A. (2018). Tips and Tactics for Securing Interviews with Political Elites. In A. Marland, T. Giasson, \& A. Lawlor (Eds.), Political Elites in Canada: Power and Influence in Instantaneous Times (pp. 29-47). Vancouver, BC: UBC Press.

Marx, L., \& Smith, M. R. (1994). Introduction. In M. R. Smith \& L. Marx (Eds.), Does Technology Drive History? The Dilemma of Technological Determinism (pp. ixxv). Cambridge, MA: MIT Press.

McGinniss, J. (1969). The Selling of the President, 1968. New York, NK: Trident Press.

McNamara, C.P. (1972). The Present Status of the Marketing Concept. Journal of Marketing, 36(1), 50-57.

Merrigan, G. M., Huston, C. L., \& Johnston, R. (2012). Communication Research Methods (Canadian Edition). Don Mills, ON: Oxford University Press.

Miller, W. J. (2013). We Can't All Be Obama: The Use of New Media in Modern Political Campaigns. Journal of Political Marketing, 12(4), 326-347.

Moloney, K., \& Colmer, R. (2001). "Does Political PR Enhance or Trivialise Democracy? Journal of Marketing Management, 17 (9/10), 957-968.

Mooney, K., \& Rollins, N. (2008). The Open Brand: When Push Comes to Pull in a WebMade World. Berkeley, CA: New Riders.

Morozov, E. (2013, October 28). Only Disconnect: Two Cheers for Boredom. The New Yorker, 33-37.

Muniz, A.M., \& O'Guinn, T.C. (2001). Brand Community. Journal of Consumer Research, 27(4), 412-432.

Narver, J. C., \& Slater, S. F. (1990). The Effect of Market Orientation on Business Profitability. Journal of Marketing, 54(4), 20-35.

Neuman, W.L. (2000). Social Research Methods: Qualitative and Quantitative Approaches ( $4^{\text {th }}$ ed.). Needham Heights, MA: Allyn \& Bacon.

Newman, B. I. (1994). The Marketing of the President: Political Marketing as Campaign Strategy. Thousand Oaks, CA: Sage Publications, Inc.

Newman, B. I. (2016). The Marketing Revolution in Politics: What Recent U.S. Presidential Campaigns Can Teach Us About Effective Marketing. Toronto, ON: Rotman-UTP Publishing. 
Nownes, A. J. (2013). Interest Groups in American Politics: Pressure and Power $\left(2^{\text {nd }}\right.$ Ed.). New York, NY: Routledge.

O’Cass, A. (1996). Political Marketing and the Marketing Concept. European Journal of Marketing, 30(10/11), 37-53.

O’Cass, A. (2001a). Political Marketing: An Investigation of the Political Marketing Concept and Political Market Orientation in Australian Politics. European Journal of Marketing, 35(9/10), 1003-1025.

O'Cass, A. (2001b). The Internal-External Marketing Orientation of a Political Party: Social Implications of Political Party Marketing Orientation. Journal of Public Affairs, 1(2), 136-152.

Ormrod, R. P. (2004). Operationalising the Conceptual Model of Market Orientation. Report Series on Political Communication No. 14. Sundsvall, Sweden: Institute for Democratic Communication.

Ormrod, R. P. (2005). A Conceptual Model of Political Market Orientation. Journal of Nonprofit and Public Sector Marketing, 14(1/2), 47-64.

Ormrod, R. P. (2006). A Critique of the Jennifer Lees-Marshment Market Oriented Party Model. Politics, 26(2), 110-18.

Ostergaard, P. \& Jantzen, C. (2000). Shifting Perspectives in Consumer Research: From Buyer Behaviour to Consumption Studies, in S. Beckmann \& R. H. Elliott (Eds.), Interpretive Consumer Research: Paradigms, Methodologies \& Applications (pp. 9-23). Copenhagen: CBS Press.

O’Sullivan, D., \& Griffin, D. (2018, May 17). Cambridge Analytica Ran Voter Suppression Campaigns, Whistleblower Claims. CNN. Retrieved from: https://www.cnn.com/2018/05/16/politics/cambridge-analytica-congresswylie/index.html

Postman, N. (1992). Technopoly: The Surrender of Culture to Technology. New York, NY: Alfred A. Knopf, Inc.

Qualter, T. (1991). Advertising and Democracy in the Mass Age. Basingstoke, U.K.: Macmillan.

Ries, A., \& Ries, L. (2002). The Fall of Advertising and the Rise of PR. New York, NY: HarperCollins.

Ritchie, J., Lewis, J., McNaughton Nicholls, C., \& Ormston, R. (Eds.). (2014). Qualitative Research Practice: A Guide for Social Science Students \& Researchers (2 ${ }^{\text {nd }}$ ed.). London, U.K.: SAGE Publications Ltd. 
Rosenberg, M., \& Confessore, N. (2018, May 15). Justice Department and F.B.I. Are Investigating Cambridge Analytica. The New York Times. Retrieved from: https://www.nytimes.com/2018/05/15/us/cambridge-analytica-federalinvestigation.html

Rowlinson, M., Booth, C., Clark, P., Delahaye, A., \& Procter, S. (2010). Social Remembering and Organizational Memory. Organizational Studies, 31(1), 69-87.

Savigny, H. (2008). The Problem of Political Marketing. London, U.K.: Continuum International Publishing Group.

Samples, J. (2006). The Fallacy of Campaign Finance Reform. Chicago, IL: University of Chicago Press.

Scammell, M. (1995). Designer Politics: How Elections are Won. New York, NY: St. Martin's Press, Inc.

Scammell, M. (2003). Citizen Consumers: Towards a New Marketing of Politics? In J. Corner \& D. Pels (Eds.), Media and the Restyling of Politics: Consumerism, Celebrity and Cynicism (pp. 117-36). Thousand Oaks, CA: Sage.

Scammell, M. (2007). Political Brands and Consumer Citizens: The Rebranding of Tony Blair. The Annals of the American Academy of Political and Social Science, 611, 176-192.

Scammell, M. (2015). Politics and Image: The Conceptual Value of Branding. Journal of Political Marketing, 14(1/2), 7-18.

Schudson, M. (2007). Citizens, Consumers, and the Good Society. The Annals of the American Academy of Political and Social Science, 611, 236-249.

Serazio, M. (2015). Managing the Digital News Cyclone: Power, Participation, and Political Production Strategies. International Journal of Communication, 9, 1907 1925.

Serazio, M. (2017). Branding Politics: Emotion, Authenticity, and the Marketing Culture of American Political Communication. Journal of Consumer Culture, 17(2), 225 241.

Shah, D.V., McLeod, D.M., Friedland, L., \& Nelson, M.R. (2007). Introduction: The Politics of Consumption/The Consumption of Politics. The Annals of the American Academy of Political and Social Science, 611, 6-15. 
Shah, D.V., McLeod, D.M., Kim, E., Lee, S.Y., Gotlieb, M.R., Ho, S.S., \& Breivik, H. (2007). Political Consumerism: How Communication and Consumption Orientations Drive "Lifestyle Politics." The Annals of the American Academy of Political and Social Science, 611, 217-235.

Sharkey, T. (2012, January 25). What's Your Tribe? Tap into Your Core Consumers' Aspirations Like Nike, Gatorade, BabyCenter and REI Do. Forbes. Retrieved from: https://www.forbes.com/sites/tinasharkey/2012/01/25/whats-your-tribe-tapinto-your-core-consumers-aspirations-like-nike-gatorade-babycenter-and-reido/\#141 ccbdd304c

Silverman, J. (2015). Terms of Service: Social Media and the Price of Constant Connection. New York, NY: Harper.

Small, T. A. (2012). Are We Friends Yet? Online Relationship Marketing by Political Parties. In A. Marland, T. Giasson, \& J. Lees-Marshment (Eds.), Political Marketing in Canada (pp. 193-208). Vancouver, BC: UBC Press.

Smith, M. L. (1994). Recourse of Empire: Landscapes of Progress in Technological America. In M. R. Smith \& L. Marx (Eds.), Does Technology Drive History? The Dilemma of Technological Determinism (pp. 37-52). Cambridge, MA: MIT Press.

Smith, M. R. (1994). Technological Determinism in American Culture. In M. R. Smith \& L. Marx (Eds.), Does Technology Drive History? The Dilemma of Technological Determinism (pp. 1-35). Cambridge, MA: MIT Press.

Solnit, R. (2013, August 29). Diary. London Review of Books, 32-31.

Sombart, W. (1915). Händler und Helden: Patriotische Besinnungen [Traders and Heroes: Patriotic Reflections]. München: Leipzig.

Sorauf, F. J. (1992). Inside Campaign Finance: Myths and Realities. New Haven, CT: Yale University Press.

Speed, R., Butler, P., \& Collins, N. (2015). Human Branding in Political Marketing: Applying Contemporary Branding Thought to Political Parties and Their Leaders. Journal of Political Marketing, 14(1-2), 129-51.

Spengler, O. (1932). Man and Technics: a Contribution to a Philosophy of Life. New York, NY: Knopf.

Tett, G. (2015). The Silo Effect: The Peril of Expertise and the Promise of Breaking Down Barriers. New York, N. Y.: Simon and Schuster Paperbacks. 
Thompson, J. A., \& Moncrief, G. F. (1998). Exploring the "Lost World" of Campaign Finance. In J. A. Thompson, \& G. F. Moncrief (Eds.), Campaign Finance in State Legislative Elections (pp. 3-17). Washington, D.C.: Congressional Quarterly Inc.

Thompson, J. B. (1995). The Media and Modernity: A Social Theory of the Media. Stanford, CA: Stanford University Press.

Thomson, S. (2018, May 12). The Global War Against the World's Data Pirates. National Post, pp. A13.

Tokofsky, J., Zupnik, S. R. (Producers) \& Foley, J. (Director). (1992). Glengarry Glen Ross [Motion picture]. United States: New Line Cinema.

Turcotte, A. (Forthcoming). Beyond Market Intelligence: New Dimensions in Public Opinion Research [Book Chapter].

Turner, F. (2006). From Counterculture to Cyberculture: Stewart Brand, the Whole Earth Network, and the Rise of Digital Utopianism. Chicago, IL: The University of Chicago Press.

Tzu, S. (2006). The Art of War. Filiquarian Publishing, LLC.

van den Hoonaard, D. K. (2015). Qualitative Research in Action: A Canadian Primer $\left(2^{\text {nd }}\right.$ ed.). Don Mills, ON: Oxford University Press.

Veroni, C. (2014). Spin: How Politics has the Power to Turn Marketing on Its Head. Toronto, ON: House of Anansi Press Inc.

Westen, D. (2007). The Political Brain: The Role of Emotion in Deciding the Fate of the Nation. New York, NY: Public Affairs.

Wheeler, T. (2006). Mr. Lincoln's T-Mails: How Abraham Lincoln Used the Telegraph to Win the Civil War. New York, NY: Collins.

Wigan, M. R. \& Clarke, R. (2013). Big Data's Big Unintended Consequences. Computer, 46(6), 46-53.

Williams, R. (1990). Television: Technology and Cultural Form. London, U.K.: Routledge.

Winston, J. (2016, November 18). How the Trump Campaign Built and Identity Database and Used Facebook Ads to Win the Election. Medium / Startup Grind. Retrieved from: https://medium.com/startup-grind/how-the-trump-campaign-built-anidentity-database-and-used-facebook-ads-to-win-the-election-4ff7d24269ac 
WIRED. (2016, January 19). Meet the 20 Tech Insiders Defining the 2016 Campaign. WIRED. Retrieved from: https://www.wired.com/2016/01/silicon-valleyinfluence-2016-election/

Wylie, C. (2018, May 16). Cambridge Analytica and Data Privacy [U.S. Senate Judiciary Committee Testimony]. Washington, D.C.

Yeo, A., Legard, R., Keegan, J., Ward, K., McNaughton Nicholls, C., \& Lewis, J. (2014). In-Depth Interviews. In J. Ritchie, J. Lewis, C. M. Nicholls, \& R. Ormston (Eds.), Qualitative Research Practice (2 ${ }^{\text {nd }}$ ed.) (pp. 177-210). London, U.K.: Sage.

Zielinski, S. (2013). [...After the Media]: News from the Slow-Fading Twentieth Century. (G. Custance, Trans.). Minneapolis, MN: Univocal Publishing. (Original work published 2011) 
Appendix A

\section{Carleton \\ U N I V E R S I T Y \\ Canada's Capital University}

\section{Consent Form}

Title: "Revisiting the Contemporary Flow of Influence in Political Marketing"

Date of ethics clearance: January 12, 2018

Ethics Clearance for the Collection of Data Expires: January 31, 2020

I , choose to participate in a study on the interplay between commercial marketing and political marketing. This study will examine the extent to which the flow of influence and innovation between commercial and political marketers is bidirectional and operating as a feedback loop rather than merely being a unidirectional flow from commercial to political marketers as is commonly assumed.

The researcher for this study is Simon Vodrey in the School of Journalism \& Communication at Carleton University. He is working under the supervision of Andre Turcotte, $\mathrm{PhD}$ in the School of Journalism \& Communication at Carleton University, which is located in Ottawa, Canada.

This study involves one approximately 30-60 minute interview. Depending upon your convenience, the interview will be conducted either in person, via the telephone, or via Skype.

In person interviews will take place either at your place of employment or at a mutually agreeable public space.

With your consent, our interview (regardless of whether it is conducted in person, via telephone, or via Skype) will be audio-recorded. Audio-recordings will be kept for up to five years after this project has been completed and defended. After that time, the audiorecordings will be destroyed.

As this project will ask you about your employment, there are some potential professional risks to you if your statements are critical of your employer. While this risk is expected to be minimal, care will be taken to protect your identity. This will be done by keeping all responses confidential, assigning pseudonyms to all responses, and allowing you to request that certain responses not be included in the final project. 
Should you experience any distress during the interview, you will be provided with contact information for counselling services available nearby.

You will have the right to end your participation in the study for any reason prior to May 1,2017 , the point at which the data analysis begins. If you choose to withdraw, all the information you have provided will be destroyed.

All research data, including the audio-recordings or any handwritten notes or USB keys (all such USB keys will be encrypted and password protected) will be kept in a locked cabinet at Carleton University. Research data will only be accessible by the researcher and the research supervisor.

Once the project is completed, all research data will be kept for five years and potentially used for other research projects on this same topic. At the end of that period, all research data will be securely destroyed. (Electronic data will be erased and hard copies will be shredded.)

If you would like a copy of the finished research project, you are invited to contact the researcher to request an electronic copy which will be provided to you.

The ethics protocol for this project was reviewed by the Carleton University Research Ethics Board, which provided clearance to carry out the research. If you have any ethical concerns with the study, please contact Dr. Andy Adler, Chair, Carleton University Research Ethics Board-A (by phone at 613-520-2600 ext. 2517 or via email at ethics@carleton.ca).

\section{Researcher contact information:}

Name: Simon Vodrey

Department: Communication

Carleton University

Tel: 613-864-3927

Email: simon.vodrey@carleton.ca
Supervisor contact information:

Name: Andre Turcotte

Department: Communication

Carleton University

Tel: 613-520-2600 x7426

Email: andre.turcotte@carleton.ca

Do you agree to be audio-recorded: __ ${ }^{\mathrm{Yes}} \_$No

Signature of participant

Signature of researcher
Date

Date 


\section{Carleton \\ U N I V E R S I T Y}

Canada's Capital University

January $31^{\text {st }}, 2019$

\section{Interviewer Guide}

*NB: The consent form. How would you like to fill it out? Email, sign, and send back?

- 1) What comes to mind when you hear the term "political marketing?"

- 2) What can political consultants and practitioners learn from commercial marketers?

- 3) What can commercial marketers learn from political consultants and practitioners?

- 4) Where is the most innovative thinking about political campaigning occurring?

- 5) What role does technology play in commercial marketing?

- 6) What role does technology play in political campaigning?

- 7) Has the role of technology in commercial marketing changed over the years?

$\circ$ 7B) If so, how?

- 8) Has the role of technology in political campaigning changed over the years?

$\circ$ 8B) If so, how?

- 9) What role does data play in political campaigning?

- 10) Does the role of data vary between federal, state, and municipal races?

- 11) Do you think that all of the mainstream political parties are on equal footing with their use of data for the purposes of political campaigning?

- 12) Where is the most innovative technology for the purposes of political campaigning being developed and by whom?

- 13) Are political parties or third-party vendors better suited to develop, test, implement, and maintain new campaign technologies?

- 14) What role does microtargeting play in political campaigning?

- 15) What role does microtargeting play in commercial marketing?

- 16) What role does marketing play in political campaigning?

- 17) Has the role of marketing in political campaigning changed over the years?

$\circ$ 17B) If so, how?

- 18) Where are the most innovative marketing techniques and strategies being formulated? 
- 19) What comes to mind when you hear the term "datafication?"

- 20) What comes to mind when you hear the term "relationship marketing?"

- 20B) Do you think there's a difference in terms of how relationship marketing is interpreted in the commercial versus the political context? Or are they interchangeable?

- 21) What comes to mind when you hear the term "consumer tribe" or "brand tribe?"

- 21B) Do you think that there's a similarity between how that term is interpreted in the commercial context versus the political context?

- 22) What comes to mind when you hear the term "consumer citizen"?

- 23) What comes to mind when you hear the term "market intelligence?"

- 24) What are your thoughts on "text-to-donate fundraising"?

- 25) Do you think that commercial advertising of brands in a fashion that appears to abandon political brand neutrality (e.g. Nike's Colin Kaepernick campaign or Gillette's recent \#MeToo campaign) in favor of taking firm political stances on hot-button political issues will become more common, or will it still remain the exception that proves the rule?

- 26) What role does social pressure play in political campaigning?

- 27) What role does social pressure play in commercial marketing?

- 28) How does speed factor into your work?

- 29) How do you think speed factors into political campaigning?

- 30) How do you think speed factors into commercial marketing?

- 31) Is there anyone else that you recommend I interview?

○ 31B) Is it alright if I say that you referred me to them? 


\section{Appendix C}

\section{Interviewee Profiles}

\section{Interviewee \#1}

- President of the Canadian public affairs division of a global market research firm and communications strategist with expertise in policy development.

- Interviewed via telephone September $12^{\text {th }}, 2018$

Interviewee \#2

- Canadian political and market researcher and former Director of Research at a Toronto-based public affairs, government relations and crisis management firm.

- Interviewed via telephone September $24^{\text {th }}, 2018$

Interviewee \#3

- CEO of the public affairs wing of a global market research firm as well as a political and social researcher.

- Interviewed via telephone October $1^{\text {st }}, 2018$

Interviewee \#4

- NDP strategist, political columnist and commentator.

- Interviewed via telephone October $11^{\text {th }}, 2018$

Interviewee \#5

- Canadian Conservative political strategist, pollster, and researcher.

- Interviewed via telephone October $12^{\text {th }}, 2018$

Interviewee \#6

- Canadian political pollster, researcher, and media commentator.

- Interviewed via telephone October $17^{\text {th }}, 2018$

Interviewee \#7

- Partner and founder of a Toronto-based government relations, strategic communications, research and digital campaign consultancy, and long-time Conservative political strategist.

- Interviewed via telephone October $25^{\text {th }}, 2018$ Interviewee \#8

- Chief Strategist at a national Canadian political and market research firm.

- Interviewed via telephone October $26^{\text {th }}, 2018$ Interviewee \#9

- Conservative political advisor, media commentator, and head of an Ottawa-based opinion research and public affairs consultancy.

- Interviewed via telephone October $30^{\text {th }}, 2018$

Interviewee \#10

- Democratic pollster, market researcher and strategic communications consultant.

- Interviewed via telephone October $30^{\text {th }}, 2018$ Interviewee \#11

- Executive at a Canadian public affairs firm and political practitioner who has ample experience with communications and government relations on behalf of the New Democratic Party (NDP),

- Interviewed via telephone October $31^{\text {st }}, 2018$ 
Interviewee \#12

- Canadian political and corporate strategist, pollster, and campaign manager with long-standing ties to the Liberal Party of Canada.

- Interviewed via telephone November $1^{\text {st }}, 2018$

Interviewee \#13

- Canadian market and opinion researcher and communications strategist who is also a Principal at a government relations and strategic communications firm with a global footprint.

- Interviewed via telephone November $7^{\text {th }}, 2018$

Interviewee \#14

- Public affairs and policy researcher and Principal at a Canadian government relations, strategic communications, public policy research and analysis firm.

- Interviewed via telephone November $7^{\text {th }}, 2018$

Interviewee \#15

- Senior Consultant at a Canadian government relations, public affairs and opinion research firm, and former Director of Market Research in the Prime Minister's Office (PMO).

- Interviewed via telephone November $7^{\text {th }}, 2018$

Interviewee \#16

- Founder and President of a Toronto-based advertising agency.

- Interviewed via telephone November $8^{\text {th }}, 2018$

Interviewee \#17

- Hybrid marketer and head of a digital marketing agency with ties to the Conservative Party of Canada.

- Interviewed via telephone November $12^{\text {th }}, 2018$

Interviewee \#18

- Canadian researcher and author with a focus on politics and political marketing.

- Interviewed via telephone November $14^{\text {th }}, 2018$

Interviewee \#19

- Associate Principal at a Canadian public affairs, government relations and crisis management firm and former NDP communications consultant with extensive experience in media relations, crisis communication and campaign management.

- Interviewed via telephone November $16^{\text {th }}, 2018$

Interviewee \#20

- General Manager of an Ottawa-based media agency and a commercial marketer.

- Interviewed via telephone November $19^{\text {th }}, 2018$

Interviewee \#21

- Co-founder and chief operating officer of an American digital and data consultancy, former director of digital strategy at the Republican National Committee (RNC), and former media executive.

- Interviewed via telephone November $23^{\text {rd }}, 2018$

Interviewee \#22

- Principal at a Canadian public affairs, government relations and crisis management firm, and former Conservative Party of Canada political consultant.

- Interviewed via telephone November $27^{\text {th }}, 2018$ 
Interviewee \#23

- Canadian political strategist and president of an Alberta-headquartered digital marketing and strategy consultancy.

- Interviewed via telephone December $5^{\text {th }}, 2018$

Interviewee \#24

- Founder and president of a California-based research firm specializing in elections and public policy and which represents non-profit, government, media, special interest, and corporate clients.

- Interviewed via telephone December $27^{\text {th }}, 2018$

Interviewee \#25

- President of an American data analytics targeting firm and former campaign manager.

- Interviewed via telephone January $15^{\text {th }}, 2019$

Interviewee \#26

- President of a California-based and Democrat-affiliated political communications strategy shop.

- Interviewed via telephone January $23^{\text {rd }}, 2019$

Interviewee \#27

- Republican political consultant and strategist.

- Interviewed via telephone January $24^{\text {th }}, 2019$

Interviewee \#28

- Managing Partner of a Democrat-aligned targeting firm and former Chief Technology Officer of the Presidential Inaugural Committee.

- Interviewed via telephone January $28^{\text {th }}, 2019$

Interviewee \#29

- Partner in a Democratic-aligned boutique digital consulting firm.

- Interviewed via telephone January $29^{\text {th }}, 2019$

Interviewee \#30

- Washington, D.C. based political marketer, digital advertising strategist and Vice President of Political Sales at a data-driven marketing firm that has a global footprint.

- Interviewed via telephone January $30^{\text {th }}, 2019$

Interviewee \#31

- Texan public affairs and communications consultant specializing in crafting tailored messaging and strategies for political campaigns, businesses, and also advocacy groups.

- Interviewed via telephone January $30^{\text {th }}, 2019$

Interviewee \#32

- Political activist, blogger, pollster and consultant practicing in New Zealand and the United Kingdom.

- Interviewed via telephone January $31^{\text {st }}, 2019$ 
Interviewee \#33

- Hybrid marketer, principal strategist at a Texas-based strategic communications consultancy and former creative advertising director for a number of recent Republican presidential candidates.

- Interviewed via telephone February $4^{\text {th }}, 2019$ 


\section{Appendix D}

Table 1. Gender Breakdown of Respondents

\begin{tabular}{lccc}
\hline & U.S.A. & Canada & New Zealand \\
\hline Male & 9 & 16 & 1 \\
Female & 2 & 5 & 0 \\
& & & \\
\hline
\end{tabular}




\section{Appendix $E$}

Table 2. Employment Breakdown of Respondents

U.S.A. $\quad$ Canada $\quad$ New Zealand

$\begin{array}{lrrr}\text { Political Marketers } & 7 & 10 & 1 \\ \text { Commercial Marketers } & 0 & 0 & 0 \\ \text { Hybrid Marketers* } & 4 & 11 & 0\end{array}$

*Marketers who practiced both political marketing and commercial marketing were labelled as Hybrid Marketers. 